INSTITUTO DE PESQUISAS ENERGÉTICAS E NUCLEARES

Autarquia Associada à Universidade de São Paulo

\title{
VIDROS E VITROCERÂMICOS COM ALTA CONCENTRAÇÃO DE METAIS OBTIDOS A PARTIR DE RESÍDUOS INDUSTRIAIS
}

\author{
ANTONIO CARLOS DA SILVA \\ Tese apresentada como parte dos \\ requisitos para obtenção do Grau \\ de Doutor em Ciências na Área \\ de Tecnologia Nuclear - \\ Materiais.
}

Orientadora:

Dra. Sonia R. Homem de Mello Castanho

São Paulo 


\section{Dedicatória}

Dedico este trabalho ao meu pai, Carlos da Silva (em memória) e à minha mãe, Izília Arrebola da Silva por tudo que eles significam para mim, assim como por todos os valores que me ensinaram.

Dedico também à minha noiva Maria Regina de Arruda, por seu carinho, amor e compreensão.

Agradecimentos 
Agradeço ao Instituto de Pesquisas Nucleares e Energéticas (IPEN), no qual realizei este estudo.

Agradeço à comissão de pós-graduação do IPEN, por todo o apoio oferecido durante este doutorado.

Agradeço ao Instituto de Ciências de Materiales de Madrid (ICMM), no qual realizei parte deste estudo.

Agradeço ao Conselho Nacional de Desenvolvimento Científica e Tecnológico (CNPq) pela concessão das bolsas de Doutorado e de Estagio de Doutorado no Exterior.

Agradeço a todos os doutores, funcionários e colegas do IPEN, USP, ICMM, ICV e outros, que direta ou indiretamente e com desprendimento, cooperaram de alguma forma para a realização deste trabalho.

Agradeço a minha Mãe Izília, e meus irmãos Kátia e Eduardo, que zelaram por mim enquanto me dedicava a pesquisa.

Agradeço a minha noiva, Regina Arruda, por seu carinho e por resignadamente adiar a realização de seus sonhos em pró dos meus.

Agradeço aos amigos Chiba, Reinaldo, Luiz Fernando, Silas, Egberto, Marco, Maria Tereza, Letícia, Antonio Cubillo, Marcos Dias, Raul, Carlos, Kenji e tantos outros, pelo seu carinho e apoio.

Agradeço aos doutores Ana Maria Segadães, Jesus Sanz, Carlos Pecharóman, Isabel Montero, Emilia S.M. Seo, Chieko Yamagata, Luis G. Martinez e José Bartolomé pela importante ajuda na realização deste.

Agradeço ao Dr. José S. Moya, que me recebeu e cooperou de forma irrestrita e fundamental para a realização deste trabalho de pesquisa.

E finalmente, agradeço a minha orientadora, Dra Sonia R. H. de Mello Castanho, pela amizade e a oportunidade de crescimento pessoal que me proporcionou, enquanto trabalharmos juntos neste projeto. 
"Qui sunt isti qui ut nubes volant?" [Isaias,60.8] (Quem são esses que voam como as nuvens?) 


\title{
VIDROS E VITROCERÂMICOS COM ALTA CONCENTRAÇÃO DE METAIS OBTIDOS A PARTIR DE RESÍDUOS INDUSTRIAIS
}

\author{
Antonio Carlos da Silva
}

\section{RESUMO}

É consenso que o reaproveitamento de materiais descartados pela indústria constitui uma importante fonte de matérias-primas para novos produtos. Entretanto a atuação dos mesmos deve ser analisada com critério para assegurar a funcionalidade e qualidade dos produtos acabados. Este trabalho estuda a viabilidade de se obter materiais vítreos utilizando-se resíduos sólidos galvânicos (indústria metalúrgica) como principal matéria prima. Para ajustes de composição foram empregados os resíduos sólidos industriais de finos de sílica (indústria cerâmica), de rochas graníticas (rochas ornamentais) e reativos comerciais. Os materiais foram concebidos a partir de formulações baseadas nos vidros soda-cal, utilizando-se o sistema $\mathrm{B}_{2} \mathrm{O}_{3}-\mathrm{CaO}-\mathrm{Na}_{2} \mathrm{O}-\mathrm{SiO}_{2}-\mathrm{MO}(\mathrm{M}=\mathrm{Cr}, \mathrm{Ni}, \mathrm{Cu}, \mathrm{Zn})$. A funcionalidade dos metais de transição na estrutura do vidro foi avaliada em função da variação da concentração presente na estrutura e da resistência química oferecida pelos produtos. As estruturas foram analisadas utilizando-se principalmente técnicas espectrométricas que forneceram informações importantes no esclarecimento sobre a incorporação e inertização destes metais de alto risco ambiental. Obteve-se materiais vítreos formulados com os resíduos propostos. O arranjo estrutural destes vidros é similar ao do vidro soda-cal, permitindo o planejamento de vidros e vitrocerâmicos utilizando resíduos sólidos industriais como componente das estruturas da rede vítrea. Obteve-se materiais vítreos utilizando-se até $22,5 \%$ em massa de finos de sílica, $8,3 \%$ de pó de rochas graníticas e $50,5 \%$ de lodo galvânico, com boa resistência química (taxa de dissolução em meio aquoso de $\left.1,5.10^{-8}\left[\mathrm{~g} \cdot \mathrm{cm}^{2} \cdot \mathrm{s}^{-1}\right]\right)$. 


\title{
GLASS AND GLASS-CERAMICS WITH HIGH METAL CONCENTRATION OF FROM INDUSTRIAL WASTES
}

\author{
Antonio Carlos da Silva
}

\begin{abstract}
The reuse of industrial waste materials is considered as an important source of raw-materials to be employed at new products. However proper criteria is needed in order to obtain vitreous materials from industrial solid wastes like solid galvanic waste (metallurgical industry) as main raw material. Ajusting the composition silica fine powder (ceramic industry) and granite stones wastes (ornamental) were used. In the present work, the formulations are based in soda lime glasses, where the relevant system is $\mathrm{B}_{2} \mathrm{O}_{3}-\mathrm{CaO}-\mathrm{Na}_{2} \mathrm{O}-\mathrm{SiO}_{2}-\mathrm{MO}(\mathrm{M}=\mathrm{Cr}, \mathrm{Ni}, \mathrm{Cu}, \mathrm{Zn})$. The functional characteristics of such components into the glass structure, in special the transition metals, are evaluated regarding the actual concentration variation and concerning the products chemistry stability. The structures are mainly analyzed by spectrometric techniques which give important informations about immobilization of hazardous environment related metals lead to there inertization.Vitreous materials formulation with the proposed wastes are obtained. The glass structural arrangements is similar to the soda lime glass, allowing ceramic glass materials project based on industrial solid wastes as the main component. Several vitreous materials are obtained contained silica fine powder wastes about 22,5\%wt, granite rocks powder wastes about $8,3 \%$ wt and galvanic sludge wastes up to $50,5 \%$ wt, with showing good chemistry resistance (dissolution rate in aqueous media of $\left.1,5 \cdot 10^{-8}\left[\mathrm{~g} \cdot \mathrm{cm}^{2} \cdot \mathrm{s}^{-1}\right]\right)$.
\end{abstract}




\section{Sumário}

Página

Introdução.

3.1 Resíduos Sólidos Industriais.

3.2 Vidros e Vitrocerâmicos................................................................... 06

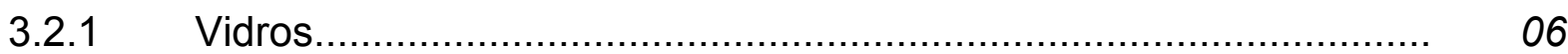

3.2.2 Tipos de Vidros....................................................................... 06

3.2.3 Formação e Estrutura dos Vidros Silicato......................................... 07

3.3 Vitrocerâmicos..................................................................... 21

3.4 Resistência Química e Dissolução dos Vidros Silicato..................... 25

3.4.1 Difusão da Água e Trocas com Hidrogênio................................... 26

3.4.2 Hidrólise da Rede do Vidro......................................................... 27

3.4.3 Formação de Camada Amorfa Superficial....................................... 27

3.4.4 Ataque da Rede Estrutural pelos Íons $\mathrm{OH}^{-}$................................... 28

$3.5 \quad$ Vitrificação de Resíduos Perigosos................................................ 28

$4 \quad$ Materiais e métodos.............................................................. 33

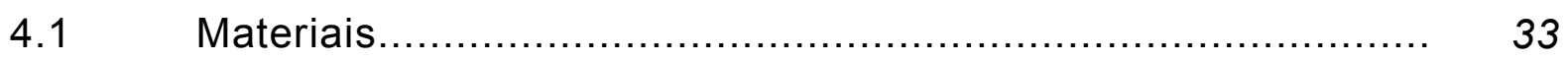

4.2 Formulação dos Vidros Estudados.................................................. 34

4.2.1 Calculo das Composições dos Vidros da Série TC .......................... 35

4.2.2 Calculo das Composições dos Vidros da Série TR ………………... 38

4.2.3 Composições dos Vitrocerâmicos................................................. 39

4.2.4 Vidro de Referência................................................................... 40

Ensaios de Fusão...................................................... 41

$4.4 \quad$ Devitrificação............................................................. 41 
$4.5 \quad$ Técnicas de Caracterização.................................................. 42

4.51 Difração de Raios X (DRX) ............................................................ 42

4.5.2 Fluorescência de Raios X (FRX) ..................................... 42

4.5.3 Espectroscopia Ultravioleta-Visível (UV-Vis)................................. 42

4.5.4 Espectroscopia Fotoeletrônica de Raios X (XPS)............................ 43

4.5.5 Microscopia Eletrônica de Varredura (MEV-EDS).................. 43

4.5.6 Microscopia Óptica de Luz Transmitida e Refletida (MOLT, MOLR). 43

4.5.7 Espectroscopia no Infravermelho na Transformada de Fourier 44 (FTIR)

4.5.8 Ressonância Nuclear Magnética (RNM-MAS)................................. 45

4.5.9 Microscopia de Calefação............................................................. 46

4.6 Resistência Química........................................................ 47

4.6.1 Estabilidade em Meio Aquoso ........................................... 47

4.6.2 Resistência Hidrolítica................................................ 48

4.6.3 Resistência ao Ataque Alcalino.......................................... 51

4.6.4 Resistência ao Ataque Ácido............................................ 51

$5 \quad$ Resultados e Discussão.................................................. 53

5.1 Caracterização das Matérias-Primas.................................... 53

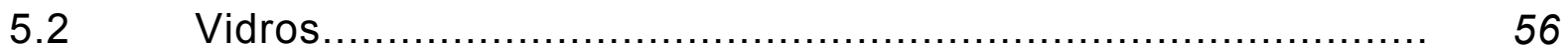

5.2.1 Fusão e Conformação.................................................. 56

5.2.2 Estudo da Estrutura dos Vidros........................................... 64

5.2.3. Macro-segregação......................................................... 73

5.2.4 Viscosidade dos Vidros............................................... 76

5.2.5 Resistência Química dos Vidros......................................... 77

5.2.5.1 Resistência Hidrolítica.................................................. 77

5.2.5.2 Resistência ao Ataque Ácido.............................................. 96

5.2.5.3 Resistência ao Ataque Alcalino......................................... 105

5.3 Vitrocerâmicos....................................................................... 114 
5.3.1 Fases Cristalinas nos Vidros Estudados............................. 114

5.3.2 Resistência Química dos Vitrocerâmicos......................... 127

5.3.2.1 Resistência Hidrolítica............................................ 127

5.3.2.2 Resistência ao Ataque Ácido....................................... 138

5.3.2.3 Resistência ao Ataque Alcalino.................................. 148

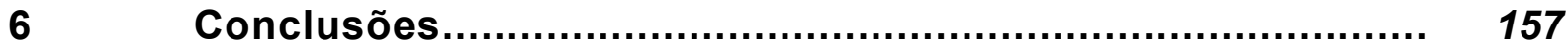

$7 \quad$ Trabalhos complementares........................................................ 160

$8 \quad$ Referências Bibliográficas.................................................... 161

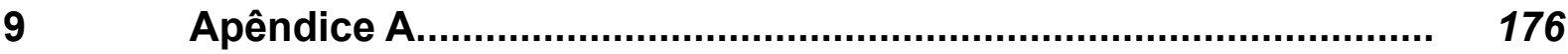




\section{Lista de figuras}

Figura

Página

3.1 Diagrama da variação do volume específico em função da temperatura....

3.2 Esquema exemplificando a ligação entre tetraedros de sílica......................

3.3 Diagrama de equilíbrio de fases do sistema $\mathrm{Na}_{2} \mathrm{O}: \mathrm{CaO}: \mathrm{SiO}_{2}$, onde está indicada a composição utilizada por Silva, A.C. et al.

4.1 Diagrama de equilíbrio de fases do sistema $\mathrm{Na}_{2} \mathrm{O}: \mathrm{CaO}: \mathrm{SiO}_{2}$, onde estão indicados os pontos composicionais T05, T10, T15, T20 e T25

4.2 Diagrama do sistema $\mathrm{B}_{2} \mathrm{O}_{3}: \mathrm{CaO}: \mathrm{SiO}_{2}$, onde $\mathrm{T} 05$ à T25 representam as composições selecionadas.

4.3 Diagrama do sistema $\mathrm{B}_{2} \mathrm{O}_{3}: \mathrm{Na}_{2} \mathrm{O}: \mathrm{SiO}_{2}$, onde T05 à T25 representam as composições selecionadas...

4.4 Diagrama esquemático dos procedimentos adotados para a formulação dos vidros e dos vitrocerâmicos.

4.5 Aparelho de extração tipo "Soxhlet".

4.6 Ataque hidrolítico em amostras pulverizadas: foto ilustrativa da montagem experimental.

5.1 Difratograma de raios $\mathrm{X}$ : resíduo de finos de sílica (RFS)

5.2 Difratograma de raios $X$ : resíduo de rochas graníticas (RRG).

5.3 Vidros das séries TC e TR, obtidos nos ensaios de fusão....................

5.4 Macro-inclusão observada na amostra T25R50

5.5 Difratogramas obtidos por DRX a partir de amostras das composições TC: (a) T05C; e, (b) T25C.

5.6 Difratogramas obtidos por DRX a partir de amostras das composições TR: (a) T20R40; e, (b) T25R50.

5.7 Micrografias de secções polidas de amostras das composições TC e TR.

5.8 Micrografias correspondentes aos vidros preparados em laminas delgadas: (a) T15R10; (b) T20R40; e, (c,d) T25R50.

5.9 Secção transversal de amostras das composições TR: (a) T20R40; e, (cb) T25R50 (MEV-EDS).

5.10 Espectros ${ }^{29}$ Si RNM-MAS de amostras dos vidros: (a) T10C; (b) T10R20; (c) T20C; e, (d) T20R40.

5.11 Espectros ${ }^{11} \mathrm{~B}$ RNM-MAS de amostras dos vidros: (a) T10C; (b) T10R20; (c) T20C; e, (d) T20R40.

5.12 Espectros $\mathrm{Cr} 2 \mathrm{p}$ obtidos por espectroscopia fotoeletrônica de raios $\mathrm{X}$ (XPS) de amostras dos vidros T05R10, T10R20, T15R30 e T20R40. 
5.13 Espectros de absorbância de UV-Vis para a as amostras das composições TR...

5.14 Espectros de FT-IR de amostras das composições: TC e TR.

5.15 Espectro DRX da macro-segregação observada no vidro T25R50....

5.16 Secção transversal da Macro-segregação observada o vidro T25R50. .(MEV-EDS).

5.17 Micrografias obtidas no ensaio de microscopia de calefação de amostras das composições T15C, T20C, T25C, T15R30, T20R40 e T25R50.

5.18 Dependência da viscosidade com a temperatura de amostras das composições T15C, T20C, T25C, T15R30, T20R40 e T25R50.

5.19 Resistência hidrolítica: Taxa de dissolução em função do tempo para amostras das composições TC e VR

5.20 Resistência hidrolítica: Taxa de dissolução em função do tempo para amostras das composições TR e VR

5.21 Taxa de dissolução após ataque hidrolítico em função da concentração de modificadores para amostras das composições TC, TR e VR

5.22 Superfície de amostras das composições TC após o ataque hidrolítico:

(a) T05C; e, (b) T10C (MEV-EDS).

5.23 Superfície de amostras das composições TC após o ataque hidrolítico: (a) T15C; e, (b) T20C (MEX-EDS).

5.24 Superfície de amostras das composições TR após o ataque hidrolítico: (a)T05R10; (b)T10R20; e (c)T15R30 (MEV-EDS).

5.25 Superfície de amostras das composições TR após o ataque hidrolítico: (a) T20R40; e, (b) T25R50 (MEV-EDS).

5.26 Micrografias ópticas, correspondentes á superfície de amostras das composições TC e TR, após 336h de ataque hidrolítico.

5.27 Micrografias ópticas, correspondentes á secção transversal de amostras das composições TC e TR, após ataque hidrolítico.

5.28 Difratogramas obtidos por DRX a partir de amostras das composições

TC, após $336 \mathrm{~h}$ de ataque hidrolítico: (a) T05C; e, (b) T25C.

5.29 Difratogramas obtidos por DRX a partir de amostras das composições TR, após $336 \mathrm{~h}$ de ataque hidrolítico: (a) T20R40; e, (b) T25R50......

5.30 Espectros de FT-IR de amostras das composições T05C e T05R10 após $0,1,3,6,12,24,72,168$ e 336 horas de ataque hidrolítico.

5.31 Espectros de FT-IR de amostras das composições T15C e T15R30 após $0,1,3,6,12,24,72,168$ e 336 horas de ataque hidrolítico.

5.32 Espectros de FT-IR de amostras das composições T25C e T25R50 após $0,1,3,6,12,24,72,168$ e 336 horas de ataque hidrolítico.

5.33 Taxa de dissolução em função da concentração de modificadores obtidas no ensaio de resistência ao ataque ácido de amostras das composições TC, TR e VR. 
5.34 Micrografias da secção transversal de amostras das composições TC

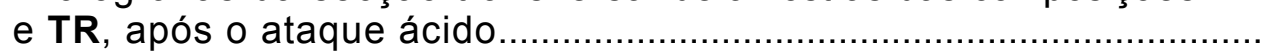

5.35 Superfície de amostras das composições TC após o ataque ácido: (a) T05C; e, (b) T10C (MEV-EDS)...

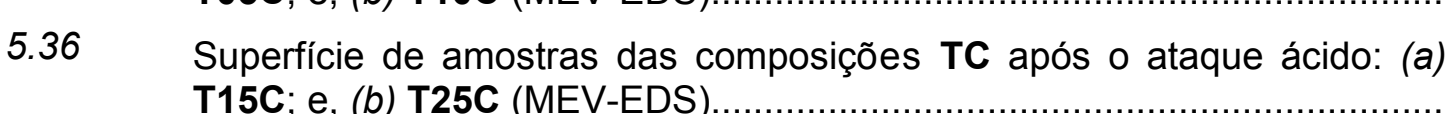

5.37 Superfície de amostras das composições TR após o ataque ácido: (a) T05R10; (b) T10R20; e, (c) T15R30 (MEV-EDS).

5.38 Superfície de amostras das composições TR após o ataque ácido: (a) T20R40; e, (b) T25R50 (MEV-EDS).

5.39 Espectros de FT-Irde amostras das composições TC e TR após ataque ácido.

5.40 Difratogramas obtidos por DRX a partir de amostras das composições TC, após o ensaio de ataque ácido.

104

5.41 Difratogramas obtidos por DRX a partir de amostras das composições TR, após o ensaio de ataque ácido

5.42 Taxa de dissolução em função da concentração de modificadores obtidas no ensaio de resistência ao ataque alcalino de amostras das composições TC, TR e VR.

5.43 Micrografias correspondentes á seccção transversal de amostras das composições TC e TR, após o ataque alcalino.

5.44 Superfície de amostras das composições TC após o ataque álcalino: (a) T05C; e, (b) T10C (MEV-EDS).

108

5.45 Superfície de amostras das composições TC após o ataque álcalino: (a) T15C; e, (b) T20C (MEV-EDS).

5.46 Superfície de amostras das composições TR após o ataque alcalino: (a) T05R10; (b) T10R20; e, (c) T15R30 (MEV-EDS).

5.47 Superfície de amostras das composições TR após o ataque alcalino: (a) T20R40; e, (b) T25R50 (MEV-EDS).

5.48 Espectros de FT-IR de amostras das composições TC e TR após ataque alcalino.

5.49 Difratogramas obtidos por DRX a partir de amostras das composições TC, após o ensaio de ataque alcalino.

5.50 Difratogramas obtidos por DRX a partir de amostras das composições $\mathbf{T R}$, após o ensaio de ataque alcalino.

5.51 Amostras das composições TC e TR após o ensaio de crescimento de fases cristalinas.

5.52 Difratogramas obtidos por DRX a partir de amostras das composições TCD: (a) T05CD; (b) T10CD; (c) T15CD; (d) T20CD; e, (d) T25CD.

5.53 Fotos obtidas por microscopia óptica de secções polidas de amostras das composições TCD........

(a) T20CD; e, (b) T25CD (MEV-EDS) 
5.56 Difratogramas obtidos por DRX de amostras das composições TRD.........

5.57 Micrografias de secções polidas de amostras das composições TRD...

5.58 Composições TRD: (a)T05R10D; (b)T10R20D; e (c)T15R30D (MEVEDS).

5.59 Composições TRD: (a) T20R40D; e, (b) T25R50D (MEV-EDS).

5.60 Espectros de FT-IR de amostras das composições TCD e TRD.....

5.61 Taxa de dissolução em função do tempo obtidas no ensaio de resistência hidrolítica de amostras das composições TCD e VR.

5.62 Taxa de dissolução em função do tempo obtidas no ensaio de resistência hidrolítica de amostras das composições TRD e VR

5.63 Micrografias correspondentes à secção transversal das amostras das TCD e TRD, após ataque hidrolítico ( $t=336 \mathrm{~h})$.

5.64 Superfície de amostras das composições TCD após ataque hidrolítico: (a) T10CD; e, (b) T15CD (MEV-EDS).

5.65 Superfície de amostras composições TCD após ataque hidrolítico: (a) T20CD; e, (b) T25CD (MEV-EDS).

5.66 Superfície de amostras das composições TRD após ataque hidrolítico:

(a) T05R10D; (b) T10R20D; e, (c) T15R30D (MEV-EDS).

5.67 Superfície de amostras das composições TRD após ataque hidrolítico: (a) T20R40D; e, (b) T25R50D (MEV-EDS).

5.68 Espectros FT-IR de amostras das composições TCD e TRD, após ataque hidrolítico (336h)....

5.69 Difratogramas obtidos por DRX a partir de amostras das composições TCD após ensaios de resistência hidrolítica.

5.70 Difratogramas obtidos por DRX a partir de amostras das composições TRD após ensaios de resistência hidrolítica.

5.71 Taxa de dissolução em função da concentração de modificadores obtidas no ensaio de resistência ao ataque ácido das amostras de composições TCD, TRD e VR

5.72 Micrografias, correspondentes á secção transversal de amostras das composições TCD e TRD, após o ensaio de ataque ácido..

5.73 Superfície de amostras das composições TCD após ataque ácido: (a) T10C; e, (b) T15C (MEV-EDS)...

5.74 Superfície de amostras das composições TCD após ataque ácido: (a) T20C; e, (b) T25C(MEV-EDS).

5.75 Superfície de amostras das composições TRD após ataque ácido: (a) T05R10D; (b) T10R20D; e, (c) T15R30D (MEV-EDS)..

5.76 Superfície de amostras das composições TRD após ataque ácido: (a) T20R40D; e, (b) T25R50D (MEV-EDS).

5.77 Espectros FT-IR de amostras das composições TCD e TRD após o ensaio de ataque ácido. 
5.78 Difratogramas obtidos por DRX a partir de amostras das composições TCD, após o ensaio de ataque ácido.

5.79 Difratogramas obtidos por DRX a partir de amostras das composições TRD, após o ensaio de ataque ácido.

5.80 Taxa de dissolução em função da concentração de modificadores obtidas no ensaio de resistência ao ataque alcalino das amostras TCD, TRD e VR.

5.81 Micrografias correspondentes á secção transversal de amostras das composições TCD e TRD, após o ensaio de ataque alcalino

5.82 Superfície de amostras das composições TCD após ataque alcalino: (a) T10CD; e, (b) T15CD (MEV-EDS).

5.83 Superfície de amostras das composições TCD após ataque alcalino: (a) T20CD; e, (b) T25CD (MEV-EDS).

5.84 Superfície de amostras das composições TRD após ataque alcalino: (a) T05R10D; (b) T10R20D; e, (c) T15R30D (MEV-EDS).

5.85 Superfície de amostras das composições TRD após ataque alcalino: (a) T20R40D; e, (b) T25R50D (MEV-EDS).

5.86 Espectros FT-IR de amostras das composições TCD e TRD, após o

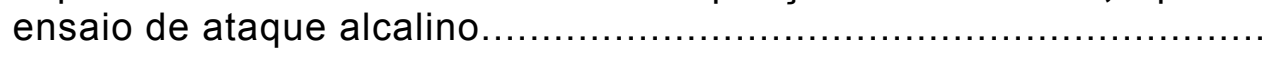

5.87 Difratogramas obtidos por DRX a partir de amostras das composições TCD, após o ensaio de ataque alcalino.

5.88 Difratogramas obtidos por DRX a partir de amostras das composições TRD, após o ensaio de ataque alcalino. 


\section{Lista de tabelas}

Tabela

Página

4.1 Principais constituintes dos materiais de partida (\% em massa). Analisados por Fluorescência de Raios X............................... 34

4.2 Composições da série de vidros TC (\% em massa)................................. 38

4.3 Composições da série de vidros TR, formuladas para os estudos de fusão (\% em massa) ...................................................................... 39

4.4 Composição química do vidro VR (Soda-cal comercial), obtidas por fluorescência de raios X (\% em massa) ................................................ 41

$4.5 \quad$ Assinaturas de FTIR para compostos de vidros de sílica..................... 45

4.6 Microscopia de calefação:Transformações típicas de do corpos de prova de materiais vítreos associadas à viscosidade.

5.1 Principais constituintes dos materiais de partida em óxido (\% em massa).

5.2 Dissolução normalizada por elemento $\left(\mathrm{g} / \mathrm{m}^{2}\right)$ para o Resíduo Galvânico após 7 dias do ensaio PCT-B.

5.3 Composições em massa da série de vidros TR calculadas, em comparação com as composições obtidas por FRX (\% em massa).

5.4 Energias de ligação e estrados de oxidação do cromo nos vidros T05R10, T10R20, T15R30 e T20R40

5.5 Taxa de dissolução normalizada por elemento $\left(\mathbf{r} \mathrm{em} \mathrm{g} / \mathrm{m}^{2}\right)$ para os vidros T15R30, T20R40 e T25R50 submetidos ao teste PCT-B por 7 dias..

5.6 Quadro indicativo dos resultados obtidos após tratamento térmico do vidro T05C.

9.1 Planilha de calculo em \% de massa dos componentes para a composição T15C.

9.2 Planilha de calculo em \% de massa dos componentes para a composição T15R30. 


\section{Lista de abreviaturas}

$\begin{array}{cl}\text { ABNT } & \text { Associação Brasileira de Normas Técnicas } \\ \text { ASTM } & \text { American Society for Testing and Materials } \\ \text { B }_{0} & \text { campos magnéticos externos } \\ \text { BO } & \text { Bridging oxigens (oxigênios ponte) } \\ \text { BSE } & \text { backscattered electrons (elétrons retro-dispersados) } \\ \text { CET } & \text { Coeficiente de expansão térmica } \\ \boldsymbol{d} & \text { Distância interplanar } \\ \text { DFS } & \text { Descarte de finos de sílica } \\ \text { DIN } & \text { Deutsches Institut fur Normung. } \\ \text { DRX } & \text { Difração de raios } X \\ \text { Ec } & \text { Energia cinética } \\ \text { EL } & \text { Energia de ionização do elétron }\end{array}$

EXAFS Estended $X$ ray absortion of fine structure

FTIR Espectroscopia no infravermelho na transformada de Fourier
FRX Fluorescência de raios $X$
I Número de rotação para um núcleo específico
ISO International Organization for Standartization
MEV-EDS Microscopia eletrônica de varredura
mf Massa final
mi Massa inicial
MOLR Microscopia óptica de luz refletida
MOLT Microscopia óptica de luz transmitida
n Ordem de difração
NBO Non-bridging oxigens (oxigênios não ponte)
NEXAFS Near edge $X$ ray absortion of fine structure
r Raio atômico
PCT-B Product consistence test ( teste de estabilidade de produto)
PDF Powder difraction file

Ral Resistência ao ataque alcalino

Rac Resistência ao ataque ácido 


\begin{tabular}{|c|c|}
\hline rc & Raio crítico \\
\hline REDOX & Equilíbrio de óxido-redução \\
\hline$R h$ & Resistência hidrolítica \\
\hline RNM-MAS & Ressonância nuclear magnética do ângulo mágico \\
\hline RRG & Resíduo de rochas ornamentais graníticas \\
\hline RSG & Resíduo sólido galvânico \\
\hline $\mathbf{s}$ & Área superficial \\
\hline$t$ & Tempo \\
\hline T C & Amostras baseadas em cálcio \\
\hline T CD & Amostras TC após tratamento térmico \\
\hline $\mathbf{T}_{\mathbf{f}}$ & Temperatura de fusão \\
\hline $\operatorname{Tg}$ & Temperatura de transição vítrea \\
\hline TR & Amostras baseadas em metais de transição \\
\hline TRD & Amostras TR após tratamento térmico \\
\hline UV-Vis & Espectroscopia ultravioleta-visível \\
\hline U.S. DOE & Departamento de Energia dos Estados Unidos \\
\hline$v_{0}$ & Freqüência de ressonância (freqüência de Larmour). \\
\hline VR & Vidro de referência \\
\hline XAFS & $X$ ray absortion of fine structure \\
\hline XPS & Espectroscopia fotoeletrônica de raios $X$ \\
\hline $\mathbf{Z}$ & Número atômico \\
\hline $\boldsymbol{\theta}$ & ângulo de incidência de um feixe de raios $X$ \\
\hline$\lambda$ & Comprimento de onda da fonte de raios $X$ \\
\hline$\mu$ & Momento nuclear magnético \\
\hline$\omega_{0}$ & Precessão giroscópica \\
\hline $\mathbf{Y}$ & Constante giromagnética \\
\hline
\end{tabular}




\section{1- Introdução}

Atualmente, presencia-se uma arriscada convivência de toda a sociedade com os crescentes problemas de contaminação ambiental. Neste contexto, a busca do desenvolvimento sustentável é amplamente aceita como um fator chave para o desenvolvimento social, técnológico e no retorno econômico dos futuros desenvolvimentos. Sobretudo, soluções ambientalmente sustentáveis primam pela manutenção da vida.

O conceito de desenvolvimento sustentável se relaciona com um amplo espectro de ações onde, uma das mais importantes é a mitigação das emissões de resíduos perigosos para a biosfera.

Um resíduo pode ser considerado ambientalmente perigoso devido a fatores tais como combustibilidade, patogeneidade, toxibilidade, etc. Os metais de transição, quando presentes em resíduos industriais, são sem dúvida, um dos mais perigosos vetores de contaminação ambiental. Estes metais quando depositados no solo, se difundem facilmente por águas, contaminando vegetais e animais, e por fim os seres humanos, tanto por ação direta quanto indiretamente pela ingestão de alimentos afetados. Metais de transição apresentam um conhecido impacto deletério na saúde humana. A presença de $\mathrm{Cr}^{3+}$ em um resíduo, por exemplo, pode ser uma fonte de cromo hexavalente $\left(\mathrm{Cr}^{6+}\right)$ o qual é carcinogênico e solúvel em água ${ }^{(1-4)}$. A produção mundial de resíduos galvânicos contendo metais de transição ultrapassa 1.000 .000 ton/ano ${ }^{(4-5)}$.

Outros resíduos, tais como finos de sílica e lamas de corte e polimento de rochas graníticas, embora quimicamente inertes, apresentam-se como perigosos por poderem provocar doenças respiratórias ou ainda pelo grande volume gerado, são ambientalmente degradantes. Estes resíduos, em geral, por não terem destinação adequada, acumulam-se no ambiente, tornando-se potenciais vetores para a ocorrência de desastres ecológicos. Desta forma, devem ser minimizados ou contidos, e quando possível, de uma maneira econômicamente viável. 
A reutilização de um resíduo consiste na forma mais eficiente para reduzir o descarte deste no meio ambiente. Neste sentido, são inúmeros os exemplos de esforços para a reciclagem de materiais nocivos, onde torna-lo apto para a matéria prima original (reciclagem primária), é possível apenas em um limitado número de casos. A obtenção de novos produtos a partir de resíduos industriais, ou seja, a reciclagem secundária é em muitos casos a melhor alternativa.

Os produtos cerâmicos são materiais que devido as suas características e processos de fabricação, permitem dispersar resíduos industriais entre as matérias-primas básicas, tornando-se assim uma atraente opção sob o ponto de vista ambiental. E neste particular, atualmente, se apresentam duas amplas linhas de desenvolvimento. Uma linha pode ser exemplificada por materiais cerâmicos tais como: telhas, cimentos, concretos, ou tijolos, que devido ao alto volume produzido podem tornar o processo de reciclagem econômicamente interessante ${ }^{(1,6-7)}$. Outra linha é a obtenção de produtos cerâmicos com maior valor agregado e menor volume de produção, tais como esmaltes, pigmentos, etc, que são produtos que para alcançarem colocação no mercado devem cumprir especificações técnicas rigorosas. Desta forma uma possibilidade de reuso de resíduos perigosos é a obtenção de produtos cerâmicos, em processos não deficitários economicamente, onde o resíduo se apresenta como uma matéria-prima funcional. Para alcançar este objetivo, tornase necessário portanto, um profundo conhecimento da função que cada elemento contido no resíduo e sua influência no produto final.

Os esmaltes e pigmentos cerâmicos são produtos em geral constituídos por uma expressiva fase vítrea. Vidros naturais, usualmente contém metais de transição em sua composição e de forma geral apresentam-se ambientalmente inertes por longos períodos de tempo, podendo representar milhões de anos. Nestas rochas, granitos e basaltos, os metais tóxicos são absorvidos numa matriz vítrea quimicamente estável ${ }^{(8)}$. Os processos industriais de vitrificação atualmente existentes, em geral simulam os fenômenos naturais de vitrificação das rochas vulcânicas (i.e., Basalto) e têm sido aplicados e/ou estudados tanto para o tratamento de resíduos radioativos $(9,10,11,12)$ como também para a inertização de cinzas provenientes de incineradores de resíduos urbanos $^{(6-7,13)}$. O vidro é assim utilizado devido às suas características fisico- 
químicas, tais como um bom comportamento durante a fusão, homogeneidade, durabilidade e estabilidade a diversas condições ambientais ${ }^{(8,14)}$. Estas características podem ser utilizadas para a inertização de resíduos industriais e em especial para os lodos galvânicos, os quais usualmente contém cromo $(\mathrm{Cr})$, níquel $(\mathrm{Ni})$, zinco $(\mathrm{Zn})$, cobre $(\mathrm{Cu})$ e chumbo $(\mathrm{Pb})^{(15-20)}$, entre outros elementos.

Este trabalho visa o estudo da interação dos metais de transição com a estrutura da rede vítrea, em materiais vítreos e vitrocerâmicos obtidos a partir de resíduos sólidos industriais provenientes das atividades metaloquímica de revestimento de metais, utilizando para ajustes de composição, resíduos industriais provenientes da manufatura envolvendo a cerâmica branca e de rochas ornamentais.

Particular destaque foi dado à obtenção de materiais vítreos ou vitrocerâmicos a partir de resíduos sólidos galvânicos, que de forma inédita estuda a possibilidade de se aplicar a funcionalidade dos metais de transição como modificadores da estrutura vítrea em substituição ao $\mathrm{CaO}$. 


\section{2- Objetivos}

Estudar a imobilização de resíduos sólidos industriais da atividade metalúrgica de revestimento de superfície por eletrodeposição, em vitrosilicatos contribuindo com uma alternativa técnica para a mitigação de problemas ambientais.

Este trabalho busca contribuir para esta questão enfocando:

- Verificar a hipótese da participação funcional dos elementos componentes dos resíduos, em particular dos metais de transição, na estrutura de vidros silicatos.

- Estudar a formação de fases cristalinas e a influência destas na resistência química destes materiais.

- Acompanhar a seqüência das alterações estruturais ocorridas nestes vidros em conseqüência dos ataques em diferentes meios.

- Utilizar como matérias-primas secundárias resíduos industriais provenientes da manufatura de cerâmica branca e de benefeciamento de rochas ornamentais. 


\section{3 - Revisão da Literatura}

\section{1 - Resíduos Sólidos Industriais}

Em termos mundiais, há uma grande variedade de parâmetros, para se definir o grau de periculosidade de um resíduo. No Brasil, os resíduos industriais são classificados em função de sua composição e estado de agregação, segundo as listagens publicadas na norma NBR $10.004^{(21)}$, editada pela ABNT - Associação Brasileira de Normas Técnicas. De acordo com esta norma, e tendo como base o estado de agregação, um resíduo industrial pode ser classificado como resíduos sólidos ou como resíduos não sólidos, sendo os primeiros, os materiais de interesse para este trabalho. Ainda segundo a NBR $10.004-2004{ }^{(21)}$, são considerados resíduos sólidos aqueles que se encontram nos estados sólidos e semi-sólido, e que por sua vez, são classificados conforme a periculosidade que apresentam:

- Resíduos classe I - perigosos. São resíduos que devido às suas características de inflamabilidade, corrosividade, reatividade, toxicidade e patogênicidade, podem apresentar riscos à saúde pública. $O$ que significa que podem provocar ou contribuir para um aumento da mortalidade ou incidência de doenças, incluindo a possibilidade de apresentarem efeitos adversos ao meio ambiente, quando manuseados ou dispostos de forma inadequada;

- Resíduos classe II-A - Não perigosos e não inertes. Constituem um grupo de resíduos que não se enquadram segundo a norma, como perigosos, mas que ao longo do tempo podem interagir com o meio ambiente e apresentar características poluentes, quando em concentrações superiores àquelas estabelecidas para esta classe;

- Resíduos classe II-B - Não perigosos e inertes. São aqueles nos quais os constituintes dos resíduos, quando submetidos aos ensaios de solubilização constantes na norma NBR $10.006^{(22)}$, ou seja, solubilizados 
em água destilada, ou deionizada à temperatura ambiente, não apresentam concentrações de impurezas superiores aos padrões de potabilidade da água, indicados pela norma NBR $10.004{ }^{(21)}$, excetuando-se os aspectos de cor, turbidez e sabor.

- Segundo uma pesquisa realizada pela Cetesb - Companhia de Tecnologia de Saneamento Ambiental, somente no estado de São Paulo são gerados 535 mil toneladas anuais de resíduos classe I, sendo que deste total 187 mil toneladas são geradas na região metropolitana da cidade de São Paulo. Este levantamento realizado no ano de 1993 ainda permanece, até o momento, praticamente como o único referencial sobre a quantidade de resíduos industriais gerados no estado de São Paulo ${ }^{(4,6-7)}$.

\section{2 - Vidros e Vitrocerâmicos}

\subsection{1 - Vidros}

O vidro é um dos materiais mais versáteis e freqüentemente utilizados desde a Antigüidade por permitir grandes variações em sua composição química e assim adaptar-se a uma infinidade de usos. Constituem um grupo de materiais com característica estrutural amorfa e apresenta um conjunto de propriedades que não o define totalmente nem como líquido, nem como sólido cristalino. Considerando-se a sua distribuição atômica, o vidro se assemelha mais aos líquidos, que aos sólidos cristalinos. Também não apresenta à pressão constante, a temperatura característica e definida, de transformação de estado sólido-líquido, como ocorre nos sólidos cristalinos. Por outro lado, ao apresentar rigidez e uma certa elasticidade, se assemelha aos sólidos cristalinos. Em adição, devido à sua natureza amorfa, isto é, não apresenta ordem a longas distâncias, o vidro não fratura em direções preferenciais. Entretanto, ele pode fluir sob a ação de uma elevada tensão de cisalhamento, como ocorre no metais (materiais cristalinos) $(23,24)$.

\subsection{2 - Tipos de Vidros}

Vários tipos de vidros podem ser produzidos com características distintas, como resultado das inúmeras possibilidades de composição química e do histórico do processo utilizado, ou ainda em função da 
aplicação desejada. Dentre estes, a mais comum é a família dos vidros silicatos obtidos por fusão e resfriamento. De acordo com a formulação, a família dos vidros silicatos é classificada, em quatro grupos principais: vidro silicato tipo soda-cal; vidro silicato com chumbo; vidro tipo boro-silicato e vidro tipo alumino-silicato. Os vidros silicato tipo soda-cal representam a quase totalidade da produção industrial de vidros e são os mais utilizados em aplicações tais como, embalagens, vidros domésticos, vidros planos entre outras. É constituído basicamente pelos óxidos: $\mathrm{SiO}_{2}, \mathrm{O} \mathrm{Na}_{2} \mathrm{O}$ e o $\mathrm{CaO}$. Em alguns casos podem apresentar na sua composição quantidades menores de outros óxidos, como $\circ \mathrm{Al}_{2} \mathrm{O}_{3}$ e $\mathrm{MgO}$. Os vidros silicato, tipo boro-silicato são comumente empregados em vidrarias de laboratório. Neste estudo, a ênfase foi dada a variações dos vidros soda-cal com adição de boro ${ }^{(23)}$.

\subsection{3 - Formação e Estrutura dos Vidros Silicato}

Os líquidos formadores de vidro, ao serem resfriados a uma velocidade adequada, conservam uma estrutura amorfa, similar à desordem estrutural apresentada no estado líquido. Este fato é atribuído à alta viscosidade destes líquidos em intervalos de temperaturas próximas à sua solidificação ou re-ordenamento estrutural que ocorre no intervalo de temperatura denominado como transição vítrea $(\mathrm{Tg})^{(24)}$.

Sob o ponto de vista termodinâmico, a solidificação do material ocorre devido à rápida retirada de temperatura do sistema, durante o superresfriamento. Sob o ponto de vista da cinética de formação, o líquido formador de vidro ao ser super-resfriado até a solidificação, apresenta um acentuado gradiente de viscosidade, atingindo diferenças de diversas ordens de grandeza ${ }^{(25)}$ em um curto espaço de tempo. Esta rápida variação da viscosidade do líquido impede que ocorra o re-ordenamento atômico necessário para que se estabeleça o processo de formação de núcleos estáveis e crescimento de fases cristalinas.

$\mathrm{Na}$ Fig.3.1 são mostrados de uma maneira esquematizada, os possíveis comportamentos de variação de volume ou calor específico em função da temperatura, em relação à velocidade de resfriamento de um 
líquido a partir de seu estado fundido $\left(\mathbf{T}_{\mathbf{f}}\right)$, ponto $\mathbf{A}$, até o seu estado solidificado, ponto D (sólido cristalino) ou ponto F (vidro).

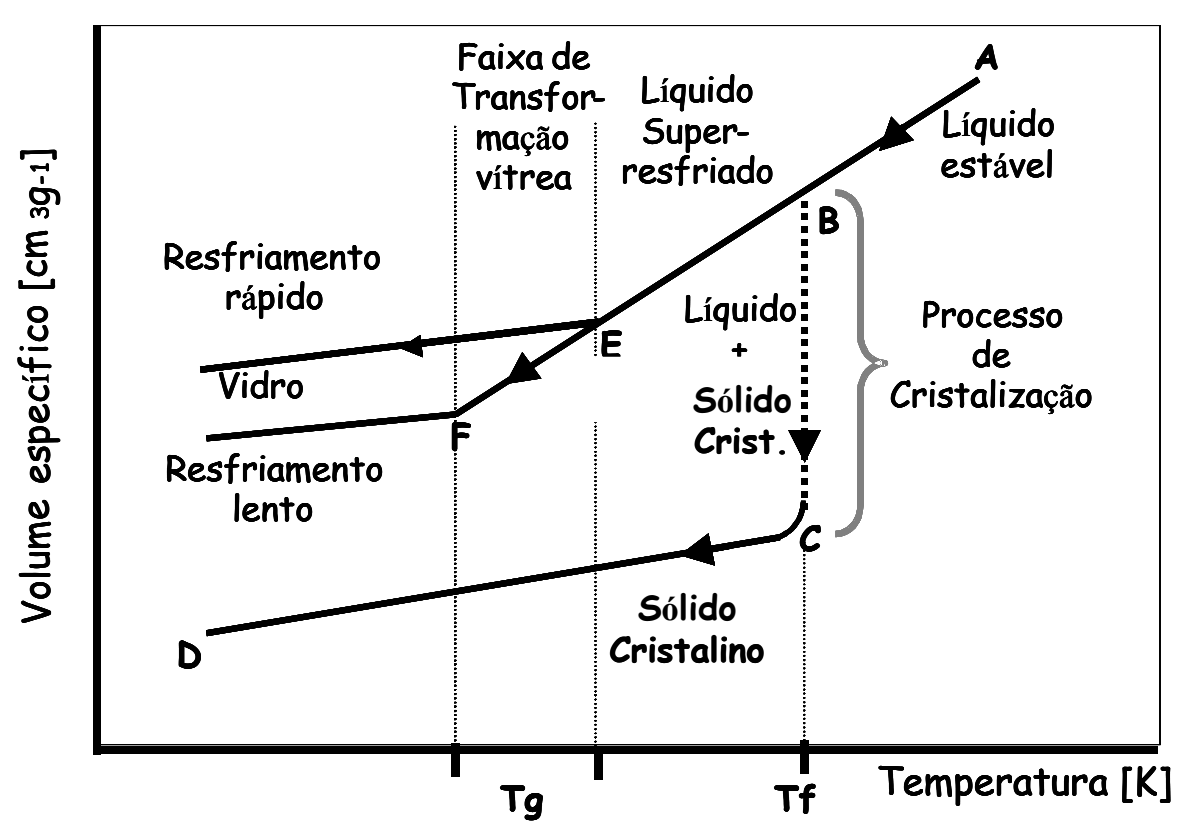

FIGURA 3.1 $1^{(23,24)}$ - Diagrama da variação do volume específico em função da temperatura. Onde: $T_{f}$ - a temperatura de fusão; $T_{g}$ - "intervalo" da temperatura de transição vítrea.

Observando no gráfico (Fig.3.1), no ponto (A) o material é um líquido estável. Um líquido (A), ao ser resfriado, apresenta redução de seu volume, de acordo com o segmento $\mathbf{A B}$, pois com menor temperatura, menor é a agitação de suas moléculas. Se a velocidade de resfriamento for suficientemente lenta, na temperatura de fusão ocorrerá uma acentuada redução de volume, pois as moléculas que antes apresentavam um significativo grau de liberdade, característico do estado líquido, passam a se ordenar de forma regular. O re-ordenamento cristalino ocorre normalmente pela formação de núcleos estáveis e crescimento destes na temperatura $\mathbf{T}_{\mathbf{f}}$. Esta temperatura permanece constante até que o processo de mudança de estado seja concluído (segmento BC). Após a completa cristalização do material (ponto $\mathbf{C}$ ), uma continuidade no resfriamento, ocasiona uma redução ainda maior no grau de agitação das moléculas do material, que se 
traduz em diminuição de volume ou aumento de densidade. A reta CD tem menor inclinação que a $\mathbf{A B}$, pois no estado sólido os átomos arranjados na forma de cristais, tem menor liberdade de movimentação. Como resultado obtém-se cristais, ou seja, arranjos tridimensionais ordenados de átomos que se repetem em períodos regulares.

Se a velocidade de resfriamento, a partir do líquido, for suficientemente alta, e como conseqüência o tempo de resfriamento se torne insuficiente para que os átomos reordenem a rede cristalina, o processo de nucleação-crescimento de cristais não ocorre. Desta maneira obtém-se um líquido super-resfriado. Com a rápida retirada de calor (segmento $\mathrm{AE}$ ), a retração do material continuará ocorrendo devido à diminuição da agitação térmica das moléculas, até próxima à temperatura $\mathbf{T}_{\mathbf{g}}$. A partir desta temperatura, os processos de difusão e re-ordenamento atômico ficam praticamente impedidos de ocorrerem devido à alta viscosidade, representado pela mudança de inclinação da curva (segmento E), onde se observa que, a variação da taxa de retração com a redução da temperatura é menor quando comparada à do processo de formação de sólido cristalino. A temperatura $\mathbf{T}_{\mathbf{g}}$ é chamada de temperatura de transição vítrea. Em temperaturas inferiores a $\mathbf{T}_{\mathbf{g}}$, o material assim resfriado é considerado um vidro. $\mathrm{Na}$ temperatura $\mathbf{T}_{\mathbf{g}}$, para vidros silicatos, a viscosidade é da ordem de $10^{13}$ Poise ${ }^{(23,24)}$.

Teoricamente é possível obter vidros a partir de qualquer material, bastando que a velocidade de resfriamento seja suficientemente elevada. Na prática porém, os materiais que podem vir a constituir vidros são aqueles que apresentam uma acentuada variação de viscosidade com a variação de temperatura antes de atingir a temperatura de transição vítrea. Entretanto, o rápido resfriamento de uma substância altamente viscosa, não é uma condição suficiente para a formação de vidro. O fenômeno de vitrificação depende da interação entre as espécies envolvidas e também de suas características moleculares ${ }^{(23,24)}$.

Vidros silicatos, assim como minerais, não são compostos por moléculas discretas, mas por redes conectadas tridimensionalmente. A unidade básica da rede de sílica é o tetraedro silício-oxigênio, no qual um átomo de silício está ligado a quatro átomos de oxigênio. Os átomos de 
oxigênio se dispõem espacialmente, formando um tetraedro. Desta forma, a estrutura do vidro tem uma ordem confinada à coordenação poliédrica (ordem de curto alcance) correspondente àquela dos cristais de composição química similar não havendo porém uma ordem cristalográfica de longo alcance $^{(26)}$.

A formação de vidros passou a ser estudada, com mais atenção, com o aperfeiçoamento das técnicas de difração de raios $X$. Desde então, várias teorias foram propostas para explicar a sua estrutura. Entretanto, todas elas se fundamentam na teoria inicial apresentada por Zachariasen (27), formulada em 1932. Esta teoria propõe, que os átomos presentes no vidro formam uma estrutura conectada, sem uma ordem periódica e contendo uma energia de ligação comparável à da forma cristalina correspondente ao material. O número de coordenação de um átomo determina, segundo esta teoria, se ele está ou não participando da estrutura do vidro. Zachariasen propôs quatro regras para um óxido formar a estrutura desordenada do vidro:

1) cada átomo de oxigênio deve estar ligado no máximo a dois cátions;

2) o número de átomos de oxigênio ligados a um cátion deve ser pequeno, ou seja, três ou quatro;

3) para formar uma rede tridimensional, o oxigênio do poliedro deve compartilhar os vértices, nunca as arestas;

4) pelo menos três vértices devem ser compartilhados.

Com o compartilhamento dos vértices entre os poliedros, forma-se a rede desordenada, que se prolonga nas três dimensões acompanhada de espaços vazios entre os poliedros que formam o vidro.

A randômicidade do arranjo dos elementos da estrutura do vidro é estabilizada por uma forte rede polimérica com ligações químicas covalentes-iônicas, como nos vidros silicatos, fosfatos e boratos ou por heterogeneidades com clusters de misturas estabilizadoras ${ }^{(26)}$, onde coesão deste tipo de material é assegurada por ligações covalentes (Si-O, B-O) e ligações iônicas $(\mathrm{Na:O})^{(28,29)}$.

A função que cada óxido desempenha na formação do vidro é melhor compreendida com o estudo das energias de ligação interatômicas e 
do seu número de coordenação. Nos vidros de múltiplos componentes, os termos, formadores, intermediários e modificadores, são freqüentemente utilizados para definir a função de um óxido individual. Entretanto, componentes tais como $\circ \mathrm{Al}_{2} \mathrm{O}_{3}$ pode ser formador ou intermediário, dependendo de seu número de coordenação e do sistema considerado $(24,30)$.

Os cátions de óxidos formadores de vidros, normalmente, são de pequeno tamanho, apresentam valência igual ou maior a três e eletronegatividade de Pauling, entre 1,5 e 2,1 ${ }^{(30)}$. Estes óxidos, geralmente possuem forças de ligação interatômica (Cátion-Oxigênio) maiores que 335 $\mathrm{KJ} / \mathrm{mol}(80 \mathrm{Kcal} / \mathrm{mol})$. Os óxidos $\mathrm{SiO}_{2}, \mathrm{~B}_{2} \mathrm{O}_{3}$ e algumas formas de $\mathrm{Al}_{2} \mathrm{O}_{3}$, por apresentarem todas estas características, são considerados "formadores primários de vidro". A flexibilidade da estrutura vítrea torna possível a mudança de número de coordenação de diversos compostos formadores, dependendo da composição química do vidro. A alumina, por exemplo, pode formar $\mathrm{AlO}_{4}$ e $\mathrm{AlO}_{6}$, a sílica $\mathrm{SiO}_{4}$ e $\mathrm{SiO}_{6}$, e ainda o boro nos vidros nas formas $\mathrm{BO}_{3}$ e $\mathrm{BO}_{4}{ }^{(26)}$.

As ligações covalentes são consideradas ligações fortes e marcadamente direcionais, favorecendo desta forma a formação de estrutura tetraédrica, como no caso da ligação Si-O ${ }^{(25)}$.

No vidro puro de sílica, todos os tetraedros estão ligados pelos vértices por meio do compartilhamento de um átomo de oxigênio por dois átomos de silício. Todos os quatro átomos de oxigênio de um tetraedro podem ser compartilhados com quatro outros tetraedros formando uma rede tridimensional, onde o arranjo à curta distância, ou seja, de átomo a átomo é idêntico ao da sílica cristalina porém a periodicidade estrutural, ao longo da rede não é reproduzida, como normalmente ocorre em materiais cristalinos, (Fig. 3.2) ${ }^{(28)}$.

Os oxigênios partilhados são chamados de oxigênio "pontes", ou "bridging oxigens" (BO). Em vidros ou em minerais de sílica pura, como o quartzo, a relação entre silício e oxigênio é de 1:2, pois, embora o tetraedro tenha a formulação $\mathrm{SiO}_{4}$, cada oxigênio é ligado a dois átomos de silício, resultando a formulação $\mathrm{SiO}_{2}$, e todos os oxigênios são pontantes (formam pontes). 


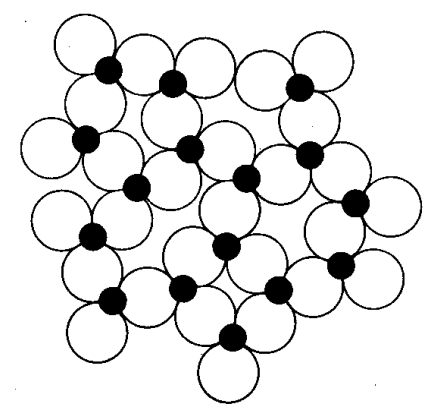

(a)

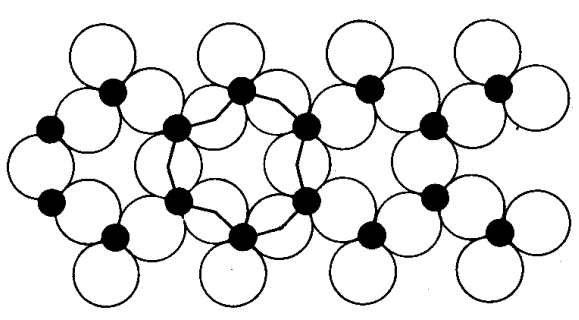

(b)

Figura $3.2^{(28)}$ - Esquema exemplificando a ligação entre tetraedros de sílica. (a) Vidro. (b) Sílica cristalina.

Segundo a teoria de Zachariassem, no caso vidros de puros de sílica, cada tetraedro de sílica (unidade estrutural) está ligado covalentemente a quatro outros tetraedros pelos BO's nas arestas, formando assim a rede estrutural randômica ${ }^{(31)}$.

Dependendo de seu número de coordenação, $\mathrm{Al}_{2} \mathrm{O}_{3}, \mathrm{Fe}_{2} \mathrm{O}_{3}, \mathrm{ZnO}, \mathrm{PbO}$, etc., podem participar da formação da rede polimérica, mas sempre em arranjos com $\mathrm{SiO}_{2}$. Por isso, são conhecidos, como "formadores intermediários de vidros". Neste tipo de arranjo da rede vítrea, parte dos oxigênios dos tetraedros $\mathrm{SiO}_{2}$ podem não ser compartilhados em arranjos com outros tetraedros. Estes oxigênios não partilhados são chamados de oxigênio "não-pontes" ou "nonbridging oxigen" (NBO) ${ }^{(31)}$. Conforme a ocorrência de NBO's os tetraedros de sílica podem ser representados da seguinte forma: $Q^{4}, Q^{3}, Q^{2}, Q^{1}, Q^{0}(0,1,2,3$ e 4, NBO's respectivamente). Esta notação por conseqüência indica a forma pela qual a rede vítrea está organizada, ou seja:

a) $Q^{4}$, rede vítrea organizada tridimensionalmente, este é o arranjo encontrado nos vidros puros de sílica;

b) $Q^{3}$, rede vítrea organizada em planos ou superfícies;

c) $Q^{2}$, rede vítrea organizada em cadeias;

d) $\mathrm{Q}^{1}$, dímeros de $\mathrm{SiO}_{2} ; \mathrm{e}$,

e) $Q^{0}$, tetraedros de sílica isolados, que não se enquadram na estrutura aleatória proposta por Zachariasen. 
Os NBO's representam pontos de descontinuidade da rede, onde há a necessidade da compensação da carga negativa do oxigênio para estabilizar a estrutura. A estabilidade de cargas é obtida com a associação com cátions (em geral $\mathrm{R}^{+}$ou $\mathrm{R}^{2+}$ ), formando ligações do tipo iônico ${ }^{(23,24,28)}$. Os óxidos fornecedores destes cátions para o vidro são conhecidos como "modificadores de rede". Por tanto, cada molécula de óxido modificador que se acrescenta à sílica pode inibir uma ligação do tipo Si-O-Si liberando um radical, para incorporar o oxigênio adicional ${ }^{(23,32)}$, como apresentado pela reação (3.1):

$$
\mathrm{Si}-\mathrm{O}-\mathrm{Si}+\mathrm{R}_{2} \mathrm{O} \longrightarrow \mathrm{Si}-\mathrm{O}-\mathrm{R}^{+}+\mathrm{R}^{+} \mathrm{O}-\mathrm{Si}
$$

Onde $\mathrm{R}^{+}$representa por exemplo um íon álcali. Deste modo, a concentração relativa de BO's e NBO's em um vidro silicato é determinada pela sua composição química ${ }^{(32)}$.

A presença de cátions modificadores associados à rede vítrea representa pontos de descontinuidade e apresentam interesse tecnológico por diminuir a temperatura de fusão destes vidros. A presença destes cátions, especialmente na forma monovalente, também pode diminuir a resistência química do vidro.

Um vidro pode incorporar quantidades crescentes de óxidos modificadores até que se atinja uma proporção na qual pode-se comprometer a coesão estrutural ${ }^{(23)}$. Em geral, para completar a sua coordenação, os cátions modificadores irão formar ligações com oxigênios em número necessário até completar a sua valência. A adição de óxidos alcalino-terrosos e, em geral, de cátions bivalentes, também pode causar uma ruptura da rede. Neste caso, a descontinuidade da rede fica em parte compensada pela dupla carga positiva destes cátions os quais passam a se ligar iônicamente a dois NBO's de distintos tetraedros ${ }^{(23)}$. Os vidros com cátions modificadores bivalentes apresentam maior temperatura de fusão e resistência química, quando comparada com os cátions monovalentes. Segundo Mysen (33) em determinadas condições alguns elementos modificadores de rede podem apresentar um comportamento estrutural similar ao dos formadores. 
A maioria dos elementos modificadores da rede, se comparados ao silício, apresentam grande raio atômico e/ou alta carga eletrônica, características estas que dificultam sua acomodação na coordenação tetraédrica com os oxigênios. Mysen ${ }^{(33)}$ propõe que a atividade dos elementos modificadores presentes nos líquido de silicato pode ser relacionada como o potencial de ionização do cátion modificador, dado pela relação $\mathbf{Z} / \mathbf{r}^{2}$, onde $\mathbf{Z}$ é número atômico e $\mathbf{r}$ é o raio atômico do cátion. $O$ aumento da relação raio/carga do modificador induz à polarização da rede (32)

Os elementos modificadores complementam-se com os formadores distribuindo-se nas posições estruturais disponíveis. Entretanto, exibem preferência por pontos estruturais específicos, ou seja, estes cátions irão apresentar afinidade por espécies específicas $\mathbf{Q}^{n}$. Nos líquidos de silicato que contêm dois ou mais cátions modificadores de rede com diferentes raios e cargas irão apresentar afinidades específicas por NBO's energeticamente distintas ${ }^{(33)}$.

As NBO's podem ser distintas umas das outras porque a densidade de elétrons a elas associadas depende do número de BO's vizinhas e para curtas distâncias, da natureza dos cátions ligados a NBO nas ligações SiNBO, desta forma é possível existir um tetraedro com oxigênios energeticamente não equivalentes. Tal arranjo pode levar ao ordenamento dos cátions modificadores da rede, afetando a relação de composição destes nos líquidos de silicato, assim como, as características que dependem da estrutura dos vidros. Por exemplo, é possível ocorrer uma situação de imiscibilidade no líquido ${ }^{(33)}$.

Desta forma, as proporções relativas entre as $\mathbf{Q}^{\mathrm{n}}$ espécies e suas interações com os cátions modificadores de diferentes $\mathbf{Z} / \mathbf{r}^{2}$ determinam as propriedades dependentes da estrutura e a cristalização do vidro silicato.

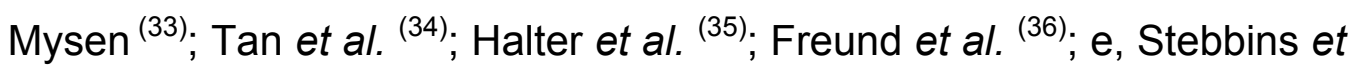
al. ${ }^{(37)}$; fundamentaram seus estudos em um modelo de distribuição relativa entre as $\mathbf{Q}^{\mathbf{n}}$ espécies segundo a equação (3.2): 


$$
2 Q^{n} \longleftrightarrow Q^{n-1}+Q^{n+1}
$$

A partir desta relação, estes autores desenvolveram cálculos sobre diversos aspectos termodinâmicos da formação de vidros. Entre propriedades e comportamentos termodinâmico, foi possível nestes estudos, estabelecer a entalpia, entropia, calor específico de formação e potencial químico entre as espécies $\mathbf{Q}^{\mathbf{n}}$, além da relação entre cristais e líquidos correspondentes.

Entretanto, todos o modelos foram desenvolvidos apenas para calcular as propriedades termodinâmicas de líquidos à base de silicatos em sistemas binários silicato/álcali. Deste modo, estes estudos, embora permitissem apresentar uma descrição detalhada das propriedades dos líquidos e vidros a base de silicatos por meio das propriedades, a utilização de um número mínimo de componentes e de condições de resfriamento estritamente controladas, faz com que seja praticamente inviável comparar estes valores com os encontrados em condições reais, ou seja, vidros constituídos de múltiplos componentes.

Os óxidos formadores intermediários de vidros que também podem atuar nos vidros como modificadores, em função de sua valência e número de coordenação ${ }^{(27)}$. Como exemplo disso pode-se citar os óxidos de alumínio ou de boro, pois tanto o $\mathrm{Al}^{3+}$ como $\circ \mathrm{B}^{3+}$ exibem uma forte tendência para substituir $\mathrm{Si}^{4+}$ nas espécies $\mathrm{Q}^{4}$ e por outro lado, também como modificadores atuam na compensação de cargas. A vantagem desta flexibilidade de comportamento é que a substituição facilita a obtenção do equilíbrio de cargas quando necessário ${ }^{(33)}$. A alta concentração de uma determinada espécie $\mathbf{Q}^{\mathbf{n}}$ é afetada de acordo com a função apresentada por estes óxidos na estrutura vítrea. Analogamente, o mesmo efeito pode ocorrer com outras espécies quando presentes nos vidros por também apresentarem vários estados de valência e coordenação como o $\mathrm{Fe}, \mathrm{Ni}, \mathrm{Cr}$, embora não sendo considerados "funcionais" na formação da estrutura do vidro ${ }^{(31,33,38-39)}$. Os metais de transição não são usualmente utilizados nos vidros silicato em concentrações maiores que $5,0 \mathrm{~mol} \%{ }^{(40)}$.

Segundo Calas et al. ${ }^{(38)}$, com as elevadas temperaturas envolvidas na fusão do vidro, os cátions de metais pesados e de metais de transição presentes em um líquido precursor, poderão se apresentar na forma de 
óxidos com diferentes números de coordenação, muitas vezes iguais ou maiores que 5, participando da rede estrutural, fazendo ligações com duas ou mais unidades estruturais (tetraedros), contribuindo para o aumento da coesão estrutural e influenciando as propriedades características dos vidros.

O ferro freqüentemente esta presente nos vidros silicato em quantidades traço, pois este elemento é uma impureza comum nas areias utilizadas para o fornecimento de sílica. Nos vários estudos realizados sobre o equilíbrio entre as espécies $\mathrm{Fe}^{2+}$ e $\mathrm{Fe}^{3+}$ no vidro ${ }^{(41-50)}$ indicam que em concentrações inferiores a $<5 \mathrm{~mol} \%$ os íons $\mathrm{Fe}$ interagem com e rede vítrea de forma similar aos metais alcalinos e alcalinos terrosos, isto é, em pequenas concentrações o $\mathrm{Fe}$ atua como modificador da rede.

A função estrutural do $\mathrm{Fe}$ nos vidros depende de sua valência e coordenação local: a) o $\mathrm{Fe}^{2+}$ atua como modificador do vidro formando octaedros $\mathrm{FeO}_{6}$ e, b) $\circ \mathrm{Fe}^{3+}$ ocorre nas formas tetraédrica (formador) e/ou octaédrica (modificador) atuando neste caso como um formador intermediário ${ }^{(51-53)}$. Em vidros silicato contendo ferro, também se verifica que a integridade estrutural da rede vítrea e a estabilidade química do material estão diretamente associadas com a interação entre os íons ferro e a estrutura, ou seja, com a sua habilidade como formador de vidros ${ }^{(49)}$. A presença de outros elementos, sejam modificadores da rede e/ou formadores intermediários, influenciam o equilíbrio $\mathrm{Fe}^{2+} / \mathrm{Fe}^{3+}$; e a distribuição da coordenação do $\mathrm{Fe}^{3+}$ entre tetraédrica e octaédrica. Holland et al ${ }^{(40)}$, comparou o $\mathrm{Fe}^{3+} \mathrm{com}^{\circ} \mathrm{Al}^{3+}$, atuando como formador intermediário de vidros. Em seus estudos relaciona este comportamento com o campo iônico, $\mathbf{Z} / \mathbf{r}^{2}$ comparando de vários íons encontrando os seguintes valores: 56,6 para $\mathrm{Al}^{3+} ; 54,5$ para $\mathrm{Fe}^{3+} ; 32,8$ para $\mathrm{Fe}^{2+} ; 100$ para $\mathrm{Si}^{4+}$; e, 9,8 para $\mathrm{Na}^{+}$. Nos vidros $0,3 \quad \mathrm{Na}_{2} \mathrm{O}: x \mathrm{Fe}_{2} \mathrm{O}_{3}:(0.7-x) \mathrm{SiO}_{2}(0,0 \leq x \leq 0,20)$, a relação $\mathbf{B O} / \mathrm{NBO}$ aumenta com a concentração de $\mathrm{Fe}_{2} \mathrm{O}_{3}$, o que é consistente com $\mathrm{Fe}^{3+}$ atuando como " formador intermediário".

MEKKI et al ${ }^{(54)}$, confirmam a atuação de formador intermediário ao verificar que a temperatura de transição vítrea $(\mathbf{T g})$ aumenta enquanto o coeficiente de expansão térmica (CET) diminui, com a substituição do $\mathrm{SiO}_{2}$ por $\mathrm{Fe}_{2} \mathrm{O}_{3}$, isto é, a rede vítrea aumenta sua rigidez.

A energia de ligação $\mathrm{Fe}-\mathrm{O}-\mathrm{Si}$ é maior que a $\mathrm{Na}: \mathrm{O}-\mathrm{Si}$, devido a covalência da ligação $\mathrm{Fe}-\mathrm{O}$, a qual é característica de um intermediário. Se um 
poliedro $\mathrm{FeO}_{4}$ substituir um tetraedro $\mathrm{SiO}_{4}$ em um vidro, uma carga negativa irá se formar devido a diferença de valência entre o $\mathrm{Si}^{4+}$ e o $\mathrm{Fe}^{3+}$. Segundo o autor, esta carga negativa é compensada pela proximidade de íons $\mathrm{Na}^{+}(40)$.

$\mathrm{Na}$ natureza, o cromo pode apresentar um grande número de estados de oxidação, dos quais apenas $\circ \mathrm{Cr}^{3+}$ e $\circ \mathrm{Cr}^{6+}$ são estáveis ${ }^{(55-61)}$.

Praticamente todo o cromo encontrado na forma mineral é trivalente ${ }^{(62)}$. $\mathrm{O}$ cromo $\mathrm{Cr}^{+6}$ é solúvel em água, e neste estado de oxidação são fortes agentes oxidantes os quais atuam em sistemas biológicos como agentes carcinogênicos e mutagênicos ${ }^{(55,63-64)}$.

O cromo é um elemento traço em silicatos minerais e nesta condição é compatível como diversos outros elementos, ocorrendo predominantemente na forma trivalente onde a formação de espinélios reforça esta tendência. Nos minerais $\circ \mathrm{Cr}^{3+}$ apresenta coordenação octaédrica ${ }^{(65-66)}$.

Em matrizes vítreas os íons $\mathrm{Cr}^{3+}$ a coordenação do mesmo é dependente do ambiente local. Os íons $\mathrm{Cr}^{3+}$ ocorreriam preferencialmente na coordenação octaédrica $\left(\mathrm{CrO}_{6}\right)$ em relação a tetraédrica porque a configuração eletrônica $3 d^{3}$, tem a energia associada ao nível $d$ do eletrón no orbital na simetria octaédrica ${ }^{(67-72)}$.

Nos vidros silicato soda-cal, o cromo pode coexistir nas formas trivalente e hexavalente, contudo, de forma oposta aos silicatos minerais, nestes vidros a forma trivalente é predominante e mais estável em condições neutras ou moderadamente redutoras ${ }^{(23,73-74)} \cdot \mathrm{O} \mathrm{Cr}^{3+}$ possui duas bandas de absorção (450 e $650 \mathrm{~nm}$ ), as quais como efeito produzem no vidro uma cor verde esmeralda. $\mathrm{O} \mathrm{Cr}^{6+}$ (banda de absorção a $370 \mathrm{~nm}$ ) contribui para a cor amarela brilhante. Embora menos freqüente, o cromo pode apresentar nos vidros outros estados de oxidação ${ }^{(75-76)}$.

A composição do líquido influência a relação do $\mathrm{Cr}^{3+/} \mathrm{Cr}^{6+}$ (77-79). Knupp et al ${ }^{(80)}$, investigaram o efeito do óxido férrico no equilíbrio do cromo em vidros verdes. Concluiu que o $\mathrm{Fe}_{2} \mathrm{O}_{3}$ produz um efeito redutor e altera o equilíbrio em favor do $\mathrm{Cr}^{3+}$. Em outro estudo destes mesmos autores ${ }^{(81)}$, o efeito do oxigênio atmosférico e o sulfato no líquido fundido foi analisado. Segundo este estudo, o oxigênio atmosférico favorece a formação de cromo 
hexavalente enquanto os produtos de decomposição dos sulfatos $\left(\mathrm{SO}_{2} \mathrm{e}\right.$ $\mathrm{SO}_{3}$ ) dificulta esta formação.

Guidal et al ${ }^{(82)}$, indicam com seu estudo que a relação $\mathrm{Cr}^{3+} / \mathrm{Cr}^{6+}$ no vidro é sensível a presença de outros compostos oxidantes ou redutores no líquido fundido. A efetividade destes agentes varia de um material para outro.

Segundo Calas ${ }^{(65)}$, vidros silicato contendo álcalis e $\mathrm{Cr}^{3+}$ apresentam uma estrutura heterogenia em escala atômica, coexistindo ligações iônicas e covalentes do Cromo com a rede vítrea, entretanto nos vidros estudados por ele, o cromo forma preferencialmente ligações iônicas.

A literatura apresenta poucos estudos sobre a solubilidade do $\mathrm{Cr}$ e do equilíbrio de óxido-redução (REDOX) para vidros boro-silicato sem a presença de elementos formadores de espinélios. Hrma et al. ${ }^{(74)}$, estudaram o comportamento do $\mathrm{Cr}$ em vidros borosilicato para a armazenagem de resíduos nucleares. Observaram que as espécies $\mathrm{Cr}^{3+}$ dissolvidas são progressivamente oxidadas para $\mathrm{Cr}^{6+} \mathrm{com}$ a redução da temperatura até abaixo de líquidus, durante a têmpera. Este fenômeno ocorre quando há a disponibilidade de oxigênios para a reação REDOX e é restrita a regiões do vidro com alta basicidade. A partir destes dados, Hrma sugere que devido a esta particular combinação entre equilíbrios de fases e de reações REDOX, é possível a produção de vidros com alto conteúdo de cromo dissolvido.

$\mathrm{O}$ cromo nos vidros boro-silicato tende a precipitar-se na forma de cristais de eskolaita $\left(\mathrm{Cr}_{2} \mathrm{O}_{3}\right)$ ou a segregar como uma fase líquida de cromatos $(2,74,83-87)$. Segundo Süssmilch ${ }^{(88)}$ a precipitação da eskolaita não causa efeitos adversos na durabilidade do vidro, e a formação do cromato pode ser evitada se o cromo presente no vidro for reduzido. A presenca de $\mathrm{Ni}$, $\mathrm{Fe}$ ou outros componentes, pode levar o cromo a formar espinélios.

Chun-Te et al. ${ }^{(89)}$; sugere que para sistemas de vidro soda-cal contendo $\mathrm{Cr}$, Fe e $\mathrm{Cu}$, o aumento da concentração de cátions $\mathrm{Na}^{+} \mathrm{e} \mathrm{Ca}^{2+}$, ocasiona o equilibro de cargas na rede vítrea necessário para o $\mathrm{Cr}_{2} \mathrm{O}_{3}$ ocorrer os vidros na função de formador intermediário da rede vítrea, de forma similar ao $\mathrm{Al}_{2} \mathrm{O}_{3}$.

O níquel ocorre nos vidros de óxidos em várias coordenações (tetraédrica, trigonal e a menos freqüente a octaédrica) e não exibe uma 
relação geométrica bem definida com a rede estrutural de silicato, tendo como segundo vizinho outro cátion $(\mathrm{Ca}, \mathrm{Na})$. $\mathrm{O}$ estado de valência do níquel muitas vezes irá influenciar na cor final apresentada pelo vidro, como verde, amarelo, marrom, púrpura e azul ${ }^{(23)}$.

Segundo Calas et al. ${ }^{(90)}$; e, Burns et al ${ }^{(66)}$; a forma de condenação do $\mathrm{Ni}^{2+}$ no vidro silicato soda-cal ocorre a partir da mistura entre as formas tetraédrica e hexaédrica. Segundo Keppler ${ }^{(91)}$ a ocorrência do $\mathrm{Ni}^{2+}$ é na forma hexaédrica distorcida. $\mathrm{O} \mathrm{Ni}^{2+}$ ocorre predominantemente pentacoordenado (como bipirâmides trigonais), com quantidades variáveis de $\mathrm{Ni}^{2+}$ coordenado tetraedricamente e hexaedricamente ${ }^{(92-94)}$.

A coordenação dos metais de transição nos vidros silicato é controlada fatores tais como: 1) A flexibilidade relativa da distância da ligação metal-oxigênio (particularmente se avizinhado de modificadores tais como $\mathrm{Na}$ e $\mathrm{Ca}$ ), que permite a adaptação destes cátions para uma dada situação de ligação em função da pressão temperatura ou composição. 2) Os pré-requisitos gerais para satisfazer a regra das valências de ligação de Pauling ${ }^{(92,95,96)}$.

A concentração relativa do $\mathrm{Ni}^{2+}$ tetraédrico e octaédrico é dependente da concentração de álcalis, das espécies alcalinas $\left(\mathrm{Na}_{2} \mathrm{O}, \mathrm{K}_{2} \mathrm{O}\right.$ ou $\left.\mathrm{Cs}_{2} \mathrm{O}\right)$ presentes e da composição do líquido ${ }^{(97-100)}$.

O potencial redox dos metais de transição é dependente da basicidade do líquido silicato alcalino. Num liquido à base de silicato sódico, a troca do sódio por outro óxido de maior basicidade, como o potássio, Faz com que o $\mathrm{NiO}$ se torne termodinamicamente instável ${ }^{(97)}$.

O zinco é encontrado com mais freqüência na coordenação tetraédrica e menos freqüente na octaédrica. Nos vidros alcalinos silicatos, são necessárias apenas pequenas adições de ZnO ( $<5 \%$ em massa), para melhorar significativamente tanto as propriedades mecânicas como também a estabilidade química ${ }^{(23)}$.

O chumbo e o zinco, coexistindo em um vidro são considerados respectivamente como intermediário e formador de vidros. Dependendo da concentração relativa, $\mathrm{Pb}$ e $\mathrm{Si}$ se complementam para formar uma cadeia polimérica da rede vítrea ${ }^{(101-102)}$. O tetraedro $\mathrm{ZnO}_{4}$ pode também compor com $\mathrm{SiO}_{4}$ em vidros com alto conteúdo de $\mathrm{Zn}{ }^{(103)}$. 
Segundo Pinakidou F. et al (104); em estudos de vidros contendo resíduos ricos em ferro e zinco, mesmo tratamentos térmicos a altas temperaturas $\left(900^{\circ} \mathrm{C}\right)$ a coordenação destes elementos se manteriam estáveis.

Silva et al. (15-16), estudou vidros silicato soda-cal com adições de resíduo industrial com alta concentração de metais de transição ( $\mathrm{Cr}$, Ni, $\mathrm{Cu}, \mathrm{Zn})$. A partir de uma composição básica de vidro, foram adicionadas quantidades variáveis de resíduo industrial (entre 10 e 40\% em massa). Neste estudo, observou-se um aumento na resistência química dos vidros, incompatível com a simples dispersão dos metais de transição nos espaços da matriz vítrea. Os autores sugeriram que estes metais poderia estar participando da formação da rede vítrea, tornando esta mais compacta. Baseando-se nestes estudos, Silva et al., à partir da composição base de vidro soda-cal, foram realizados cálculos de composição onde os metais de transição adicionados foram normalizados como "modificadores da rede" $\left(\mathbf{R}^{2+}\right)$, à semelhança do cátion $\mathrm{Ca}^{2+}$. Estas composições foram plotadas aproximando-se de uma linha binária de compatibilidade. Este binário indicou a possibilidade de utilizar os metais provenientes do resíduo sólido galvânico em seus constituintes funcionais na rede dos vidros soda cal modificados com boro. A composição original de vidro soda-cal, as composições calculadas e o respectivo corte representativo ${ }^{(17)}$, são mostrados na Fig. 3.3.

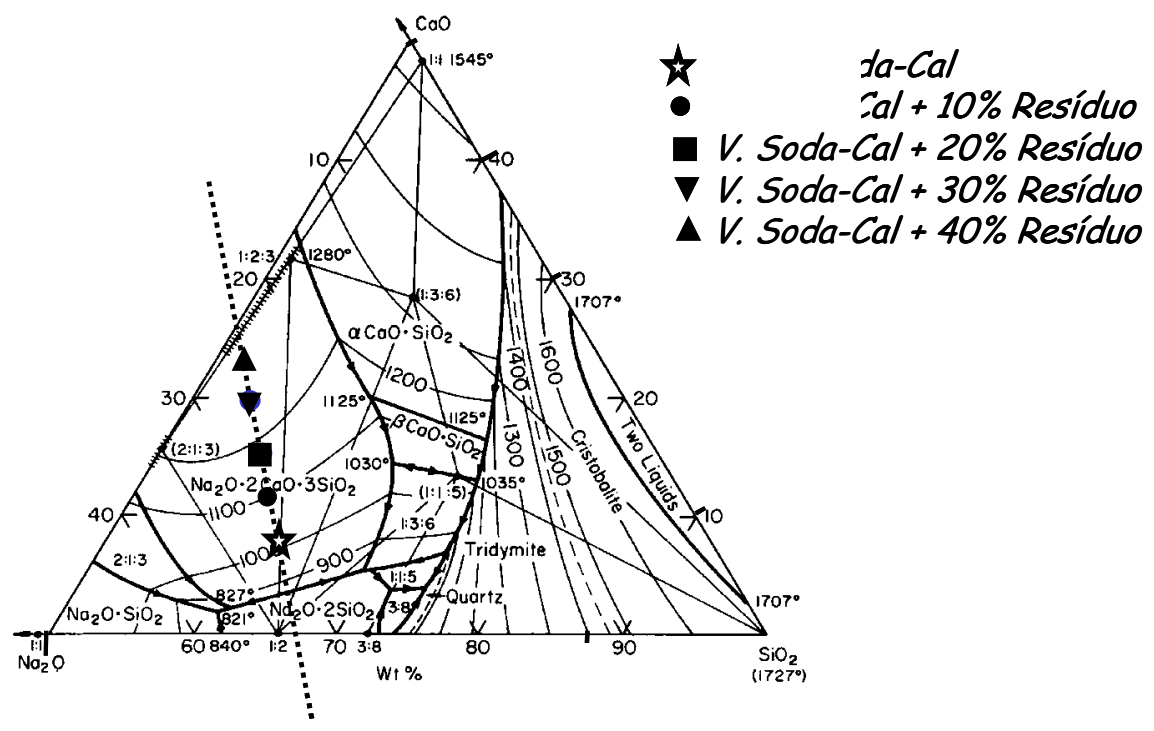

FIGURA 3. $3^{(105)}$ - Diagrama de equilíbrio de fases do sistema $\mathrm{Na}_{2} \mathrm{O}: \mathrm{CaO}: \mathrm{SiO}_{2}$, onde estão indicadas a composição utilizada por Silva, A.C. et al. ${ }^{(17)}$. 


\section{3 - Vitrocerâmicos}

Vitrocerâmicos se caracterizam por serem materiais compostos onde uma ou mais fases cristalinas estão envolvidas por uma fase amorfa (vidro) $(106,107)$. A composição original do vidro-mãe é alterada com a formação de cristais. A composição da(s) fase(s) cristalina(s) formada(s) e a do vidro matriz, assim como a proporção entre estas, depende de fatores tais como os elementos constituintes presentes, a historia térmica do vidro e do vitrocerâmico e a presença de defeitos de superfície ou agentes nucleantes ${ }^{(108)}$.

O conhecimento dos mecanismos de nucleação e cristalização para um dado vidro é importante para prever sua estabilidade em aplicações práticas e/ou obter-se um vitrocerâmico com microestrutura controlada e por conseqüência, propriedades determinadas ${ }^{(107)}$.

No planejamento de um produto é essencial o controle de sua microestrutura uma vez que esta interfere diretamente em suas propriedades. No caso dos vitrocerâmicos este fato é alcançado com o controle da história térmica do tratamento térmico para projetar a obtenção do vidro-mãe, as taxas de resfriamento críticas, formação e precipitação de cristais estáveis ou metaestáveis (109-114).

A devitrificação pode ocorrer tanto espontaneamente, durante 0 resfriamento e formação do vidro (têmpera) ou ser induzida por um tratamento térmico ${ }^{(115-116)}$. Os materiais vitrocerâmicos são usualmente preparados por tratamento térmico à partir de um vidro de composição determinada para se poder controlar o processo de cristalização. A formação da fase cristalina ocorre pelo processo usual de nucleação e crescimento

A nucleação em um vidro ocorre quando há um acúmulo local de agregados de acordo com o princípio de ordenação correspondente a um determinado agrupamento cristalino. Durante este fenômeno podem ocorrer flutuações de composição, de temperatura e do número de moléculas, em um dado momento em um certo volume. Este fenômeno altera a energia do sistema, uma vez que esta é resultante, fundamentalmente, de duas contribuições: a energia de cristalização e o trabalho necessário para a criação de uma nova superfície. A nucleação pode ocorrer de duas formas diferentes: homogênea (núcleos se originam a partir dos próprios constituintes do vidro); e heterogênea 
(núcleos se originam a partir de materiais estranhos à composição do vidro fundido) ${ }^{(117)}$.

Na nucleação homogênea, a estabilidade da partícula da nova fase, irá depender da diferença da energia livre entre as duas fases e da diferença da energia interfacial. Os núcleos de raio menor que o raio crítico (rc), instáveis devido à variação da energia. O núcleo se torna estável ao atingir dimensões superiores ao rc.

Na nucleação heterogênea, o núcleo se desenvolve na superfície de um substrato. A presença de partículas de composição estranha à fase nucleante modifica 0 trabalho de formação de núcleos. Superfícies preexistentes (heterogeneidades) como agentes nucleantes, impurezas, bolhas e etc, reduzem a energia interfacial e também contribuem para a formação de núcleos. O rc para um cristal formado a partir de um substrato é o mesmo para uma esfera formada na nucleação homogênea, contudo, o valor de rc de um determinado material é o mesmo independentemente de ser homogêneo ou heterogêneo, embora a a energia livre, $\Delta G$ envolvida na formação do "cluster" seja menor.

Usualmente adiciona-se aos vidros componentes conhecidos como agentes nucleantes, os quais auxiliam na nucleação interna ${ }^{(118)}$. Os agentes nucleantes se fundem homogeneamente com o vidro e promovem separação de fases numa escala fina durante um reaquecimento. A fase dispersa apresenta tipicamente uma estrutura incompatível com o vidro matriz e precipita na forma de cristais durante aquecimento até temperaturas entre 30 e $100^{\circ} \mathrm{C}$ acima da temperatura de recozimento dos vidros. Estes cristais constituem-se de núcleos sobre os quais ocorre a nucleação e crescimento das fases cristalinas primárias ${ }^{(118)}$. Dois tipos de agentes nucleantes podem se distinguir nos vidros:

1) Substâncias capazes de formar cristais momentâneos de baixa solubilidade no vidro. Eles possuem tendência de se reduzir da forma iônica para um estado neutro no fundido (ex: $\mathrm{Pt}, \mathrm{Au}, \mathrm{Ag}$. $\mathrm{Cu}$ ); e,

2) óxidos tais como $\mathrm{TiO}_{2}, \mathrm{ZrO}_{2}, \mathrm{P}_{2} \mathrm{O}_{5}$, etc, os quais são solúveis em vidros silicato e podem ser adicionados em quantidades variáveis, dependendo da composição do vidro, antes de ocorrer a nucleação. Estas substâncias raramente se cristalizam como óxidos independentes no início da cristalização, mas precipitam como um componente complexo (ex: $\mathrm{MgTiO}_{3}, \mathrm{Li}_{2} \mathrm{TiO}_{3}$ ). A nucleação é 
seguida por um ou mais tratamentos térmicos a alta temperatura para promover a cristalização da fase(s) primária e crescimento da microestrutura desejada ${ }^{(118)}$.

O crescimento é o processo pelo qual os átomos se unem normalmente a superfície de um núcleo cristalino, participando se sua estrutura e contribuindo para o aumento de seu volume. Para que os átomos possam juntar-se ao cristal, ele deve adquirir uma energia de ativação, $\Delta G_{a}$. Como no processo de nucleação, a temperatura correspondente à máxima velocidade de crescimento aumenta com a energia de ativação para difusão, o $\Delta G_{a}$ também aumenta. Finalmente, pode-se mencionar que as energias de ativação de difusão para crescimento e nucleação podem não ser necessariamente iguais para um dado sistema, uma vez que os movimentos atômicos envolvidos podem ser diferentes para os dois processos.

A teoria de crescimento pressupõe que todos átomos disponíveis podem ser incorporados no crescimento do cristal. Contudo, para o crescimento continuar, é necessário que parte dos átomos ocupem pontos inicialmente desfavoráveis e assim iniciar outra camada. Cada camada pode ser nucleada separadamente ${ }^{(119)}$.

A aplicação das teorias de nucleação para a análise da taxa de nucleação experimental em líquidos super-resfriados, depende da identificação de qual fase deverá nuclear inicialmente a partir das sementes até o raio crítico de nucleação. Normalmente, os cristais micrométricos podem ser detectados e contados somente após o núcleo ter crescido desde que tenha atingido seu tamanho crítico de origem em alguns nanômetros ${ }^{(119)}$.

Durante a cristalização, os sistemas instáveis ou meta-estáveis, geralmente não se dirigem diretamente para a configuração mais estável, que corresponde à mais abaixa energia livre, mas preferencialmente para estágios intermediários (correspondendo à outras possíveis modificações meta-estáveis) com menor diferença de energia livre ${ }^{(119)}$.

O processo de crescimento pode ser realizado até um cristal atingir a fronteira dos cristais vizinhos, obtendo-se um material altamente cristalino envolvido em uma fase residual de vidro. Entretanto, alguns vitrocerâmicos são projetados para possuir uma microestrutura uniformemente dispersa, sem que as superfíces dos cristais se toquem permanecendo contidos numa matriz vítrea 
contínua (118). De forma geral a devitrificação resulta em uma redução da resistência química da matriz amorfa ${ }^{(115-116)}$.

Os vitrocerâmicos podem ser obtidos utilizando-se tratamentos térmicos para induzir a nucleação interna de monolítos de vidro ou pela sinterização e cristalização de fritas e/ou vidro pulverizado. De acordo com o processo adotado, a estruturara micro-cristalina das fases cristalinas resultantes serão diferentes ${ }^{(118,120)}$.

A rota a partir de monolítos de vidro permite a formação de maior variedade de microestruturas. Esta rota favorece a nucleação interna (nos processos industriais se procura evitar a nucleação superficial). Usualmente, o tratamento térmico consiste em dois estágios: um para promover a nucleação e outro para promover o crescimento cristalino ${ }^{(118,121)}$.

A rota a partir do processamento do pó (sinterização) favorece a cristalização a partir da superfície, e em geral a performance mecânica do produto é menor que nos vidros obtidos pela nucleação interna, contudo os vidros possuem uma maior tendência para a nucleação superficial ${ }^{(119,110)}$. Nesta rota o vidro pulverizado, é conformado e sintetizado. Durante o tratamento térmico as partículas de vidro se densificam através do mecanismo de fluxo viscoso e a nucleação e o crescimento ocorrem a partir das fronteiras originais da partícula de vidro ${ }^{(109)}$.

Considerando o efeito da adição de resíduos contendo metais de transição na devitrificação, o efeito do $\mathrm{Cr}_{2} \mathrm{O}_{3}$ como agente nucleante é controverso. Segundo Williamson, ${ }^{(122)}$, este óxido não é efetivo para induzir a formação de fases cristalinas em vidros do sistema $\mathrm{CaO}-\mathrm{MgO}-\mathrm{Al}_{2} \mathrm{O}_{3}-\mathrm{SiO}_{2}$, por outro lado Shelestak,et al. (123-124) apresenta $\mathrm{O}^{\mathrm{Cr}_{2} \mathrm{O}_{3}}$ como um efetivo agente nucleante para este mesmo sistema. Omar et al. ${ }^{(125)}$, sugerem que e $\circ \mathrm{Cr}_{2} \mathrm{O}_{3}$ favorece a cristalização em misturas formadas por areias quartziticas, dolomita e magnesita. A presença de outros metais de transição torna $\circ \mathrm{Cr}_{2} \mathrm{O}_{3}$ mais efetivo como agente nucleante ${ }^{(126)}$. Barbieri et al. ${ }^{(127)}$, obteve a formação de espinélios $\mathrm{MgCr}_{2} \mathrm{O}_{4}$ em vidros do sistema $\mathrm{CaO}-\mathrm{MgO}-\mathrm{SiO}_{2}-\mathrm{Al}_{2} \mathrm{O}_{3}$, com a adição de $\mathrm{Cr}_{2} \mathrm{O}_{3}$. Segundo Karamanov et al. ${ }^{(128)}$, o $\mathrm{Cr}_{2} \mathrm{O}_{3}$ induz a nucleação de fases espinélio em vidros do sistema $\mathrm{SiO}_{2}-\mathrm{Al}_{2} \mathrm{O}_{3}-\mathrm{CaO}-\mathrm{Fe}_{2} \mathrm{O}_{3}$, com a presença de quantidades menores de $\mathrm{PbO}, \mathrm{ZnO}, \mathrm{Na}_{2} \mathrm{O}$ e $\mathrm{K}_{2} \mathrm{O}$. Marghussian et al. ${ }^{(129-130)}$, sugere que em 
vidros do sistema $\mathrm{SiO}_{2}-\mathrm{Al}_{2} \mathrm{O}_{3}-\mathrm{MgO}-\mathrm{CaO}\left(\mathrm{R}_{2} \mathrm{O}\right)$, a nucleação somente ocorre na presença de $\mathrm{Cr}_{2} \mathrm{O}_{3}, \mathrm{Fe}_{2} \mathrm{O}_{3}$ e $\mathrm{TiO}_{2}$.

\section{4 - Resistência Química e Dissolução dos Vidros Silicato}

A resistência química nos vidros é definida pela dificuldade de remoção de seus constituintes em função de sua interação com o meio onde se encontra, sendo um processo irreversível ${ }^{(131-132)}$.

O estudo do comportamento de dissolução dos vidros é particularmente importante na previsão de sua integridade e ciclo de vida quando o vidro é utilizado para inertizar componentes perigosos ${ }^{(23,132)}$.

A complexidade de composição e a presença de heterogeneidades em um vidro acentuam o caráter metaestável e dificultam o equilíbrio termodinâmico, por exemplo, com a água ou com qualquer meio que seja exposto $^{(14,117,133)}$.

Os vidros possuem uma energia termodinâmica tão alta quanto os materiais cristalinos de mesma composição. Entretanto, por serem materiais em um equilíbrio meta-estável, tendem a reagir com soluções aquosas para formar fases hidratadas mais estáveis ${ }^{(119)}$. A variação de energia livre de hidratação $\left(\Delta G_{\text {Hidr. }}\right)$ em uma estrutura de tetraedros de sílica de um vidro, pode ser estimada como a soma das energias livres de hidratação proporcionais às massas molares dos seus constituintes (24,119,134,135). A durabilidade dos vidros é iniciada principalmente pela razão entre elementos formadores e modificadores da rede (119)

A dissolução de um vidro ocorre em geral, por um limitado número de processos, que são influenciados pelo $\mathrm{pH}$ do meio de ataque ${ }^{(14)}$. O mecanismo de dissolução pode ser dividido, em quatro etapas $(23,133,136)$ :

1) Difusão da água através da matriz do vidro - onde ocorre o processo de remoção de íons modificadores, presentes na estrutura do vidro, substituídos pelos íons hidrogênio da água;

2) Hidrólise da rede - ocorre pelo rompimento das ligações estruturais que aceleram os mecanismos de dissolução do vidro;

3) Formação de uma camada amorfa superficial;

4) Ataque da rede do vidro pelos íons $\mathrm{OH}^{-}$. 
Sob o ponto de vista cinético da dissolução de vidros, estas etapas podem ser descritas respectivamente como ${ }^{(137)} ; 1$ e 2 . Dissolução seletiva; 3. Formação de fases secundárias nas interfaces entre as superfícies dos vidros e a solução; e, 4. Dissolução da matriz.

\subsection{1 - Difusão da Água e Trocas com Hidrogênio}

O processo de difusão na estrutura do vidro pelas espécies da água, como o hidrôxonio $\left(\mathrm{H}_{3} \mathrm{O}^{+}\right)$ou do ácido, como os prótons $\left(\mathrm{H}^{+}\right)$, facilitam a reação preferencial destas espécies com os oxigênios "não ponte" $(4,133,138)$. Em adição, devido aos mecanismos de compensação de cargas, estas espécies irão remover e ocupar os sítios pertencentes aos íons alcalinos. Este mecanismo de remoção é favorecido por valores de $\mathrm{pH}$ baixo. Como resultado deste processo, em particular, para os vidros silicatos, ocorrerá a formação de uma camada hidratada (equações $3.3 \mathrm{e}$ $3.4)^{(133,139-142)}$.

$$
\begin{aligned}
&(\mathrm{Si}-\mathrm{O}-\mathrm{R})_{\text {Vidro }}+ \mathrm{H}_{3} \mathrm{O}^{+} \leftrightarrow(\mathrm{Si}-\mathrm{OH})_{\text {Vidro }}+\mathrm{R}^{+}+\mathrm{H}_{2} \mathrm{O} \quad\left(\mathrm{R}^{+}=\mathrm{Na}^{+}, \mathrm{K}^{+}, . .\right) \\
&(\mathrm{Si}-\mathrm{O}-\mathrm{R})_{\text {Vidro }}+\mathrm{H}^{+} \leftrightarrow(\mathrm{Si}-\mathrm{OH})_{\text {Vidro }}+\mathrm{R}^{+}
\end{aligned}
$$

Os íons alcalinos por sua vez apresentam boa mobilidade e são removidos com facilidade, apresentando elevados coeficientes de difusão. Entretanto, esta difusidade diminui devido ao empobrecimento na concentração de alcalinos presentes na superfície dos vidros, que forma uma barreira para a continuidade da reação ${ }^{(23-24,133-137,139-142)}$.

As reações discutidas até o momento se referem ao ataque protônico nos íons $\mathrm{R}^{+}$, porém, este mesmo mecanismo de ataque também ocorre para cátions bivalentes, $\mathrm{R}^{2+}$, como os alcalinos terrosos (por ex.: $\mathrm{Ca}^{2+}$ e $\mathrm{Mg}^{2+}$ ) presentes nas posições intersticiais, como apresentado nas reações 3.5 à 3.7:

$$
\begin{gathered}
(\mathrm{Si}-\mathrm{O}-\mathrm{R}-\mathrm{O}-\mathrm{Si})_{\text {Vidro }}+2 \mathrm{H}_{2} \mathrm{O}--->2\left(\mathrm{HOSi}^{3+}\right)_{\text {Vidro }}+\mathrm{R}^{\prime}(\mathrm{OH})_{2} \\
\left(\text { Onde } \mathrm{R}^{2+}=\mathrm{Ca}^{2+}, \mathrm{Mg}^{2+},\right. \text { etc...) }
\end{gathered}
$$

$\mathrm{Ou}$; 


$$
\begin{gathered}
(\mathrm{RO})_{\text {vidro }}+2 \mathrm{H}_{2} \mathrm{O}--->\mathrm{R}^{2+}+2 \mathrm{OH}^{-} \\
\left(\mathrm{RSiO}_{3}\right)_{\text {vidro }}+3 \mathrm{H}_{2} \mathrm{O}--->\mathrm{R}^{2+}+\mathrm{H}_{4} \mathrm{SiO}_{4}+2 \mathrm{OH}^{-}
\end{gathered}
$$

Como resultado da extração do cálcio, por exemplo, também aparecem as descontinuidades que enfraquecem a rede dos vidros ${ }^{(4,133)}$. Os óxidos com valência maior ou igual a 2, ao formarem mais de uma ligação, determinam um reforçamento reticular que dificulta a difusão dos íons alcalinos. Entretanto, existe para cada óxido, uma relação estreita nos limites de concentração nos quais ocorre o efeito de reforçamento reticular ${ }^{(13,23)}$.

\subsection{2 - Hidrólise da Rede do Vidro}

Durante a hidrólise, ocorre a hidratação dos óxidos formadores, por meio do rompimento das ligações dos "oxigênios ponte" quebrando assim a continuidade da rede e formando um gel sobre a superfície do vidro $(23,142)$

De uma maneira simplificada, a reação de hidrólise pode ser expressa segunda as equações $3.8,3.9,3.10^{(133,141)}$ :

$$
\begin{gathered}
(\mathrm{Si}-\mathrm{O}-\mathrm{Si})_{\text {Vidro }}+\mathrm{H}_{2} \mathrm{O} \leftrightarrow(\mathrm{Si}-\mathrm{OH})_{\text {dissolvido }}+(\mathrm{Si}-\mathrm{O}-)_{\text {Vidro }}+\mathrm{H}^{+} \\
(\mathrm{Si}-\mathrm{O}-)_{\text {Vidro }}+\mathrm{H}^{+} \leftrightarrow(\mathrm{Si}-\mathrm{OH})_{\text {dissolvido }} \\
(\mathrm{Si}-\mathrm{O}-\mathrm{Si})_{\text {Vidro }}+\mathrm{H}_{2} \mathrm{O} \leftrightarrow 2(\mathrm{Si}-\mathrm{OH})_{\text {dissolvido }}
\end{gathered}
$$

Estas reações ilustram a seqüência da dissolução na superfície do vidro pela hidrólise dos óxidos formadores e intermediários em uma solução. A taxa de dissolução para o vidro é determinada pela remoção do formador menos resistente ${ }^{(14)}$. Segundo Hamilton, J.P. et al. ${ }^{(139)}$; os metais pesados e de transição também podem ser envolvidos nas reações de hidrólise.

\subsection{3 - Formação de Camada Amorfa Superficial}

A hidrólise via oxigênios ponte tem como conseqüência a formação de uma camada de gel na superfície do vidro, que dificulta a difusão da água e a extração dos íons modificadores, retardando a degradação do vidro. Esta camada 
superficial de gel, ao se tornar suficientemente espessa, pode se desprender, expondo uma nova superfície de vidro exposta ao meio que sofrerá ataque tanto pela extração de modificadores como pela hidrólise da rede. O progresso deste processo leva a dissolução do vidro ${ }^{(14,24,119,142)}$.

Metais tais como $\mathrm{Al}, \mathrm{Fe}, \mathrm{Zn}, \mathrm{Cu}, \mathrm{Pb}$ podem estabilizar-se quimicamente durante o processo, favorecendo a nucleação de produtos secundários ou formando hidróxidos, os quais irão inibir futuros ataques $(24,131-132,143)$.

\subsection{4 - Ataque da Rede Estrutural pelos Íons $\mathrm{OH}^{-}$}

Paralelamente ao mecanismo de ataque por prótons, se estabelece o ataque pelos íons $\mathrm{OH}^{-}$. Estes íons são provenientes tanto dos meios alcalinos ou íons livres resultantes da progressiva dissociação da água nos processos anteriores . A reação do vidro com os grupos $\mathrm{OH}^{-}$ocorre sempre com a ruptura das "pontes de oxigênio", com conseqüente destruição parcial da rede (reações 3.11 e 3.12$)^{(23,138)}$.

$$
\begin{aligned}
& (\text { 三 } \mathrm{Si}-\mathrm{O}-\mathrm{Si}=)_{\text {vidro }}+\mathrm{OH}^{-} \rightarrow(\text { ESi-O- })_{\text {dissolvido }}+(\text { 三Si-OH })_{\text {dissolvido }} \\
& \left(\text { (ES-O-) }+\mathrm{H}_{2} \mathrm{O} \rightarrow(\text { ( } \mathrm{Si}-\mathrm{OH})+\mathrm{OH}^{-}\right.
\end{aligned}
$$

\section{5 - Vitrificação de Resíduos Perigosos}

Atualmente, a deposição e armazenagem de resíduos perigosos (contendo $\mathrm{Pb}, \mathrm{Cr}, \mathrm{Zn}, \mathrm{Cu}, \mathrm{Cd}$ e $\mathrm{Hg}$ ) é desencorajada, pois mesmo quando observadas todas as regras de segurança ambiental, não há garantia da integridade dos aterros e/ou depósitos ao longo do tempo. A legislação nos paises industrializados impõe também a inertização preliminar destes resíduos. Processos de incineração são por si mesmo geradores de novos tipos de resíduos perigosos que necessitam tratamentos de estabilização. As tecnologias mais recentes apontam para a imobilização de resíduos em matrizes poliméricas (resinas) e cerâmicas (cerâmica vermelha, cimentos, vidros e vitrocerâmicos). 
A vitrificação é uma tecnologia estabelecida que envolve a inertização de um resíduo perigoso em uma num vidro silicato quimicamente estável e de aparência homogenea, com a adição de resíduo a uma frita ou a adição de aditivos vitrificantes. As principais vantagens do processo de vitrificação são:

Os vidros inorgânicos podem incorporar uma grande variedade de íons de diferentes elementos, encapsulando os mesmos na rede vítrea;

2) Os vidros obtidos são inertes para a maioria dos agentes químicos e biológicos, podendo ser depositados no solo ou usado em pavimentos, rodovias, etc. sem ocorrência de contaminação;

3) $\quad 0$ processo de vitrificação pode aceitar resíduos de diferentes composições e formas de agregação, tais como líquidos, lodos, sólidos ou a mistura destes.

4) A vitrificação resulta em uma grande redução de volume do resíduo.

A principal desvantagem deste processo para a o tratamento de resíduos é o custo do processo. Os custos operacionais são normalmente superiores ao da deposição em aterros devido ao alto consumo de energia durante a fusão do vidro. Uma possibilidade para reverter o elevado custo é a obtenção de vidros e vitrocerâmicos com valor de mercado. A vitrificação possui alta potencialidade no desenvolvimento de tecnologias de inertização e reuso de resíduos.

A aplicação mais usual da tecnologia de vitrificação está na estabilização de resíduos da industria nuclear ${ }^{(9,131,144)}$. Que constitui um grande atrativo para a disseminação deste processo, considerando-se o rigor de segurança ambiental inerentes a esta indústria. Quando utilizada para o tratamento de resíduos não-radioativos, esta tecnologia apresenta diversidade no desenvolvimento de produtos e possui um grande potencial para o desenvolvimento, envolvendo a inertização e o reuso de resíduos perigosos tais como, cinzas volantes geradas em usinas termoelétricas, pós finos de moagem, escórias da industria metalúrgica e lodos das mais diferentes origens. 
A vitrificação das cinzas volantes geradas em incineradores do lixo urbano, consiste em uma importante opção(145-157). Os estudos de Romero et al. (146) e, Boccaccini et al. ${ }^{(147)}$ demonstraram a eficiência da vitrificação para imobilizar os metais perigosos $(\mathrm{Cd}, \mathrm{Cr}, \mathrm{Cu}, \mathrm{Pb})$ e destruir os compostos orgânicos. Como vantagem adicional, obteve-se a redução de até 90\% em volume destes resíduos.

Vitrocerâmicos foram obtidos induzindo o crescimento de fases cristalinas em vidros obtidos a partir de cinzas contendo $\mathrm{Fe}_{2} \mathrm{O}_{3}, \mathrm{P}_{2} \mathrm{O}_{5}$ e $\mathrm{TiO}_{2}$, utilizando ou não a adição de fritas tendo como referência os sistemas $\mathrm{Al}_{2} \mathrm{O}_{3}-\mathrm{SiO}_{2}$

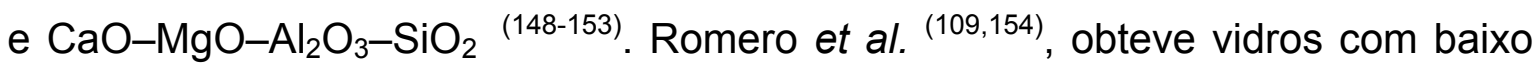
conteúdo de sílica (menos que $12 \%$ em massa), com grande potencial para a formação de vitrocerâmicos. Károly et al. (158), obteve vitrocerâmicos quimicamente resistentes em tocha de arco de plasma. Entretanto este processo é energeticamente dispendioso.

Resíduos finos contendo $\mathrm{Cr}, \mathrm{Pb}, \mathrm{Zn}, \mathrm{Cu}, \mathrm{Cd}, \mathrm{Ni}$, são gerados nos fornos de arco elétrico para a produção de aço. Como principal característica este resíduo possui alto teor de ferro e baixo teor de sílica e cerca de 15\% em massa de cromo. Pelino et al. ${ }^{(159)}$, incorporaram até $40 \%$ em massa deste resíduo a uma frita de vidro, obtendo um vidro ambientalmente inerte.

As cinzas volantes geradas em usinas termoelétricas são ricas em sílica (> 45\% em massa) e alumina. Leroy et al ${ }^{(160)}$, estudaram a vitrificação destes resíduos com a adição de $\mathrm{CaCO}_{3}$ e $\mathrm{Na}_{2} \mathrm{CO}_{3}$, seguida da obtenção de vitrocerâmicos. A vitrificação direta deste foi estudada por Erol et al. ${ }^{(161)}$. Este tipo de resíduo, rico em ferro foi estudado para a produção de vitrocerâmicos contendo fases magnéticas ${ }^{(151,162)}$. Kavouras et al. ${ }^{(163)}$; obteve vitrocerâmicos com adições de $\mathrm{SiO}_{2}, \mathrm{Na}_{2} \mathrm{O}$ e $\mathrm{CaO}$ e imobilizando contaminantes tais como $\mathrm{Zn}$ e $\mathrm{Pb}$.

A vitrificação de cinzas volantes geradas em diferentes processos foi estudada por Cheng et al. ${ }^{(148-149)}$, contudo, obteve vitrocerâmicos onde o conteúdo de Cromo apresentou pouca estabilidade química. Barbieri et al. ${ }^{(6,164-}$ 165); realizou estudos similares, porém com a adição de fritas de vidro e dolomita, obtendo vitrocerâmicos quimicamente resistentes com dases secundárias baseadas em Zn e Fe. 
Kavouras et al. ${ }^{(7,163)}$; estudou a vitrificação de cinzas geradas após a incineração de lamas acumuladas em tanques de armazenagem de gasolina. Estas cinzas caracterizam-se por serem ricas em chumbo. Utilizou a adição de quartzo e $\mathrm{Na}_{2} \mathrm{CO}_{3}$ obtendo a incorporação de até $60 \%$ em massa de cinzas ao vidro.

A vitrificação de escórias e outros resíduos contendo ferro, geradas na indústria metalúrgica é um processo consolidado, existindo exemplos do início da década de 1970 sobre estudos com vitrocerâmicos obtidos com estes resíduos $(2,145-158,160-161,164,176-179)$

Ferreira et al ${ }^{(170)}$; estudaram a incorporação de lama gerada no processo de obtenção de alumínio em fritas de vidro, obtendo vitrrocerâmicos.

Brume et al. ${ }^{(169)}$; e, Huang et al (2); estudaram a obtenção de vitrocerâmicos a partir de resíduo em pó fino em contendo $\mathrm{Fe}$ e $\mathrm{Cr}$, gerados em fornos siderúrgicos por arco de indução. Nestes estudos, visando obter materiais abrasivos, foi induzida a formação de espinélio $(\mathrm{Mg}, \mathrm{Fe})(\mathrm{Fe}, \mathrm{Al}, \mathrm{Cr})_{2} \mathrm{O}_{4}$.

Bernstein et al. ${ }^{(171)}$; e, Brusatin et al. ${ }^{(172)}$; estudaram a vitrificação de lamas oriundas de areas ambientalmente degradadas pela deposição de resíduos de curtume (contendo cromo hexavalente) e do processo de beneficiamento de cerâmica. Para a vitrificação deste resíduo foi preciso utilizar aditivos para a correção de composição.

A vitrificação de asbestos, com a destruição da estrutura em fibras deste material foi estudada por Robert, D. et al. ${ }^{(173)}$.

Silva et al. ${ }^{(15,16,19)}$ estudaram a vitrificação de resíduos sólidos galvânicos, gerados na industria de tratamento de superfícies em com resíduos da industria da cerâmica branca. O resíduo galvânico utilizado continha $\mathrm{Cr}, \mathrm{Ni}, \mathrm{Cu}, \mathrm{Zn}$ e $\mathrm{Pb}$. Incorporou-se até $40 \%$ deste resíduo em vidros com boa estabilidade ambiental. Os resultados obtidos sugeriram a participação dos metais contidos na formação da rede vítrea. Estudos da vitrificação de resíduos sólidos galvânicos, contendo $\mathrm{Cr}$, Fe e $\mathrm{Cu}$. indicam a possibilidade da participação destes metais na formação da rede vítrea ${ }^{(89)}$. 
O processo de vitrificação utiliza uma grande quantidade de energia, e somente é viável com a valoração e uso do produto obtido. $\mathrm{O}$ vidro é um material possível de ser aplicado a uma ampla variedade de usos. O desafio tecnológico para o uso de vidros obtidos a partir de resíduos, consiste no desvio de composição destes em relação aos vidros comerciais e/ou tecnológicos.

Devido à presença de elementos tais como $\mathrm{Fe}$ e outros, os vidros obtidos pela vitrificação de resíduos, de modo geral são aptos à produção de vitrocerâmicos. A maioria dos estudos para a obtenção de produtos a partir de resíduos industriais enfoca este tipo de material $(6,109,147,149,163,164,184,171-172,174-188)$. A produção de fibras de vidros a partir de resíduos industriais para reforço têxtil e outras aplicações é proposta por diversos autores ${ }^{(189-191)}$. Outros autores propõem a produção de espumas de vidro para isolamento térmico e proteção antichama ${ }^{(192-195)}$.

O uso de resíduos na obtenção de materiais compostos, onde um material vítreo é reforçado com o uso de um material vitrocerâmico é aplicável na industria militar e aeroespacial, com significativo valor agregado (192-196)

Bernardo et al (174,197-198) propôs a obtenção de painéis e agregados leves de construção a partir da vitrificação de tubos de raios catódicos de monitores de televisão e de computadores.

Outras aplicações estudadas para o uso de resíduos industriais vitrificados são: Utensílios de domésticos ${ }^{(199,200)}$, abrasivos vitrocerâmicos $(2,169)$, fertilizantes ${ }^{(201-202)}$, leves para a construção de pavimentos e rodovias ${ }^{(199,203-205)}$, e abrasivos ${ }^{(206)}$. 


\section{4 - Materiais e métodos}

\section{1 - Materiais}

Os materiais utilizados neste estudo foram alguns resíduos industriais e insumos usualmente utilizados na indústria química e cerâmica.

Resíduo sólido galvânico. Resultante de atividades de tratamento de superfícies metálicas e é classificado como resíduo perigoso classe I (ABNT 1004-2004 ${ }^{(21)}$ ). Neste estudo denominado "RSG".

$\underline{R e s i ́ d u o ~ d e ~ f i n o s ~ d e ~ s i ́ l i c a ~(q u a r t z o-~} \alpha$ ). São gerados na indústria cerâmica como descarte das operações de moagem e classificação granulométrica da sílica. É classificado como resíduo perigoso classe IIB (ABNT 1004-2004(21) ${ }^{(21}$ Denominado "RFS".

Resíduo de rochas ornamentais graníticas. São gerados nas atividades de beneficiamento de rochas ornamentais. Este resíduo é classificado como resíduo perigoso classe II-B (ABNT 1004-2004 ${ }^{(18)}$ ). Denominado "RRG".

A tabela 4.1 apresenta a composição química de todos os resíduos utilizados.

Os reagentes empregados para ajustes de composição são de pureza comercial apresentada em porcentagem em massa, sendo o Carbonato de sódio $\left(\mathrm{Na}_{2} \mathrm{CO}_{3}\right), 95 \%$, Hidróxido de sódio $(\mathrm{NaOH}), 97 \%$, Óxido de cálcio ( $\mathrm{CaO}$ ), 95\% produzidos poela Nuclear Ltda.; Carbonato de potássio $\left(\mathrm{K}_{2} \mathrm{CO}_{3}\right), 99 \%$, da Carlo Erba Reagenti SDS; Ácido bórico $\left(\mathrm{H}_{2} \mathrm{BO}_{3}\right)$, 97\%, da Química Moderna Ltda. e, Óxido de alumínio $\left(\mathrm{Al}_{2} \mathrm{O}_{3}\right), \mathrm{A}-1000$, Alcoa, Inc. 
TABELA 4.1 - Principais constituintes dos materiais de partida, expressos em óxidos e em \% em massa, analisados por Fluorescência de Raios X.

\begin{tabular}{|c|c|c|c|}
\hline Elemento & RSG & RFS & RRG \\
\hline $\mathrm{SiO}_{2}$ & 22,0 & 98,0 & 71,4 \\
\hline $\mathrm{Al}_{2} \mathrm{O}_{3}$ & 0,9 & 0,9 & 16,0 \\
\hline $\mathrm{CaO}$ & 14,0 & 0,1 & 0,6 \\
\hline $\mathrm{K}_{2} \mathrm{O}$ & 0,2 & 0,2 & 6,2 \\
\hline $\mathrm{Na}_{2} \mathrm{O}$ & 1,2 & 0,2 & 4,9 \\
\hline $\mathrm{Fe}_{2} \mathrm{O}_{3}$ & 1,1 & 0,2 & 0,7 \\
\hline $\mathrm{SO}_{3}$ & 7,4 & 0,1 & 0,1 \\
\hline MnO & 0,1 & - & 0,1 \\
\hline $\mathrm{Cr}_{2} \mathrm{O}_{3}$ & 21,0 & - & - \\
\hline $\mathrm{CuO}$ & 6,9 & - & - \\
\hline $\mathrm{NiO}$ & 13,0 & - & - \\
\hline $\mathrm{ZnO}$ & 4,7 & - & - \\
\hline $\mathrm{PbO}$ & 1,3 & - & - \\
\hline $\mathrm{MgO}$ & 3,5 & - & - \\
\hline $\mathrm{P}_{2} \mathrm{O}_{5}$ & 1,2 & - & - \\
\hline Outros & 1,5 & 0,3 & - \\
\hline
\end{tabular}

\section{2 - Formulação dos Vidros Estudados}

Visando atender com os objetivos propostos nesta tese, ou seja obter os vidros a partir dos resíduos e com características adequadas ao estudo, tais como; baixa temperatura de fusão para evitar a volatização dos metais de transição, viscosidade do líquido adequada para a conformação e destacando-se a capacidade de incorporação e o mecanismo pelo qual os constituintes do RSG interagem com a estrutura do vidro, partiu-se de duas séries com composições químicas similares porém com material de partida distinto.

1 - A série TC, baseada no Cao como modificador, consiste na composição de vidros silicato tipo soda-cal modificados com boro, formulados a partir dos resíduos RFS e RRG. Supondo que, os metais de transição podem ocupar em sua maioria, funções análogas ao modificador, 
ex. o cálcio ( $\mathrm{CaO}$ ), esta série foi planejada para acompanhar o comportamento dos vidros soda-cal quando a concentração de cálcio varia. A influência desta variação foi acompanhada com os ensaios de determinação de estrutura e de avaliação de propriedades finais.

2 - A série TR, baseada nos metais de transição como modificador, foi formulada a partir da série TC planejando-se as possíveis substituições com os componentes do resíduo galvânico - RSG, em concentrações análogas às preparadas na série TC. O comportamento destes vidros também foi acompanhado utilizando-se as mesmas técnicas de caracterização.

\subsection{1 - Cálculo das Composições dos Vidros T C}

As composições dos vidros da série TC (baseadas em $\mathrm{CaO}$ ) foram calculadas utilizando-se metodologia desenvolvida em estudos anteriores para obtenção de vidros soda-cal modificados pela adição de boro ${ }^{(15-16,20)}$, de acordo com a Fig. 3.3.

Deste modo, partindo-se da hipótese de se utilizar os metais de transição presentes no RSG como "modificadores" dos vidros, selecionou-se sobre a linha de composição adotada as concentrações de modificador ( $\mathrm{CaO}$ ) correspondentes a 5, 10, 15, 20 e 25 de porcentagem em massa do total. Tais composições foram denominadas respectivamente como T05, T10, T15, T20 e T25. Estas composições estão representadas no diagrama $\mathrm{Na}_{2} \mathrm{O}: \mathrm{CaO}: \mathrm{SiO}_{2}{ }^{(105)}$, Fig. 4.1. Baseando-se na projeção da isopleta $\mathrm{Na}_{2} \mathrm{O} \cdot 2 \mathrm{SiO}_{2}-\mathrm{Na}_{2} \mathrm{O} \cdot 2 \mathrm{CaO} \cdot 3 \mathrm{SiO}_{2}{ }^{(207)}$.

Visando melhorar as condições de vertimento e conformação dos vidros, se utilizam temperaturas de fusão superiores a temperatura "liquidus". Entretanto a temperatura máxima utilizada para a fusão, no caso de vidros com RSG, é limitada para se evitar possíveis volatilização dos metais de transição contido nos mesmos ${ }^{(17,19)}$. Por este motivo, procurou-se obter vidros com menores temperaturas de preparação modificando-se as composições inicialmente calculadas substituindo parcialmente o $\mathrm{SiO}_{2}$ por $\mathrm{B}_{2} \mathrm{O}_{3}$, seguindo os critérios: Adições de $\mathrm{B}_{2} \mathrm{O}_{3}$ até $10 \%$ em massa para evitar a formação de fases segregadas ${ }^{(208)}$ e, ajuste das composições utilizando-se o diagrama do sistema $\mathrm{CaO}: \mathrm{B}_{2} \mathrm{O}_{3}: \mathrm{SiO}_{2}{ }^{(209)}$ (Fig. 4.2), de forma a acompanhar a isoterma a $1300^{\circ} \mathrm{C}$. Estes cálculos foram realizados considerando-se a relação $\mathrm{CaO}: \mathrm{SiO}_{2}$ no sistema 
$\mathrm{Na}_{2} \mathrm{O}: \mathrm{CaO}: \mathrm{SiO}_{2}{ }^{(105)}$ para as composições estudadas. Esta mesma relação foi plotada no sistema $\mathrm{CaO}: \mathrm{B}_{2} \mathrm{O}_{3}: \mathrm{SiO}_{2}{ }^{(209)}$, onde mantendo-se o conteúdo de $\mathrm{CaO}$ fixo, substituíu-se parte do $\mathrm{SiO}_{2}$ pelo $\mathrm{B}_{2} \mathrm{O}_{3}$, considerando pontos de composição na isoterma a $1300^{\circ} \mathrm{C}$. Convém destacar que as projeções das composições $\mathbf{T}$ realizadas sobre os sistemas ternários que compõe o sistema quaternário $\mathrm{B}_{2} \mathrm{O}_{3}: \mathrm{CaO}: \mathrm{Na}_{2} \mathrm{O}: \mathrm{SiO}_{2}{ }^{(210)}$.

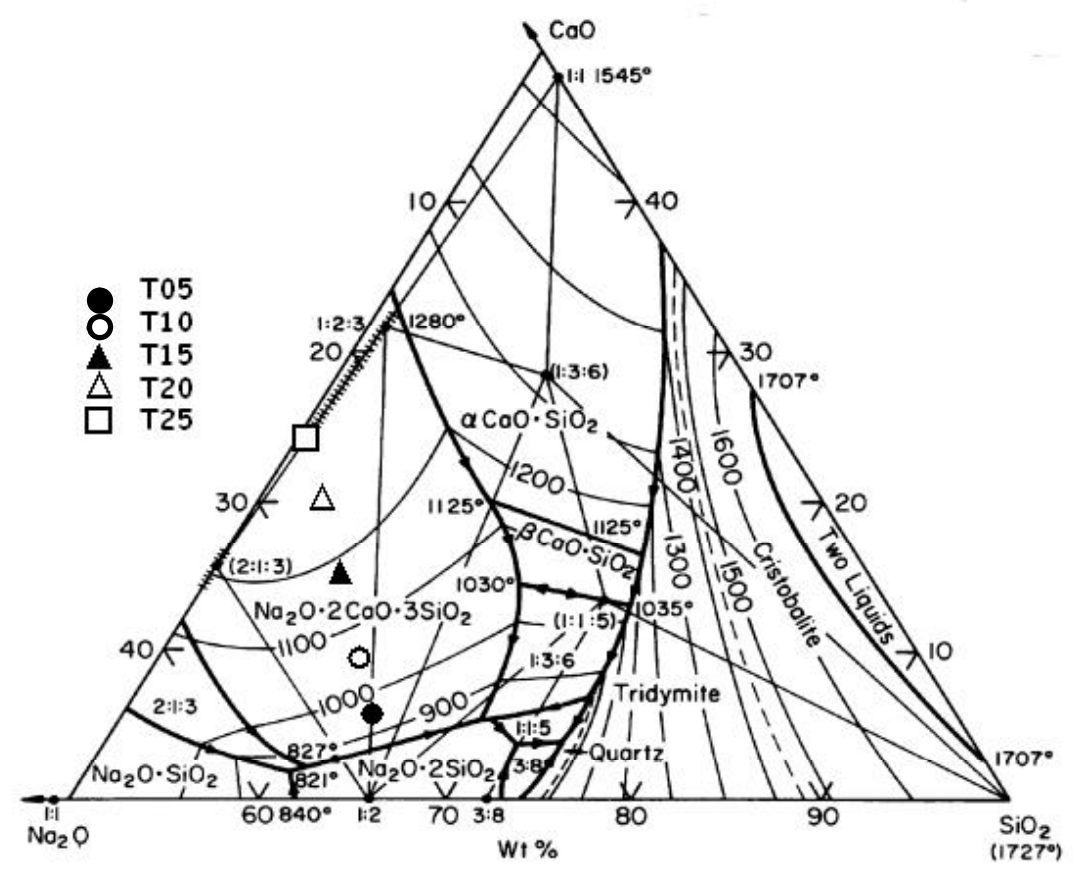

FIGURA 4. $1^{(105)}$ - Diagrama de equilíbrio de fases do sistema $\mathrm{Na}_{2} \mathrm{O}: \mathrm{CaO}: \mathrm{SiO}_{2}$, onde estão indicados os pontos composicionais T05, T10, T15, T20 e T25

As composições modificadas com boro foram denominadas série TC, ou seja, T05C, T10C, T15C, T20C e T25C.

Para confirmar os critérios anteriormente adotados, as composições TC foram também projetadas sobre sistema $\mathrm{B}_{2} \mathrm{O}_{3}: \mathrm{Na}_{2} \mathrm{O}: \mathrm{SiO}_{2}{ }^{(211)}$ (Fig. 4.3), observando-se também a influência do sódio na temperatura de formação e estabilidade (homogeneidade) destes vidros. 
O ajuste das composições TC foram realizados utilizando-se planilhas de cálculo. Um exemplo de planilha (composição T15C) é apresentado no Apêndice A, Tab. 10.1). As composições finais são mostradas na Tab. 4.2.

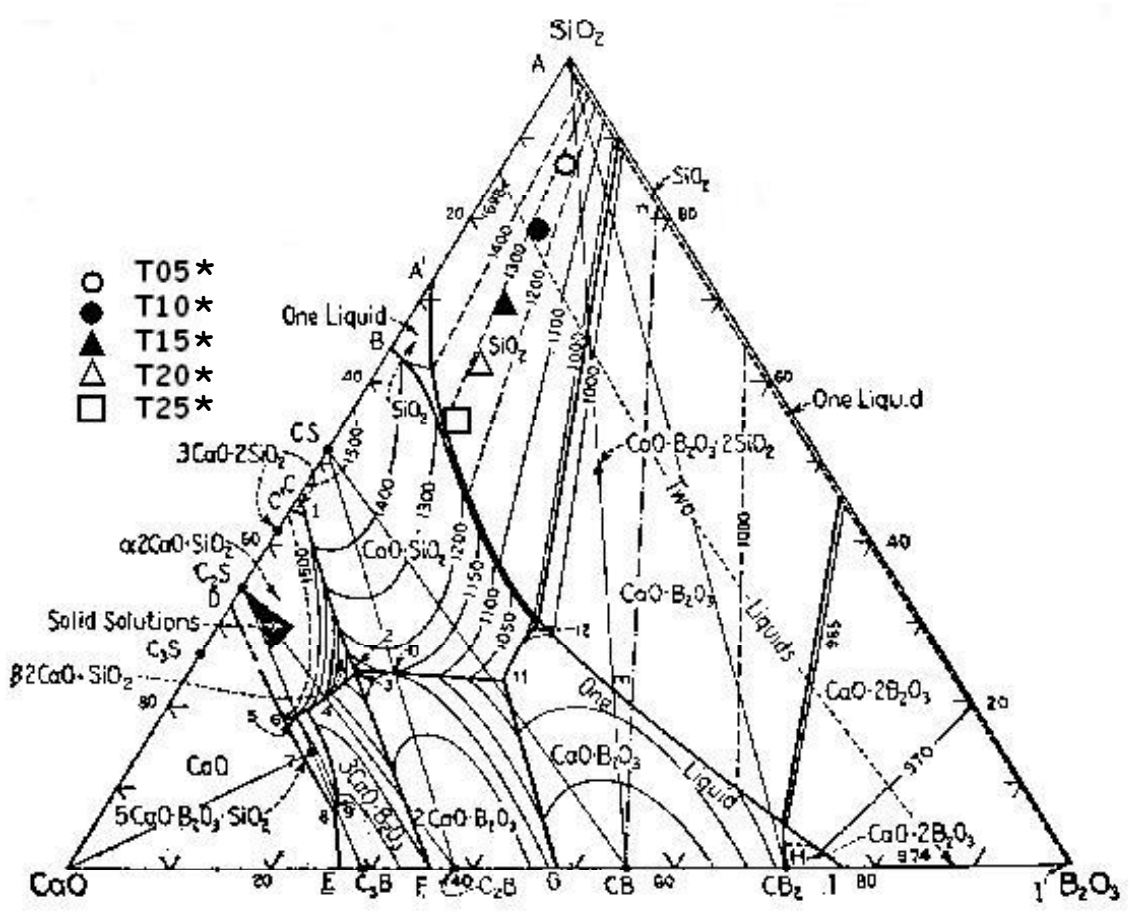

FIGURA $4.2^{(209)}$ - Diagrama $\mathrm{B}_{2} \mathrm{O}_{3}: \mathrm{CaO}: \mathrm{SiO}_{2}:$ T05 a T25 representam as composições selecionadas (proporções indicadas em \% de massa).

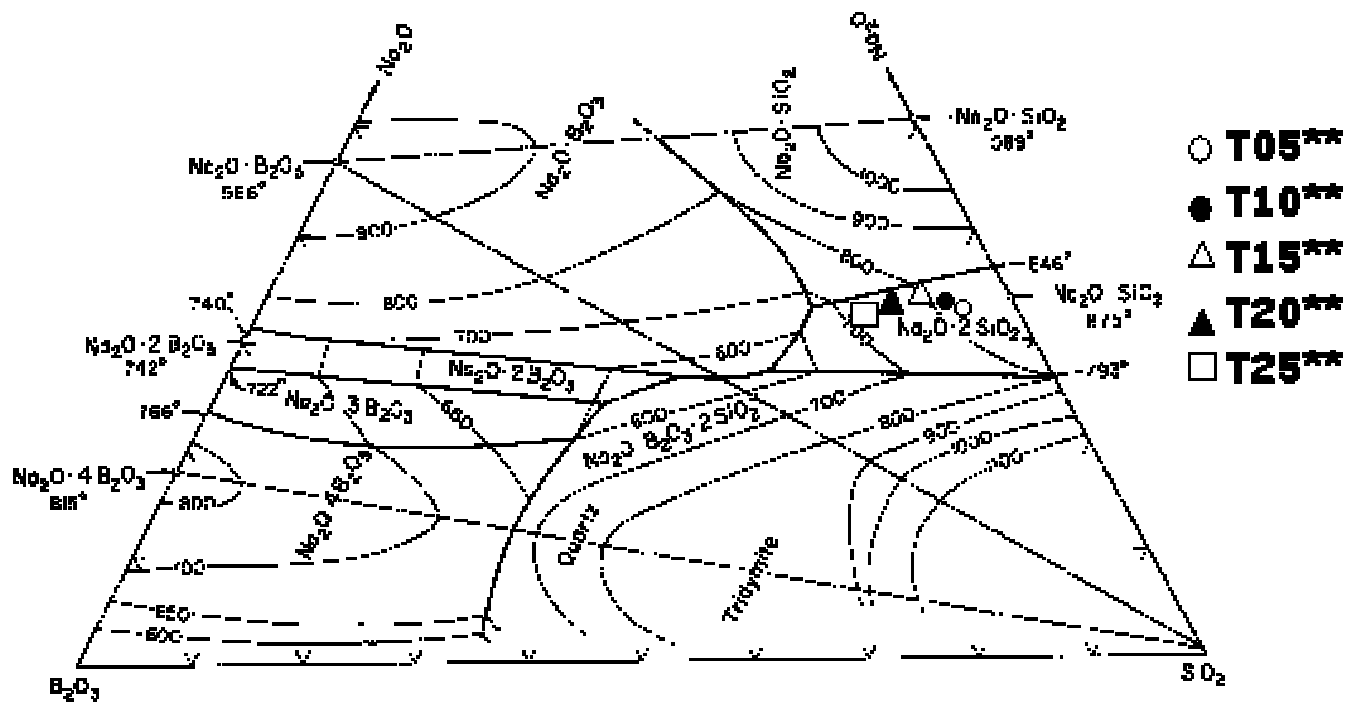

FIGURA 4.3 - Diagrama do sistema $\mathrm{B}_{2} \mathrm{O}_{3}: \mathrm{Na}_{2} \mathrm{O}: \mathrm{SiO}_{2}{ }^{(211)}$, onde T05 à T25 representam as composições selecionadas. 
TABELA 4.2 - Composições da série de vidros TC (\% em massa).

\begin{tabular}{l|ccccc}
\hline Composição & T05C & T10C & T15C & T20C & T25C \\
\hline $\mathbf{S i O}_{2}$ & 57,2 & 53,0 & 47,6 & 43,5 & 39,1 \\
$\mathbf{B}_{2} \mathbf{O}_{3}$ & 4,3 & 5,5 & 6,9 & 8,0 & 9,4 \\
$\mathrm{Na}_{2} \mathbf{O}$ & 30,5 & 28,5 & 27,5 & 25,5 & 23,5 \\
$\mathbf{C a O}$ & 4,9 & 9,9 & 14,9 & 19,9 & 24,9 \\
$\mathbf{K}_{2} \mathbf{O}$ & 1,0 & 1,0 & 1,0 & 1,0 & 1,0 \\
$\mathbf{A l}_{2} \mathbf{O}_{3}$ & 2,0 & 2,0 & 2,0 & 2,0 & 2,0 \\
$\mathbf{F e}_{2} \mathbf{O}_{3}$ & 0,1 & 0,1 & 0,1 & 0,1 & 0,1 \\
Outros & 1,5 & 1,7 & 1,9 & 2,1 & 2,3 \\
\hline
\end{tabular}

\subsection{2 - Cálculo das Composições dos Vidros TR}

Os vidros da série TR foram formulados visando a máxima concentração de RSG adicionada. O cálculo destas composições teve como base a série TC e foram realizados utilizando-se planilhas de cálculo. Um exemplo de planilha (composição T15R30) é apresentado no Anexo I, Tab. 10.2).

As composições finais TR são mostradas na Tab.4.3. Considerou-se a participação funcional dos óxidos metálicos presentes no RSG, classificados como modificadores dos vidros. Ressaltando que cada mol de $\mathrm{CaO}$ corresponde a duas ligações com o oxigênio, que serão os disponíveis, na substituição, para introduzir os metais na estrutura do vidro. Como exemplo, cada mol de $\mathrm{Cr}_{2} \mathrm{O}_{3}$, substitui 1,5 moles de $\mathrm{CaO}$, e cada mol de $\mathrm{NiO}, \mathrm{ZnO}, \mathrm{CuO}$ ou $\mathrm{PbO}$, substitui um mol de $\mathrm{CaO}$. Como o RSG contém $\mathrm{CaO}$, este óxido não é totalmente substituído nas formulações.

As composições calculadas contendo RSG, partindo-se das composições $T$ são designadas por: T05R10, T10R20, T15R30, T20R40 e T25R50. Onde $\mathbf{R}$, indica o uso de resíduos galvânicos (RSG) e os números finais $(10,20,30,40$ e 50, respectivamente) indicam a fração aproximada em massa de RSG utilizada. 
TABELA 4.3 - Composições da série de vidros TR, formuladas para os estudos de fusão (\% em massa).

\begin{tabular}{|c|c|c|c|c|c|}
\hline Composição & T05R10 & T10R20 & T15R30 & T20R40 & T25R50 \\
\hline $\mathrm{SiO}_{2}$ & 57,2 & 53,0 & 47,6 & 43,5 & 39,1 \\
\hline $\mathrm{B}_{2} \mathrm{O}_{3}$ & 4,3 & 5,5 & 6,9 & 8,0 & 9,4 \\
\hline $\mathrm{Na}_{2} \mathrm{O}$ & 30,5 & 28,5 & 27,5 & 25,5 & 23,5 \\
\hline $\mathrm{CaO}$ & 1,5 & 2,9 & 4,3 & 5,7 & 7,1 \\
\hline $\mathrm{K}_{2} \mathrm{O}$ & 1,0 & 1,0 & 1,0 & 1,0 & 1,0 \\
\hline $\mathrm{Al}_{2} \mathrm{O}_{3}$ & 2,0 & 2,0 & 2,0 & 2,0 & 2,0 \\
\hline MgO & 0,3 & 0,7 & 1,1 & 1,4 & 1,8 \\
\hline $\mathrm{Cr}_{2} \mathrm{O}_{3}$ & 2,1 & 4,2 & 6,3 & 8,5 & 10,6 \\
\hline $\mathrm{NiO}$ & 1,3 & 2,6 & 3,9 & 5,2 & 6,6 \\
\hline CuO & 0,7 & 1,4 & 2,1 & 2,8 & 3,5 \\
\hline $\mathrm{ZnO}$ & 0,5 & 0,9 & 1,4 & 1,9 & 2,4 \\
\hline $\mathrm{PbO}$ & 0,1 & 0,3 & 0,4 & 0,5 & 0,7 \\
\hline $\mathrm{Fe}_{2} \mathrm{O}_{3}$ & 0,2 & 0,3 & 0,4 & 0,5 & 0,6 \\
\hline Outros & 2,2 & 3,2 & 4,2 & 5,1 & 6,1 \\
\hline
\end{tabular}

\subsection{3 - Composições dos Vitrocerâmicos}

A obtenção de vitrocerâmicos visou o estudo da influência das composições estudadas com e sem RSG na nucleação e crescimento de fases cristalinas nas propriedades (características) finais dos vidros. Utilizaram-se os vidros das series TC e TR submetidos a tratamento térmico para a devitrificação. Após este tratamento térmico, as séries foram denominadas TCD e TRD, respectivamente.

A Fig. 4.4, mostra de forma esquemática os procedimentos adotados para a formulação dos vidros e dos vitrocerâmicos. 


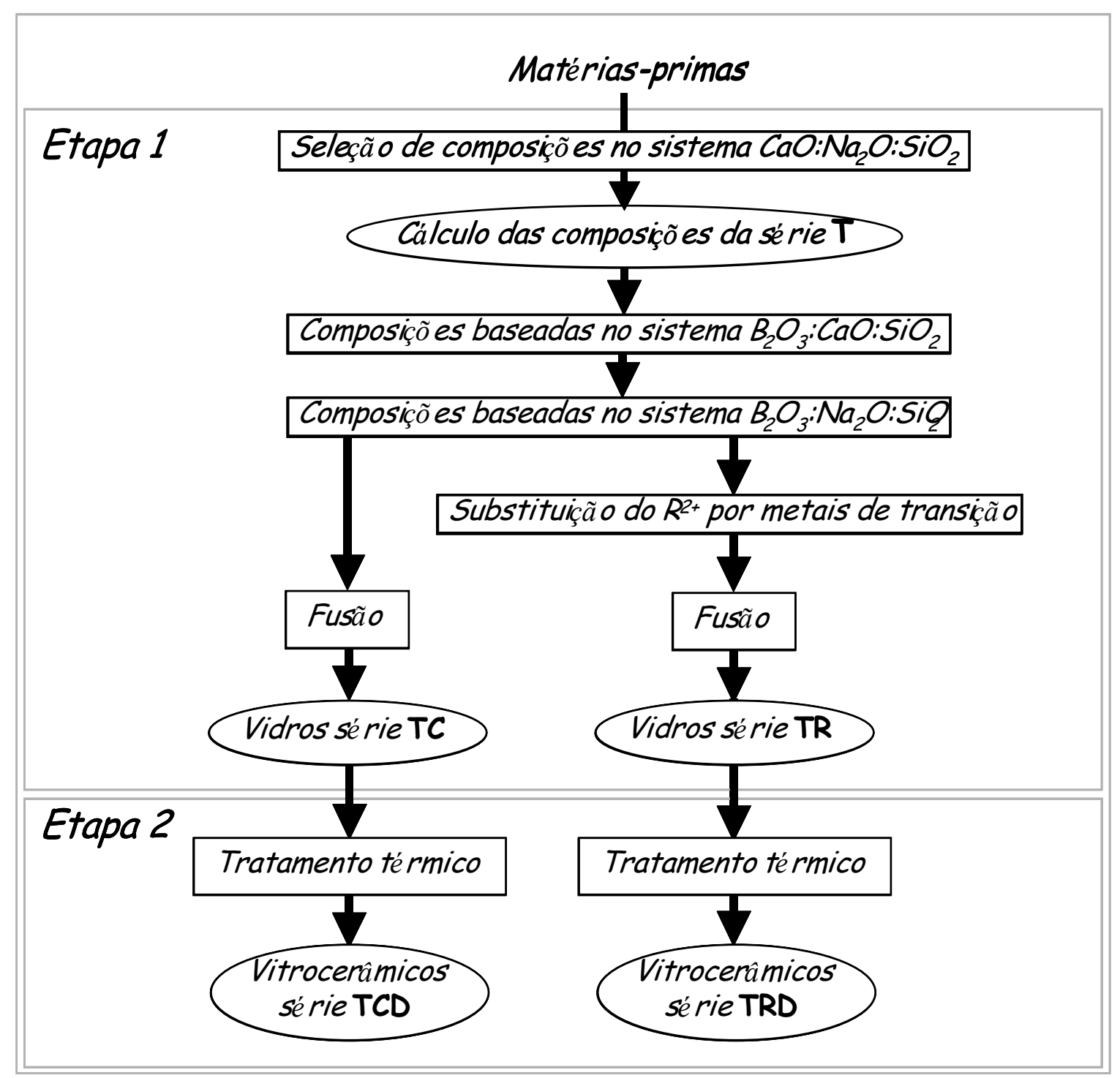

Figura 4.4 - Diagrama esquemático dos procedimentos adotados para a formulação dos vidros e dos vitrocerâmicos.

\subsection{4 - Vidro de Referência}

Um vidro comercial do tipo soda-cal foi utilizado como um padrão para comparação dos vidros produzidos neste trabalho com os vidros de uso comercial.

Este vidro de referência (VR) foi obtido a partir de uma amostra de um vidro utilizado em embalagem alimentícia. A composição química deste vidro, obtida por fluorescência de raios X é apresentada na tabela 4.4. 
TABELA 4.4 - Composição química do vidro VR (Soda-cal comercial), obtidas por fluorescência de raios $\mathrm{X}$ (\% em massa).

\begin{tabular}{c|ccccccc}
\hline Composição & $\mathrm{SiO}_{2}$ & $\mathrm{Na}_{2} \mathrm{O}$ & $\mathrm{CaO}$ & $\mathrm{K}_{2} \mathrm{O}$ & $\mathbf{A l}_{2} \mathrm{O}_{3}$ & $\mathrm{Fe}_{2} \mathrm{O}_{3}$ & Outros \\
\hline VR & 69,9 & 12,6 & 12,7 & 0,9 & 3,4 & 0,1 & 0,4 \\
\hline
\end{tabular}

\section{3- Ensaios de Fusão}

As misturas formuladas foram homogeneizadas em almofariz de porcelana e acondicionadas em cadinhos de alumina. Posteriormente as amostras foram fundidas nas seguintes condições: $1300^{\circ} \mathrm{C}$, durante $2 \mathrm{~h}$ ao ar; taxa de aquecimento de $10^{\circ} \mathrm{C} / \mathrm{min}$; e forno elétrico vertical (Lindenberg/Blue M). O vazamento foi realizado em moldes de aço (prismático, secção transversal de $10 \mathrm{~mm}$ de lado), previamente aquecidos até a temperatura de $500^{\circ} \mathrm{C}$, para diminuir os efeitos do choque térmico e nesta temperatura fez-se o recozimento dos vidros, durante 2 horas, seguido de esfriamento natural no próprio forno ${ }^{(134,136,214-216)}$.

\section{4 - Devitrificação}

Para o estudo da devitrificação optou-se pela rota de obtenção de fritas seguida de tratamento térmico.

Este ensaio é realizado em duas etapas principais que consistem em: obtenção de fritas; e, tratamento térmico.

Os vidros fundidos como anteriormente descritos (4.3) foram vertidos diretamente em água destilada à temperatura ambiente (têmpera). Após o resfriamento as fritas foram lavadas em acetona e secas por $24 \mathrm{~h}$ e pulverizadas utilizando-se almofariz de ágata e selecionadas em peneira até atingirem dimensões inferiores a 65 mesh, $(<210 \mu \mathrm{m})$.

Os pós obtidos foram compactados em prensa isostática a uma pressão de $1000 \mathrm{MPa}$, atingindo uma diâmetro final médio de $20 \mathrm{~mm}$.

Os ensaios de devitrificação foram realizados em forno elétrico vertical (Lindenberg/Blue M - Blue) com suportes de alumina (cadinhos), ao ar em pressão atmosférica.

As amostras foram tratadas em temperaturas selecionadas de acordo com as composições. A temperatura do primeiro patamar, de 
ativação foi determinada tendo como critério os resultados dos ensaios de microscopia de calefação.

O segundo patamar, ou seja, o patamar de temperatura/tempo para o crescimento cristalino foi determinado variando-se a temperatura de $50^{\circ} \mathrm{C}$ em cada teste ${ }^{(106-116)}$. O período de tempo experimental foi fixado em 24, 48, 72 e 96hs. A formação de fases cristalinas foi verificada utilizandose análises por difração de raios X (DRX).

\section{5 - Técnicas de Caracterização}

A caracterização dos vidros e dos vitrocerâmicos foi realizada utilizando-se as seguintes técnicas:

\subsection{1 - Difração de Raios X (DRX)}

A técnica de DRX foi utilizada para determinar as fases cristalinas presentes. Os parâmetros adotados foram: ângulo $2 \theta$ entre $10^{\circ}$ e $80^{\circ} \mathrm{com}$ passos de $0,05^{\circ}$ e tempo de medida de 5 segundos. Utilizou-se amostra em pó (mesh $65,<210 \mu \mathrm{m}$ ) fixada em suporte de alumínio. O equipamento utilizado foi o modelo AXS D8 Advance diffractometer da marca Bruker Corporation (Madison, WI, U.S.A.).

\subsection{2 - Fluorescência de Raios X (FRX)}

Esta técnica foi utilizada para determinar a composição química de matérias-primas e dos vidros e vitrocerâmicos obtidos.

As amostras foram pulverizadas $(<210 \mu \mathrm{m})$ e secas a $90^{\circ} \mathrm{C}$ durante 24 horas. O equipamento utilizado foi o modelo X-Ray Rix2000 da marca Rigaku (Rigaku Corporation, Tokyo, Japão).

\subsection{3 - Espectroscopia Ultravioleta-Visível (UV-Vis)}

Esta técnica foi utilizada para determinar a coordenação dos metais de transição ${ }^{(220)}$.

Para este estudo preparou-se lâminas delgadas ( $20 \mu \mathrm{m})$ e montadas sobre laminas de vidro (suporte). Utilizou-se o equipamento modelo UV-Vis 
Thermo Nicolet 4000, da marca Thermo Nicolet, (Thermo Fisher Scientific, Waltham, Estados Unidos).

\subsection{4 - Espectroscopia Fotoeletrônica de Raios X (XPS)}

A técnica de XPS utiliza a radiação incidente dos fótons emitidos por uma fonte de raios $\mathrm{X}$ e detecta as radiações emergentes produzidas pelos elétrons dos níveis mais internos dos átomos da superfície do material analisado. $(221,222)$.

Neste trabalho, a técnica de XPS foi utilizada para determinar o estado de oxidação dos metais de transição nos vidros obtidos. As amostras para as análises foram pulverizadas $(<210 \mu \mathrm{m})$. O equipamento utilizado foi o modelo XPS-VGS ESCALAB 210, da marca ESCALAB (Seoul, Korea). O equipamento esta equipado com uma fonte de raios $\mathrm{X}$ não-monocromática $\mathrm{Mg} \mathrm{K} \propto$ de raio-X ( $h v=1253.6 \mathrm{eV}$.), combinada com analisador de resolução de linha $\mathrm{K} \propto 1,2$ de $0.75 \mathrm{Ev}$.

\subsection{5 - Microscopia Eletrônica de Varredura (MEV-EDS)}

A microscopia eletrônica de varredura MEV-EDS foi utilizada para a análise morfológica das fases segregadas e análises locais de elementos presentes nas amostras ${ }^{(223)}$.

A preparação da amostra consiste no corte em forma de pastilhas com dimensões aproximadas de $3,0 \times 3,0 \times 1,0 \mathrm{~mm}$. O equipamento utilizado foi o modelo 6400 da marca Jeol (Tokyo, Japan), equipado com varredura de dispersão de raios X da marca INCA Oxford Instruments (Oxford, Inglaterra).

\subsection{6 - Microscopia Óptica de Luz Transmitida e Refletida (MOLT, MOLR)}

Utilizou-se a microscopia óptica de luz refletida para a análise de superfície e de luz transmitida para acompanhar a formação de fases secundárias através dos vidros ("bulk").

As amostras foram preparadas em lâminas delgadas $(\approx 20 \mu \mathrm{m})$ cortadas em micrótono e montadas sobre laminas de vidro (luz transmitida). 
Para as análises com luz refletida, as amostras foram embutidas em resina poliéster cristal, para posterior corte transversal e polimento com $\mathrm{CeO}$ até $<13,0 \mu \mathrm{m}$.

As observações foram realizadas em microscópio e modos de luz refletida e luz transmitida, até 500X. Utilizou-se equipamento modelo DM $\mathrm{RM}$, da marca Leica Microsystems $\mathrm{GmbH}$.

\subsection{7 - Espectroscopia no Infravermelho na Transformada de Fourier (FTIR)}

A espectroscopia na região do infravermelho identifica espécies químicas e principalmente grupos funcionais como resultado da interação entre os modos de vibração e a energia realtiva ao feixe da fonte de infravermelho incidente ${ }^{(140-141,224-227)}$. Neste trabalho, esta técnica foi utilizada para:

1- Identificar os grupos funcionais componentes de vidros e de vitrocerâmicos;

2- Verificar a ocorrência na rede de sílica, de possíveis alterações na estrutura devido às adições de lodo galvânico; e,

3- Auxiliar na identificação de alterações estruturais nos vidros e vitrocerâmicos quando submetidos à ataques químicos.

As amostras pulverizadas $(<210 \mu \mathrm{m})$, foram dispersas em $\mathrm{KBr}$ (Merck P.A.) e pastilhadas em prensa a vácuo. $O$ equipamento utilizado foi o modelo Nexus 870 FT-IR da marca Thermo Nicolet, (Thermo Fisher Scientific, Waltham, Estados Unidos).

Para a identificação dos grupos funcionais, utilizou-se diversos espectros característicos para vidros de sílica encontrados na literatura (141,225-226). Estes espectros estão ordenados na Tab. 4.5. 
TABELA 4.5 - Assinaturas de FTIR para compostos de vidros de sílica.

\begin{tabular}{|c|c|c|}
\hline $\begin{array}{c}\text { Comp. de Onda } \\
\left(\mathrm{cm}^{-1}\right)\end{array}$ & Modo vibracional & Ref. \\
\hline $440-460$ & Si-O-Si $\left[\mathrm{Q}^{4}\right]-\mathrm{SiO}_{4}$ tetraédrico. & 225 \\
\hline 475 & O-Si-O & 225 \\
\hline 580 & $\mathrm{Al}-\mathrm{O}_{\mathrm{n}}$ & 225 \\
\hline $620-670$ & Si-O-B & 141 \\
\hline 780 & $\mathrm{SiO}_{4}[\mathrm{BO}]$ em grupos de tetraédros & 225 \\
\hline 794 & $\mathrm{Si}-\mathrm{O}-\mathrm{Si}$ & 225 \\
\hline 800 & $\begin{array}{l}\text { Modo de pico dos oxigênios ponte perpendicular ao } \\
\text { eixo Si-Si com o plano Si O Si. }\end{array}$ & 225 \\
\hline 800 & Estrutura de rede do vidro $\mathrm{SiO}_{4}$ & 225 \\
\hline 805 & Si O Si superfície entre tetraedros (streaching) & 225 \\
\hline $850-880$ & $\mathrm{Si}-\mathrm{O}[\mathrm{NBO}],\left[\mathrm{Q}_{0}\right]$ & 225 \\
\hline 900920 & $\mathrm{Si}-\mathrm{O}[\mathrm{NBO}],\left[\mathrm{Q}_{1}\right]$ & 225 \\
\hline 940 e 952 & $\mathrm{Si}-\mathrm{OH}$ & 225 \\
\hline 950 & $\mathrm{Si}-\mathrm{O}-[\mathrm{NBO}],\left[\mathrm{Q}_{2}\right]$ & 225 \\
\hline 960 & Si-O- & 141 \\
\hline 970 e 980 & Si-O-[NBO], plano & 225 \\
\hline 1000 & Superfície do tetraedro $\mathrm{SiO}_{4}$, matriz $\mathrm{SiO}_{2}$ & 225,226 \\
\hline $1060-1065$ & Superfície do Si-O-Si com o tetraedro & 225 \\
\hline $1060-1090$ & Si-O-Si superfície $(1,0$ e 0,7$)$ & 225 \\
\hline 1080 & Si-O-[NBO], plano & 225 \\
\hline 1090 & $\mathrm{SiOSi}$ & 141 \\
\hline 1100 e 1150 & $\mathrm{Si}-\mathrm{O}[\mathrm{NBO}],\left[\mathrm{Q}^{3}\right]$ & 225 \\
\hline 1200 & $\mathrm{Si}-\mathrm{O},\left[\mathrm{Q}^{4}\right]$ & 225 \\
\hline 1406 & $\mathrm{~B}-\mathrm{O}$ & 125 \\
\hline 1470 & $\mathrm{Na}-\mathrm{O}$ & 225 \\
\hline 1500 & $\mathrm{H}_{2} \mathrm{O}$ Absorvida & 225 \\
\hline 1600 & Água livre & 141 \\
\hline 1640 & $\mathrm{H}-\mathrm{O}-\mathrm{H}$ & 141 \\
\hline
\end{tabular}

Obs: $\left[Q^{x}\right](x=4,3,2,1,0)$ onde $x$ se refere ao número de átomos de "oxigênios ponte" entre átomos de silício. $\mathrm{Obs}_{2}$ : [NB] se refere a átomos de oxigênio que não formam pontes.

\subsection{8 - Ressonância Nuclear Magnética (RNM-MAS)}

A interação entre os momentos magnéticos dos núcleos com os campos magnéticos criados por outros átomos (campos internos) produz 
alterações nos níveis de energia, assinaladas nos espectros de RNM. Desta forma, é possível identificar o entorno ocupado pelos átomos no interior do sólido através da freqüência de ressonância característica do átomo em um dado entorno. O deslocamento químico, como o resultado desta interação é expresso em partes por milhão em relação à posição da linha de um composto de referência ${ }^{(228-230)}$.

Este deslocamento identifica o tipo de possíveis distorções presentes nos poliedros de coordenação dos átomos ${ }^{(230)}$. O aumento no número de coordenação produz um deslocamento do sinal de RNM para valores negativos no espectrograma. Em compostos contendo sílica amorfa e/ou cristalina, o estudo do sinal de ${ }^{29}$ Si permite identificar duas regiões bem diferenciadas: uma compreendida entre -70 e $-110 \mathrm{ppm}$, devido a Si tetraédrica e outra na região entre -180 e -210 ppm, devido à sílica octaédrica. No caso dos silicatos, à medida que se aumenta o grau de condensação tetraédrica, a linha no espectrograma se desloca para valores negativos. No espectro dos silicatos, são características cinco regiões, cada qual correspondente a um tipo de arranjo entre os tetraedros ${ }^{(229)}$, ou seja, cada região do espectro é específica para a sílica em tetraedros isolados $\left(Q^{0}\right)$, em dímeros $\left(Q^{1}\right)$, em cadeias $\left(Q^{2}\right)$, em planos $\left(Q^{3}\right)$ e em estruturas tridimensionais $\left(Q^{4}\right)$.

O equipamento utilizado foi o MAS-NMR - Advance 400, da marca Bruker Corporation (Madison, WI., U.S.A.), equipado com bobina de - 9.4 Tesla, da marca Kaelsruhe GbmH (Kaelsruhe, Alemanha). Utilizou-se também para a calibração, sondas ${ }^{29} \mathrm{Si} \mathrm{e}{ }^{11} \mathrm{~B}$.

\subsection{9 - Microscopia de Calefação}

A análise das alterações da forma projetada do material nas diferentes temperaturas permite identificar vários fenômenos envolvendo a forma do corpo de prova. Em particular para os vidros destacam-se: 1) Ponto de início da contração; 2) Ponto de "amolecimento" ; 3) Ponto de semi-esfera; e, 4) Ponto de fluidez ${ }^{(231-234)}$. Scholze et al. ${ }^{(235)}$, determinou para os vidros silicato os intervalos ou faixas de viscosidade relativos a cada um dos processos anteriormente descritos (Tab. 4.6). 
Neste trabalho as amostras de vidro foram utilizadas na forma de

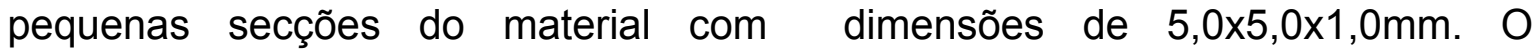
equipamento utilizado foi da marca Hesse Instruments (Osterode am Harz, Germany).

Tabela 4.6- Microscopia de calefação. Transformações típicas do corpo de prova de materiais vítreos associadas à viscosidade ${ }^{(235)}$.

\begin{tabular}{c|c}
\hline & Intervalo de Viscosidade \\
\cline { 2 - 2 } Início do ensaio & - \\
$\begin{array}{c}\text { Ponto de inicio da } \\
\text { contração }\end{array}$ \\
Ponto de amolecimento & $10^{10} \mathrm{dPas}$ \\
\hline Ponto de semi-esfera & $10^{6}-10^{7,6} \mathrm{dPas}$ \\
\hline & $10^{4,2}-10^{4,7} \mathrm{dPas}$ \\
\hline
\end{tabular}

\section{6 - Resistência Química}

Para a avaliação da resistência química tanto dos resíduos utilizados, como para os vidros e vitrocerâmicos obtidos, utilizou-se procedimentos segundo as normas: ASTM 1285 -02 (Standard Test Methods for Determining Chemical Durability of Nuclear, Hazardous, and Mixed Waste Glasses: The Product Consistency Test (PCT) ${ }^{(236)}$; ISO 695-1984 (E) (Glass Resistance to attack by a boiling aqueus solution of mixed alkali - Method of test and classification) ${ }^{(237)}$ e DIN 12116 - $1976{ }^{(238)}$ (Prufung von glass; Griessverfahen zur prufung der wasserbestandigkeit von glass als werstoff bei $98^{\circ} \mathrm{C}$ und Einteilung der glasser in hydrolytiscle klassen). Adicionalmente foram realizados ensaios de resistência hidrolítica com uso de coluna sohxlet ${ }^{(10-11)}$. 


\subsection{1 - Estabilidade em meio aquoso}

O procedimento ASTM $1285-02{ }^{(236)}$, avalia a durabilidade química relativa, de cada elemento que compõe amostra ensaiada (dissolução por elemento com o tempo em função meio ambiente). A norma se sub-divide em dois procedimentos: PCT-A e PCT-B. O método PCT-A destina-se ao ensaio de vidros e vitrocerâmicos contendo resíduo nuclear de alta atividade. O ensaio PCT-B destina-se a vidros e vitrocerâmicos contendo resíduos nucleares de baixa atividade, resíduos industriais, etc. Neste estudo utilizou-se o ensaio PCT-B.

Segundo a norma utilizou-se recipiente de Teflon com $100 \mathrm{ml}$ de volume interno. Para todos os testes foram usados $1,0 \mathrm{gr}$ de amostra pulverizada ( $\leq 149$ $\mu \mathrm{m})$ e seca em estufa a $100^{\circ} \mathrm{C}$ por $24 \mathrm{~h}$. A solução de ataque constituiu-se de água ultra-pura (Milli- $\mathrm{Q}^{\circledR}$, condutividade $<18 \mathrm{mV} \cdot \mathrm{cm}$ à $25^{\circ} \mathrm{C}$ ). Os recipientes com as amostras e a solução de ataque foram postos em estufa pré-aquecida à $90^{\circ} \mathrm{C} \pm$ $2^{\circ} \mathrm{C}$. O tempo de ensaio foi de $148 \mathrm{~h}$ (7dias). A concentração das espécies dissolvidas foi determinada pela técnica ICP. Os cálculos de concentração foram realizados para cada espécie química específica de interesse, ou seja, para o $\mathrm{Si}$, $\mathrm{Ca}, \mathrm{Na}, \mathrm{Cr}, \mathrm{Ni}, \mathrm{Cu}, \mathrm{Zn}$ e Pb.

\subsection{2 - Resistência Hidrolítica}

O parâmetro para realizar a medida da resistência ao ataque hidrolítico é a perda de massa na camada superficial da amostra em função o tempo. $O$ método utilizado é o descrito por Day ${ }^{(10)}$, porém neste estudo modificado para o uso de uma coluna de "Soxhlet" assemelhando-se assim ao método MCC-5S ${ }^{(11)}$.

O conjunto utilizado para os ensaios de resistência ao ataque é apresentado na Fig. 4.5. Neste esquema, água destilada entra em ebulição no balão de aquecimento (evaporador) (1). O vapor gerado é (2) captado no aparelho de Soxhlet (3) o qual contém a amostra. Esta por sua vez, permanece na água recém condensada, ou seja destilada. O líquido é mantido sob aquecimento a temperatura de $90^{\circ} \mathrm{C}$. O reservatório do Soxhlet possui um dispositivo de vasos comunicantes (sifão), que devolve o líquido (condensado) para o balão de aquecimento (1) quando este atinge o volume limite dos vasos comunicantes (4). Ao retornar ao balão a solução arrasta 
consigo as possíveis espécies químicas dissolvidas a partir da superfície da amostra ensaiada.

A principal vantagem deste processo é que a amostra está sempre em contato com a água destilada recém condensada, reduzindo a possibilidade de reincorporação na superfície da amostra de espécies já dissolvidas ${ }^{(14,11,131)}$. Este sistema também minimiza variações de $\mathrm{pH}$ na solução de ataque, às quais podem influenciar nos possíveis mecanismos de ataque do vidro.

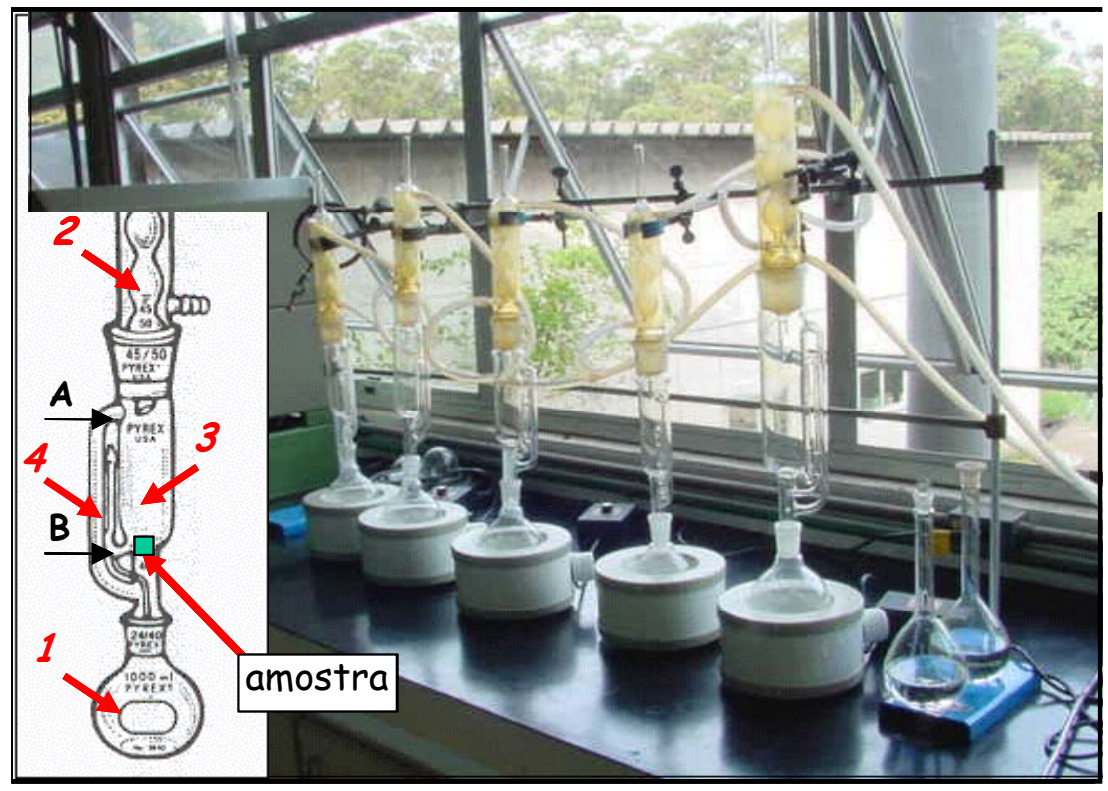

(a)

(b)

FIGURA 4.5 - Aparelho de extração tipo "Soxhlet": (a) detalhe esquemático do aparelho; e, (b) foto ilustrativa da montagem experimental, onde " $A$ " indica o nível máximo da solução de ataque ; "B" o nível mínimo.

As amostras com dimensões de $1 \times 10 \times 10 \mathrm{~mm}$ foram desbastadas com lixa $240(\leq 60,0 \mu \mathrm{m})$. Antes do ensaio, todas as amostras foram submetidas (ou limpas) em ultra-som e lavadas com acetona (PA Merck) e secas a $110^{\circ} \mathrm{C}$ por 2 horas em estufa (Lindberg Blue M mod. MO 1490 C-1). O resfriamento foi realizado em um dessecador para posterior pesagem em balança analítica de precisão $( \pm 0,00005 \mathrm{~g}$, Mettler $\mathrm{H} 16)$. As dimensões das amostras foram medidas utilizando-se um paquímetro (Starrett 125 MEB - Precisão 0,05mm). 
A variação de massa das amostras foi avaliada pesando-se as mesma após 24, 72, 168 e 336 horas de ensaio. Antes de cada pesagem cada amostra foi lavada com acetona (Merck P.A.) e secas a $110^{\circ} \mathrm{C}$ durante duas horas em estufa. A taxa de desgaste ou de ataque $\left(\mathrm{g} \cdot \mathrm{cm}^{-2} \cdot \mathrm{s}^{-1}\right)$ é expressa pela perda de massa (g) na superfície total $\left(\mathrm{cm}^{2}\right)$ da amostra em função tempo de exposição (s), segundo a equação (4.2):

$$
R \boldsymbol{h}=(\boldsymbol{m i}-\boldsymbol{m f}) /(\mathrm{s} \times \boldsymbol{t})
$$

Onde: $\boldsymbol{R} \boldsymbol{h}=$ resistência hidrolítica $\left(g \cdot \mathrm{cm}^{-2} \cdot \mathrm{s}^{-1}\right) ; \boldsymbol{m i}=$ massa inicial $(g) ; \boldsymbol{m} \boldsymbol{f}=$ massa final $(\mathrm{g}) ; \boldsymbol{s}=$ área superficial $\left(\mathrm{cm}^{2}\right) ; \mathrm{e}, \boldsymbol{t}=$ tempo $(\mathrm{s})$.

Para o estudo do processo de dissolução, amostras foram pulverizadas (65 mesh; < 210 $\mu \mathrm{m}$ ), para aumentar significamente a área de superfície específica exposta ao ensaio e por conseqüência, a sua reatividade das amostras. Este método, aqui desenvolvido aumenta a área exposta e permite a obtenção de maior quantidade de produto de reação.

As amostras foram acondicionadas nos porta-amostras, microtubos de reação (Eppendorf ${ }^{\circledR}$ 2,0 ml). Estes microtubos foram modificados com orifícios de modo a permitir a livre circulação do líquido de ataque (água) através da amostra (Fig. 4.6).

A evolução do ataque hidrolítico neste caso foi acompanhada com a análise de amostras (alíquotas) coletadas após 01, 03, 06, 12, 24, 72, 168 e 336 horas de ensaio. 


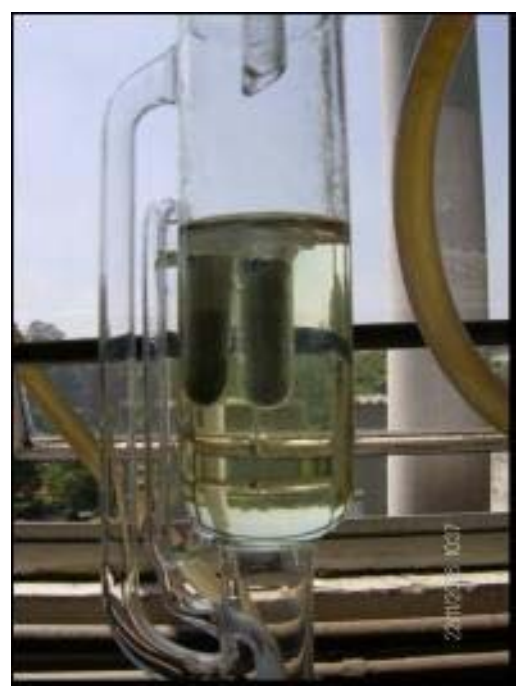

(a)

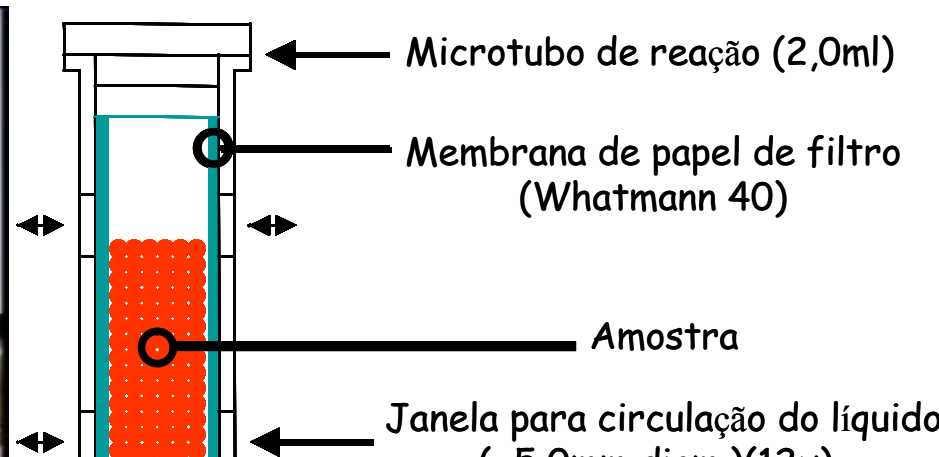

$(\sim 5,0 \mathrm{~mm}$ diam.)(12x)

FIGURA 4.6 - Ataque hidrolítico em amostras pulverizadas: (a) foto ilustrativa da montagem experimental, $(b)$ detalhe esquemático do porta amostra.

\subsection{3 - Resistência ao Ataque Alcalino}

Baseado na Norma ISO 695-1984 (E) (Glass - Resistance to attack by a boiling aqueous solution of mixed alkali - Method of test and classification International Organization for Standartization) ${ }^{(237)}$, este ensaio é do tipo "extração sem agitação". As amostras de sessão quadrada de dimensões $1 \times 10 \times 10 \mathrm{~mm}$, foram preparadas com o mesmo critério apresentado no item 4.62. Neste ensaio, as amostras são mantidas suspensa por um fio de nylon em um Becker, imersas na solução de ataque sem tocar as paredes do recipiente. A solução utilizada é preparada a partir de uma mistura 1:1 em volumes de soluções de carbonato de sódio $(0,5 \mathrm{M})$ e hidróxido de sódio $(0,1 \mathrm{M})$, aquecidas até uma temperatura próxima à ebulição. Após 3 horas de imersão a amostra é lavada com água destilada e posteriormente com acetona, seca e pesada. Conforme a norma citada, a resistência é avaliada pela relação entre a perda de massa $(\mathrm{mg})$ por área de superfície $\left(\mathrm{dm}^{2}\right)$, após 3 horas de exposição, segundo a equação (4.3):

$$
R a l=(m i-m f) / s
$$

Onde: $\boldsymbol{R a l}=$ resistência ao ataque alcalino $\left(\mathrm{mg} / \mathrm{dm}^{2}\right) ; \boldsymbol{m i}=$ massa

inicial $(m g) ; \boldsymbol{m} \boldsymbol{f}=$ massa final $(m g) ; \boldsymbol{e}, \boldsymbol{s}=$ área superficial $\left(d m^{2}\right)$. 
O mesmo ensaio do item anterior foi realizado para as amostras na forma de pó preparadas de acordo com o item 4.6.2.

\subsection{4 - Resistência ao Ataque Ácido}

Este procedimento se baseia na norma DIN 12116 - 1976 (Prufung von glass; Griessverfahen zur prufung der wasserbestandigkeit von glass als werstoff bei $98^{\circ} \mathrm{C}$ und Einteilung der glasser in hydrolytiscle klassen) ${ }^{(238)}$. A solução de ataque utilizada, é uma solução aquosa de alta concentração de ácido clorídrico (6M) e a duração do ensaio é de 6 horas. A preparação da amostra è a descrita no item 4.6.3.

Conforme a norma, a análise é avaliada pela perda de massa (mg) em função área total de superfície $\left(\mathrm{dm}^{2}\right)$, após 6 horas, segundo a equação (4.4):

$$
\operatorname{Rac}=(m i-m f) / 2 s
$$

Onde: $\boldsymbol{R a c}=$ resistência ao ataque ácido $\left(\mathrm{mg} / \mathrm{dm}^{2}\right) ; \boldsymbol{m i}=$ massa inicial $(m g) ; m f=$ massa final $(m g) ; e, s=$ área superficial $\left(d m^{2}\right)$.

A avaliação da dissolução pelo ataque ácido foi realizado visando aumentar a área de material exposto à solução ataque ácida, e desta forma aumentar a quantidade dos produtos de reação. $O$ arranjo experimental foi 0 mesmo adotado para os ensaios de ataque alcalino. 


\section{Resultados e discussão}

\section{1 - Caracterização das matérias-primas}

A Tab. 5.1 apresenta as principais componentes encontrados a partir da análise quantitativa dos materiais de partida (FRX, \% em massa). $O$ $\mathrm{SiO}_{2}$ está presente em todos as matérias primas analisadas e em maior quantidade, no RFS (resíduo de finos de sílica).

TABELA 5.1 - Principais constituintes dos materiais de partida em óxido (\% EM massa): RFS - resíduo fino de sílica; RRG - resíduo de rocha granítica; RSG - resíduo sólido galvânico.

\begin{tabular}{c|ccr}
\hline Elemento & RFS & RRG & RSG \\
\hline $\mathrm{SiO}_{2}$ & 98,0 & 71,4 & 22,0 \\
$\mathrm{Al}_{2} \mathbf{O}_{3}$ & 0,9 & 16,0 & 0,9 \\
$\mathbf{C a O}$ & 0,1 & 0,6 & 14,0 \\
$\mathbf{K}_{2} \mathbf{O}$ & 0,2 & 6,2 & 0,2 \\
$\mathrm{Na}_{2} \mathbf{O}$ & 0,2 & 4,9 & 1,2 \\
$\mathrm{Fe}_{2} \mathbf{O}_{3}$ & 0,2 & 0,7 & 1,1 \\
$\mathbf{S O}_{3}$ & 0,1 & 0,1 & 7,4 \\
$\mathrm{MnO}$ & - & 0,1 & 0,1 \\
$\mathrm{Cr}_{2} \mathbf{O}_{3}$ & - & - & 21,0 \\
$\mathbf{C u O}$ & - & - & 6,9 \\
$\mathbf{N i O}$ & - & - & 13,0 \\
$\mathbf{Z n O}$ & - & - & 4,7 \\
$\mathbf{P b O}$ & - & - & 1,3 \\
$\mathbf{M g O}$ & - & - & 3,5 \\
$\mathbf{P}_{2} \mathbf{O}_{5}$ & - & - & 1,2 \\
Outros & 0,3 & - & 1,5 \\
\hline
\end{tabular}

No RSG o conjunto dos óxidos de metais tóxicos é significativo e representa em torno de $47 \%$ da massa total. Estes constituintes podem ser interessantes na obtenção de vidro como modificadores na estrutura. $O$ restante dos constituintes são os componentes resultantes dos processos de 
floculação e precipitação da lama galvânica tais como o $\mathrm{CaO}$, o $\mathrm{SiO}_{2}$ entre outros.

O resíduo de sílica, de alta pureza ( $98 \%$ em massa em óxido de silício), e o resíduo de granito, composto em cerca de $88 \%$ de sua massa por de sílica e alumina, tornam-se atrativos candidatos para a produção de vidros.

A Fig. 5.1 mostra o difratograma de raios $X$ correspondente ao resíduo de finos de sílica indexado como quartzo- $\propto$ (PDF 85-1053).

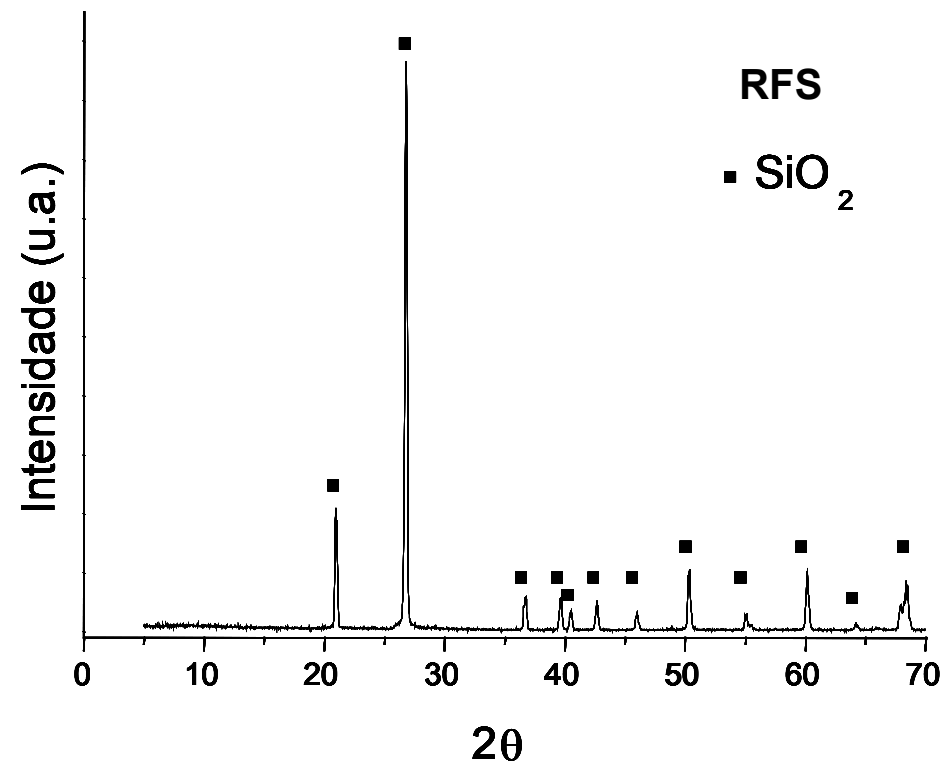

FIGURA 5.1 - Difratograma de raios X: resíduo de finos de sílica (RFS)

A Fig. 5.2 apresenta o difratograma de raios $\mathrm{X}$ correspondente ao RRG, onde se observa claramente os picos correspondentes ao quartzo- $\propto$ (PDF 88-2302) como fase dominante secundado pela presença de albita $\mathrm{Na}\left(\mathrm{AlSi}_{3} \mathrm{O}_{8}\right)$ (PDF 84-0752) e $\mathrm{Na}\left(\mathrm{AISi}_{2} \mathrm{O}_{6}\right)$ (PDF 80-1561). Estes resultados indicam o carater mineralógico de feldspato sódico. A presença de Nefelina, também foi observada, ainda que em menor intensidade (PDF 76-1858).

O difratograma de raios $X$ correspondente ao resíduo lodo galvânico revela a presença de fases cristalinas correspondentes à $\mathrm{SiO}_{2}$ (quartzo- $\propto$; PDF 88-2302) e à $\mathrm{CaCO}_{3}$ (Calcita; PDF 88-1807). 


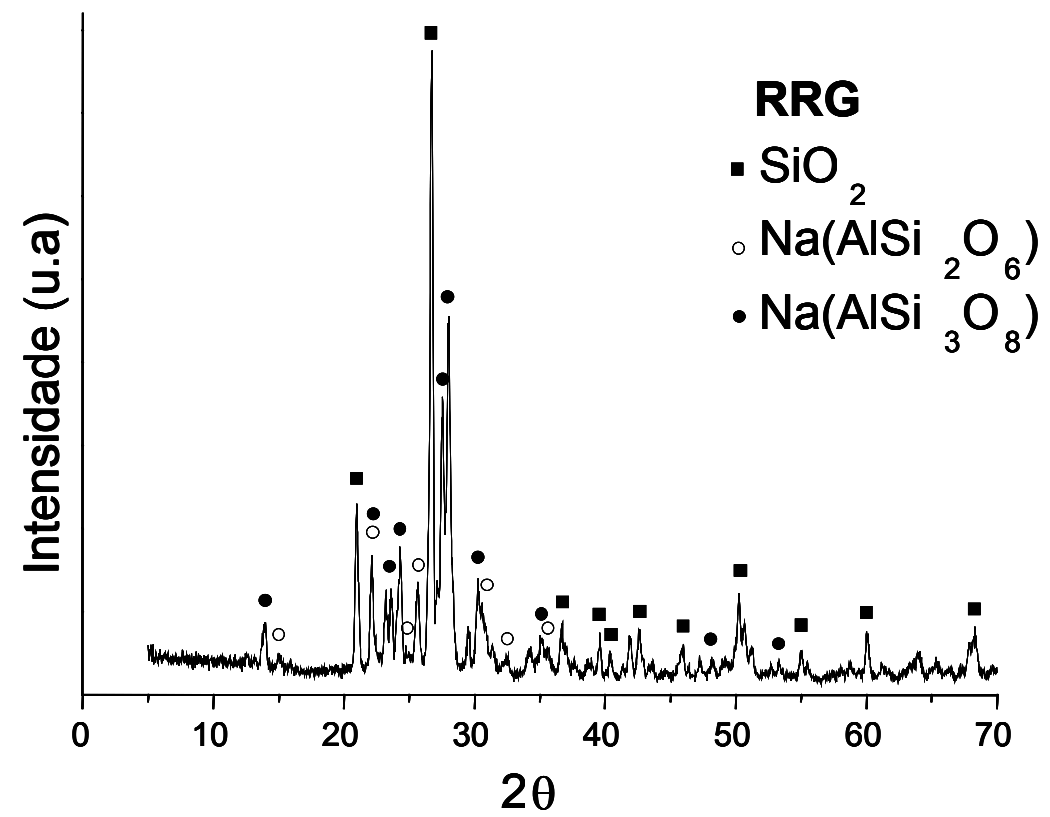

FIGURA 5.2 - Difratograma de raios X: resíduo de rochas de granito (RRG)

Os resultado da avaliação de estabilidade (PCT-B, ASTM C 1285-029) realizada para o resíduo quando em solução aquosa, são mostrados na Tab. 5.2. Nesta norma a taxa de dissolução por elemento, é expressa pela letra $\mathbf{R}$. Comparando-se os elementos presentes, particular atenção deve ser atribuída ao cromo por apresentar alto risco de contaminação ambiental, tanto pela concentração no resíduo como por estar presente pelo menos em parte, na forma hexavalente, à qual é solúvel em água. Os demais metais de transição presentes foram observados, em concentrações menores, porém ainda assim consideradas de risco ambiental ${ }^{(21)}$.

TABELA 5.2 - Dissolução normalizada por elemento $\left(\mathrm{g} / \mathrm{m}^{2}\right)$ para o Resíduo Galvânico após 7 dias do ensaio PCT-B

\begin{tabular}{c|lcccccc}
\hline PCT-B (7 dias) & $\mathbf{R}_{\mathbf{S i}}$ & $\mathbf{R}_{\mathbf{C a}}$ & $\mathbf{R}_{\mathbf{N a}}$ & $\mathbf{R}_{\mathbf{C r}}$ & $\mathbf{R}_{\mathbf{N i}}$ & $\mathbf{R}_{\mathbf{C u}}$ & $\mathbf{R}_{\mathbf{Z n}}$ \\
\hline$R S G$ & 1,54 & 1,08 & 3,76 & 1,44 & 0,09 & 0,16 & 0,21 \\
\hline
\end{tabular}




\section{2 - Vidros}

\subsection{1 - Fusão e Conformação}

As composições de vidros formuladas, das series TC e TR (Item. 4.2), foram fundidas e recozidas segundo os parâmetros definidos (Item. 4.3). Todos os vidros, sem exceção, apresentaram desempenho de acordo com o planejado durante a fusão e verteram com facilidade no molde, exibindo fluidez e viscosidade aparente adequadas para a conformação.

As composições químicas dos vidros TR foram determinadas por FRX e são mostrados na Tab. 5.3. Comparando-se os resultados obtidos com a composição calculada, se observa uma perda negligenciável de metais de transição, especialmente do cromo.

TABELA 5.3 - Composições em massa da série de vidros TR calculadas, em comparação com as composições obtidas por FRX (\% em massa).

\begin{tabular}{|c|c|c|c|c|c|c|c|c|c|c|}
\hline \multirow[t]{2}{*}{ Composição } & \multicolumn{2}{|c|}{ T05R10 } & \multicolumn{2}{|c|}{ T10R20 } & \multicolumn{2}{|c|}{ T15R30 } & \multicolumn{2}{|c|}{ T20R40 } & \multicolumn{2}{|c|}{ T25R50 } \\
\hline & Calc. & FRX & Calc. & FRX & Calc. & FRX & Calc. & FRX & Calc. & FRX \\
\hline $\mathrm{SiO}_{2}$ & 57,2 & 61,37 & 53,0 & 57,58 & 47,6 & 49,39 & 43,5 & 43,67 & 39,1 & 38,81 \\
\hline $\mathrm{B}_{2} \mathrm{O}_{3}$ & 4,3 & 4,30 & 5,5 & 5,50 & 6,9 & 6,90 & 8,0 & 8,00 & 9,4 & 9,40 \\
\hline $\mathrm{Na}_{2} \mathrm{O}$ & 30,5 & 19,54 & 28,5 & 15,97 & 27,5 & 14,19 & 25,5 & 12,87 & 23,5 & 15,11 \\
\hline $\mathrm{CaO}$ & 1,5 & 2,02 & 2,9 & 2,92 & 4,3 & 4,96 & 5,7 & 6,46 & 7,1 & 7,08 \\
\hline $\mathrm{K}_{2} \mathrm{O}$ & 1,0 & 1,08 & 1,0 & 1,18 & 1,0 & 1,05 & 1,0 & 1,05 & 1,0 & 0,79 \\
\hline $\mathrm{Al}_{2} \mathrm{O}_{3}$ & 2,0 & 5,92 & 2,0 & 6,68 & 2,0 & 9,93 & 2,0 & 8,04 & 2,0 & 10,2 \\
\hline MgO & 0,3 & - & 0,7 & - & 1,1 & - & 1,4 & - & 1,8 & - \\
\hline $\mathrm{Cr}_{2} \mathrm{O}_{3}$ & 2,1 & 2,55 & 4,2 & 3,97 & 6,3 & 6,16 & 8,5 & 9,06 & 10,6 & 8,45 \\
\hline $\mathrm{NiO}$ & 1,3 & 1,26 & 2,6 & 2,01 & 3,9 & 3,09 & 5,2 & 3,99 & 6,6 & 4,33 \\
\hline CuO & 0,7 & 0,54 & 1,4 & 0,85 & 2,1 & 1,30 & 2,8 & 1,57 & 3,5 & 1,62 \\
\hline $\mathrm{ZnO}$ & 0,5 & 0,33 & 0,9 & 0,54 & 1,4 & 0,83 & 1,9 & 1,12 & 2,4 & 1,23 \\
\hline $\mathrm{PbO}$ & 0,1 & 0,10 & 0,3 & 0,11 & 0,4 & 0,31 & 0,5 & 0,43 & 0,7 & 0,48 \\
\hline $\mathrm{Fe}_{2} \mathrm{O}_{3}$ & 0,2 & 0,35 & 0,3 & 0,66 & 0,4 & 0,64 & 0,5 & 0,74 & 0,6 & 0,73 \\
\hline $\mathrm{SO}_{3}$ & 0,8 & 0,29 & 1,5 & 1,53 & 2,3 & 0,54 & 3,0 & 2,27 & 3,8 & 0,70 \\
\hline Outros & 1,4 & 0,25 & 1,7 & 0,50 & 1,9 & 0,71 & 2,1 & 0,73 & 2,3 & 0,66 \\
\hline
\end{tabular}

Tal perda é atribuída em parte à sublimação dos metais com as altas temperaturas do processo e em parte pela difusão destas espécies nos cadinhos de alumina utilizados. Uma evidência da ocorrência de um processo de difusão e ataque, envolvendo o vidro fundido e os cadinhos utilizados, está no fato do aumento significativo do teor de $\mathrm{Al}_{2} \mathrm{O}_{3}$ nas amostras analisadas. 
Os vidros obtidos nos primeiros testes são apresentados na Fig. 5.3. Os vidros preparados apenas com RFS e RRG são translúcidos e homogêneos (série TC). Por outro lado, os vidros preparados com adição de RSG, apresentam-se opacos, com coloração verde-esmeralda intenso, provavelmente, devido ao efeito colorificante dos metais presentes no RSG.

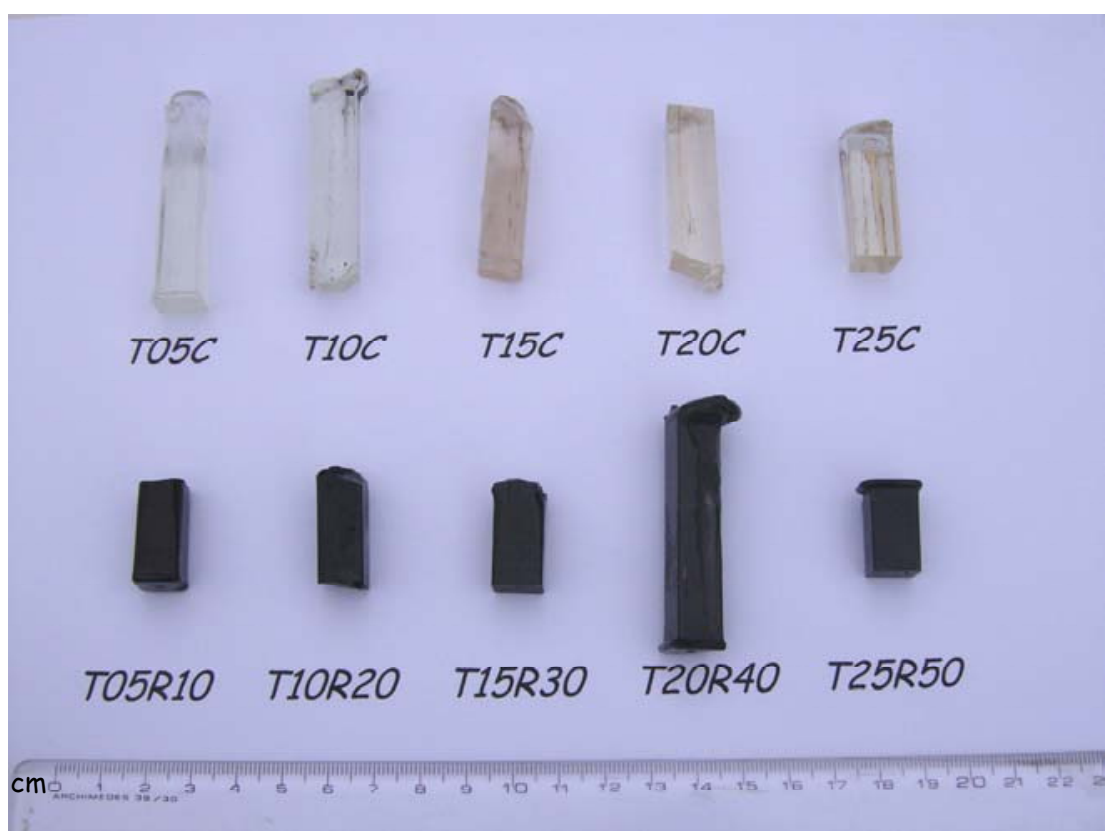

FIGURA 5.3 - Vidros das séries TC e TR, obtidos nos ensaios de fusão.

Após o recozimento, e inspeção visual, os vidros aparentaram, consistência homogênea $e$ isenta de trincas. Apenas no vidro de composição T25R50, se observou freqüentemente a segregação de uma fase de brilho metálico quando observada em microscópio óptico. Devido à morfologia desta fase (esferóide), tem-se como indicativo a sua formação pode ter ocorrido a partir da segregação de um líquido de composição distinta da matriz do vidro (Fig. 5.4) destes macro-inclusões. O estudo da composição e estrutura dos mesmos é discutido no item 5.2.5.

Os difratogramas correspondentes aos ensaios de difração por raios $\mathrm{X}$ dos vidros TC, são apresentados nas Fig. 5.5(a e b b)). Estes espectros representam os vidros preparados com os resíduos de finos de sílica (RFS) e de granito (RRG), porém, sem o uso de resíduo galvânico (RSG). Estes materiais apresentam um caráter tipicamente amorfo vítreo, 
onde se observam os halos espectrais entre $15^{\circ}$ e $40^{\circ}(2 \theta)$, indicativos da possibilidade de cristalização para estas composições. Os espectros obtidos para as demais composições intermediárias, também apresentaram aspecto similar aos da Fig. 5.5. Analisando o sistema do diagrama de equilíbrio da Fig. 4.1, no triângulo de compatibilidade onde se inserem as composições estudadas $\mathbf{T}$, as possíveis fases a se cristalizarem são $\mathrm{Na}_{2} \mathrm{O}: \mathrm{SiO}_{2}$, $\mathrm{Na}_{2} \mathrm{O}: 2 \mathrm{CaO}: 3 \mathrm{SiO}_{2}$ e $2 \mathrm{Na}_{2} \mathrm{O}: \mathrm{CaO}: 3 \mathrm{SiO}_{2}$.

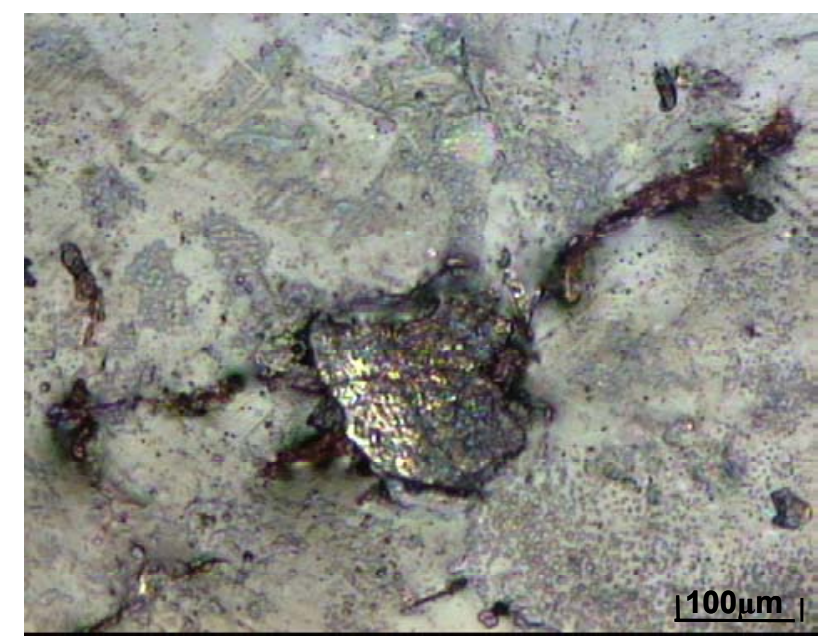

FIGURA 5.4 - Macro-inclusão observada na amostra T25R50

Os espectros correspondentes aos ensaios de difração por raios $X$ dos vidros TR, também apresentam caráter amorfo, com halos de cristalização característicos. Entretanto, para as composições T20R40, (Fig.5.6(a)) e T25R50 (5.6(b)), observa-se a presença de fases cristalinas formadas à partir dos metais fornecidos pelo RSG, identificadas como: $\mathrm{Cr}_{2} \mathrm{O}_{3} ; \mathrm{Ca}_{3}\left(\mathrm{CrO}_{4}\right)_{2} ; \mathrm{Ni}\left(\mathrm{CrO}_{4}\right) ; \mathrm{Cu}_{2} \mathrm{~S} ; \mathrm{e}, \mathrm{Ni}_{3} \mathrm{~S}_{2}$ (PDF 85-0730; 71-2488; 880108; 83-1462; e, 76-1870, respectivamente). O grupo TR é composto pelos vidros preparados com RFS, RGG e RSG. 


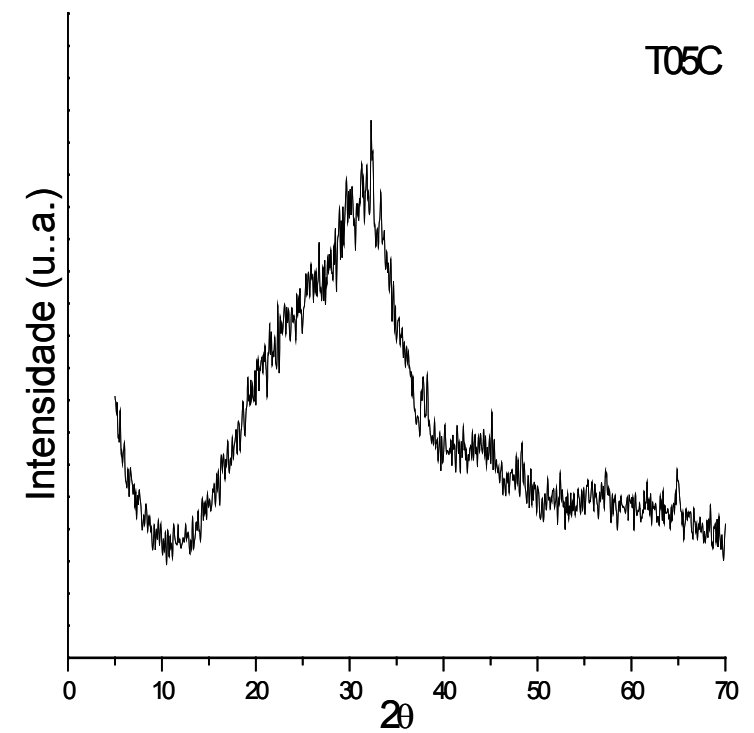

(a)

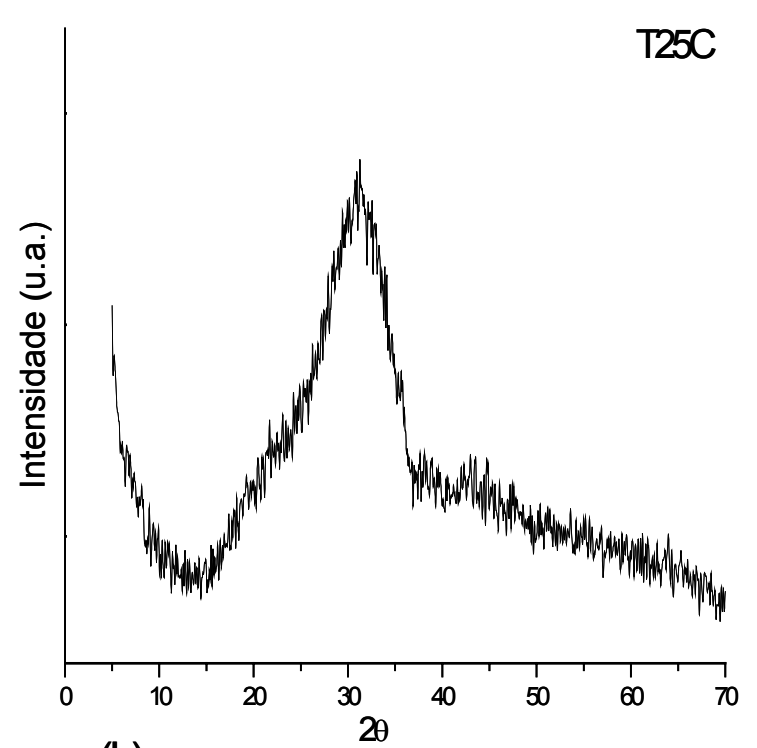

(b)

FIGURA 5.5 - Difratogramas obtidos por DRX a partir de amostras das composições TC: (a) T05C, (b) T25C.

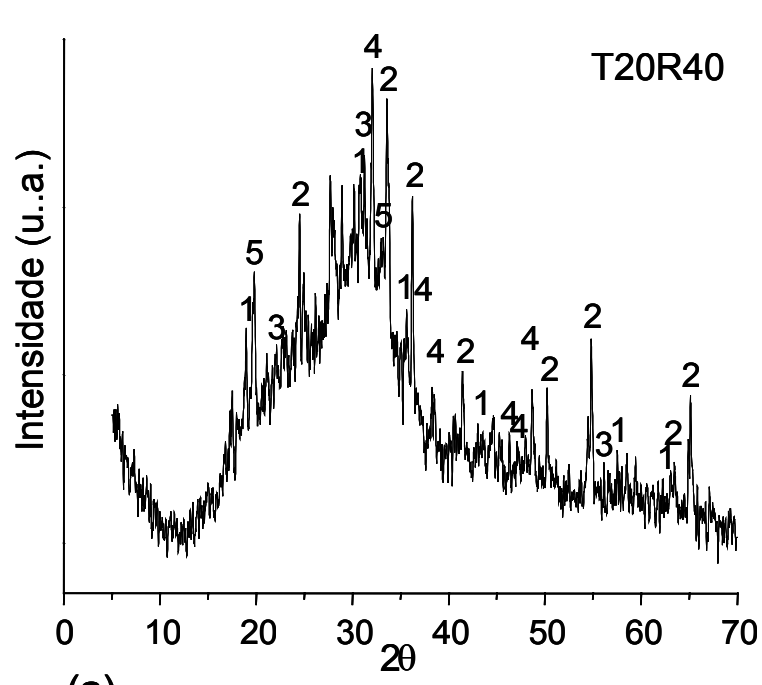

(a)

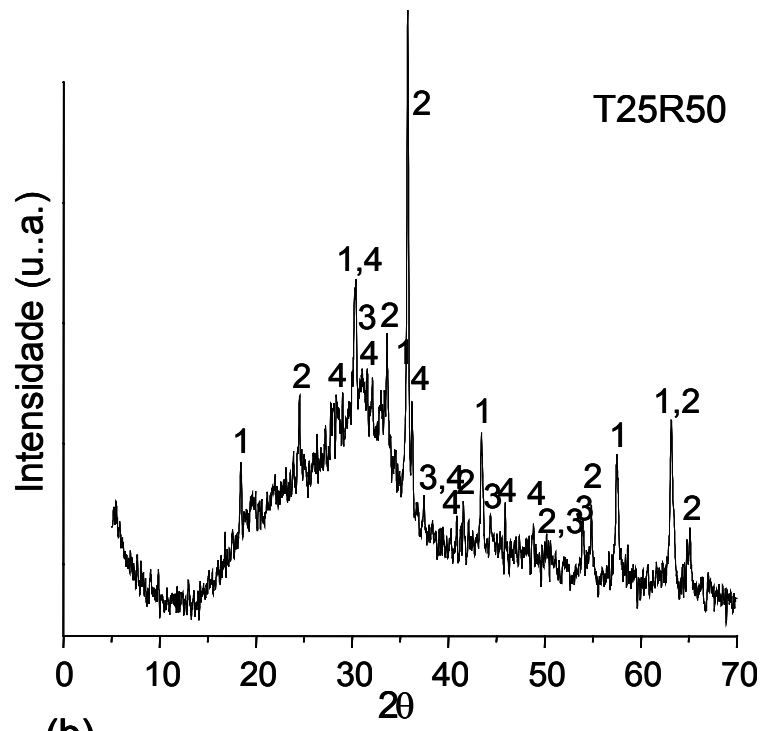

(b)

$$
1-\mathrm{Ni}\left(\mathrm{Cr}_{2} \mathrm{O}_{4}\right) ; 2-\mathrm{Cr}_{2} \mathrm{O}_{3} ; \mathbf{3}-\mathrm{Ni}_{3} \mathrm{~S}_{2} ; \mathbf{4}-\mathrm{Cu}_{2} \mathrm{~S} ; \mathbf{5}-\mathrm{Ca}_{3}\left(\mathrm{CrO}_{4}\right)_{2}
$$

FIGURA 5.6 - Difratogramas obtidos por DRX a partir de amostras das composições TR: (a) T20R40, (b) T25R50 
Observou-se experimentalmente que para adições de RSG maiores que $30 \%$ em massa (T15R30), a estrutura dos vidros pode saturar e favorecer a formação de fases cristalinas e/ou arranjos estruturais distintos da estrutura vítrea original.

Considerando-se o critério do campo iônico, $Z / r^{2}$ (onde $Z$ representa a carga nominal do íon e $r$ o raio iônico em $n m){ }^{(40)}$, os metais nestas condições apresentam limite de solubilidade na seguinte ordem: $\mathrm{Cr}$, Ni, $\mathrm{Cu}$ e $\mathrm{Zn}$. Nas composições TR, as primeiras fases secundárias a precipitar observadas, contêm $\mathrm{Cr}$ e Ni (T20R40, Fig. (5.6(a)) e, para maiores adições de RSG, também se observa fases secundárias contendo Cu (T20R40, Fig. (5.6(b)).

Na Fig. 5.7 são apresentadas micrografias (microscopia óptica, luz refletida) de seções transversais polidas de amostras das séries TC e TR. Nos vidros TC, não se observou presença de fases cristalinas e/ou fases segregadas. Nas amostras da série TR, as fases cristalinas foram observadas somente para as composições T20R40 e T25R50 onde parte significativa dos cristais apresentam a forma de placas hexagonais, possivelmente de cromita.

Na Fig. 5.8 são apresentadas micrografias (m. o. luz transmitida), referente as amostras T15R30, T20R40 e T25R50, preparadas na forma de lâminas finas $(\approx 30 \mu \mathrm{m})$.

Para o vidro T15R30 (fig. 5.8(a)), não se observa a presença de fazes cristalinas, entretanto nas micrografias dos vidros T20R40 (Fig. 5.8(b)) e T25R50 (Fig. 5.8(c), e 5.8(d), respectivamente), se observa a presença de cristais em formas de placas hexagonais, morfologia esta, típica dos cristais de cromita. A atribuição da composição destes cristais à cromita é suportada pelas análises por DRX (Fig. 5.6). Ainda comparando o vidro T20R40 com o vidro T25R50, percebe-se o aumento da freqüência de cristais de cromita com o aumento da adição de RSG.

As micrografias referentes aos vidros T20R40 e T25R50, e resultados das análises por EDS são apresentadas na Fig. 5.9. 

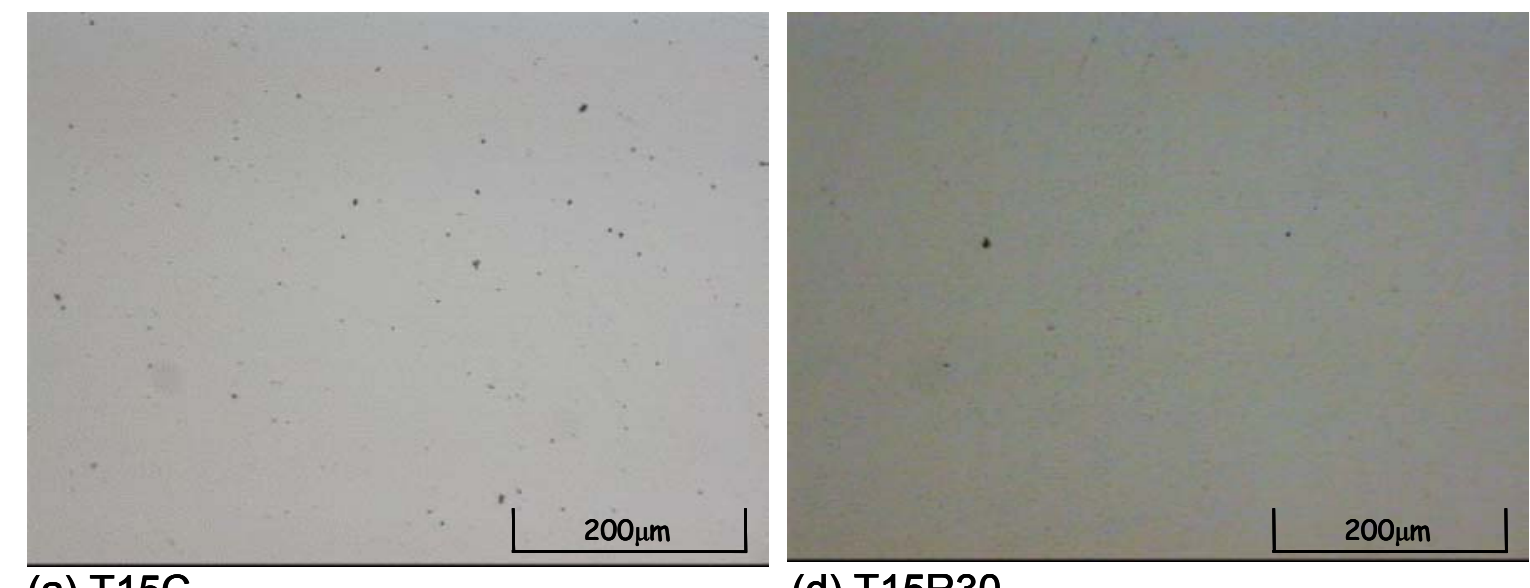

(a) T15C

(d) T15R30
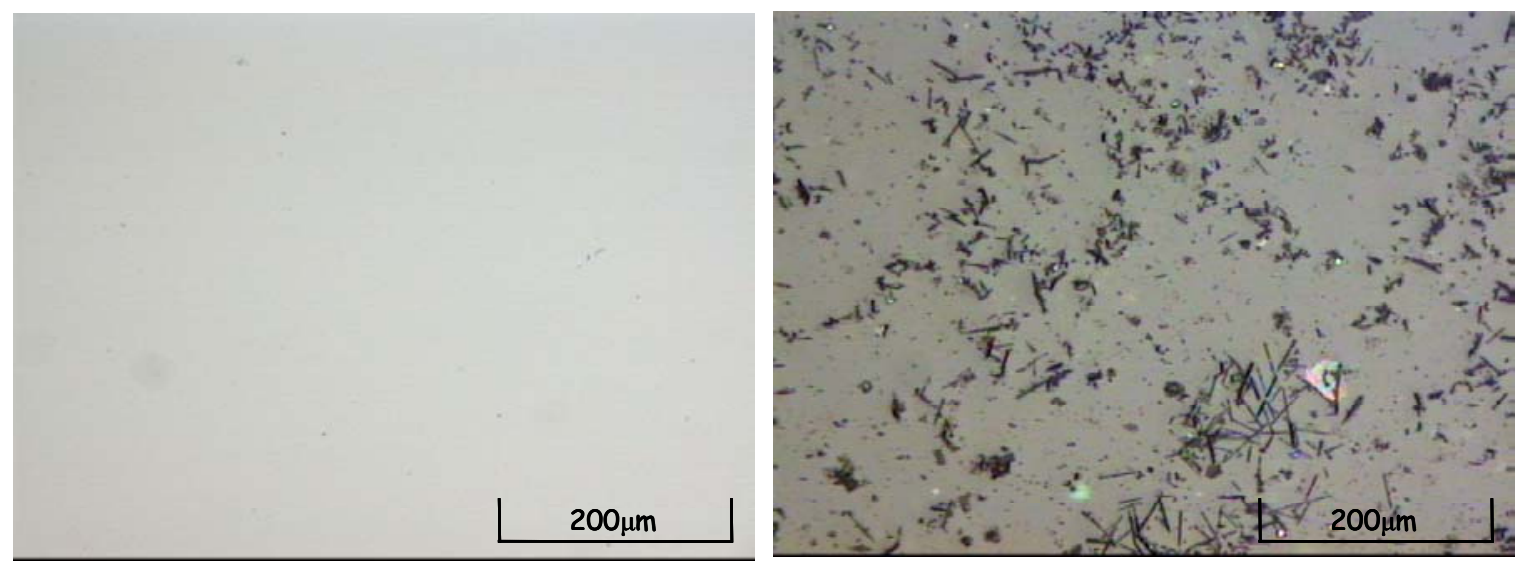

(b) T20C

(e) T20R40

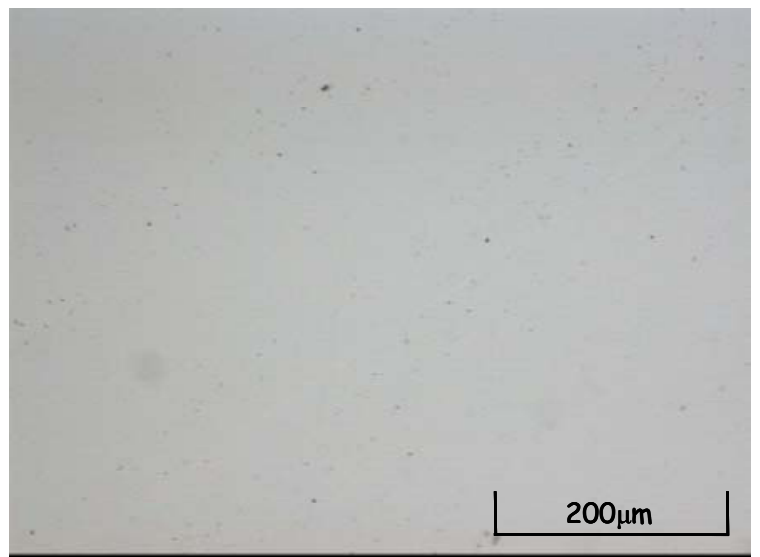

(c) T25C

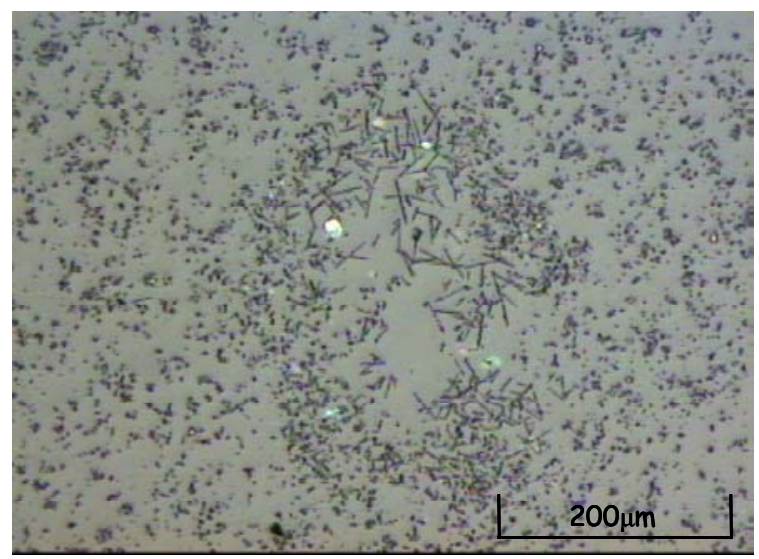

(f) $\mathrm{T} 15 \mathrm{R} 30$

FIGURA 5.7 - Micrografias de secções polidas de amostras das composições TC e TR: (a) T15C (b) T20C (c) T25C (d) T15R30 (e) T20R40 e (f) T25R50 


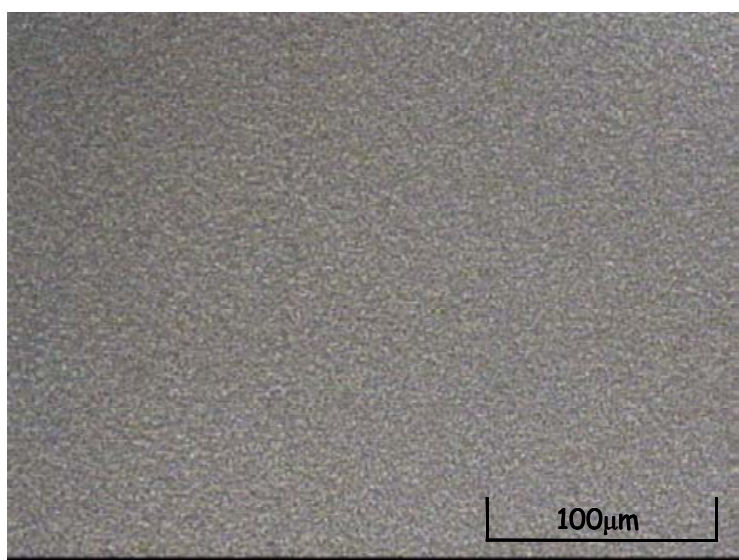

(a) T15R30

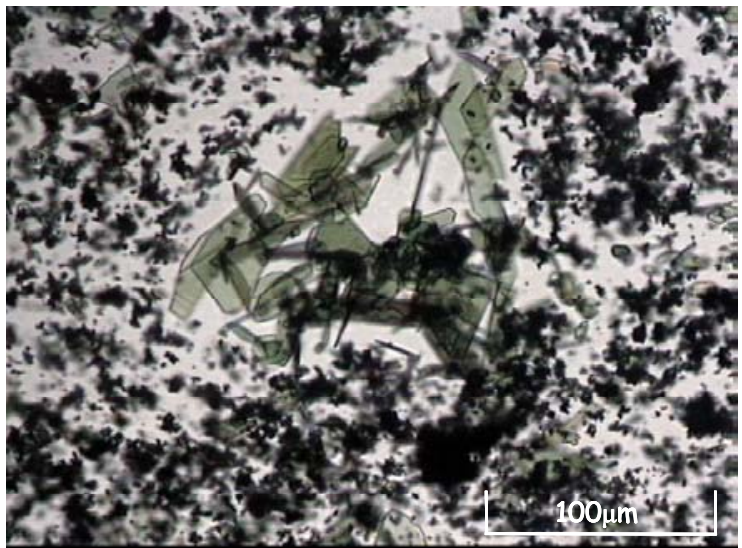

(c) T25R50

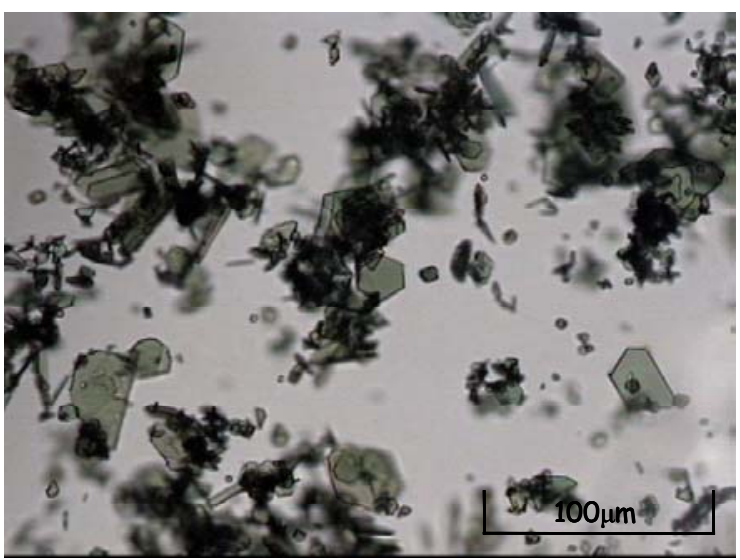

(b) T020R40

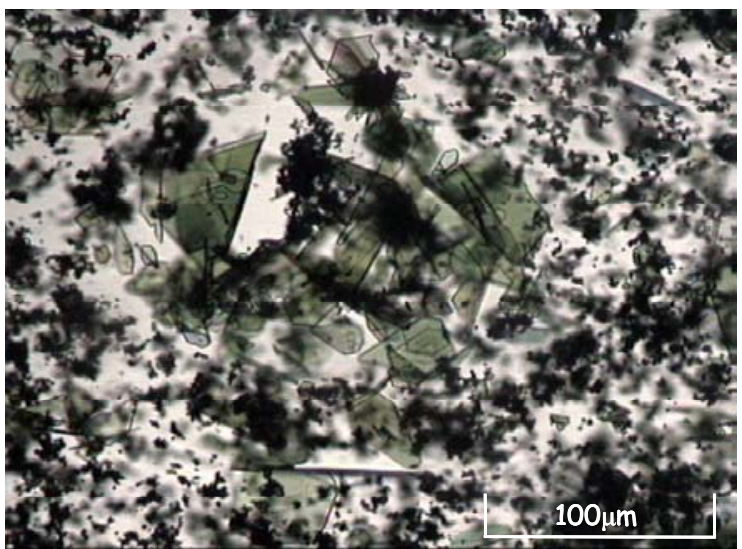

(d) T25R50

FIGURA 5.8 - Micrografias correspondentes aos vidros preparados em laminas delgadas: (a) T15R30, (b) T20R40 e (c,d) T25R50.

A micrografia correspondente ao vidro T20R40, mostra uma fase de coloração mais clara, relativa a presença de cristais de cromita, (região a na Fig. 5.9(a) e uma matriz composta por duas fases de composição similar, embora apresentem colorações distintas: cinza escuro a de menor freqüência e, cinza claro a predominante na matriz. A análise de EDS na região (a), revela uma composição química compatível com a cromita, ou seja, cromo e oxigênio, também observados nos espectros da figura 5.6(d). As análises por EDS das distintas regiões restantes, observadas na amostra (pontos $\boldsymbol{b}$ e $\boldsymbol{c}$ na figura 5.9) revelam que embora hajam pequenas diferenças na composição, a fase mais clara, apresentou um maior conteúdo relativo de metais de transição. 
Microanálise

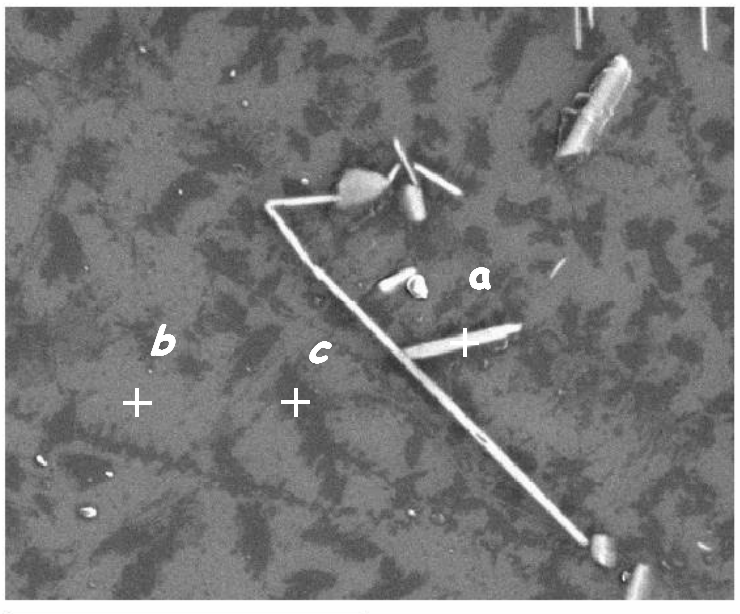

\begin{tabular}{|c|c|c|c|}
\hline $\begin{array}{l}\text { T20R40 } \\
\text { Elem. }\end{array}$ & & Massa\% & \\
\hline & (a) & (b) & (c) \\
\hline C & - & - & 7,95 \\
\hline 0 & 42,19 & 46,12 & 45,77 \\
\hline $\mathrm{Na}$ & - & 8,96 & 7,89 \\
\hline Mg & - & 0,69 & 0,59 \\
\hline Al & - & 4,69 & 4,13 \\
\hline Si & 4,67 & 26,67 & 21,74 \\
\hline $\mathbf{K}$ & - & 0,75 & 0,63 \\
\hline $\mathrm{Ca}$ & - & 5,06 & 4,32 \\
\hline $\mathrm{Cr}$ & 53,14 & 2,16 & 1,87 \\
\hline Fe & - & - & 0,31 \\
\hline $\mathbf{N i}$ & - & 2,95 & 2,57 \\
\hline $\mathrm{Cu}$ & - & 1,68 & 1,32 \\
\hline Zn & 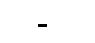 & 0,91 & 0,89 \\
\hline & 100 & & \\
\hline
\end{tabular}

(a) T20R40

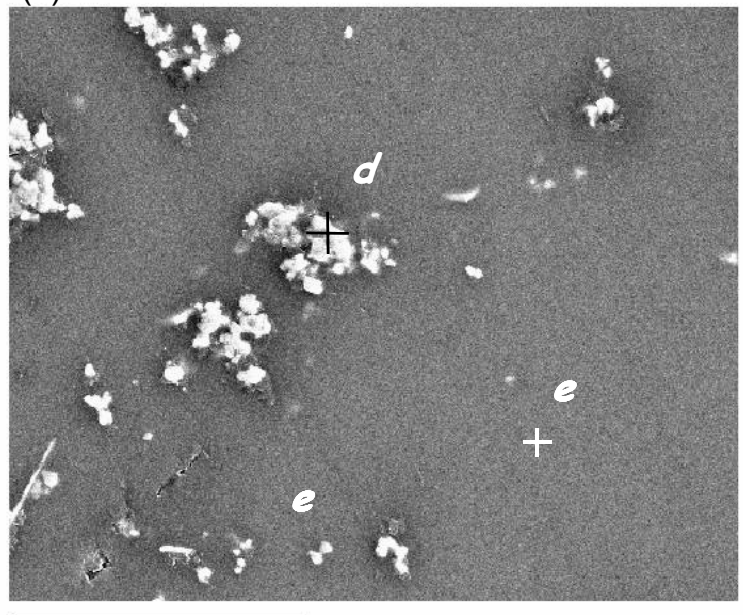

$200 \mu m$

(b) T25R50
T25R50

Elem. Massa\%

$\begin{array}{lcr}\mathbf{O} & \mathbf{( d )} & \mathbf{( e )} \\ \mathbf{N a} & 27,47 & 41,59 \\ \mathbf{M g} & - & 15,96 \\ \mathbf{A l} & - & 0,76 \\ \mathbf{S i} & - & 6,68 \\ \mathbf{K} & - & 24,88 \\ \mathbf{C a} & - & 0,79 \\ \mathbf{C r} & - & 4,82 \\ \mathbf{F e} & 0,65 & 1,07 \\ \mathbf{N i} & 13,59 & 0,40 \\ \mathbf{C u} & 1,30 & 0,13 \\ \text { Zn } & 7,42 & - \\ \text { Total } & \mathbf{1 0 0} & \mathbf{1 0 0}\end{array}$

FIGURA 5.9 - Secção transversal de amostras das composições TR: (a) T20R40, (b) T25R50 (MEV-EDS)

A micrografia correspondente ao vidro T25R50 (Fig. 5.9(b)), além de alguns cristais de cromita, revela uma outra fase cristalina (região $\boldsymbol{d}$ ), em uma matriz amorfa. A análise dos espectros EDS da região (d) (Fig 5.9) mostra que estes cristais contêm cromo, níquel, e oxigênio. A presença destes elementos nesta fase é compatível com a formação de $\mathrm{Ni}\left(\mathrm{Cr}_{2} \mathrm{O}_{4}\right)$, foi identificado anteriormente no espectro da Fig. 5.6. A composição média em massa da matriz vítrea (ponto e na Fig. 5.9(b)) relaciona-se à composição calculada para o vidro. 


\subsection{2 - Estudo da estrutura dos vidros}

A estrutura local dos vidros de composição T10C, T20C, T10R20, e T20R40, foi analisada por espectroscopia RNM-MAS. Os espectros ${ }^{29} \mathrm{Si}$ destes vidros são mostrados na Fig. 5.10.

Nos vidros T10C, T20C e T10R20, a componente principal no espectrograma foi detectada por em torno de $-86,5$ ppm (Fig. 5.10(a,b,c)), e corresponde ao arranjo tetraédrico do $\mathrm{Si}$ em cadeias (arranjos $\mathrm{Q}^{2}$ ). Nos espectros dos vidros T10R20 e T20R40, a intensidade e a espessura dos picos correspondentes aos diferentes componentes aumentam consideravelmente. Este comportamento pode ser resultado da incorporação na rede vítrea de metais fornecidos pelos resíduos galvânicos. No caso dos silicatos, à medida que se aumenta o grau de condensação tetraédrica, a linha no espectrograma se desloca para valores negativos ${ }^{(230)}$. Na amostra T20R40 (Fig. 5.10(d)), o pico principal desloca-se de $-86,5$ ppm para -90 ppm e uma nova componente a -110 ppm, foi também detectada, indicando a segregação da sílica em arranjos tridimensionais $\left(Q^{4}\right)$.

Os tetraedros de sílica no vidro T10R20 se organizam em cadeias $\left(Q^{2}\right)$, da mesma forma que no vidro T10C. Para estas duas composições a presença do $\mathrm{CaO}$ ou dos metais de transição pode desempenhar função similar na estrutura da rede vítrea. Contudo no vidro T20R40, ocorre a precipitação de parte dos metais. A formação desta fase cristalina ocorre principalmente envolvendo o cromo. Neste vidro, embora a sílica continue predominantemente organizada na forma $Q^{2}$, uma parte da rede vítrea se organiza na forma tridimensional, ou seja, sílica $Q^{4}$. Esta configuração é indicativa de uma pouca disponibilidade de cátions modificadores no vidro T20R40, em relação ao seu análogo T20C. Possivelmente no vidro T20R40, uma fração dos metais de transição está sendo consumida para formar fases cristalinas. Esta deficiência em "modificadores" não é conseqüência da falta de habilidade dos metais de transição em participar da rede vítrea (38,49,52,65,242), como se pode perceber pela comparação entre T10R20 e T10C, entretanto é o resultado da precipitação destes metais por influência de fatores tais como campo iônico dos cátions e/ou equilíbrios de oxidação/redução no líquido do vidro fundido. 

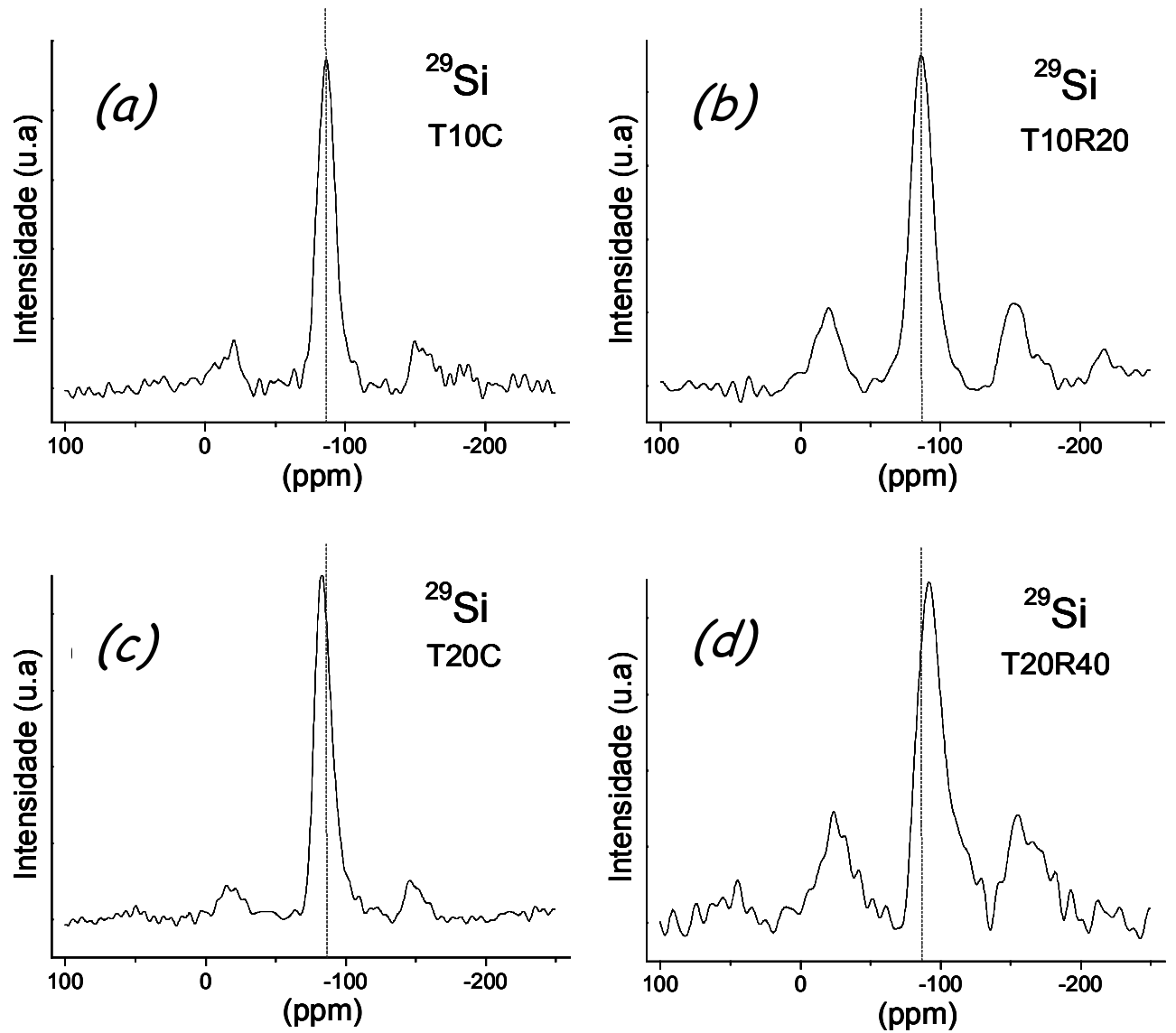

FIGURA 5.10 - Espectros ${ }^{29}$ Si RNM-MAS de amostras dos vidros: (a) T10C, (b) T10R20, (c) T20C e (d) T20R40.

Analisando a participação do boro, como formador ou modificador nestas estruturas utilizando-se esta mesma técnica, verifica-se na Fig. 5.11 que os espectros ${ }^{11} \mathrm{~B}$ MAS-RNM são formados basicamente por duas componentes, relativas aos átomos de $B$ em coordenação tetraédrica $(0,1 \mathrm{ppm})$ e trigonal (17ppm). O aumento da concentração dos cátions paramagnéticos (RSG) da composição T10R20 para a T20R40, causa um aumento na intensidade e espessura dos picos componentes. Interessante observar que apenas nos vidros da série TC os picos relativos ao boro trigonal são bem definidos e na série TR diminuem de intensidade com o aumento da concentração de metais de transição. Este fato é indicativo que a presença dos metais de transição (RSG) nos vidros da série TR, favorece a localização do boro em coordenação tetraédrica. 

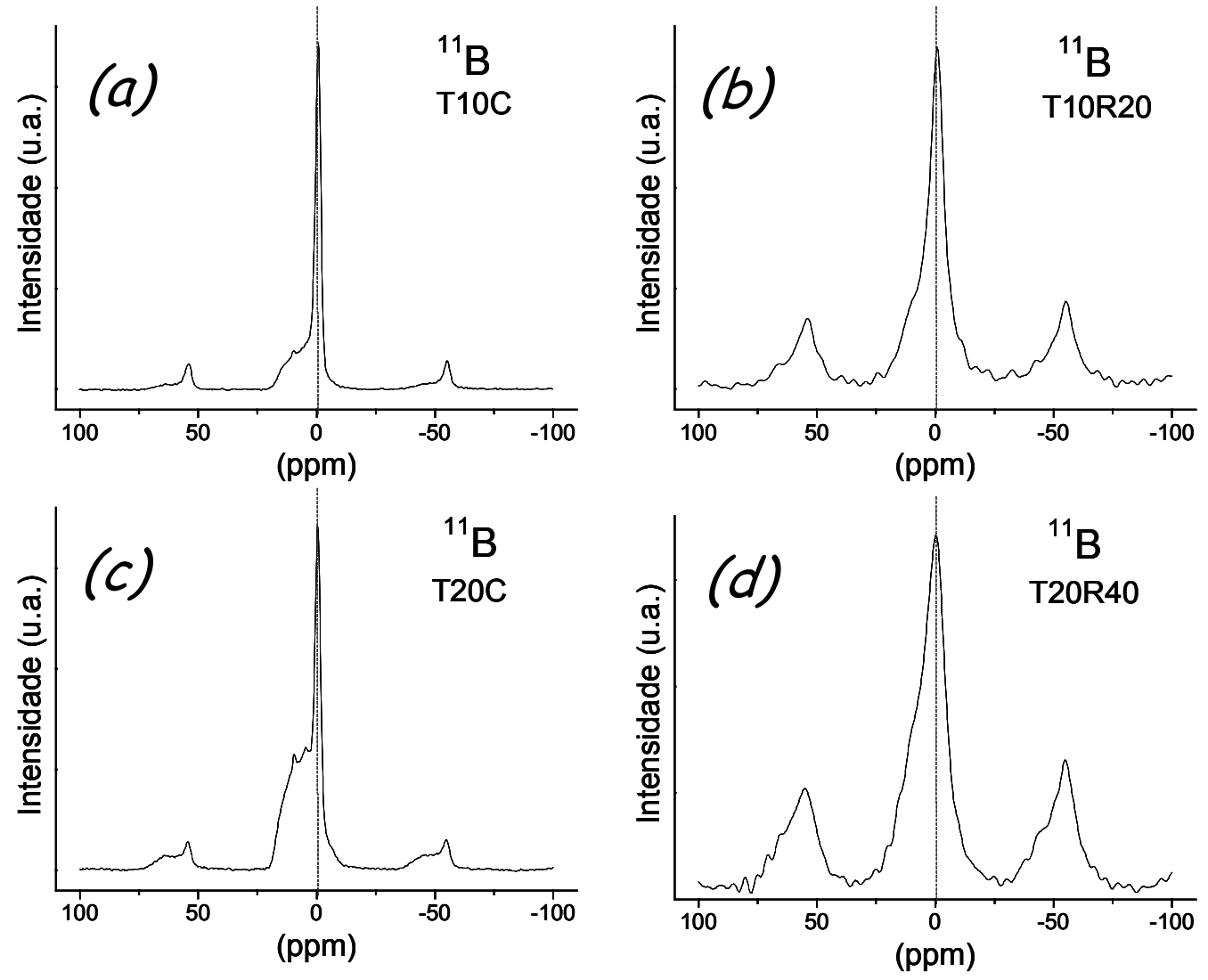

Figura 5.11 - Espectros ${ }^{11}$ B RNM-MAS de amostras dos vidros: (a) T10C,

(b) T10R20, (c) T20C, e (d) T20R40.

O comportamento dos metais de transição na estrutura amorfa foi estudado fixando-se no comportamento do cromo, pois, além da sua participação ativa durante as mudanças estruturais observadas nos vidros analisados, ele pode apresentar vários estados de oxidação, alterando deste modo o seu entorno estrutural e conseqüentemente a sua estabilidade na estrutura vítrea. Para a análise do estado de oxidação do cromo e sua participação na estrutura dos vidros, amostras relativas às composições T15R30, T20R40 e T25R50, foram estudadas utilizando-se espectroscopia fotoeletrônica de raios X (Fig.5.12). 


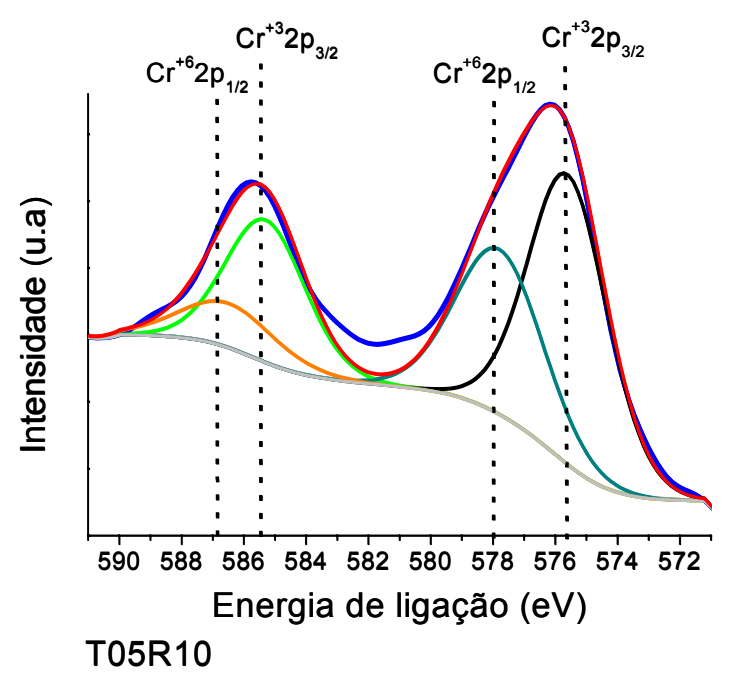

(a)

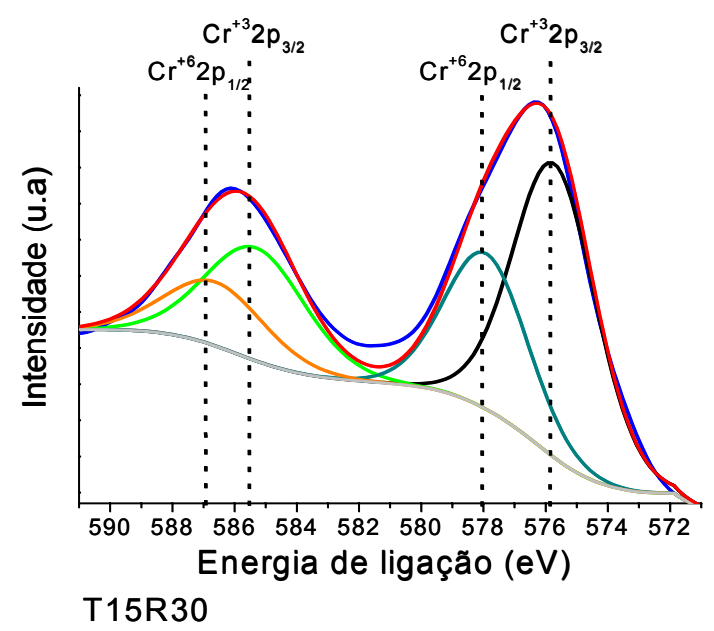

(c)

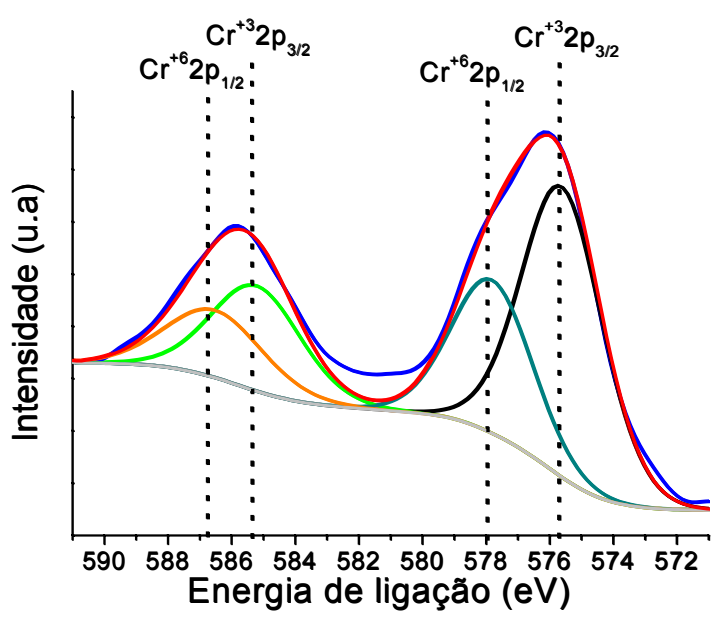

T10R20

(b)

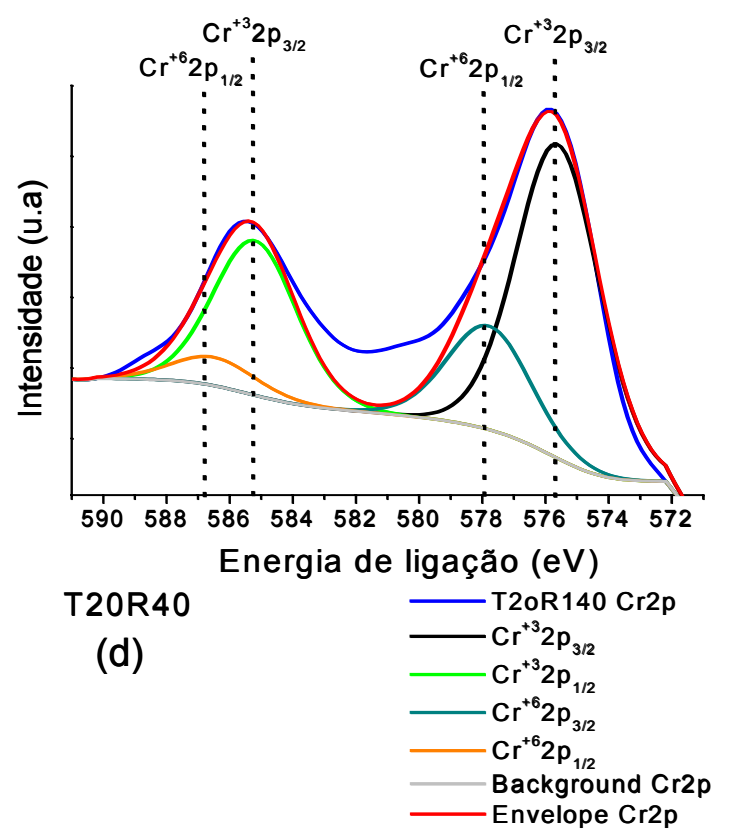

FIGURA 5.12 - Espectros $\mathrm{Cr} 2 p$ obtidos por espectroscopia fotoeletrônica de raios X (XPS) de amostras dos vidros T05R10, T10R20, T15R30 e T20R40.

Em todas as analises identificou-se o orbital $1 \mathrm{~s}(285,0 \mathrm{eV})$, relativo ao cromo. Estes resultados relatam que o cromo se encontra apenas em dois estados de oxidação e bem definidos, cromo trivalente $\left(\mathrm{Cr}^{3+}\right)$ e cromo hexavalente $\left(\mathrm{Cr}^{6+}\right)$. Estes orbitais foram classificados, de acordo com sua energia de vibração como $2 p_{1 / 2}(585,4 \mathrm{eV})$ e $2 \mathrm{p}_{3 / 2}(575,6 \mathrm{eV})$ para o $\mathrm{Cr}^{3+}$, e $2 \mathrm{p}_{1 / 2}(586,8 \mathrm{eV})$ e $2 p_{3 / 2}(578,0 \mathrm{eV})$ para o $\mathrm{Cr}^{6+}$. A participação dos distintos estados de oxidação (valências) variam de acordo com a composição do vidro. As freqüências das 
ligações, em \% atômica, de ambos estados de valência do cromo são apresentados Tab. 5.4, onde se observa que a concentração relativa de $\mathrm{Cr}^{6+}$ diminui com o aumento da concentração de resíduo participante na estruturação do vidro.

TABELA 5.4 - Energias de ligação e estados de oxidação do cromo nos vidros T05R10, T10R20, T15R30 e T20R40.

\begin{tabular}{|c|c|c|c|c|c|}
\hline & \multirow{2}{*}{ ENERGIA (eV) } & \multicolumn{4}{|c|}{ Frequência das ligações (\% átomos) } \\
\hline & & T05R10 & T10R20 & T15R30 & T20R40 \\
\hline $\mathrm{Cr}^{3+}$ & $2 p_{1 / 2}(585,4), 2 p_{3 / 2}(575,6)$ & 61,5 & 65,4 & 70,3 & 75,2 \\
\hline $\mathrm{Cr}^{6+}$ & $2 p_{1 / 2}(586,8), 2 p_{3 / 2}(578,0)$ & 38,5 & 34,6 & 29,7 & 24,8 \\
\hline
\end{tabular}

Sabe-se da literatura que o $\mathrm{Cr}^{+6}$ participa na estrutura do vidro devido à sua facilidade se solubilizar-se e atividade química. $\mathrm{O}^{+3}$, que também pode participar na estrutura, em ligações com as cadeias de Si-O, apresenta menor solubilidade ${ }^{(23,73-74)}$ e precipita na forma de óxido $\left(\mathrm{Cr}_{2} \mathrm{O}_{3}\right)$, com foi observado nas microestruturas da Fig. 5.9. $\mathrm{O}$ aumento de $\mathrm{Cr}^{+3}$ com a concentração de RSG adicionado, observado nos resultados das análises por XPS, pode ser atribuído à reação de redução $\mathrm{Cr}^{6+} \rightarrow \mathrm{Cr}^{3+}$, na presença de um agente redutor (ex. O enxofre, tab. 4.1).

Sumarizando-se os resultados das análises espectrométricas, RNMMAS e XPS, tem-se que os vidros estão formados por cadeias de tetraedros Si-O $\left(Q^{2}\right)$. O boro em coordenação trigonal participaria como elemento ponte entre os tetraedros Si-O $\left(Q^{2}\right)$, atuando nesta situação como modificador da rede. Ao utilizar-se o RSG, os cátions dos metais de transição podem estar participando da estrutura, de uma forma similar ao boro ou ao cálcio, ou seja, formando "pontes" entre os tetraedros de silício. Dependendo do tipo de ligação destes cátions com o oxigênio associado à rede vítrea, o arranjo estrutural pode assemelhar-se tanto ao observado para o cálcio (ligações iônicas), como para o boro (ligações covalentes). Uma possibilidade é que os cátions dos metais de transição ao formar ligações covalentes, ocupem as posições na rede vítrea normalmente ocupadas pelo boro trigonal na função de modificador do vidro, o qual passaria 
para a função de formador da rede vítrea, num arranjo que pode favorecer o equilíbrio de cargas.

Considerando a formulação proposta para os vidros TR (no ítem 4.2.2), os cátions dos metais de transição substituem os cátions $\mathrm{Ca}^{2+}$. Nestes vidros, o raio iônico dos cátions, podem impor um limite para a ocupação dos sítios intersticiais entre as cadeias $\mathrm{SiO}_{2}\left(Q^{2}\right)$ pelos cátions dos metais de transição, acima do qual, ocorre segregação, favorecendo a formação de fase cristalina.

Visando avaliar as posições do cromo como metal adicionado pelo RSG, na estrutura do vidro, forma realizadas as análises por UV-Vis nas amostras dos vidros da série TR. Os resultados são apresentados na Fig. 5.13. Nas amostras das composições T05R10 e T10R20, revelam a presença das bandas espectrais relativas ao cromo hexavalente $\left(\mathrm{Cr}^{6+}\right)\left(370 \mathrm{~cm}^{-1}\right)$ e cromo trivalente $\left(\mathrm{Cr}^{3+}\right)$ em duas coordenações, tetraédrica $\left(650 \mathrm{~cm}^{-1}\right)$ e octaédrica $(430 \mathrm{e}$ $\left.610 \mathrm{~cm}^{-1}\right)$. Em maiores concentrações de resíduo adicionado, amostras relativas aos vidros T15R30, T20R40 e T25R50, praticamente não apresentam as interações destas energias com os íons $\mathrm{Cr}^{3+}$ tanto na coordenação tetraédrica como na octaédrica. ${ }^{(243-244)}$.

Nos vidros, o cromo usualmente é encontrado em ambos estados de valência, $\mathrm{Cr}^{6+}$ e $\mathrm{Cr}^{3+}$, em coordenação octaédrica $\left(\mathrm{Cr}^{6+}\right.$ e $\left.\mathrm{Cr}^{3+}\right)$ ou tetraédrica $\left(\mathrm{Cr}^{3+}\right)^{(17,243-244)}$. Os vidros T05R10 e T10R20, com baixa concentração de RSG, apresentam o mesmo comportamento descrito na literatura. Nos vidros T15R30, T20R40 e T25R50 o aumento da concentração de cromo favorece a formação de cromita $\left(\mathrm{Cr}_{2} \mathrm{O}_{3}\right)$, conforme observado nos difratogramas de DRX (Fig. 5.6) e nas micrografias (Fig. 5.8-9). Por efeito da seção eficaz de espalhamento da luz (scattering), quanto mais disperso estiver a espécie em analisada, melhor será sua detecção pela técnica UV-Vis, ou seja, o $\mathrm{Cr}^{3+}$ é de difícil detecção se estiver concentrando-se em regiões propícias à cristalização e/ou organizado em cristais de cromita ${ }^{(220)}$. Este fato justifica a baixa detecção do cromo trivalente nas amostras de maior concentração. Desta forma, esta técnica indica que o cromo quando em menores concentrações (T05R10 e T10R20) se incorpora a estrutura amorfa do vidro, constituindo uma estrutura aleatória, enquanto que, em concentrações maiores (T15R30, T20R40 e T25R50), a redução do cromo $\mathrm{Cr}^{6+}$ para $\mathrm{Cr}^{3+}$, facilita a segregação e formação de fase cristalina. 


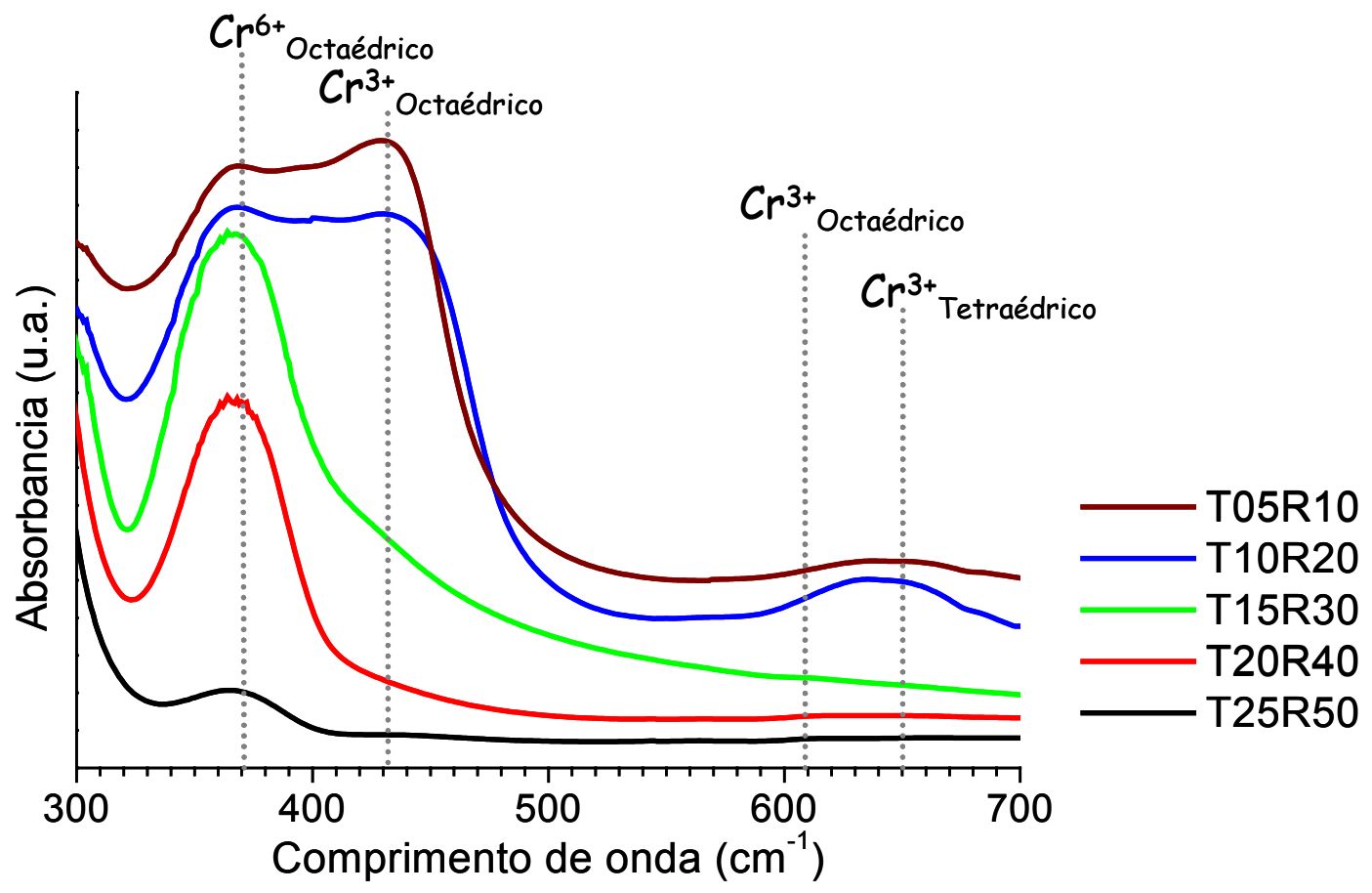

FIGURA 5.13 - Espectros de absorbância de UV-Vis para a as amostras das composições TR, com indicações dos picos relativos às espécies de cromo e seus estados de oxidação e coordenação.

Os grupos funcionais da estrutura dos vidros TC e TR, foram estudados utilizando-se a técnica de espectrometria no infravermelho (FT-IR). Os resultados obtidos nesta análise são mostrados na Fig. 5.14.

Em todas as composições TC (Fig. 5.14(a)) observa-se os três modos de freqüência característicos para o arranjo estrutural dos vidros soda-cal, ou seja; bandas em torno de $1010 \mathrm{~cm}^{-1}$ (superfície de tetraedros $\mathrm{SiO}_{4}$ ), $780 \mathrm{~cm}^{-1}$ (ligações entre tetraedros $\mathrm{SiO}_{4}$ ) e $460 \mathrm{~cm}^{-1}\left(\mathrm{Si}-\mathrm{O}-\mathrm{Si}\left[Q^{4}\right]\right.$ tetraédrico), ainda que, estes vidros contenham significativo teor de boro e alcalinos.

A incorporação do boro é indicada por bandas de pequena intensidade que ocorrem à $620-670 \mathrm{~cm}^{-1}$ (B-O-Si). Os modos de vibração associados às interações com boro segregado é indicado na banda à $1406 \mathrm{~cm}^{-1}$. A segregação de parte dos metais alcalinos terrosos é registrada pela banda, distribuída em torno à $500 \mathrm{~cm}^{-1}$, indicada pelo número 16 na Fig. 5.14 .

Nestes vidros, é possível observar modos de vibração associados às ligações formadas pelas espécies $\mathrm{SiO}_{2}$ desde $Q^{4}$ até $Q^{0}$. Entretanto, observa-se 
maior intensidade para as formas $Q^{2}\left(950 \mathrm{~cm}^{-1}\right)$ e $Q^{1}\left(900\right.$ e $\left.920 \mathrm{~cm}^{-1}\right)$, em arranjos com os metais alcalinos terrosos $(\mathrm{CaO})$, como indicado pelas bandas associadas a estes tipos de ligações, presentes nas regiões próximas a 800 e a $1000 \mathrm{~cm}^{-1}$, representadas pelo número 15 na Fig. 5.14. Os arranjos $Q^{2}$ (cadeias) e $\mathrm{Q}^{1}$ (dímeros) se associariam com o boro. Desta forma a rede vítrea nas série TC é interconectada pelo boro e metais alcalinos terrosos. À partir destes resultados e da informação fornecida pelas bandas indicadas por 1, 3 e 10 na Fig. 5.14 (805 $\mathrm{cm}^{-1}, 440-460 \mathrm{~cm}^{-1}$, e $970-980 \mathrm{~cm}^{-1}$, respectivamente), revela-se que a estrutura destes vidros é formada principalmente por ligações entre tetraedros associadas a formação de cadeias $\left(Q^{2}\right.$, como verificado também por RNM-MAS, Fig. 5.10). Os espaços entre cadeias consiste de regiões propícias para acomodar os metais alcalinos. Neste arranjo as cadeias entrelaçadas podem compartilhar tetraedros de $\mathrm{SiO}_{2}$. Os pontos de aglutinação formam pequenos núcleos volumétricos $Q^{4}$. A possibilidade de que o boro e os alcalinos terrosos reforcem a interconexão entre os arranjos estruturais é fortalecida nestes resultados.

Nos Vidros da série TR, os espectros de FTIR (Fig. 5.14(b)), demonstram os três modos de freqüência, característico para o arranjo estrutural vidro silicato soda-cal, onde de forma idêntica aos vidros da série TC. Contudo para os vidros TR, a banda à $620-670 \mathrm{~cm}^{-1}$ é comparativamente mais intensa e corresponde à banda que indica a incorporação do boro à rede vítrea (ligações BO-Si), que está sendo favorecida pela presença dos metais de transição contidos no RSG, como também observado nas análises por RNM-MAS (Fig. 5.11). Nesta caso, os tetraedros de boro estão compondo a rede com tetraedros de silício. De forma similar aos vidros TC, nos vidros TR a ocorrência de boro segregado é indicada por bandas à $1406 \mathrm{~cm}^{-1}$.

Nestes espectros a banda distribuída em torno à $500 \mathrm{~cm}^{-1}$ (16 na Fig. 5.14) indica a segregação de parte dos metais alcalinos e alcalinos terrosos em todos os vidros contendo RSG.

Como nos vidros anteriores, nos vidros TR, é possível observar modos de vibração associados às ligações formadas pelas espécies $\mathrm{SiO}_{2}$ desde $\mathrm{Q}^{4}$ até $\mathrm{Q}^{0}$, sendo mais intensos os picos associados aos modos de vibração das ligações entre tetraedros de $\mathrm{SiO}_{2} \mathrm{Q}^{2}\left(950 \mathrm{~cm}^{-1}\right)$ e $\mathrm{Q}^{1}\left(900\right.$ e $\left.920 \mathrm{~cm}^{-1}\right)$. Com o aumento da concentração de RSG, a ocorrência dos modos de vibração associados aos dímeros $Q^{1}$ é acentuada (T20R40). Estes resultados indicam uma estrutura 
composta por maior freqüência de dímeros de tetraedros de sílica nos vidros TR que nos vidros TC. O boro tetraédrico por um lado contribui para a formação destas seqüências menores ao substituir tetraedros de sílica nas cadeias. Por outro lado o boro trigonal também exerce devido a sua localização na rede, função de modificador similar aos metais alcalinos terrosos.

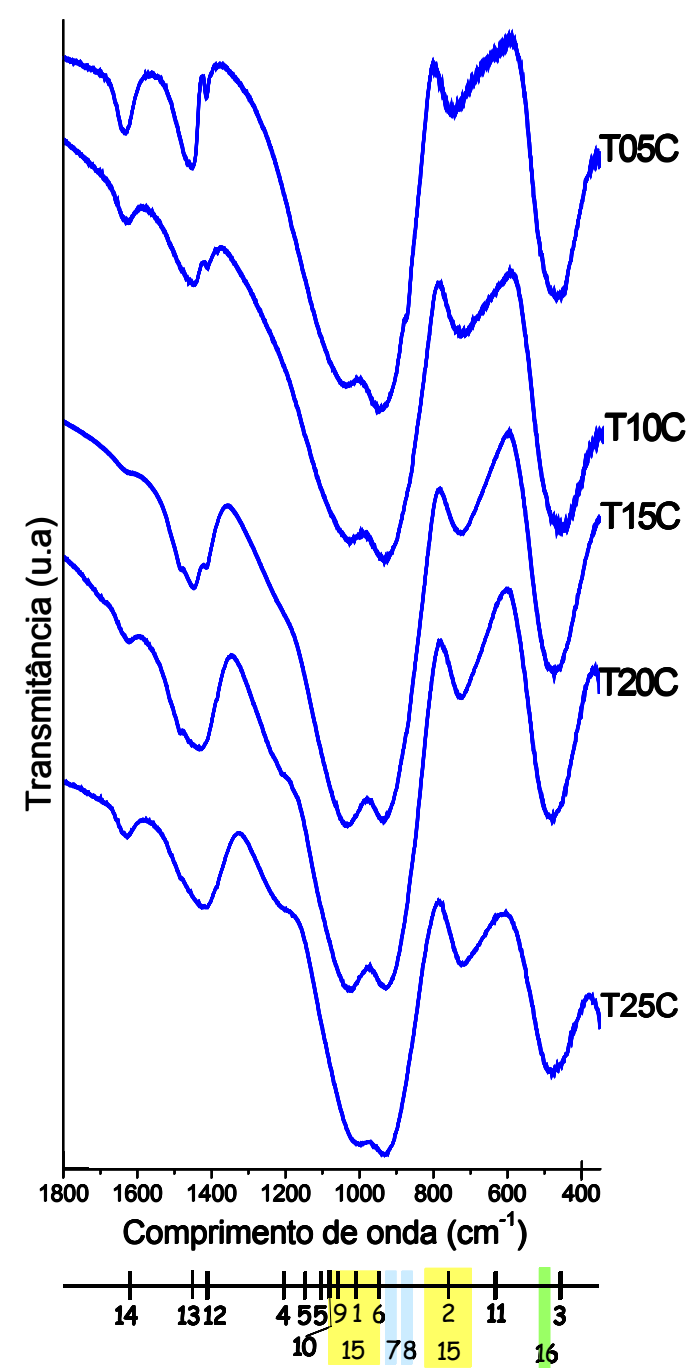

(a) Série TC

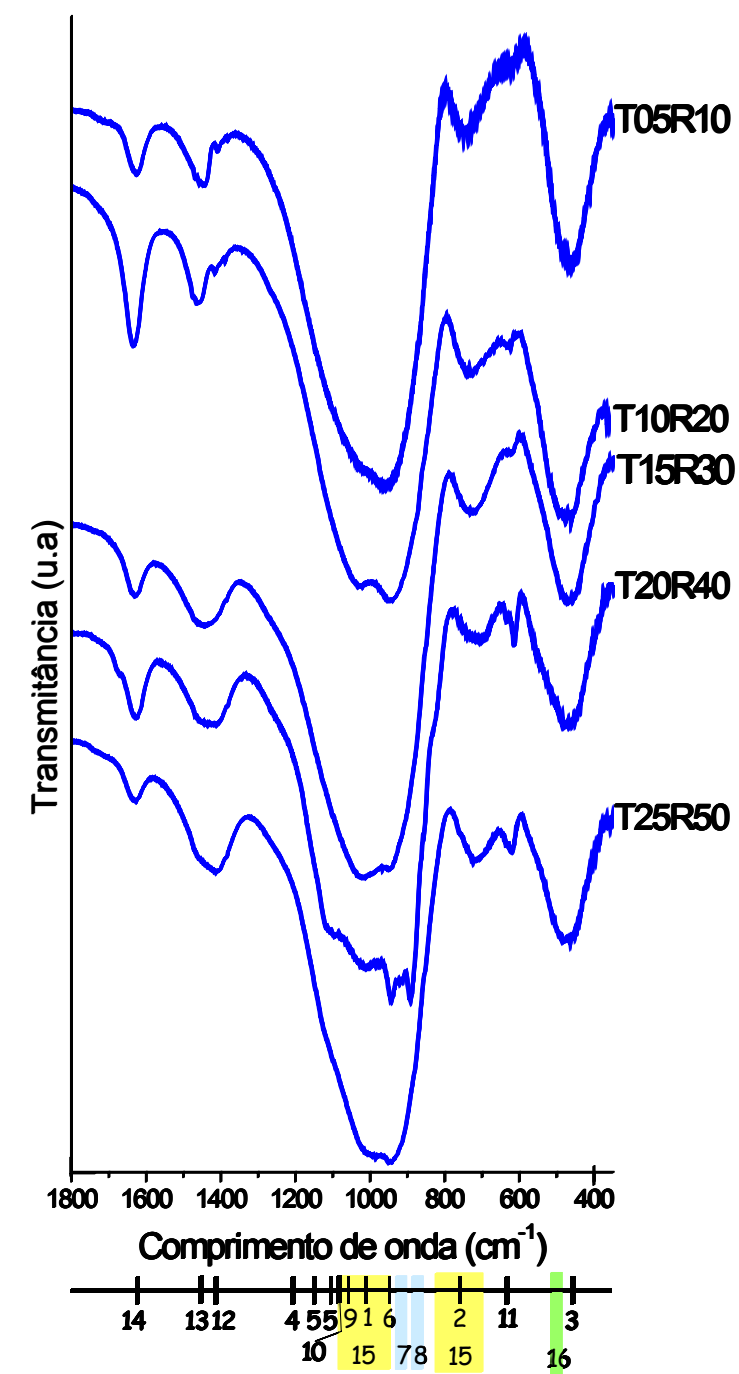

(b) Série TR

(1) Superfície de tetraedros $\mathrm{SiO}_{4}$; (2) Ligações entre tetraedros $\mathrm{SiO}_{4}$; (3) $\mathrm{Si}-\mathrm{O}-\mathrm{Si}\left[\mathrm{Q}^{4}\right]$;

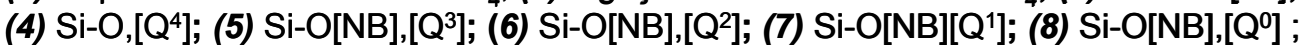

(9) Si-O-Si; (10) Si-O-[NB], plano ; (11) Si-O-B Estrutural; (12) B-O Livre; (13) Na-O; (14) Água livre; (15) Silicatos de metais; (16) Óxidos metálicos segregados.

FIGURA 5.14 - Espectros de FT-IR de amostras das composições: (a) série TC, (b) série TR 
Modos de vibração associados a ligações entre a sílica e metais de transição são indicados pelas bandas distribuídas nas regiões próximas a 800 e a $1000 \mathrm{~cm}^{-1}$, representadas pelo número 15 da Fig. 5.14(b). Desta forma, a rede vítrea para os vidros TR, compõe-se por pequenos segmentos de tetraedros de sílica, interconectados pelo boro e pelos metais de transição. A acentuada ocorrência da sílica $Q^{1}$ no vidro T20R40, corresponde com a concentração de RSG (40\% em massa) a partir da qual ocorre intensa formação de fases secundárias, como visto nas análises de DRX (Fig. 5.7 e 5.9). Como a rede vítrea pode incorporar uma alta concentração de metais de transição antes de se saturar, a precipitação do excesso destes metais significa que estes ocuparam todos os locais energeticamente favoráveis na rede vítrea. A ocorrência do cromo na forma hexavalente na estrutura vítrea, como observado nos ensaios por UVVis (Fig. 5.13) esta de acordo com este fato. A formação das fases secundárias é muito mais intensa no vidro T25R50 que no vidro T20R40, como observado por microscopia óptica (Fig. 5.8). A formação destas fases "consomem" parte significativa dos metais de transição e desta forma reduz a saturação da matriz vítrea, como se pode observar pela redução da intensidade relativa do pico $Q^{1}$ no vidro T25R50 (indicado pelo número 7 na Fig. 5.14).

A partir destes resultados e da informação fornecida pelas bandas a $805 \mathrm{~cm}^{-1}, 440-460 \mathrm{~cm}^{-1}$, e $970-980 \mathrm{~cm}^{-1}$ (indicadas por 1, 3 e 10 respectivamente nos espectros da Fig. 5.14, revela-se que a estrutura destes vidros, de forma similar aos vidros TC, é formada principalmente por ligações entre tetraedros associadas a às cadeias de sílica tetraédrica $\left(Q^{2}\right.$, como verificado por RNM-MAS, Fig. 5.10), A sílica $Q^{4}$ exibe bandas mais intensas com o aumento da concentração de metais de transição, o mesmo comportamento e também observado para T20R40 no ensaio por RNM (Fig. 5.10). Este fato, pode ser um indicador do aumento na complexidade do vidro com o aumento da concentração de modificadores. Uma possibilidade consiste no fato de que o boro e os metais de transição reforçam a interconexão entre os arranjos estruturais.

\subsection{3 - Macro-segregação}

Como citado anteriormente no item 5.2.1 foi observada na amostra T25R50 a ocorrência de inclusões, macro-segregadas de aparência metálica e forma esferóide (Fig.5.4). O difratograma deste precipitado é apresentado na Fig. 
5.15. O espectro DRX indica que este material é composto predominantemente por dois compostos: $\mathrm{Cu}_{2} \mathrm{~S}$ (PDF 83-1462) e $\mathrm{Ni}_{3} \mathrm{~S}_{2}$ (PDF 76-1870). Este tipo de estrutura não foi observado diretamente nos demais vidros, entretanto, a presença de $\mathrm{Cu}_{2} \mathrm{~S}$ foi identificada em amostras do vidro T20R40, no difratograma apresentado na Fig. 5.6(a). Os picos relativos ao Alumínio metálico (PDF 851327), são conseqüência da interferência do porta-amostra.

As análises por MEV-EDS sobre os pontos destacados na micrografia da Figura 5.16 referentes às duas fases de crescimento dendrítico, (a) e (b) mostram na tabela ao lado, na mesma figura, que a relação entre o $\mathrm{Cu}$ e o $\mathrm{S}$ é correspondente a estequiometria do $\mathrm{Cu}_{2} \mathrm{~S}$. A análise na região (b) também apresenta a relação Ni:S, relativa a estequiometria do composto $\mathrm{Ni}_{3} \mathrm{~S}_{2}$. Ambos compostos foram identificados no difratograma apresentado na Fig. 5.15. A proporção estimada, entre $\mathrm{Cu}_{2} \mathrm{~S}: \mathrm{Ni}_{3} \mathrm{~S}_{2}$ encontrados nos vidros de composição T25R50, foi de 63,0:37,0 $\%$ em massa.

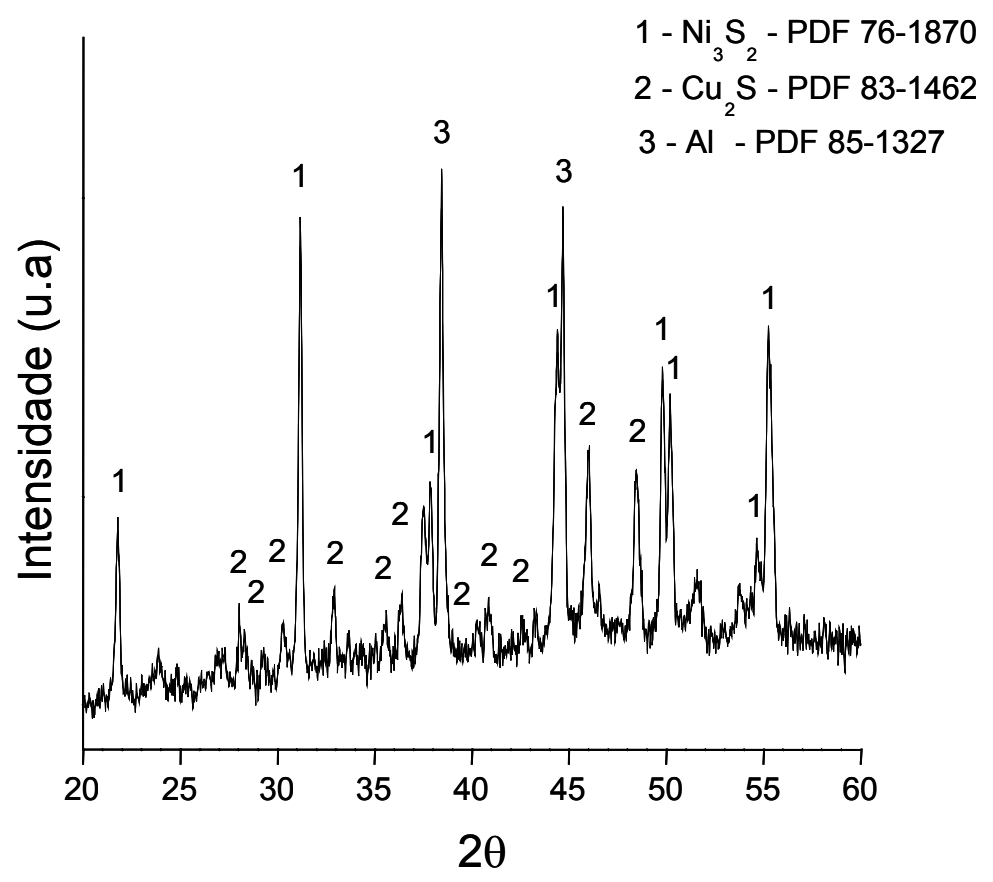

FIGURA 5.15 - Espectro correspondente ao ensaio de difração por raios $\mathrm{X}$ da Macro-segregação observada no vidro T25R50.

Os diagramas de equilíbrio para os sistemas Cu:Ni:S ${ }^{(239)}$ e $\mathrm{Cu}_{2} \mathrm{~S}: \mathrm{Ni}_{3} \mathrm{~S}_{2}{ }^{(240)}$, mostram o início da formação de $\mathrm{Cu}_{2} \mathrm{~S}$ a $900^{\circ} \mathrm{C}$ para a 
composição do líquido correspondente. O tipo de estrutura formada está de acordo com o diagrama $\mathrm{Cu}_{2} \mathrm{~S}: \mathrm{Ni}_{3} \mathrm{~S}_{2}{ }^{(240)}$, o que indica que a solidificação destes líquidos pode ter ocorrido em condições de equilíbrio, ou seja, como líquidos segregados e sem a interferência dos demais componentes presentes no vidro T25R50 fundido.

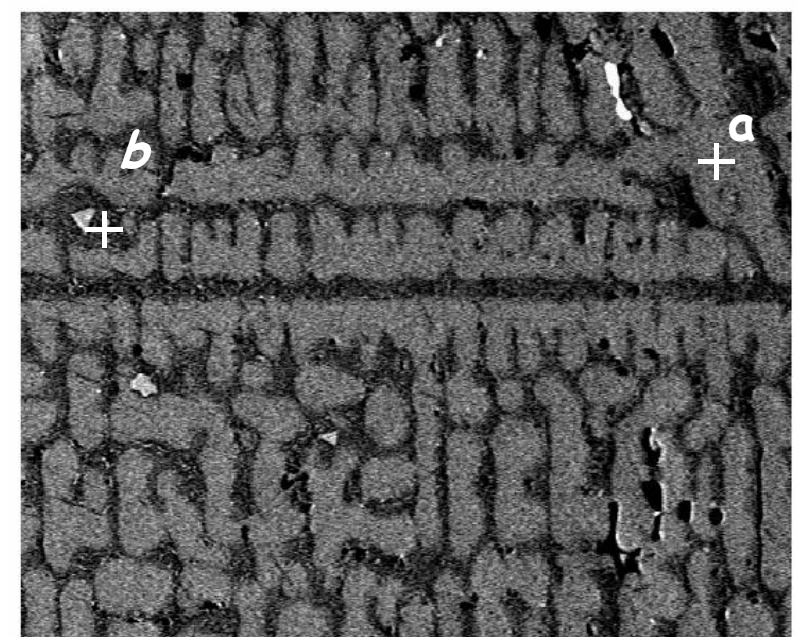

$100 \mu m$

Microanálise

T25R50 - Macro-segregação

Elem. Massa \%

(a)

$\begin{array}{ccc}\mathbf{S} & 22,75 & 27,74 \\ \mathbf{N i} & 0,92 & 67,35 \\ \mathbf{C u} & 76,33 & 5,18 \\ \text { Total } & 100 & 100\end{array}$

T25R50

FIGURA 5.16- Secção transversal da Macro-segregação observada o vidro

T25R50. A composição por elemento em massa \% dos pontos indicados é tabelada a direita da micrografia (MEV-EDS)

Estes resultados indicam que o enxofre proveniente da decomposição do $\mathrm{SO}_{3}$ e/ou de outros sulfatos presentes no resíduo sólido galvânico, não é totalmente eliminado na forma de gases durante a fusão dos vidros, sendo uma parcela retida na massa fundida, reagindo com os metais presentes no líquido. Por outro lado, dependendo da concentração, o enxofre livre pode alterar o equilíbrio de oxidação-redução no presente vidro fundido. Entretanto a atuação do enxofre neste sistema é influenciada também pelos metais alcalinos ${ }^{(23,24)}$, ou seja, a relação de concentração entre o enxofre e os álcalis poderá influenciar na oxidação ou redução dos metais presentes no resíduo galvânico. Com o aumento de concentração de lodo galvânico, temos conseqüentemente, um aumento de concentração 
deste elemento. Em maiores concentrações, o enxofre além de reagir e formar compostos com cobre e níquel, também espera-se que proporcione a redução e precipitação por exemplo do cromo na forma de cromita devido ao ambiente redutor gerado. A redução do cromo da forma hexavalente para trivalente é tecnologicamente importante para se obter uma boa estabilidade ambiental e baixa toxidade dos vidros obtidos.

\subsection{4 - Viscosidade dos vidros}

A viscosidade dos vidros de composição T15C, T20C, T25C, T15R30, T20R40 e T25R50, foi calculada a partir das análises "in situ" em microscópio óptico de calefação (estágio à quente) cujas as micrografias são apresentadas na Fig. 5.17.

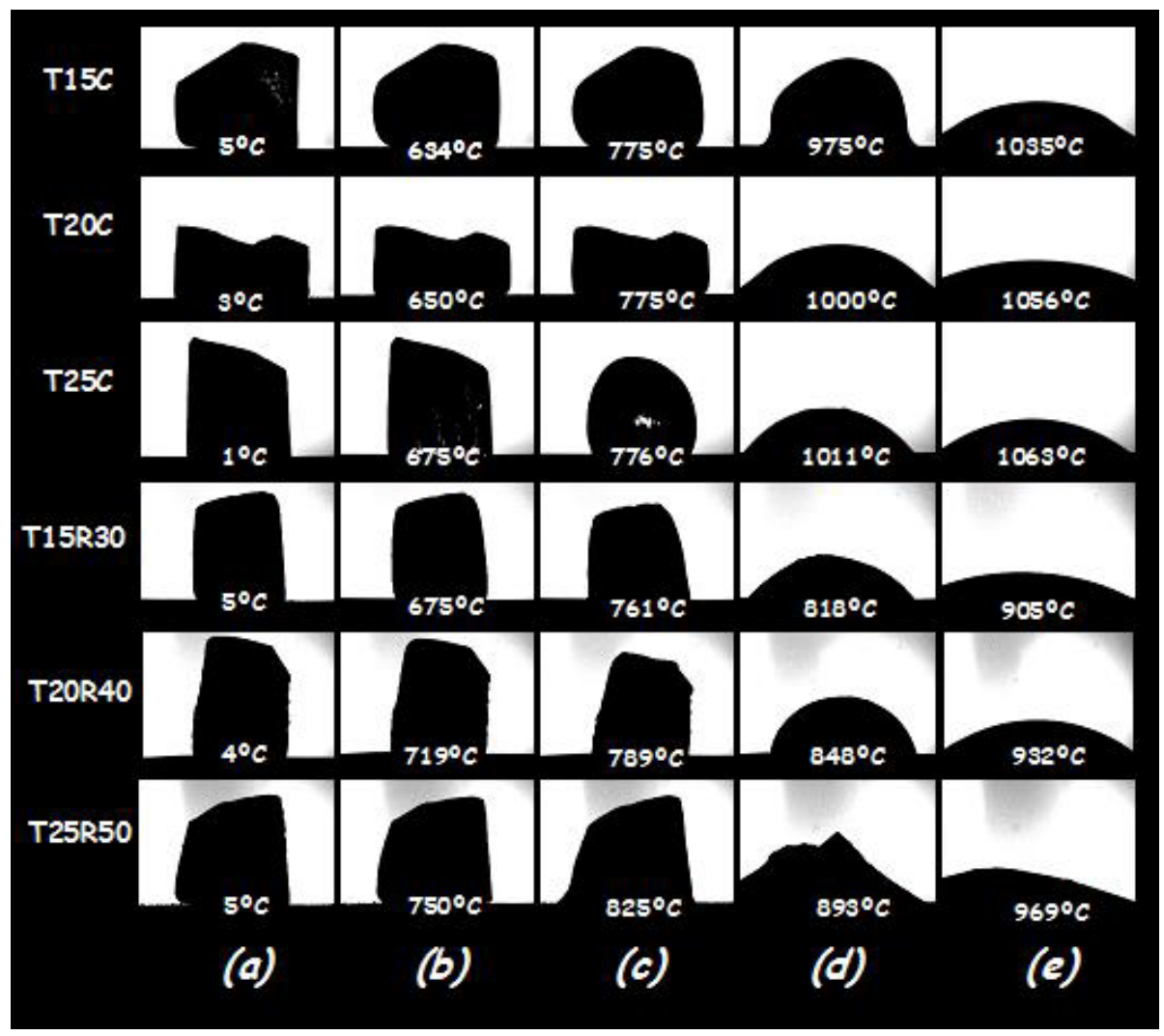

FIGURA 5.17 - Micrografias obtidas no ensaio de microscopia de calefação de amostras das composições T15C, T20C, T25C, T15R30, T20R40 e T25R50, onde: a) início do ensaio; b) ponto de retração (10 $10 \mathrm{dPas})$; c) ponto de amolecimento $\left(10^{6.0}-10^{7.6} \mathrm{dPas}\right)$; d) ponto de meia-bola $\left(10^{4.2}-10^{4.7} \mathrm{dPas}\right)$, e) ponto de fluidez $\left(10^{3.0}-10^{3.5} \mathrm{dPas}\right)^{(235,345-246)}$ 
A análise da dependência da viscosidade com a temperatura é apresentada na Fig. 5.18. Como se pode observar, os vidros T15C, T20C e T25C, possuem comportamento similar, independente da concentração do modificador (cálcio). Por sua vez, nos vidros da série TR, a presença dos metais de transição altera este comportamento para todo o intervalo de temperatura, em função da concentração de metal (RSG), presente nas composições. A formação de fases cristalinas ou de diferentes fases amorfas vai influenciar no comportamento de fluxo dos vidros com o aumento da temperatura, entre os vidros TC e aos vidros TR.

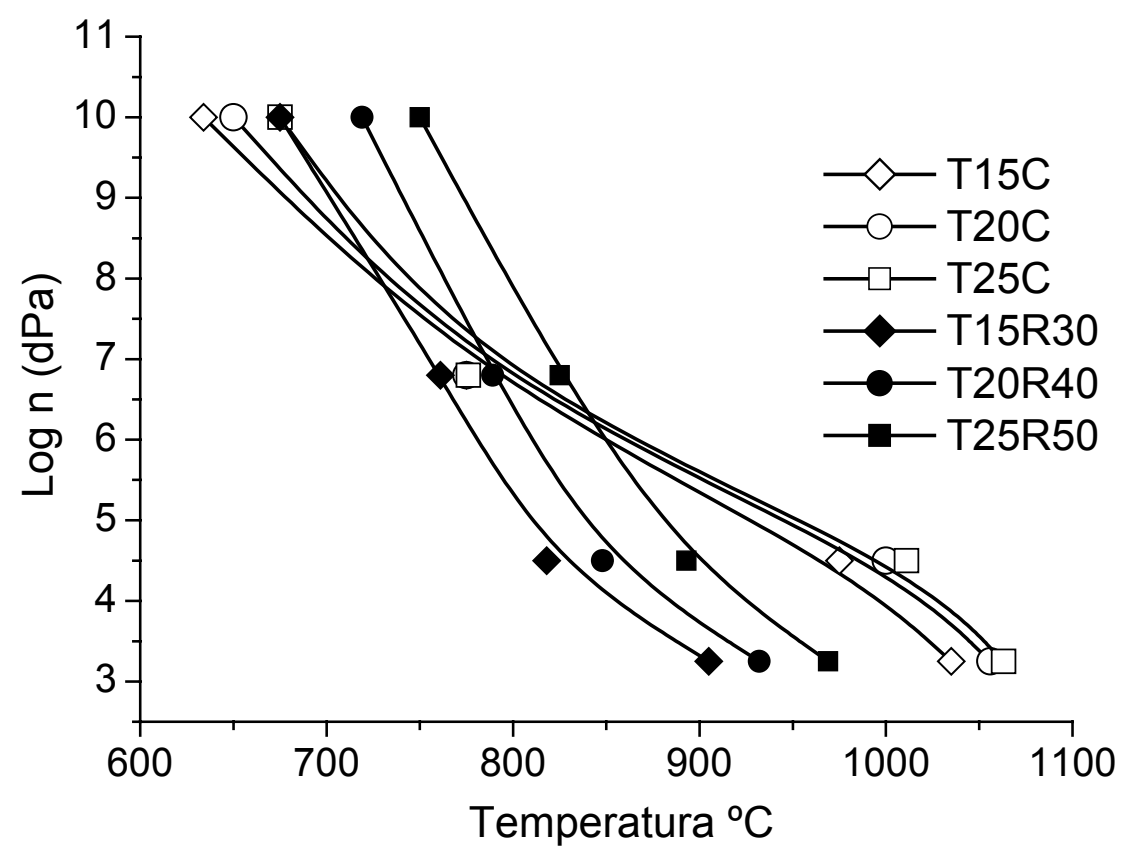

FIGURA 5.18 - Dependência da viscosidade com a temperatura de amostras das composições T15C, T20C, T25C, T15R30, T20R40 e T25R50.

\subsection{5 - Resistência química dos vidros}

\subsubsection{1 - Resistência hidrolítica}

A resistência ao ataque hidrolítico dos vidros T15R30, T20R40 e T25R50, conforme a norma ASTM C 1285-02 (PCT-B) ${ }^{(236)}$ é mostrada na Tab. 5.5. Observa-se nesta tabela que a taxa de dissolução normalizada por elemento 
(r) para os vidros T15R30, T20R40 e T25R50, são inferiores que as especificações correspondentes ao mesmo ensaio equivalente (PCT-A) encontrado em um vidro planejado para o armazenamento e deposição de resíduos nucleares citado na literatura $\left(0,08 \mathrm{~g} / \mathrm{m}^{2}\right.$ para o $\left.\mathrm{Cr}\right){ }^{(12)}$. Mesmo considerando a troca do $\mathrm{Si}$ e do $\mathrm{Na}$, os resultados para os vidros TR, continuam inferiores aos valores máximos permitidos em especificações do Departamento de Energia dos Estados Unidos (U.S.DOE) para vidros para inertização de resíduos nucleares referenciada no mesmo trabalho (i.e. $2,0 \mathrm{~g} / \mathrm{m}^{2}$ para a Si e para o $\mathrm{Na})$.

TABELA 5.5 - Taxa de dissolução normalizada por elemento ( $\mathbf{r}$ em $\mathrm{g} / \mathrm{m}^{2}$ ) para os vidros T15R30, T20R40 e T25R50 submetidos ao teste PCT-B por 7 dias.

\begin{tabular}{c|lllllc}
\hline Vidro & $\mathbf{r}_{\mathrm{Si}}$ & $\mathbf{r}_{\mathrm{Na}}$ & $\mathbf{r}_{\mathrm{Cr}}$ & $\mathbf{r}_{\mathrm{Cu}}$ & $\mathbf{r}_{\mathbf{N i}}$ & $\mathbf{r}_{\mathbf{Z n}}$ \\
\hline T15R30 & 0,1023 & 0,1550 & 0,0515 & 0,0006 & 0,0022 & 0,0122 \\
T20R40 & 0,0746 & 0,1396 & 0,0743 & 0,0003 & 0,0016 & 0,0060 \\
T25R50 & 0,0506 & 0,0922 & 0,0231 & 0,0002 & 0,0005 & 0,0072 \\
IP30-LAW-C* $^{*}$ & -- & 0,6700 & 0,0800 & -- & -- & -- \\
U.S.DOE** & 2,0000 & 2,0000 & -- & -- & -- & -- \\
\hline
\end{tabular}

* Vidro estudado para inertização de resíduos nucleares ${ }^{(12)}$.

** Especificação do U.S.DOE para vidros destinados inertização de resíduos nucleares ${ }^{(12)}$.

Complementando estes resultados, a resistência ao ataque dos vidros TC e TR, também foi avaliada pela técnica do ataque hidrolítico, com o uso de uma coluna de Soxlhet. As Fig. 5.19 e 5.20 apresentam respectivamente os resultados destes ensaios para os vidros das séries TC e TR, acompanhado dos resultados do vidro de referencia ((VR).

Na Fig. 5.19, correspondente aos vidros TC, se observa um aumento da estabilidade química após as primeiras horas de ensaio. Este resultado esta de acordo com a literatura ${ }^{(23,24)}$ para vidros de composição similar aos ensaiados. A única exceção é dada pelo vidro T05C, que se desagrega entre 72 e 148 horas de ensaio. Este fato também esta de acordo com a literatura ${ }^{(23,24)}$, considerandose o conteúdo de álcalis fundente $\left(\mathrm{Na}_{2} \mathrm{O}\right)$ em relação ao conteúdo de modificador ( $\mathrm{CaO})$ neste vidro específico (30,5 e 4,9\% em massa, respectivamente). Observa- 
se ainda nesta figura que as taxas de dissolução dos vidros T20C e T25C, são significantemente inferiores que as dos vidros T05C, T10C e T15C. É interessante observar que ocorre um intervalo significativo entre estes dois grupos.

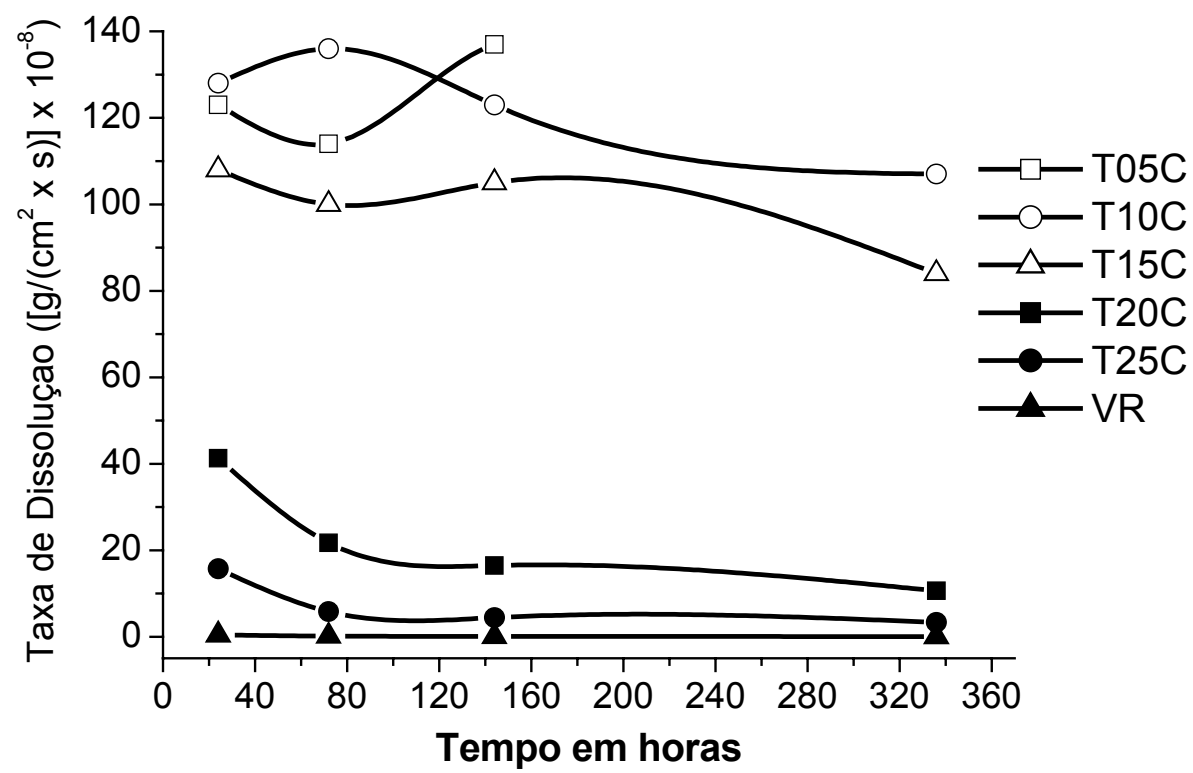

FIGURA 5.19 - Resistência hidrolítica: Taxa de dissolução em função do tempo para amostras das composições TC e VR.

Comparando-se a resistência hidrolítica entre os vidros apresentados na Fig. 5.19, percebe-se que todas amostras da série TC são menos resistentes ao ataque hidrolítico que VR, vidro de referência.

Na Fig. 5.20, são apresentadas as curvas de dissolução com o tempo durante o ataque hidrolítico dos vidros da série TR. Para estes vidros, a resistência hidrolítica aumenta com o aumento da concentração de metais de transição, sugerindo um comportamento similar ao observado nos vidros contendo apenas cálcio (modificador), porém mais efetivo, uma vez que as taxas de dissolução são menores. A única composição que apresentou uma taxa crescente de dissolução com o tempo foi o vidro T05R10. Como observado anteriormente na Fig. 5.19, para os vidros da série TC, ocorre "um intervalo" entre as taxas de dissolução dos vidros T05R10 e T10R20 e dos vidros T15R30, T20R40 e T25R50. Entretanto, nestes vidros (TR), este "intervalo", ocorre entre a concentração calculada de modificadores de $10 \%$ e $15 \%$ em massa, enquanto 
nos vidros TC, esta é observada entre $15 \%$ e $20 \%$ em massa. Este comportamento somado à maior resistência hidrolítica observada para os vidros TR, sugerem que os metais de transição são mais efetivos como modificadores do que o $\mathrm{CaO}$.

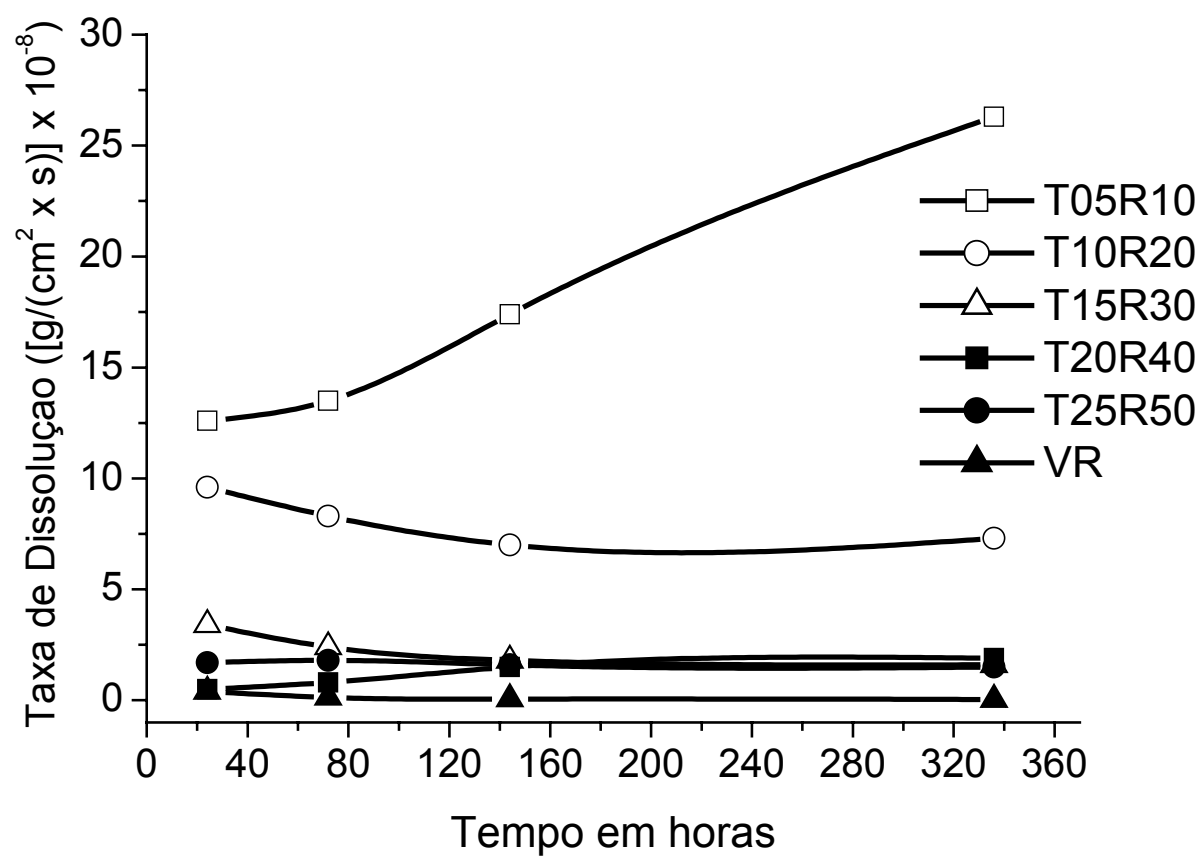

FIGURA 5.20 - Resistência hidrolítica: Taxa de dissolução em função do tempo para amostras das composições TR e VR.

Os vidros da série TR (T15R30, T20R40 e T25R50) apresentaram resistência ao ataque equivalente ao do vidro de referência, mesmo contendo a concentração de álcalis $\left(\mathrm{Na}_{2} \mathrm{O}\right)$ idêntica à de sua composição equivalente na série TC. Neste caso, considerando-se o efeito de "batelada", em um processo de produção industrial, torna possível utilizar menores adições de álcalis, resultando em vidros com resistência hidrolítica superior a do vidro VR.

De acordo com a literatura ${ }^{(23)}$, a estabilidade química em um vidro soda-cal aumenta com o conteúdo do modificador $\left(\mathrm{Ca}^{2+}\right)$. Nos vidros analisados o decréscimo monotônico nas curvas de dissolução em função do tempo, observado nas Fig. 5.19 e 5.20. indicam que este processo do ataque hidrolítico obedeceu as seguintes etapas: a) inicialmente ocorre à extração dos cátions alcalinos ( $\mathrm{Na}, \mathrm{K})$ das camadas mais próximas a superfície do vidro; b) formação 
de uma capa rica em sílica formando uma barreira à difusão e ao ataque protônico $\left(\mathrm{H}_{3} \mathrm{O}^{+}\right)$. Entretanto, estas camadas ricas em sílica, não são resistentes sob o ponto de vista mecânico, podendo facilmente desprender-se ("spalling") expondo novamente uma nova superfície de vidro ao ataque protônico. Por este motivo, a camada superficial atacada, não pode ser considerada uma proteção permanente para os vidros. O comportamento de dissolução dos vidros com alta concentração de lodo galvânico (T15R30, T20R40 e T25R50), ilustrado na Fig.5.20, não demonstram a formação da camada superficial rica em sílica, pois não exibem o decrescimento monotônico. Estas curvas são similares à curva do vidro VR, porém para este último, tal efeito deve ser atribuído ao seu baixo conteúdo em álcalis.

Para explicar o comportamento dos vidros T15R30, T20R40 e T25R50, considerou-se os estudos ${ }^{(40,247-250)}$ dos vidros com alto conteúdo de ferro discutidos no item 3.2.3. Neste caso nos vidros T15R30, T20R40 e T25R50, a alta resistência hidrolítica observada pode ser explicada considerando-se a covalência nas ligações Si-O- $\left(\mathrm{Cr}^{3+}, \mathrm{Ni}^{2+}, \mathrm{Cu}^{2+}\right)$ vs. Si-O:Na ou Si-O:Ca (iônicas), que resulta em uma estrutura mais fechada e coesa devido as adições de lodo galvânico ${ }^{(17)}$. O maior patamar de resistência hidrolítica observado é obtido para a concentração correspondente ao vidro T15R30. Para maiores conteúdos de metais de transição, nem mesmo a formação de precipitados (Fig. 5.8) parece interferir na resistência hidrolítica.

A Fig. 5.21, apresenta os valores das taxas de dissolução de ataque hidrolítico em função da concentração de modificadores, para os vidros das séries TC e TR, e para o vidro VR após 336h de ensaio, onde se observa a variação da taxa de dissolução em função da concentração de modificadores. Nesta figura observa-se com maior clareza que as adições de RSG em todo o intervalo de concentração estudado, aumentou significativamente a resistência do vidro ao ataque hidrolítico, quando comparado com sua composição similar com adições apenas de cálcio (TC). 


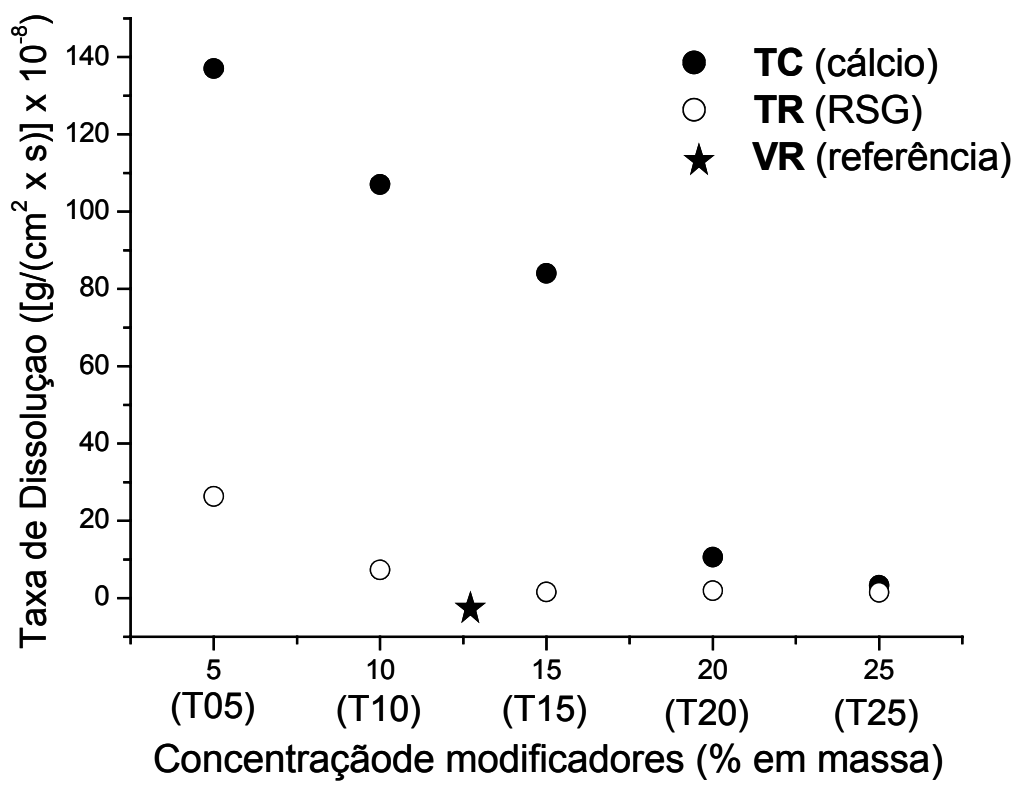

FIGURA 5.21 - Taxa de dissolução após ataque hidrolítico em função da concentração de modificadores para amostras das composições TC,TR e VR

As Fig. 5.22 e 5.23 apresentam as micrografias (MEV-EDS) da superfície dos vidros TC após ataque hidrolítico. Os pontos indicados nestas micrografias apontam as regiões analisadas por EDS.

Observa-se que em todas as composições TC, ocorre o ataque na superfície. Nos vidros T05C e T10C (Fig. 5.22(a,b)) se observa também trincas na superfície após $\mathrm{O}$ ataque. No vidro T20C, observou-se a formação de uma camada superficial com baixo teor em álcalis (d da Fig. 5.23(b)). Nesta micrografia, observa-se também uma região onde ocorreu o desprendimento desta camada superficial ( $c$ da Fig. 5.23(b)). Comparando-se as duas regiões, observa-se que ocorre uma redução da concentração de sódio na região $\boldsymbol{d}$. Para os demais vidros, observou-se a matriz vítrea exposta após o desprendimento da camada superficial. Em todos estes vidros a composição analisada é compatível com a composição original correspondente. 


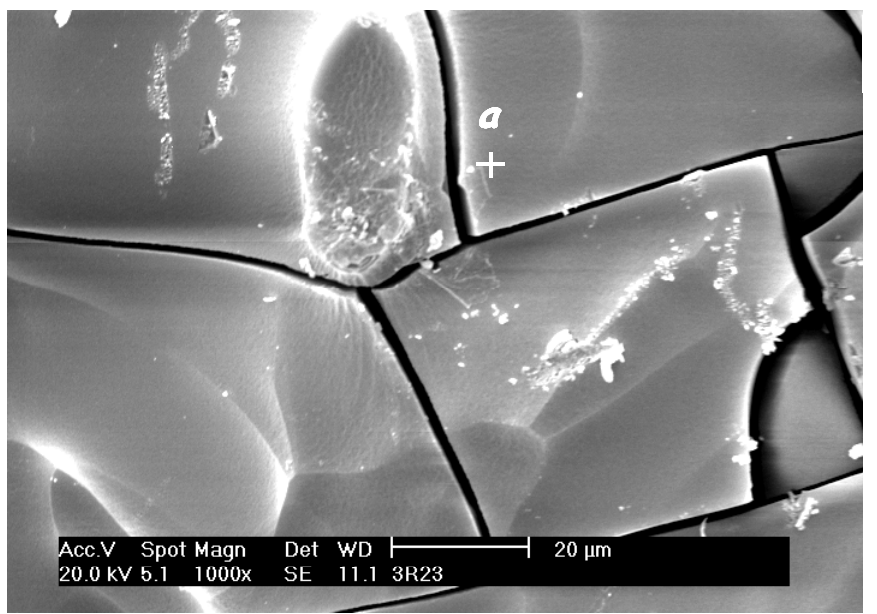

Microanálise

T05C

Elemento Massa\%

(a)

$\mathrm{Si} \quad 61,60$

Al $\quad 17,60$

$\mathrm{Na} \quad 11,20$

Ca $\quad 9,60$

Total 100

(a) $\mathrm{T05C}$

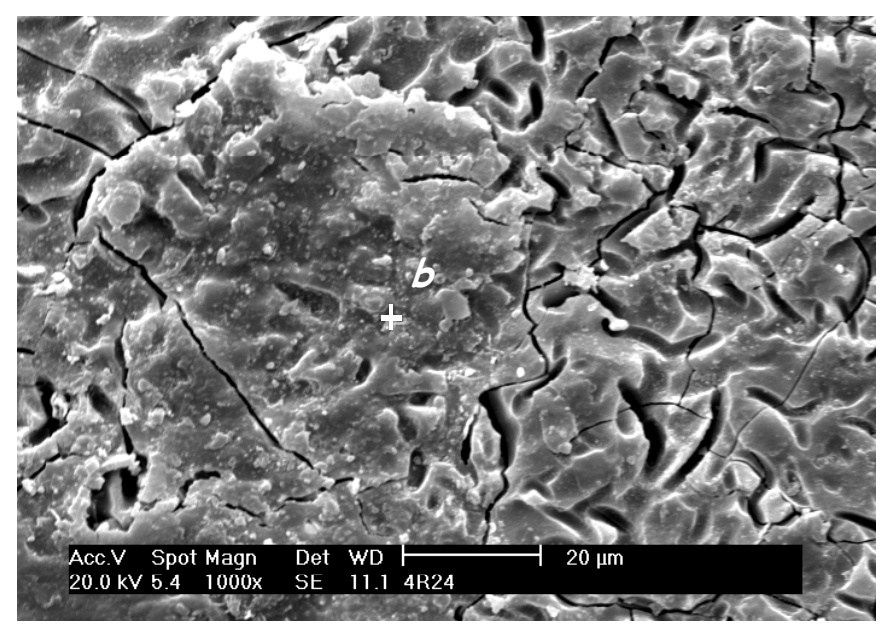

Microanálise

T10C

Elemento Massa\%

(b)

Si $\quad 74,53$

Al $\quad 12,74$

$\mathrm{Na} \quad 5,66$

$\mathrm{Ca} \quad 7,08$

Total $\quad 100$

(b) $\mathrm{T} 10 \mathrm{C}$

FIGURA 5.22 - Superfície de amostras das composições TC após o ataque hidrolítico: (a) T05C e (b) T10C (MEV-EDS)

As Fig. 5.24 e 5.25 mostram as micrografias e as composições em massa (MEV-EDS) da superfície dos vidros TR após ataque hidrolítico nas mesmas condições dos vidros TC. Nestas micrografias observa-se que as alterações produzidas nas camadas superficiais pelo ataque hidrolítico são mais intensas para os vidros contendo menor concentração de RSG.

Na Fig. 5.24(a), para o vidro T05R10, as duas camadas sobrepostas na superfície do vidro, são resultado do ataque hidrolítico, ou seja, uma camada externa e outra interna. Ambas apresentam trincas que facilitam a degradação. As análises de composição dos pontos representativos da camada interna (ponto a) e da camada externa (ponto b), mostram um conteúdo menor de $\mathrm{Na}_{2} \mathrm{O}$ quando 
comparado com a composição calculada (Tab. 4.3), este fato, indica a ocorrência do ataque protônico, como nos dados publicados para vidros soda-cal usuais ${ }^{(24)}$.

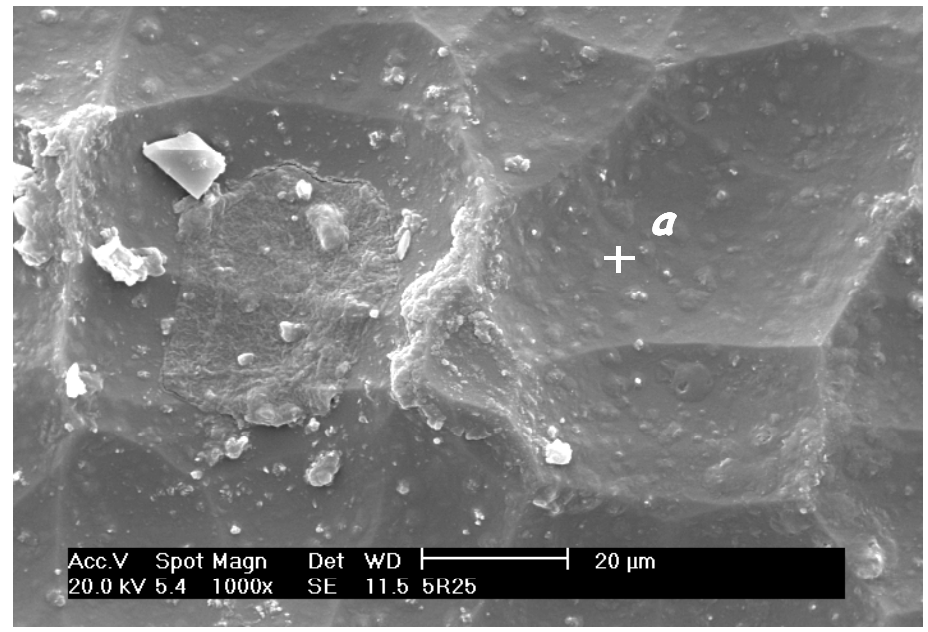

$\begin{array}{lc}\begin{array}{l}\text { Análise elemental } \\ \text { T15C } \\ \text { Elemento }\end{array} & \begin{array}{c}\text { Massa\% } \\ (\mathbf{a})\end{array} \\ & 71,10 \\ \mathrm{Si} & 13,76 \\ \mathrm{Al} & 5,96 \\ \mathrm{Na} & 9,17 \\ \mathrm{Ca} & 100 \\ \text { Total } & \end{array}$

(a) $\mathrm{T} 15 \mathrm{C}$

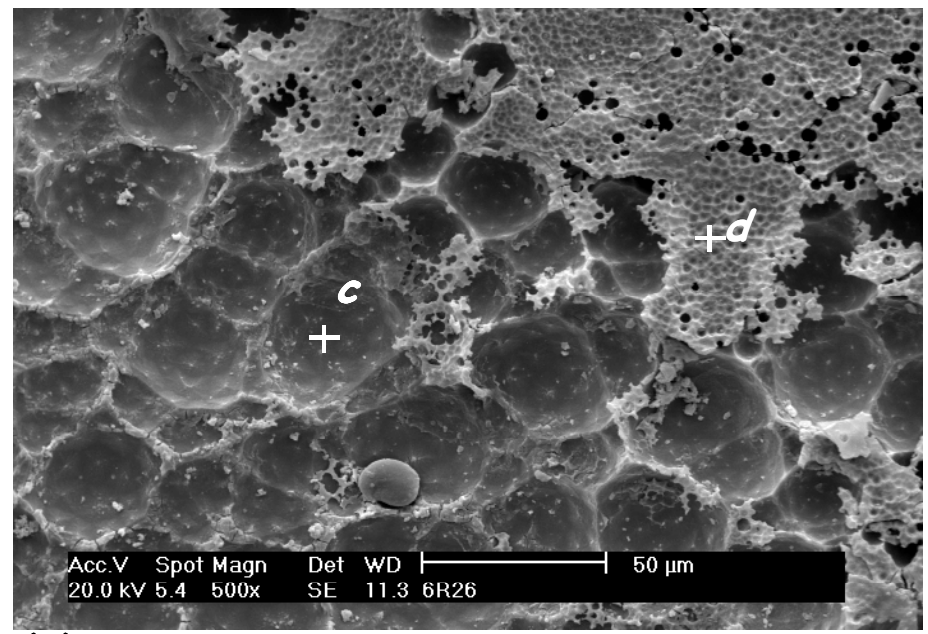

Análise elemental

T20C

Elem. Massa\%

(c) (d)

Si $\quad 52,46 \quad 59,87$

Al $\quad 16,39 \quad 17,11$

$\mathrm{Na} \quad 12,30 \quad 8,55$

Ca $\quad 18,85 \quad 14,47$

(b) $\mathrm{T} 20 \mathrm{C}$

Total $100 \quad 100$

FIGURA 5.23 - Superfície de amostras das composições TC após o ataque hidrolítico: (a) T15C e (b) T20C (MEX-EDS)

Por outro lado a diferença no conteúdo em massa de $\mathrm{SiO}_{2}$, entre as análises dos pontos $\boldsymbol{a}$ e $\boldsymbol{b}$, sugere que, na camada externa ocorreu com maior intensidade a hidrofilização das ligações Si-O-Si. Em ambas camadas, foram encontrados os mesmos valores do conteúdo de $\mathrm{Ca}$ e $\mathrm{Ni}$. 


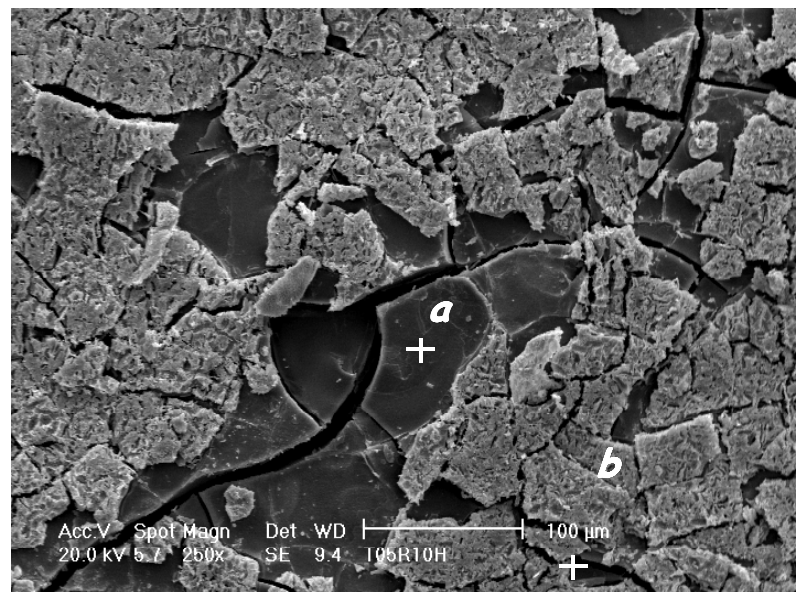

\section{Microanálise \\ T05R10 \\ Elem. Massa \%}

$\begin{array}{ccc} & \text { (a) } & \text { (b) } \\ \mathbf{N a} & 2,48 & 2,09 \\ \mathbf{A l} & 7,15 & 7,23 \\ \mathbf{S i} & 74,27 & 69,79 \\ \mathbf{C a} & 2,9 & 5,08 \\ \mathbf{N i} & 13,2 & 15,81 \\ \text { Total } & 100 & 100\end{array}$

(a) T05R10

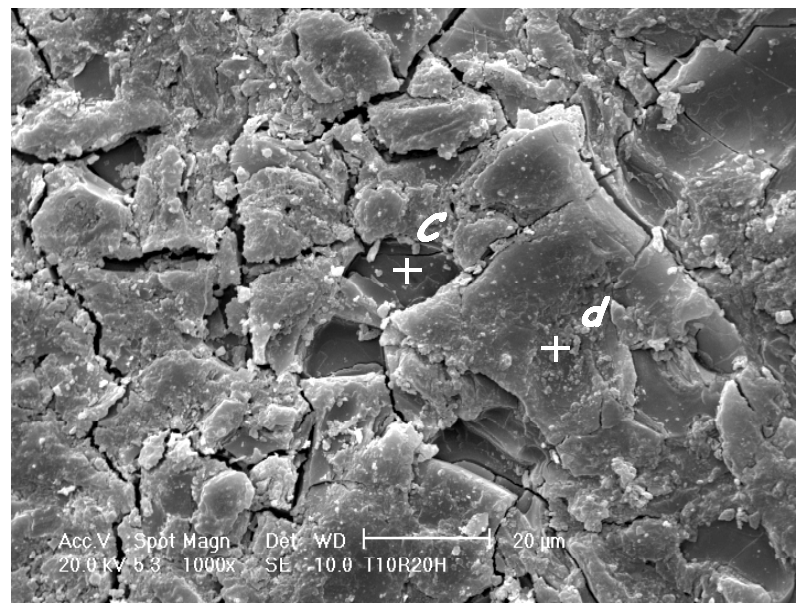

Microanálise

T10R20

Elem . Massa \%

(c) (d)

$\begin{array}{ccc}\text { Na } & 0,36 & 1,81 \\ \text { Al } & 10,41 & 14,59 \\ \text { Si } & 80,53 & 75,22 \\ \text { Ca } & 8,71 & 8,39 \\ \text { Total } & 100 & 100\end{array}$

(b) T10R20

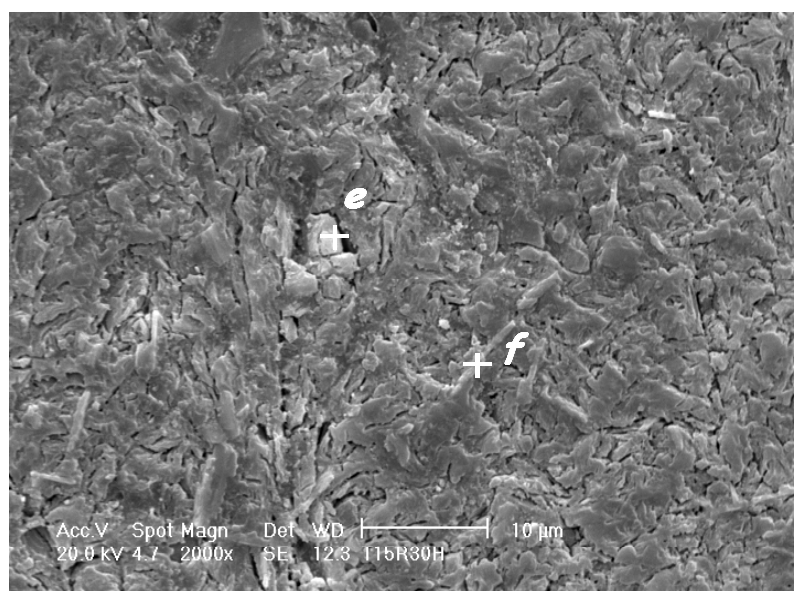

Microanálise

T15R30

Elem . Massa \%

$\begin{array}{ccc} & (\mathbf{e}) & (\mathbf{f}) \\ \mathbf{N a} & 10,65 & 8,91 \\ \mathbf{A l} & 12,65 & 8,38 \\ \mathbf{S i} & 70,03 & 36,67 \\ \mathbf{C a} & 6,67 & 3,1 \\ \mathbf{C r} & - & 42,93 \\ \text { Total } & 100 & 100\end{array}$

FIGURA 5.24 - Superfície de amostras das composições TR após o ataque hidrolítico: (a) T05R10, (b) T10R20 e (c) T15R30 (MEV-EDS)

Para concentração de $40 \%$ em massa de RSG, representada pelo vidro T20R40 (Fig. 5.25(a)), as alterações na superfície por efeito do ataque hidrolítico, 
são menores e quase não podem ser observadas. Neste vidro, a composição da matriz (ponto $\boldsymbol{h}$ ), indica a presença de cromo.

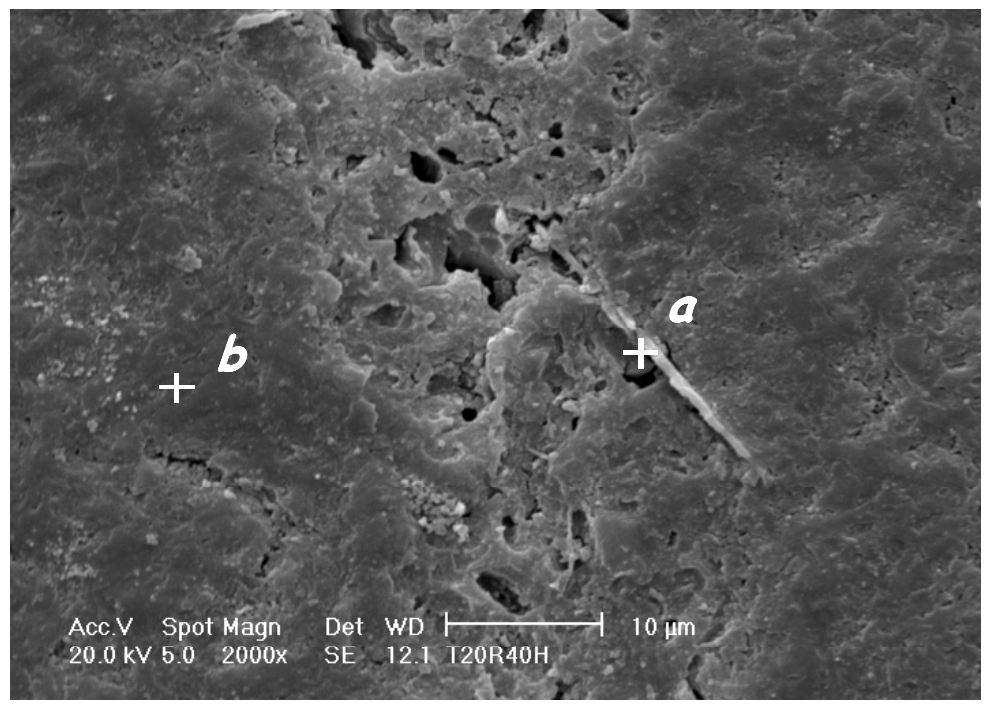

(a) T20R40

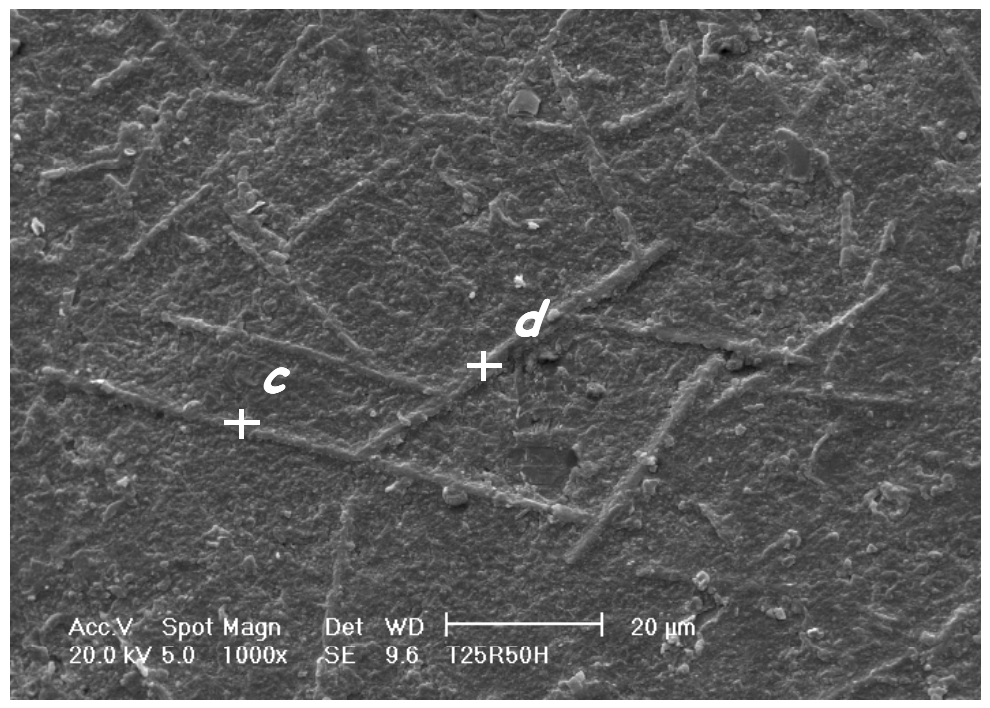

(b)T25R50

\section{Microanálise}

T20R40
Elem. Massa \%

$\begin{array}{ccc} & (\mathbf{a}) & \mathbf{( b )} \\ \mathbf{N a} & 1,87 & 4,54 \\ \mathbf{A l} & 4,56 & 11,33 \\ \mathbf{S i} & 18,05 & 69,26 \\ \mathbf{C a} & 1,56 & 8,23 \\ \mathbf{C r} & 73,96 & 6,64 \\ \text { Total } & 100 & 100\end{array}$

\section{Microanálise}

\section{T25R50}

Elem. Massa \%

$\begin{array}{ccc} & \text { c) } & (\mathbf{d}) \\ \mathrm{Na} & 3,05 & 1,88 \\ \mathbf{A l} & 0 & 0,73 \\ \mathrm{Si} & 14,63 & 11,75 \\ \mathbf{C a} & 1,62 & 0,28 \\ \mathbf{C r} & 70,08 & 78,31 \\ \mathbf{N i} & 10,63 & 7,05 \\ \text { Total } & 100 & 100\end{array}$

FIGURA 5.25 - Superfície de amostras das composições TR após o ataque hidrolítico: (a) T20R40 e (b) T25R50 (MEV-EDS)

Ainda considerando as micrografias das Fig. 5.24 e 5.25, as análises de composição obtidas durante o ensaio confirmam a presença do cromo nos cristais observados nos vidros T15R30, T20R40 e T25R50. Estes resultados indicam que a fase cristalina correspondente à cromita não foi dissolvida durante o ataque hidrolítico, confirmando estabilidade ambiental do $\mathrm{cromo}\left(\mathrm{Cr}^{3+}\right)$ após o 
processo de vitrificação do RSG, mesmo formando uma fase de composição distinta da matriz.

A Fig. 5.26 apresenta micrografias obtidas por microscopia óptica de luz refletida, correspondentes à superfície dos vidros das séries TC, e TR, após ataque hidrolítico. Nas micrografias obtidas a partir dos vidros T05C e T10C apresentam uma marcante presença de trincas e a camada superficial típica do processo de corrosão. No vidro T15C, observa-se a formação de uma estrutura peculiar, atribuída ao produto da reação de hidrolização da sílica ou a dissolução da mesma pelo íon $\mathrm{OH}^{-}$. Nos vidros T20C e T25C, as transformações superficiais foram menores. Estas duas composições correspondem aos vidros que apresentam maior resistência ao ataque hidrolítico.

Nos vidros da série TR, não se observa transformações superficiais significativas, a exceção do vidro T05R10, o qual apresenta trincas e degradação superficial, ainda que em menor intensidade quando comparada com as demais composições.

As micrografias (MOLR) da Fig. 5.27 correspondem á à sessão transversal a partir de amostras dos vidros das séries TC e TR, após o ensaio de resistência ao ataque hidrolítico. A formação da camada superficial foi observada nas micrografias correspondentes às composições T05C, T10C e T15C (Fig. 5.27(a,b,c) respectivamente), observa-se formação da camada superficial rica em sílica como conseqüência da remoção dos álcalis da superfície do vidro, ou seja do ataque protônico ${ }^{(23,24)}$. Nos vidros mais resistentes ao ataque hidrolítico desta série, ou seja, T20C e T25C (Fig. 5.27(d,e)), a formação desta camada não foi observada.

Nos vidros da série TR, a formação da camada superficial foi observada apenas na composição T05R10 (Fig. 5.27(f)). Os resultados obtidos nas análises de microscopia e de microanálise, ilustram o comportamento verificado nas curvas de dissolução obtidas durante o ensaio de ataque hidrolítico (Fig. 5.19 e 5.20). 


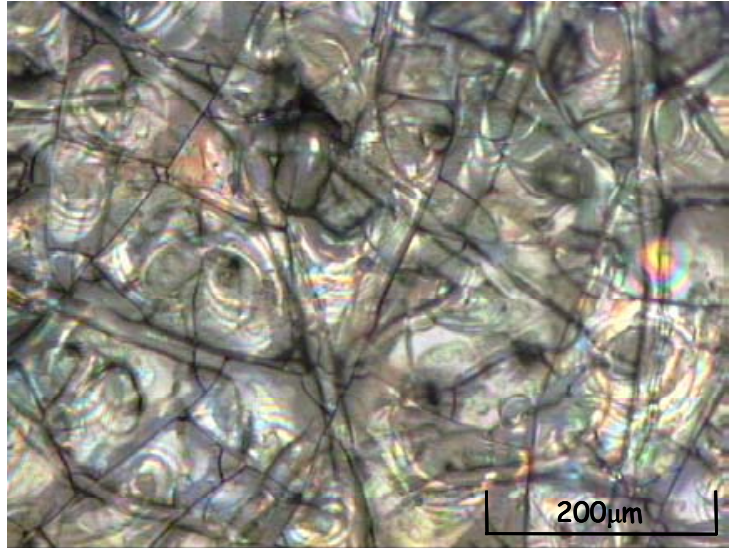

(a) $\mathrm{T05C}$

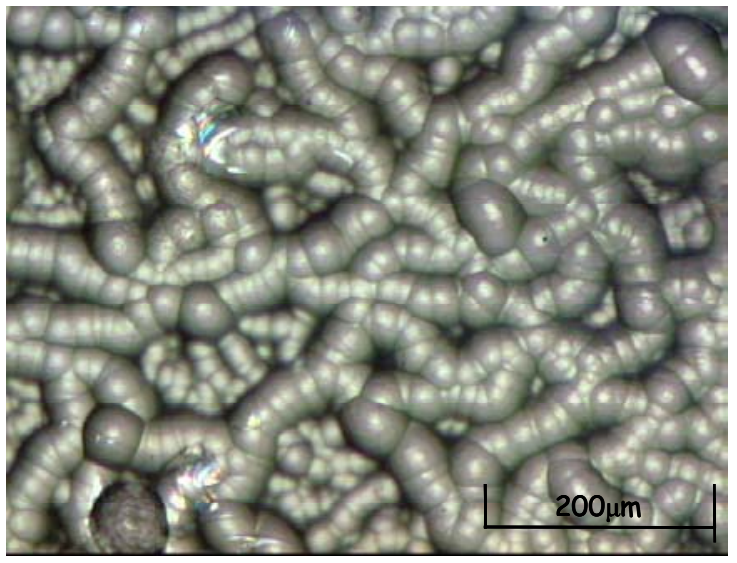

(b) $\mathrm{T} 15 \mathrm{C}$

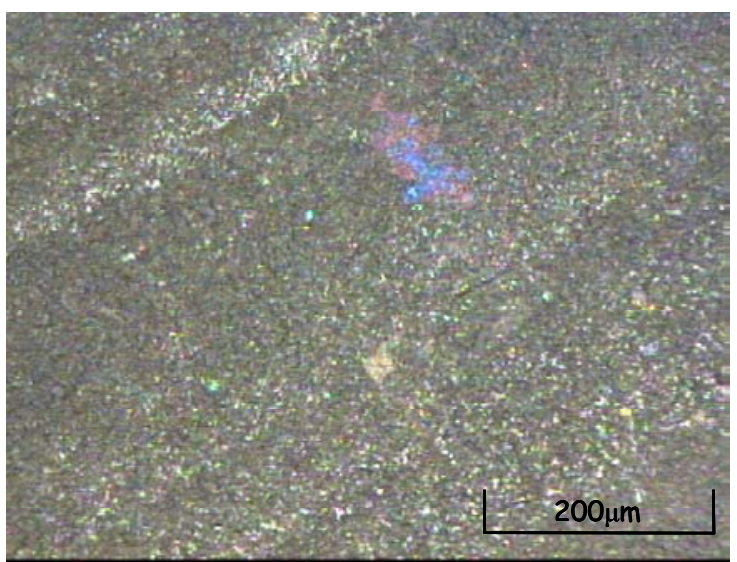

(c) $\mathrm{T} 25 \mathrm{C}$

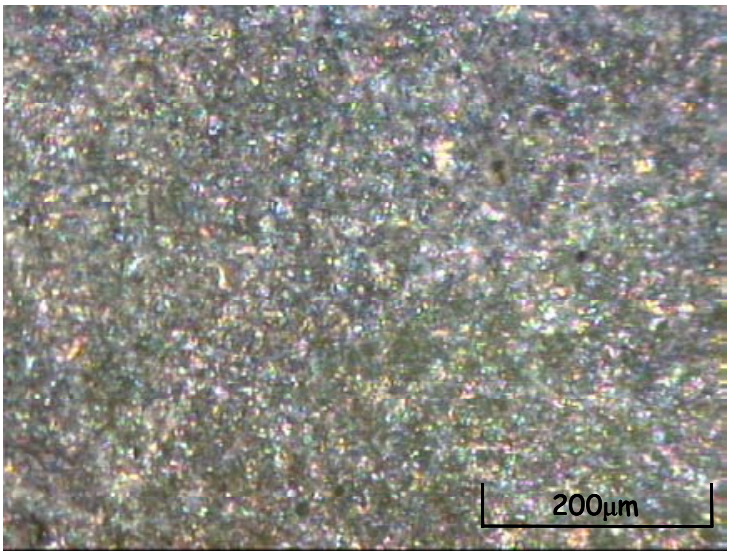

(d) T05R10

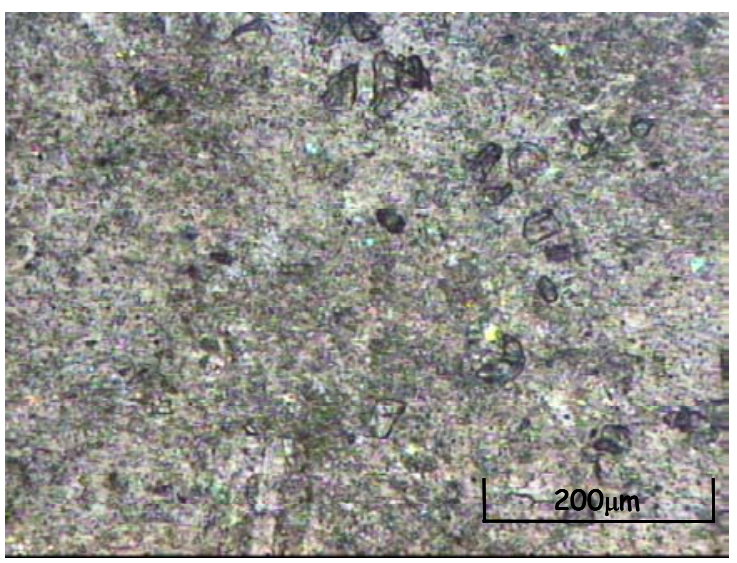

(e) T15R30

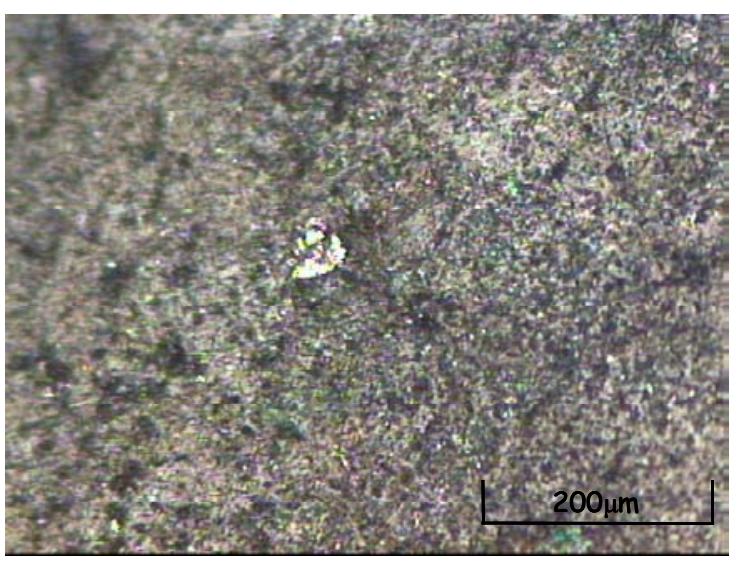

(f) $\mathrm{T} 25 \mathrm{R} 50$

FIGURA 5.26 - Micrografias ópticas, correspondentes á superfície de amostras das composições TC e TR, após 336h de ataque hidrolítico 


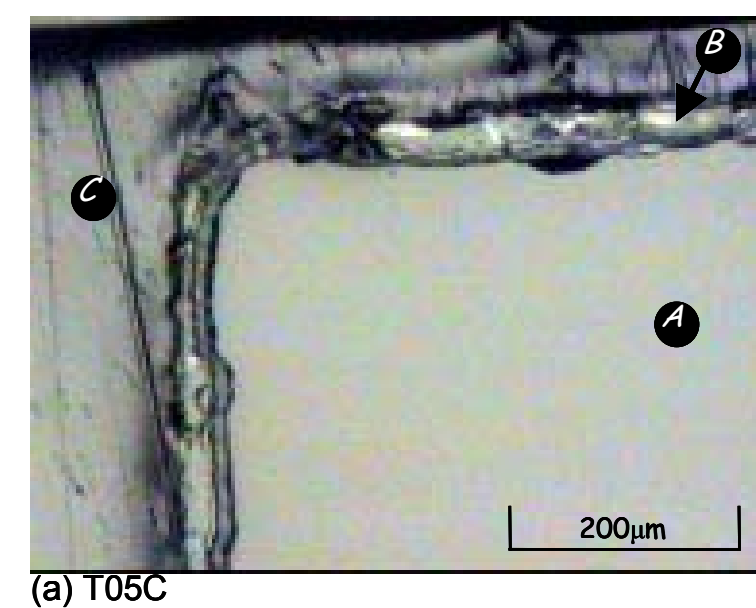

(a) $\mathrm{T} 05 \mathrm{C}$

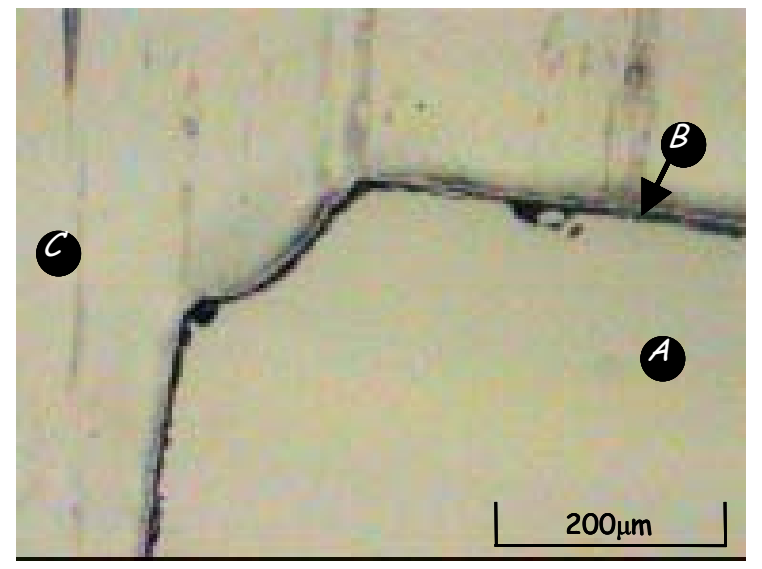

(b) T15C

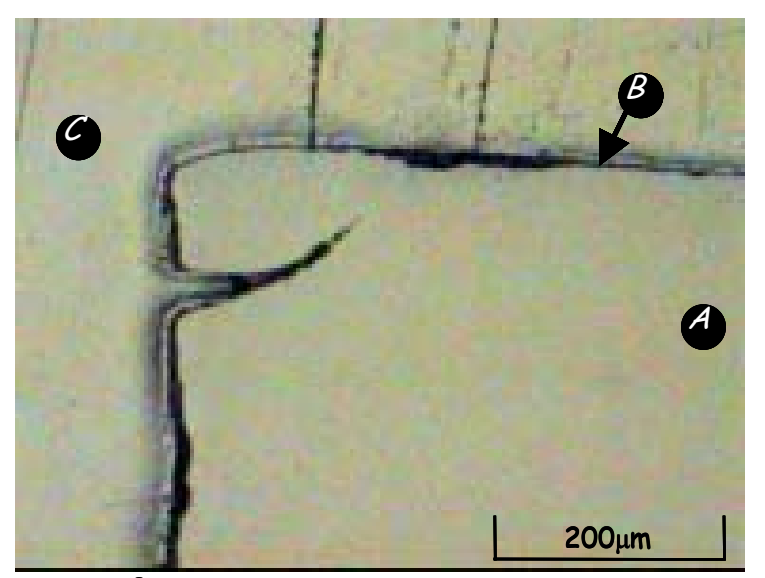

(c) $\mathrm{T} 25 \mathrm{C}$

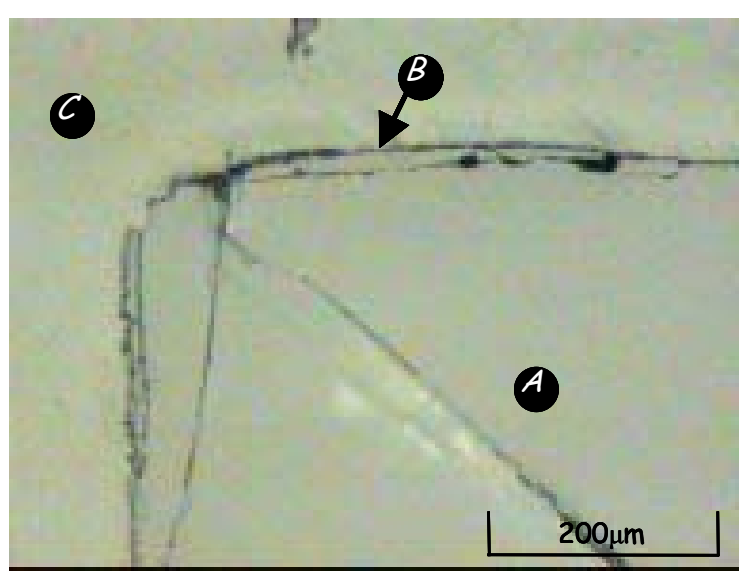

(d) T05R10

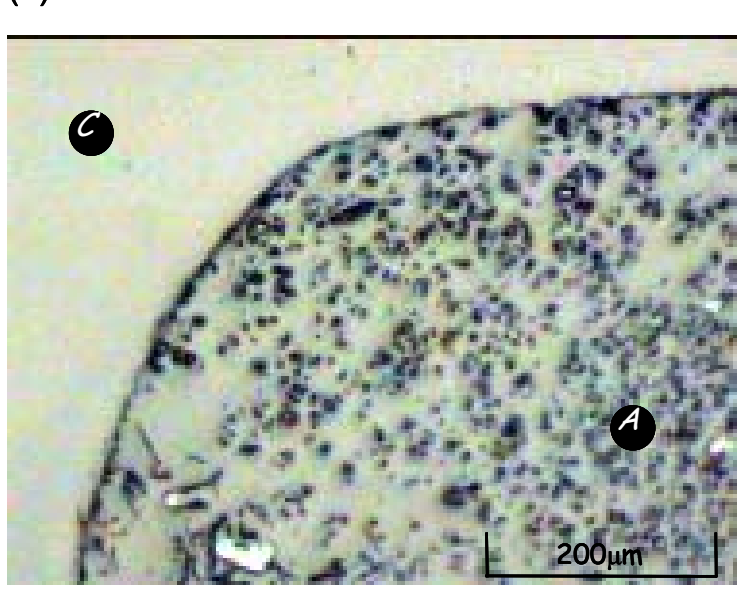

(e) T15R30

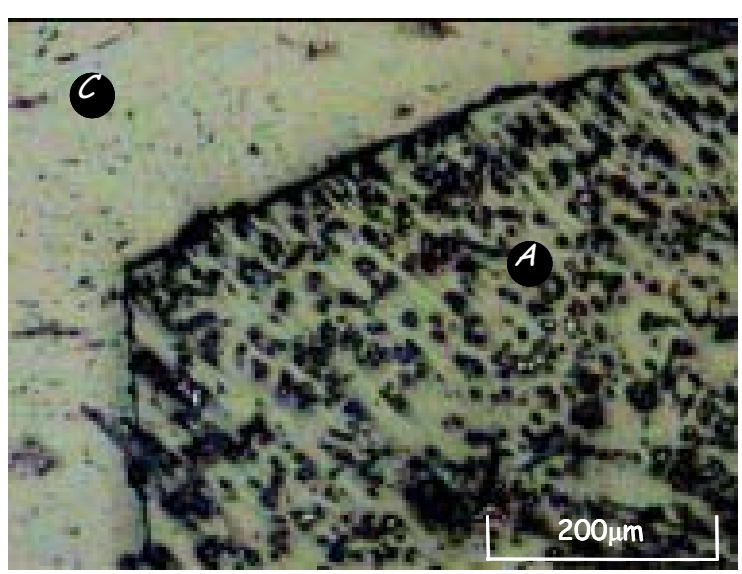

(f) $T 25 R 50$

A matriz vitrea; Bcamada atacada; Cresina do suporte

FIGURA 5.27 - Micrografias ópticas, correspondentes á secção transversal de amostras das composições TC e TR, após ataque hidrolítico

As Fig. 5.28 e 5.29 representam respectivamente os difratogramas dos pós relativos às séries TC e TR após o ataque hidrolítico. 


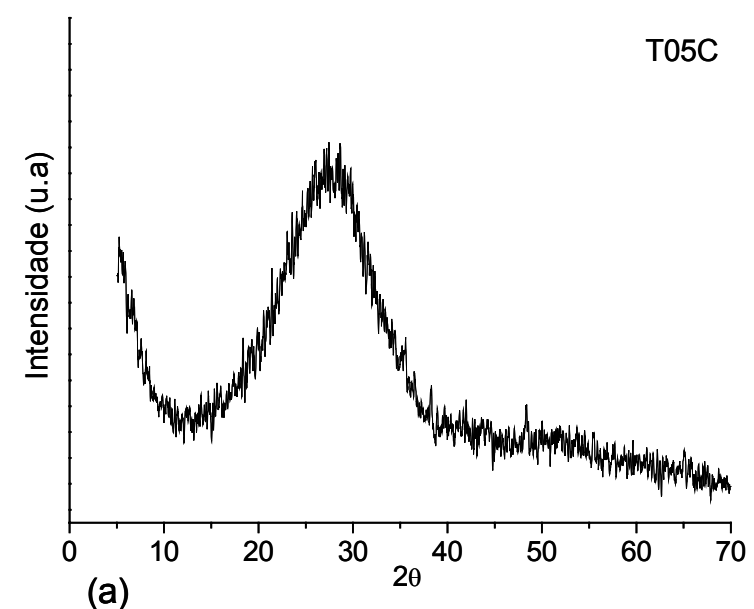

(a)

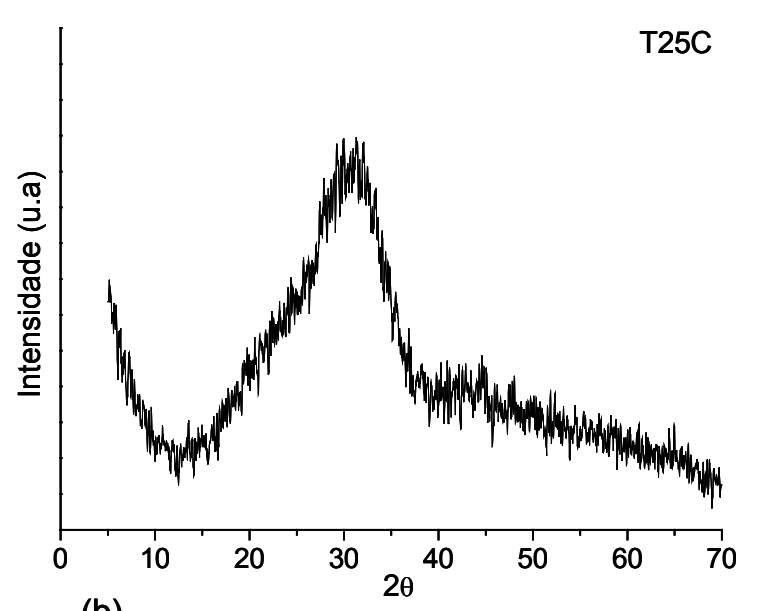

(b)

FIGURA 5.28 - Difratogramas obtidos por DRX a partir de amostras das composições TC, após ataque hidrolítico: (a) T05C e (b) T25C

Comparando-se os difratogramas dos vidros da série TC antes (Fig. 5.5) e após o ensaio (Fig. 5.28), não se observou alterações significativas nos espectros analisados, ou seja, os eventuais produtos da dissolução, que poderiam formar sais na superfície, foram removidos pela solução de ataque.

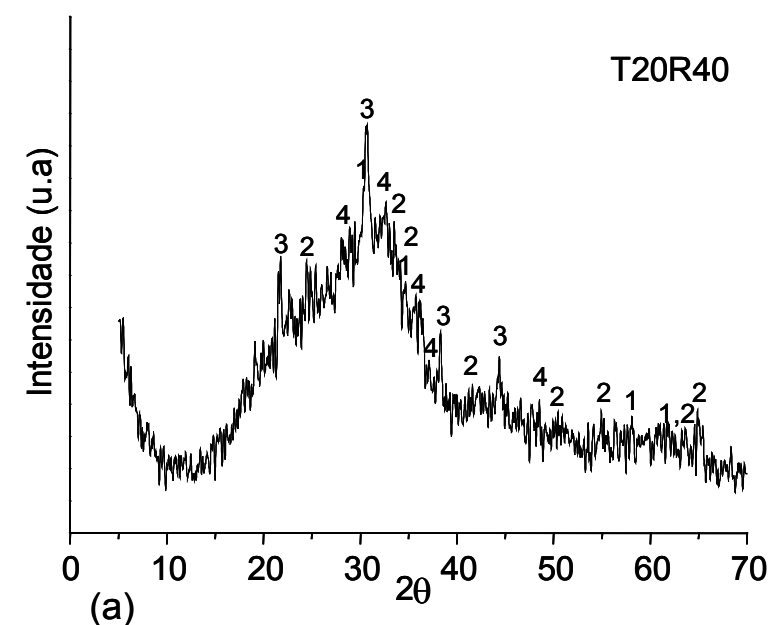

(a)

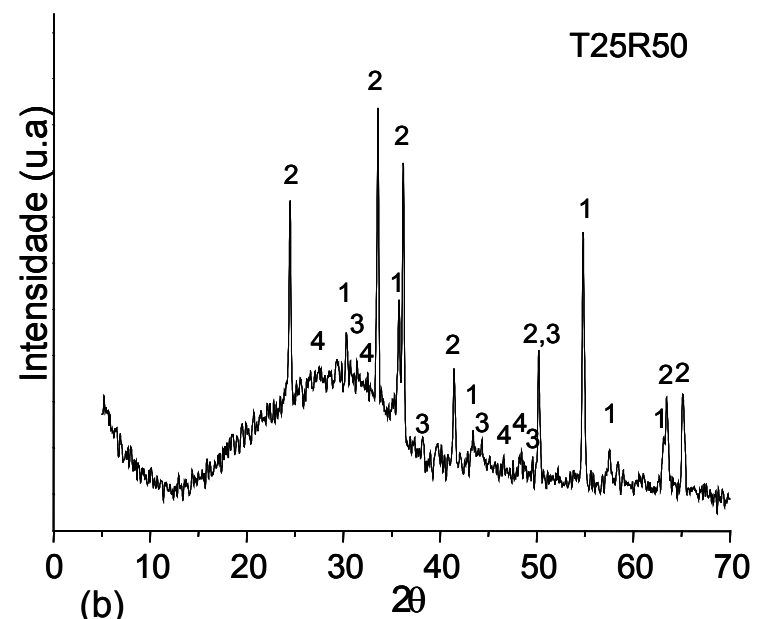

(b)

$$
1-\mathrm{Ni}\left(\mathrm{Cr}_{2} \mathrm{O}_{4}\right) ; 2-\mathrm{Cr}_{2} \mathrm{O}_{3} ; \mathbf{3}-\mathrm{Ni}_{2} \mathrm{~S}_{3} ; 4-\mathrm{Cu}_{2} \mathrm{~S}
$$

FIGURA 5.29 - Difratogramas obtidos por DRX a partir de amostras das composições TR, após ataque hidrolítico: (a) T20R40 e (b) T25R50 
Da mesma forma, nos vidros TR (Fig. 5.29) os espectros de DRX não foram significativamente alterados por efeito do ataque hidrolítico sendo observadas as mesmas fases presentes no vidro antes do ataque (Fig. 5.6), ou seja, $\mathrm{Cr}_{2} \mathrm{O}_{3} ; \mathrm{Ni}\left(\mathrm{CrO}_{4}\right) ; \mathrm{Cu}_{2} \mathrm{~S} ; \mathrm{e}, \mathrm{Ni}_{3} \mathrm{~S}_{2}$. Apenas o $\mathrm{Ca}_{3}\left(\mathrm{CrO}_{4}\right)_{2}$, foi envolvido no processo de dissolução. Deste modo, a presença de cromo e de outros metais observada no ensaio de consistência de produto (PCT-B, Tab. 5.5), seria principalmente, conseqüência da dissolução da matriz vítrea.

As Fig. de 5.30 à 5.32 representam os espectros FTIR a partir das amostras recolhidas dos vidros da série TC (T05C, T15C e T25C) e TR (T05R10, T15R30 e T25R50) durante o ataque hidrolítico $(0,1,3,6,12,24,72,168$ e 336h de ensaio).

Os espectros resultantes de FTIR para os vidros TC, figuras de 5.302(a), observa-se alterações em função do tempo de ensaio. Estas alterações são observadas nos modos de freqüência característicos no arranjo estrutural dos vidros soda-cal, em particular as composições T05C e T10C, e,com maior intensidade, na banda $780 \mathrm{~cm}^{-1}$, que se refere ligações entre tetraedros $\mathrm{SiO}_{4}$. No vidro T05C esta banda desaparece após $168 \mathrm{~h}$ de ensaio. Este fato é, indicativo da ocorrência da hidrolização da sílica e do ataque pelo íon $\mathrm{OH}^{-}$durante o processo de dissolução, e por conseqüência do rompimento da rede vítrea de sílica.

O boro associado à rede de sílica (ligações $\mathrm{B}-\mathrm{O}-\mathrm{Si}$ ) mantém a unidade estrutural durante $\mathrm{o}$ ataque, pois nos espectros não se observa qualquer alteração nas bandas de energia de vibração, características desta estrutura ,620-670 cm-1 ( $n^{\circ}$ 11, nas figuras). Também não ocorrem alterações nas bandas relacionadas com o boro unido indiretamente à estrutura do vidro, por meio de ligações com um modificador (1406 $\mathrm{cm}^{-1}$, ponto 12$)$.

Nos vidros TC, observa-se alterações nas bandas associadas às ligações formadas pelo $\mathrm{SiO}_{2}$ dos tipos $Q^{1}$ e $Q^{0}$. Entretanto, a redução da intensidade relativa em função do tempo de ensaio, é menos acentuada com o aumento da concentração do modificador $(\mathrm{CaO})$, ou seja, varia do vidro T05C até o vidro T25C. A diminuição da intensidade relativa para a banda relacionada com as ligações associadas ao $\mathrm{SiO}_{2} \mathrm{Q}^{2}$ (ponto 6 na figura), é observada com maior intensidade até $24 \mathrm{~h}$ de ataque. É interessante observar que este fato acentua-se 
à medida que a concentração de modificador diminui, provavelmente devido à formação das camadas superficiais.

As alterações na banda indicativa das ligações $\mathrm{Na}-\mathrm{O}$ (ponto 13) revelam a remoção continua do sódio durante o ataque hidrolítico em todos vidros TC. Contudo observa-se mais uma vez que este efeito é menos intenso com a maior quantidade de modificadores. As bandas relativas à formação de silicatos de metais alcalinos-terrosos (ponto 15 na figura) são pouco alteradas durante o ataque hidrolítico.

Apesar dos vidros TC apresentarem uma formulação diversa dos vidros soda cal, de uma maneira geral sob o ponto de vista de comportamento de dissolução observou-se que os mesmos guardam estreita semelhança com os processos descritos na literatura para esta classe de vidro ${ }^{(23,24)}$.

Os espectros de FTIR para os vidros TR, Fig. 5.30-2(b), também revelam a ocorrência alterações em função do tempo de ensaio.

A banda a $780 \mathrm{~cm}^{-1}$ representada (ponto 2 nas figuras), indica a hidrolização do $\mathrm{SiO}_{2}$ da rede vítrea (ligações entre tetraedros $\mathrm{SiO}_{4}$ ), principalmente para os vidros T05R10 e T10R20. Nestes vidros também se observa uma redução na intensidade relativa na banda à $460 \mathrm{~cm}^{-1}$, ligações Si-OSi $\left[Q^{4}\right]$ tetraédrico (ponto 3 nos espectros das figuras). Nos vidros TR também o aumento da concentração do modificador inibe o processo de corrosão (banda à $780 \mathrm{~cm}^{-1}$ ). Neste caso, a maioria do conteúdo de $\mathrm{CaO}$ foi substituído pelos equivalentes molares de metais de transição, conforme os cálculos de composição propostos (4.2.2). Desta forma os metais de transição passam a atuarem como os "modificadores" usuais $(\mathrm{CaO})$ os quais contribuem para o aumento da resistência hidrolítica dos vidros TR.

A presença das ligações do tipo B-O-Si (banda a 620-670 $\mathrm{cm}^{-1}$, representadas pelo ponto 11 nas figuras), que indicam que o boro não é removido durante o ataque hidrolítico são, todavia mais intensas nos vidros TR. (Fig. 5.2931). Ou seja, possivelmente, o boro também pode estar contribuindo para o aumento da resistência hidrolítica nos vidros contendo RSG. Este fato pode estar associado ao fato de que os metais de transição favorecem a coordenação tetraédrica do boro, como foi observado nas análises por RNM-MAS (Fig. 5.11). 


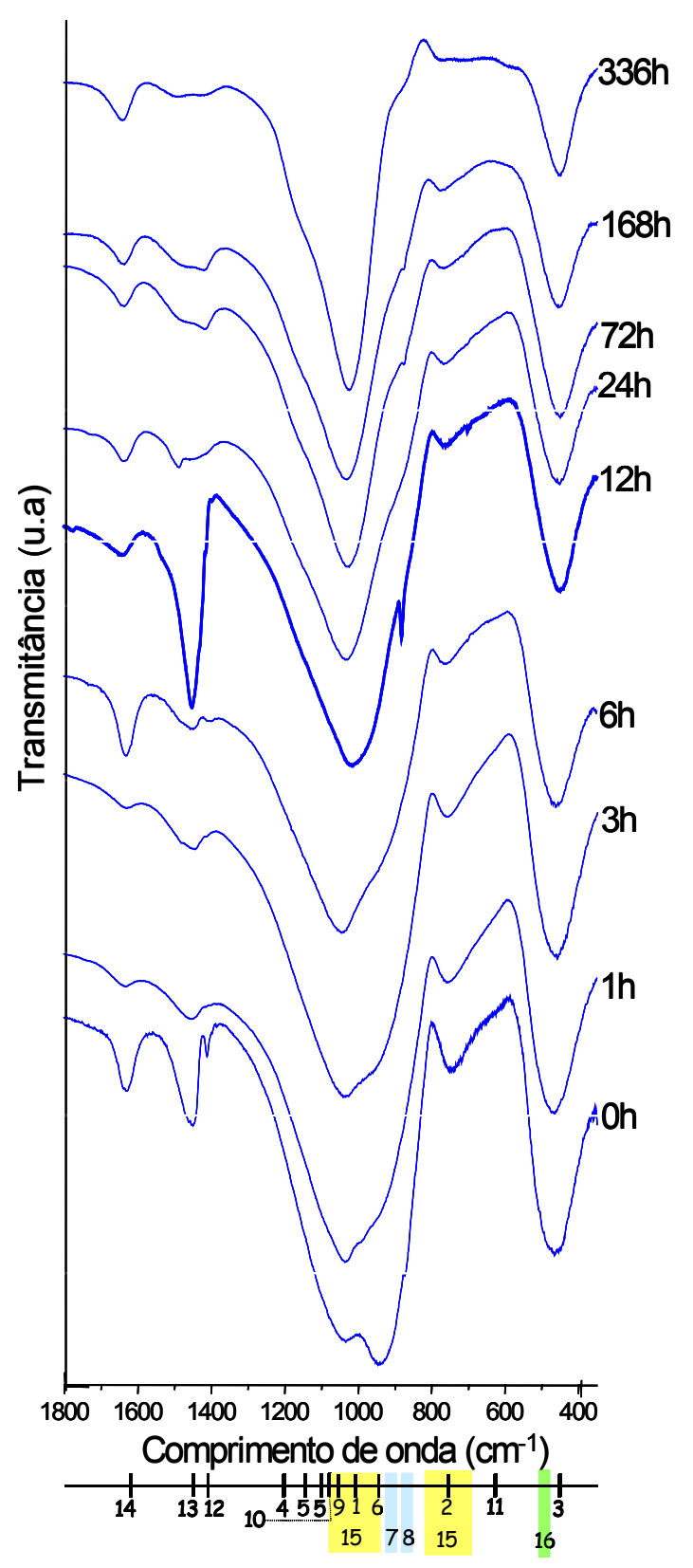

(a) T05C

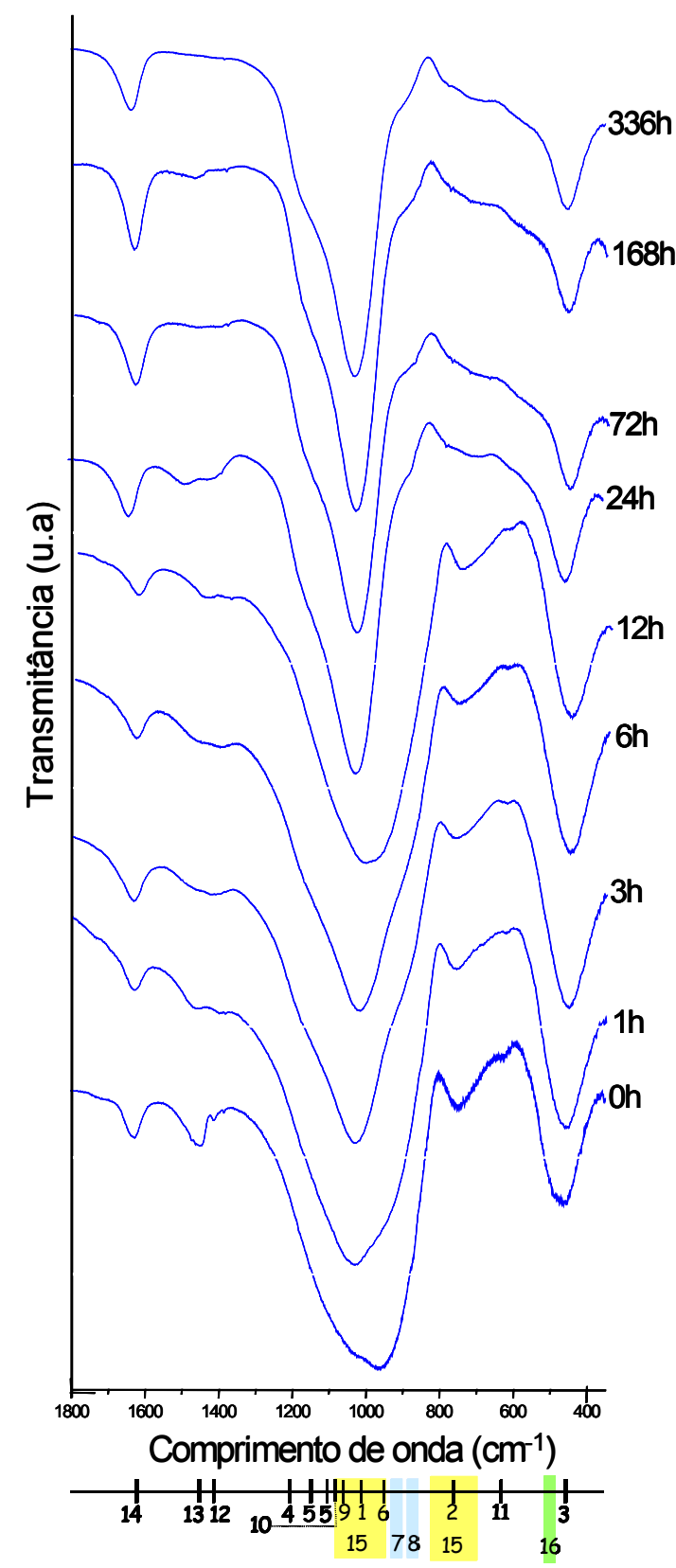

(b) T05R10

(1) Superfície de tetraedros $\mathrm{SiO}_{4}$; (2) Ligações entre tetraedros $\mathrm{SiO}_{4}$; (3) $\mathrm{Si}-\mathrm{O}-\mathrm{Si}\left[\mathrm{Q}^{4}\right]$;

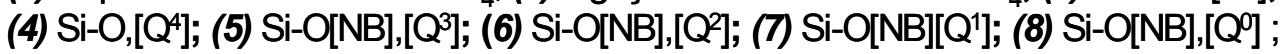

(9) Si-O-Si; (10) Si-O-[NB], plano ; (11) Si-O-B Estrutural; (12) B-O Livre; (13) Na-O;

(14) Água livre; (15) Silicatos de metais; (16) Óxidos metálicos segregados.

FIGURA 5.30 - Espectros de FT-IR de amostras das composições T05C e T05R10 após 0, 1, 3, 6, 12, 24, 72, 168 e 336 horas de ataque hidrolítico. 


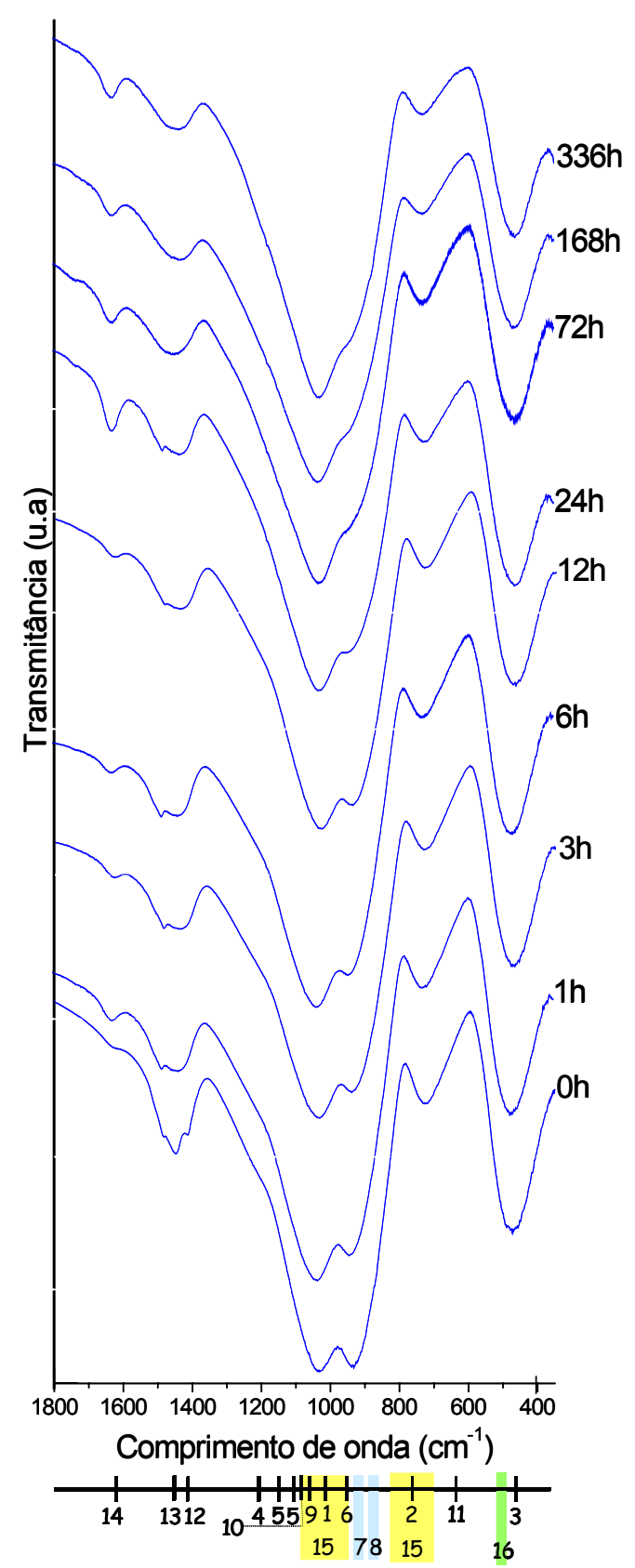

(a) T15C

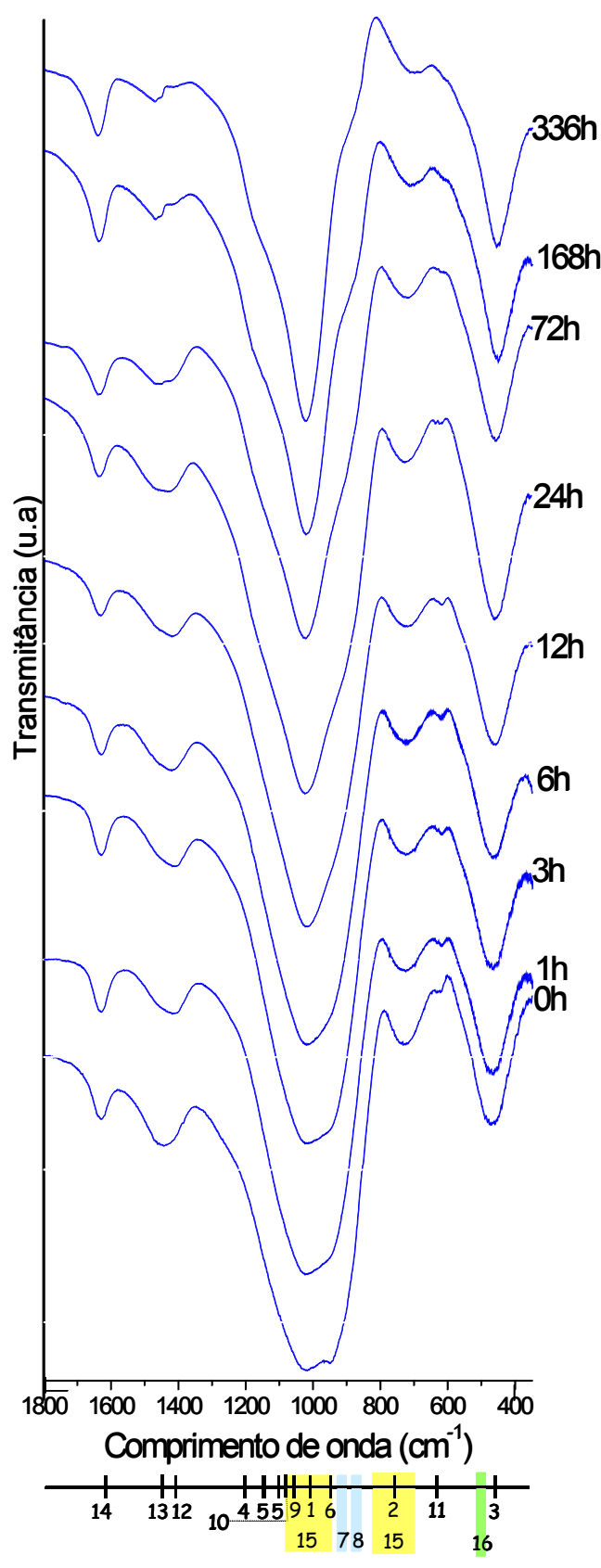

(b) T15R30

(1) Superfície de tetraedros $\mathrm{SiO}_{4}$; (2) Ligações entre tetraedros $\mathrm{SiO}_{4}$; (3) Si-O-Si [Q4]

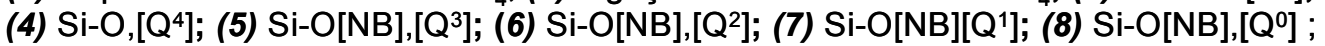
(9) Si-O-Si; (10) Si-O-[NB], plano ; (11) Si-O-B Estrutural; (12) B-O Livre; (13) Na-O; (14) Água livre; (15) Silicatos de metais; (16) Óxidos metálicos segregados.

FIGURA 5.31 - Espectros de FT-IR de amostras das composições T15C e T15R30 após $0,1,3,6,12,24,72,168$ e 336 horas de ataque hidrolítico. 


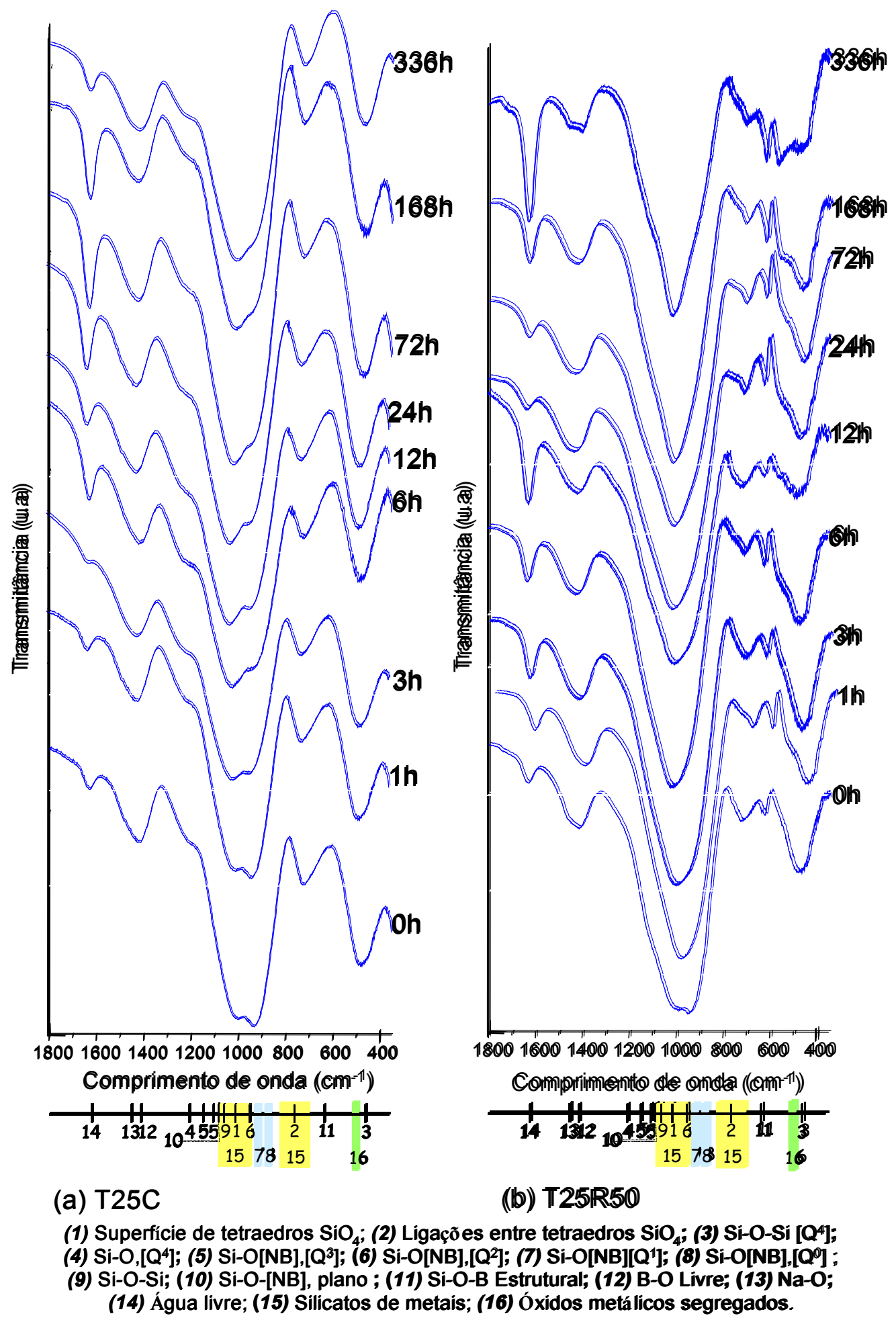

FIGURA 5.32 - Espectros de FT-IR de amostras das composições T25C e T25R50 após 0, 1, 3, 6, 12, 24, 72, 168 e 336 horas de ataque hidrolítico. 
Ainda para os vidros TR, verifica-se acentuadas modificações nos modos de oscilação nas bandas das ligações pertencentes às estruturas do tipo $Q^{1}$ e $Q^{0}$, devido a variação do tempo de exposição ao ataque (pontos 7 e 8 ). A redução de intensidade relativa nestas bandas de energia com o tempo de ensaio é menos intensa com o aumento da concentração de modificadores, ou seja, do vidro T05R10 para o vidro T25R50.

A banda indicativa das ligações associadas à $\mathrm{SiO}_{2} \mathrm{Q}^{2}$ (ponto 6 nas figuras), de uma forma geral diminui sua intensidade relativa até $12 \mathrm{~h}$ de ensaio. $\mathrm{A}$ ocorrência deste fato é influenciada pela variação da concentração do modificador. Mais uma vez a influência das camadas superficiais e a similaridade deste comportamento com o observado para os vidros da série TC, indica ser o mesmo independente da natureza do modificador utilizado.

As alterações na banda indicativa das ligações $\mathrm{Na}-\mathrm{O}$ (ponto 13) revelam a remoção continua do sódio durante o ataque hidrolítico em todos os vidros TR. Observa-se mais uma vez que este efeito diminui com o aumento da concentração de modificadores. As bandas relativas à formação de silicatos de metais alcalinos e com os metais de transição (indicadas por $\mathbf{1 5}$ nas figuras) são pouco alteradas durante $o$ ataque hidrolítico.

Os espectros de FTIR indicam que o comportamento durante o ataque hidrolítico é similar para as séries TC e TR, com a exceção sob o ponto de vista da atuação do boro, que nos vidros TR contribui para o aumento da resistência hidrolítica.

\subsubsection{2 - Resistência ao ataque ácido}

Na Fig. 5.33 são representadas as taxas de dissolução dos vidros TC, TR e VR, de acordo com os procedimentos descritos no item 4.6.4. Esta figura aponta que ocorre o aumento da taxa de dissolução com o aumento da concentração de modificadores. Este fato observado para ambas as séries de vidros mostra que o tipo de ligação formado entre estes modificadores e a rede de vidro é suscetível a um forte ataque protônico $\left(\mathrm{H}^{+}\right.$em soluções de ácidos). Entretanto para os vidros $\mathbf{T R}$, que contém resíduo galvânico $(\mathrm{Cr}, \mathrm{Ni}, \mathrm{Cu}, \mathrm{Zn}, \mathrm{Pb})$, a resistência ao ataque ácido mostra-se ligeiramente superior em relação aos 
vidros formulados com base em cálcio (TC) para todo o intervalo de composição estudado.

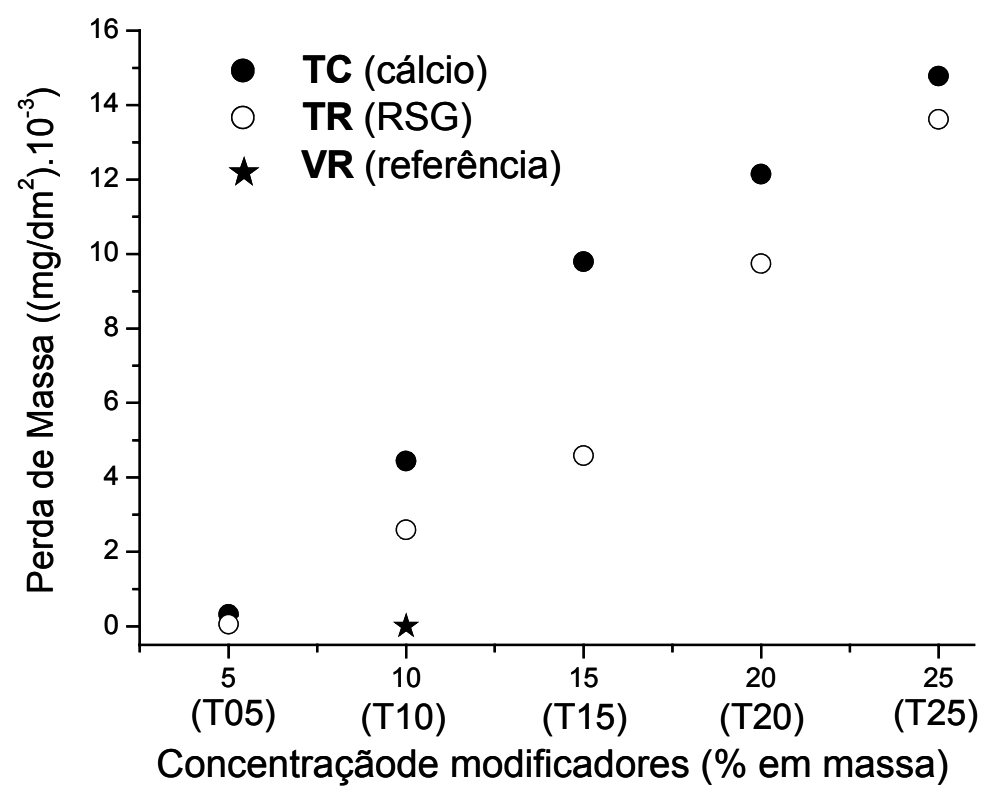

FIGURA 5.33 - Taxa de dissolução em função da concentração de modificadores obtidas no ensaio de resistência ao ataque ácido de amostras das composições TC, TR e VR.

O aumento da taxa de dissolução em função da concentração de modificadores durante o ensaio de resistência ao ataque ácido consiste em um comportamento inverso ao observado no ensaio de ataque hidrolítico. Em ambos os ensaios, o ataque protônico é, segundo a literatura, o mecanismo dominante durante a dissolução ${ }^{(24)}$. Entretanto, durante $\mathrm{o}$ ataque ácido os cátions $\mathrm{R}^{+}$e $\mathrm{R}^{2+}$ são envolvidos no processo de dissolução.

A resistência ao ataque ácido observada no vidro VR, esta associada à menor fração de alcalinos fundentes ( $\mathrm{NaO}$ ) presentes no material (VR, 12,6 \% em massa; Vidros TC e TR variando entre 23,5 e 30,5\% em massa, como mostrado nas Tab. 4.2-4).

As micrografias correspondentes à secção transversal ("crosssection") dos vidros TC e TR, após o ataque ácido, são apresentadas na Fig. 5.34. Na série TC apenas as composições com maior concentração de modificadores $(\mathrm{CaO})$, apenas a composição T05C e T10C permitiram a 
preparação para observação em microscópio. A composição T05C não apresentou ataque visível em sua superfície.

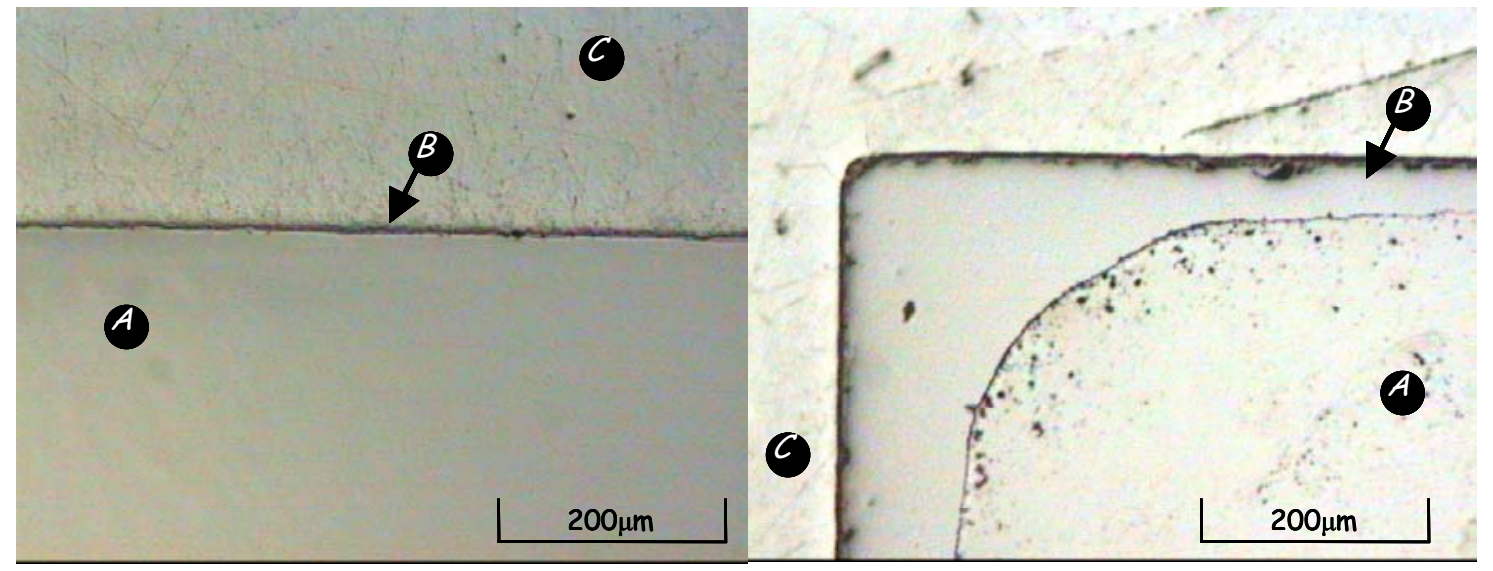

(a) T05C

(c) T05R10

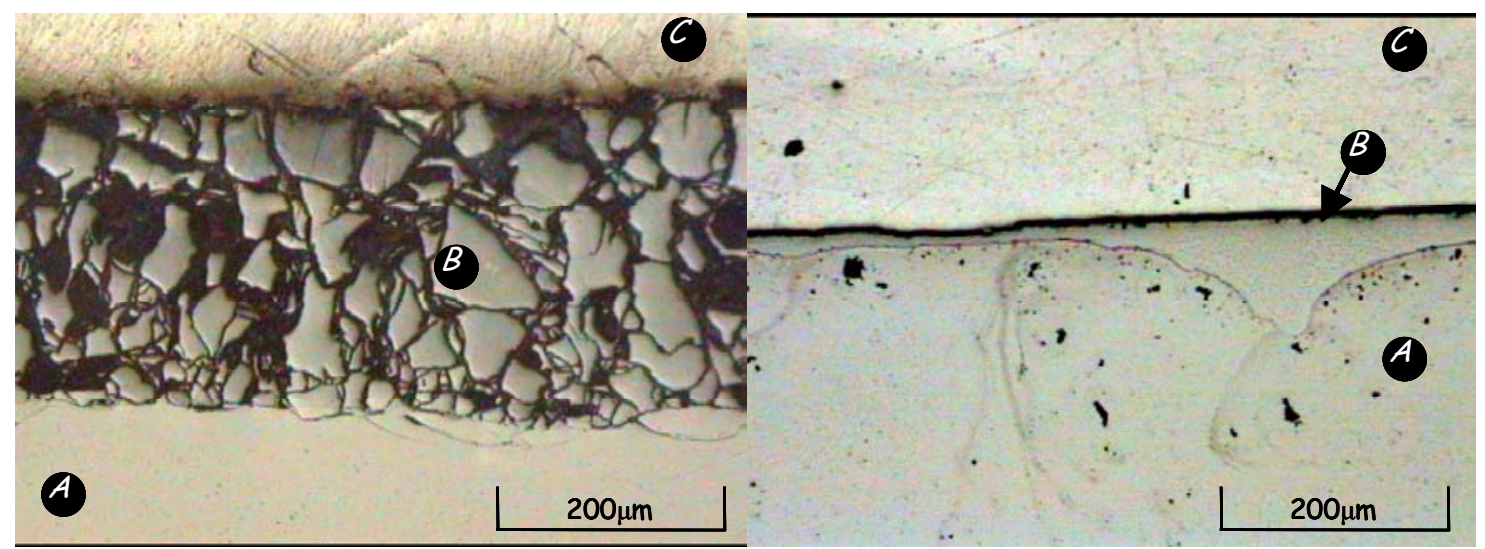

(b) T10C

(d) T10R20

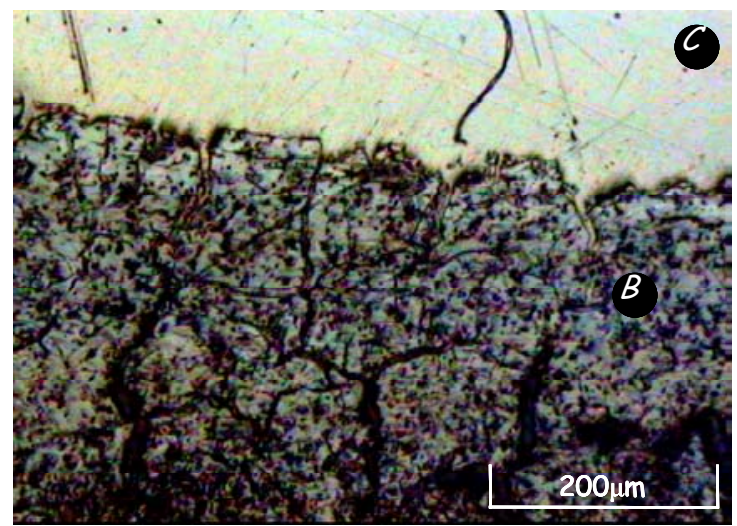

(e) T25R50

A matriz vitrea; $B$ camada atacada; $\mathcal{C}$ resina do suporte

FIGURA 5.34 - Micrografias da secção transversal de amostras das composições TC e TR, após o ataque ácido: (a) T05C, (b) T10C, (c) T05R10, (d) T10R20 e (e) T25R50 
Todos os vidros da série TR apresentaram alteração da camada superficial. Com exceção do vidro T05R10, observa-se que o ataque ocorre em regiões preferenciais, possivelmente devido à segregação de alguma espécie mais suscetível a este ataque. Estas espécies ao serem dissolvidas facilitam o desprendimento de blocos (pequenas porções). Estes blocos de vidro, ao se desprenderem da superfície do vidro (spalling), aceleram o processo de degradação do mesmo.

As micrografias dos vidros TC obtidas por MEV-EDS são mostradas na Fig. 5.35 e 5.36 .

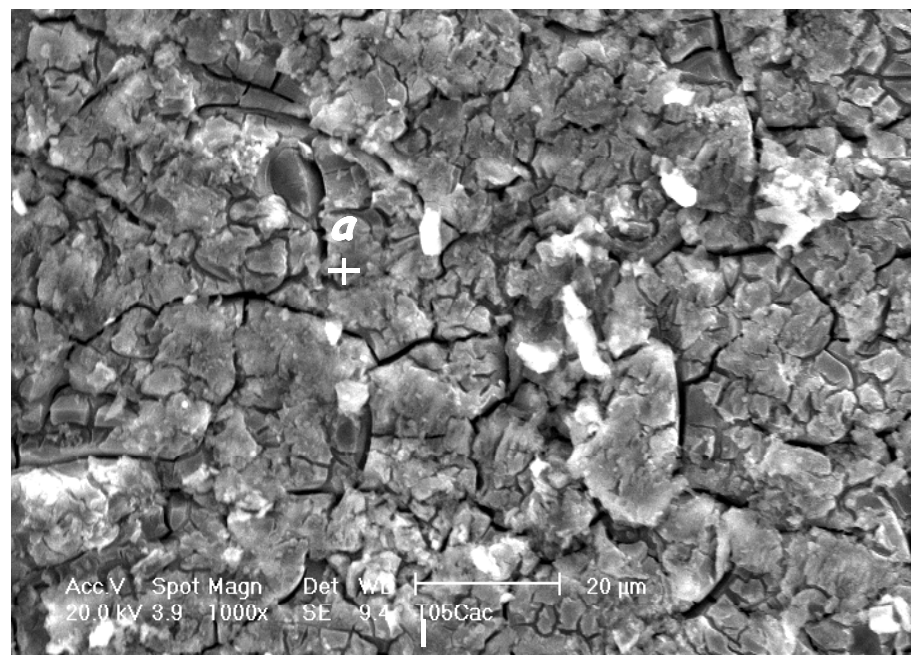

(a) $\mathrm{T} 05 \mathrm{C}$

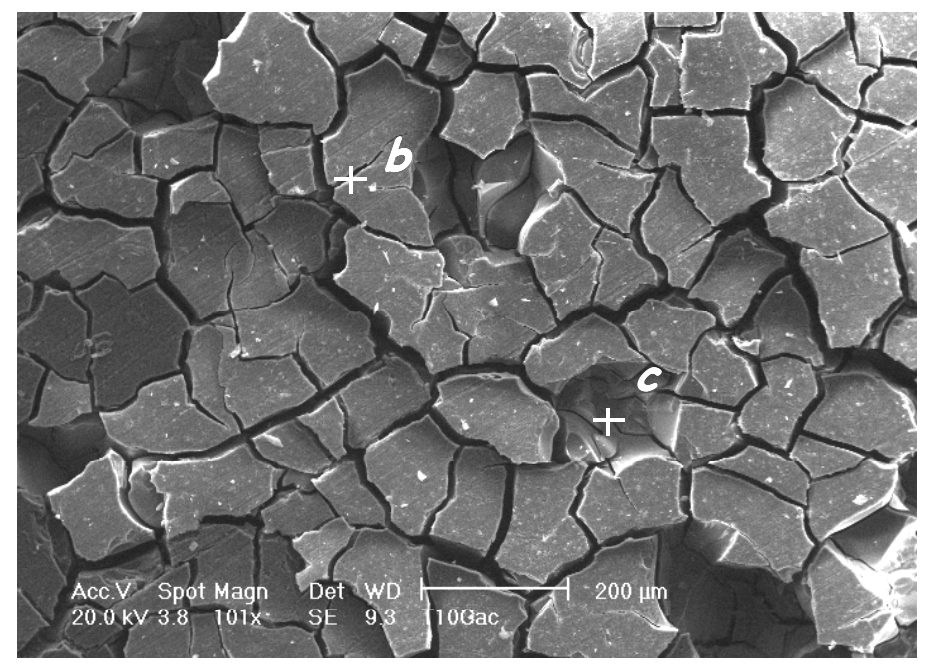

Microanálise

T05C

Elemento Massa\%

(a)

Al $\quad 1,14$

Si $\quad 98,91$

$\mathrm{Na} \quad 0,00$

$\mathrm{Ca} \quad 0,00$

Total $\quad 100,00$

Microanálise

T10C

Elem. Massa\%

(b) (c)

Al $\quad 1,49 \quad 2,28$

Si $\quad 98,43 \quad 95,64$

$\mathrm{Na} \quad 0,00 \quad 0,00$

$\begin{array}{lll}\mathrm{Ca} & 0,00 & 2,09\end{array}$

Total $\quad 100,00 \quad 100,00$

(b) T10C

FIGURA 5.35 - Superfície de amostras das composições TC após o ataque ácido: (a) T05C e (b) T10C (MEV-EDS) 
Nestas micrografias se observa que para menores concentrações de cálcio, ou seja, nos vidros T05C e T10C, a dissolução devido ao ataque ácido é acompanhada pelo aparecimento de alta concentração de trincas. As composições obtidas por EDS para todas as amostras revelam que a camada superficial é composta principalmente por sílica, indicando a preferência de remoção dos cátions alcalinos e alcalinos terrosos pelo ataque ácido (protônico).

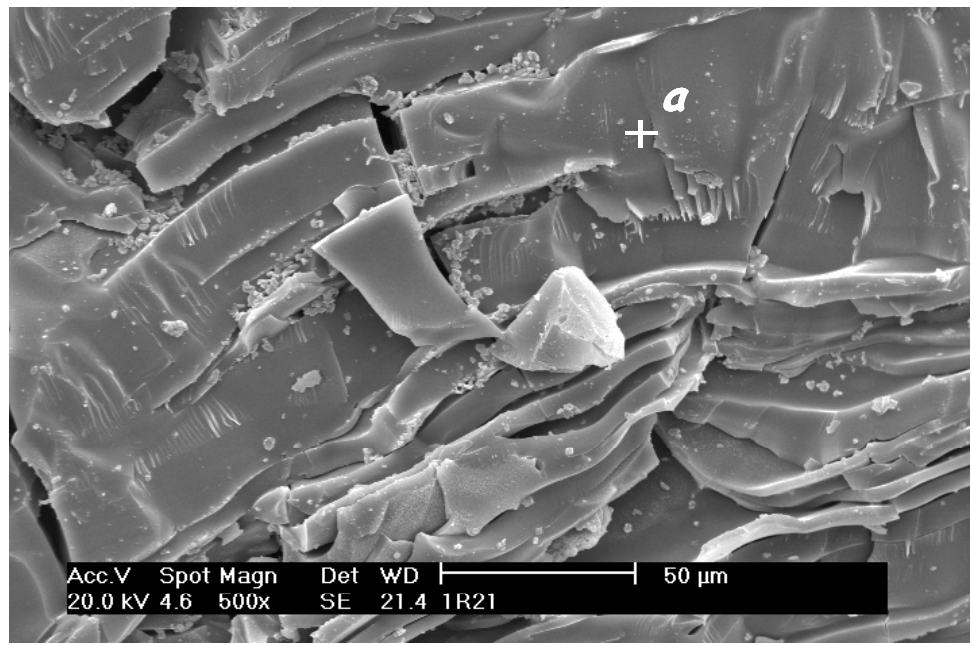

Microanálise

T15C

Elemento

Massa\%

(a)

Al $\quad 0,88$

Si $\quad 99,12$

$\mathrm{Na} \quad 0,00$

$\mathrm{Ca} \quad 0,00$

Total $\quad 100,00$

(a) $\mathrm{T} 15 \mathrm{C}$

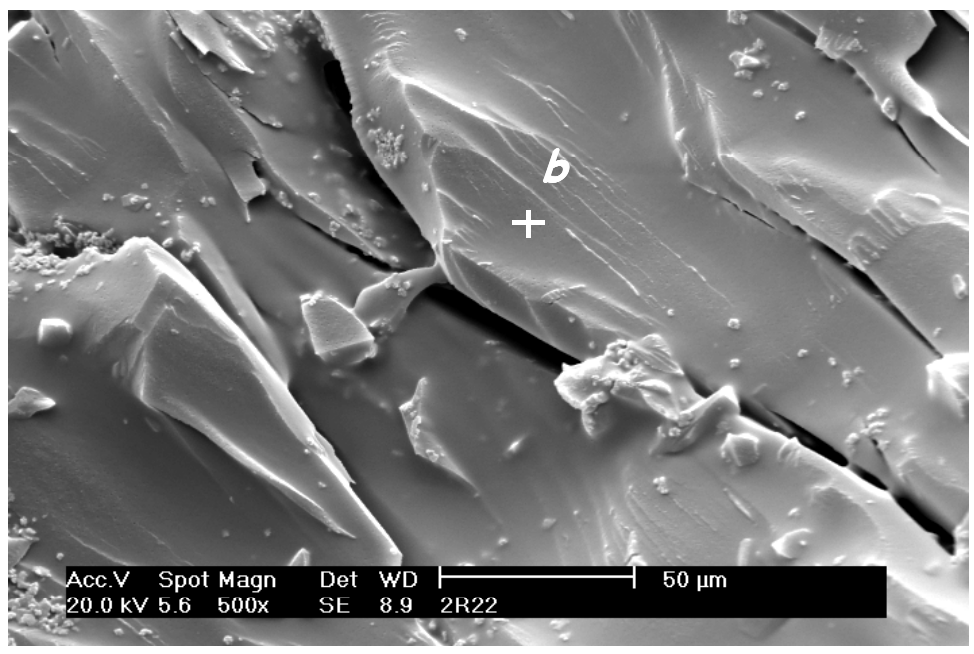

Microanálise

T25C

Elemento Massa\%

(b)

Al $\quad 1,37$

Si $\quad 98,63$

$\mathrm{Na} \quad 0,00$

Ca $\quad 0,00$

Total $\quad 100,00$

(b) $\mathrm{T} 25 \mathrm{C}$

FIGURA 5.36 - Superfície de amostras das composições TC após o ataque ácido: (a) T15C e (b) T25C (MEV-EDS)

As micrografias dos vidros TR são apresentadas na Fig. $5.37 \mathrm{e}$ 5.38. O comportamento desta série é análogo ao observado para a série TC. 
A análise química EDS, realizada para a composição T25R50, revelou a presença de cromo na da superfície deste vidro, indicando que o mesmo não foi totalmente removido pelo ataque ácido.

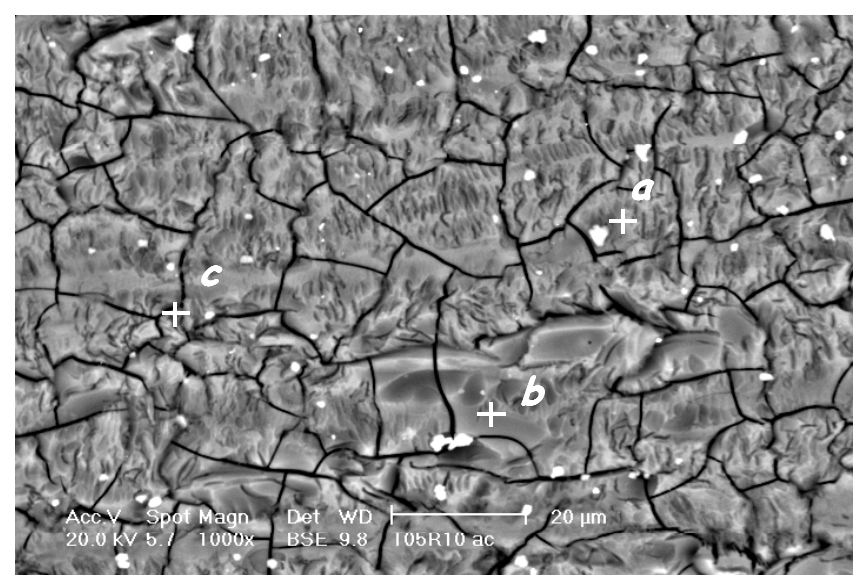

(a) T05R10

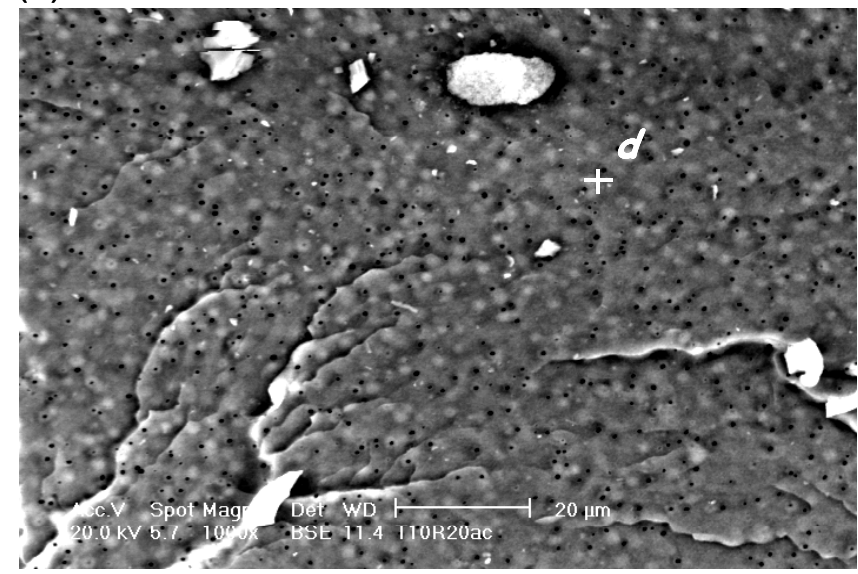

(b) T10R20

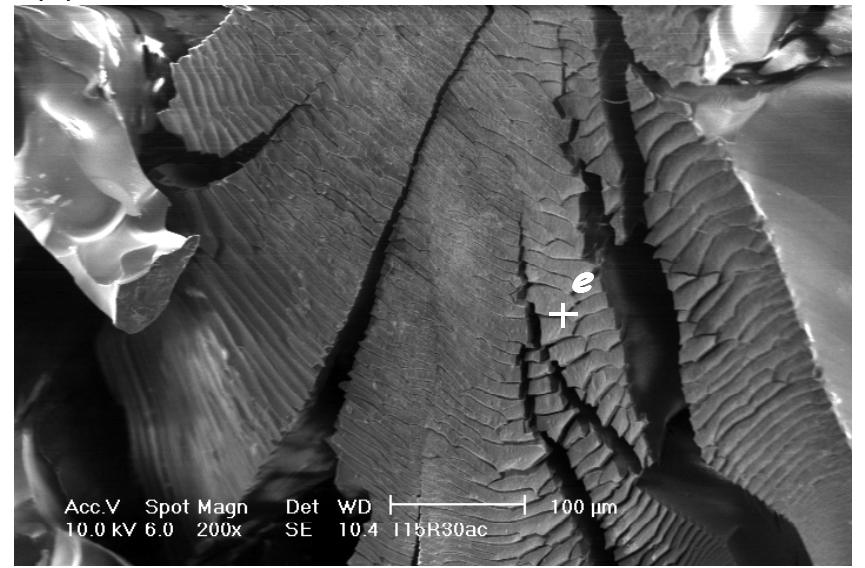

(c) T15R30
Microanálise

T05R10

Elem.

Massa \%

(a) (b) (c)

Al $\quad 6,92 \quad 5,99 \quad 5,95$

Si $\quad 93,08 \quad 94,01 \quad 94,05$

Na $\quad 0,00 \quad 0,00 \quad 0,00$

Ca $\quad 0,00 \quad 0,00 \quad 0,00$

Total $100,00 \quad 100,00 \quad 100,00$

Microanálise

T10R20

Elem. Massa\%

(d)

Al 2,29

Si $\quad 97,71$

$\mathrm{Na} \quad 0,00$

Ca $\quad 0,00$

Total 100,00

Microanálise

T15R30

Elem. Massa\%

(e)

$\begin{array}{lc}\text { Al } & 4,70 \\ \text { Si } & 97,47 \\ \text { Na } & 0,00 \\ \text { Ca } & 0,00 \\ \text { Total } & 100,00\end{array}$

FIGURA 5.37 - Superfície de amostras das composições TR após o ataque ácido: (a) T05R10, (b) T10R20 e (c) T15R30 (MEV-EDS) 


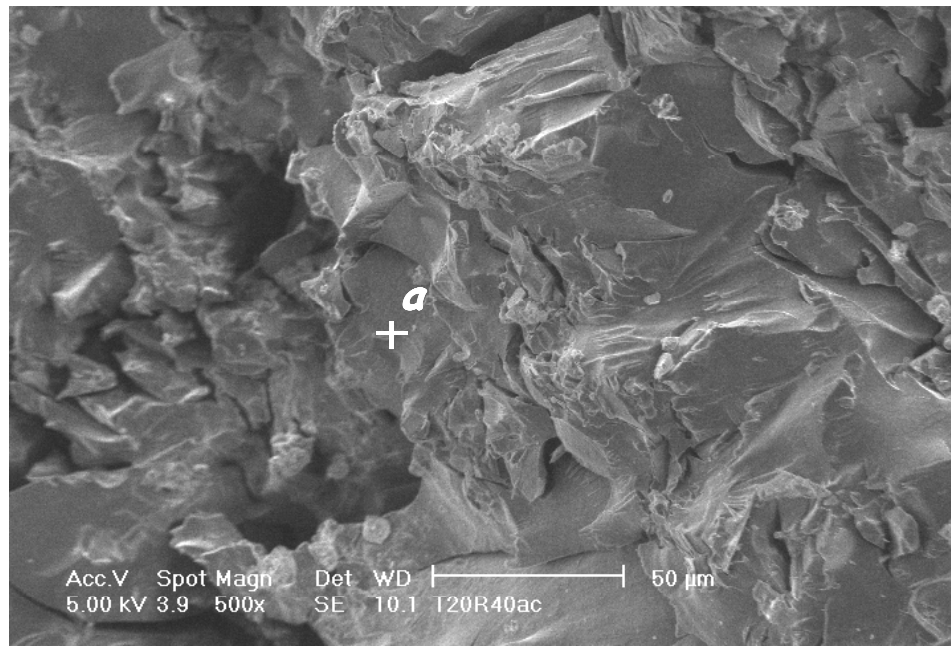

\section{T20R40}

Elem. Massa\%

$\begin{array}{lc} & \mathbf{( a )} \\ \text { Al } & 1,17 \\ \text { Si } & 139,07 \\ \mathbf{N a} & 0,00 \\ \text { Ca } & 0,00 \\ \text { Total } & 100,00\end{array}$

(a) T20R40

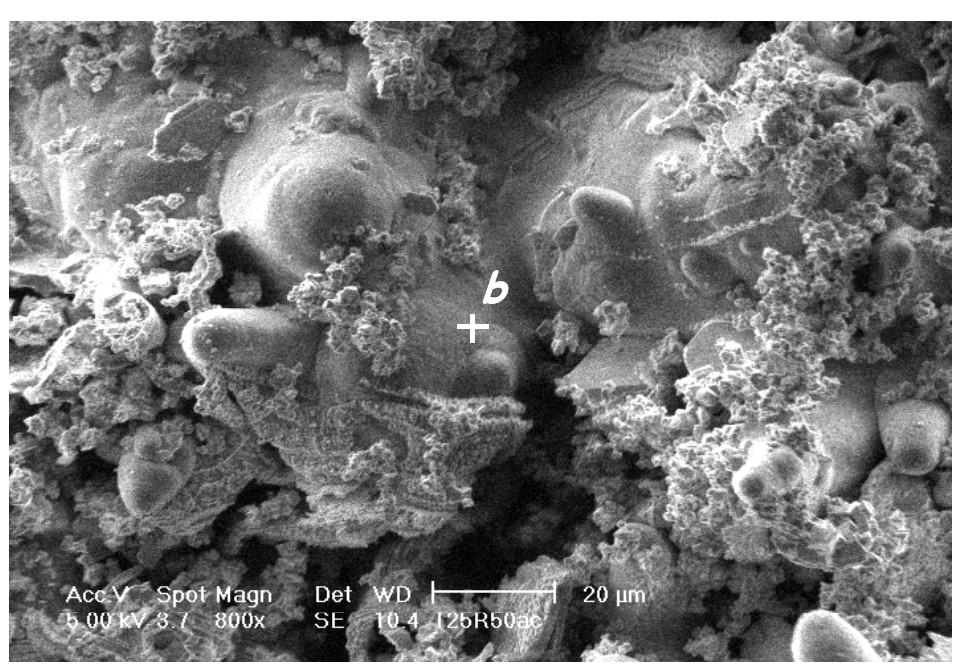

Microanálise

T25R50

Elem. Massa\%

$\begin{array}{lc} & (\mathbf{b}) \\ \text { Al } & 0,74 \\ \mathrm{Si} & 71,78 \\ \mathrm{Na} & 0,00 \\ \mathrm{Ca} & 0,00 \\ \mathrm{Cr} & 27,48 \\ \text { Total } & 100,00\end{array}$

(b) $T 25 R 50$

FIGURA 5.38 - Superfície de amostras das composições TR após o ataque ácido: (a) T20R40 e (b) T25R50 (MEV-EDS)

A Fig. 5.39 mostra os espectros obtidos pela técnica de FT-IR para os vidros TC e TR após o ataque ácido. Comparando-se estes resultados com os obtidos para as mesmas composições antes do ataque (Fig. 5.14), observa-se que todas as estruturas foram envolvidas na dissolução, ou seja, ocorre em ambas as séries de vidros após ataque ácido, uma significativa redução na intensidade das bandas correspondentes às freqüências 1010,780, e $460 \mathrm{~cm}^{-1}$, referentes aos pontos 1, 2, e 3, Fig. 5.39). Entretanto os vidros T05R10 e T10R20 apresentam maior estabilidade. 
A remoção da sílica segregada e dos dímeros de tetraedros é indicada pela significativa redução na intensidade das bandas relativas às ligações associadas à sílica do tipo $Q^{0}$ e $Q^{1}$ (pontos 7 e 8), nos vidros TC e TR.

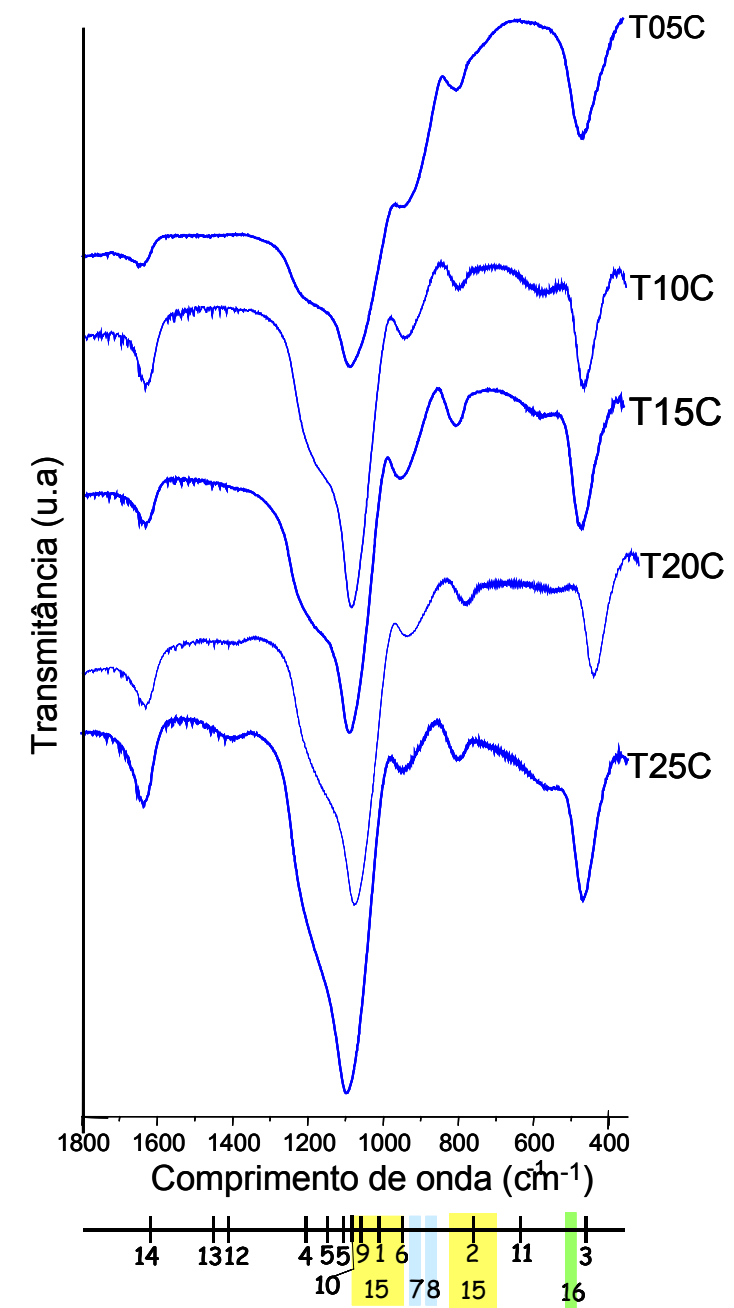

(a) Série TC

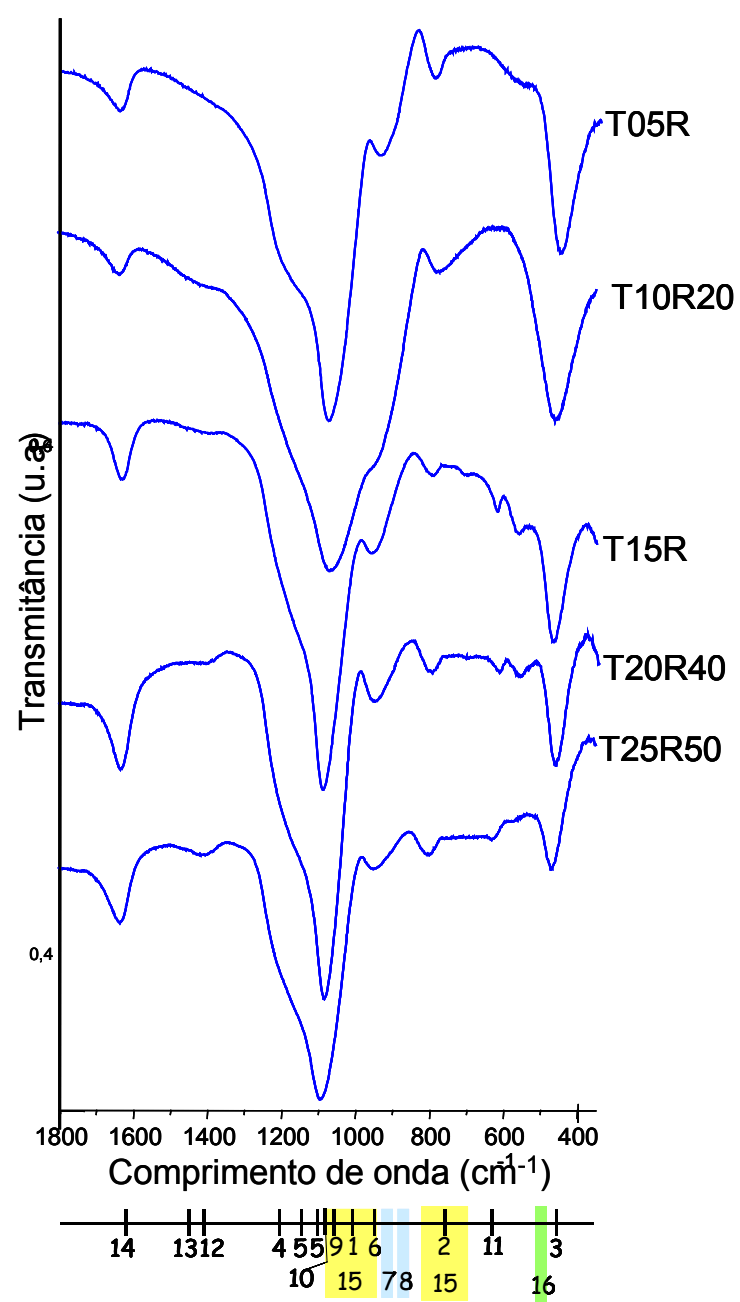

(b) Série TR

(1) Superfície de tetraedros $\mathrm{SiO}_{4}$; (2) Ligações entre tetraedros $\mathrm{SiO}_{4}$; (3) Si-O-Si [Q $\left.{ }^{4}\right]$;

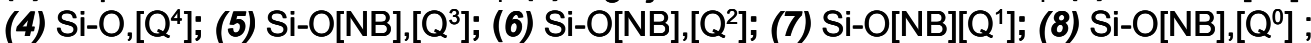

(9) Si-O-Si; (10) Si-O-[NB], plano ; (11) Si-O-B Estrutural; (12) B-O Livre; (13) Na-O;

(14) Água livre; (15) Silicatos de metais; (16) Óxidos metálicos segregados.

FIGURA 5.39 - Espectros de FT-Irde amostras das composições TC e TR após ataque ácido

Nos vidros contendo RSG (série TR), as bandas para as estruturas $Q^{4} \mathrm{e}$ $Q^{3}$, são menos alteradas que nos vidros TC (pontos 4 e 5 na figura).

Nos vidros das duas séries observa-se que as ligações com os tetraedros de sílica formados com cálcio (vidros TC) ou com metais de transição 
(vidros TR) foram também envolvidos no processo de dissolução (banda entre 950 e $1050 \mathrm{~cm}^{-1}$, indicada por 15 nas figuras). Estes resultados indicam que a dissolução ocorre principalmente nas NBO's (oxigênios não ponte) envolvendo modificadores $\left(\mathrm{R}^{2+}\right.$ nos vidros $\left.\mathrm{TC}\right)$.

Os difratogramas de raios $\mathrm{X}$ correspondentes aos pós dos vidros TC, e TR, após serem submetidos ao ataque ácido, são apresentados nas Fig. 5.40 e 5.41 , respectivamente.

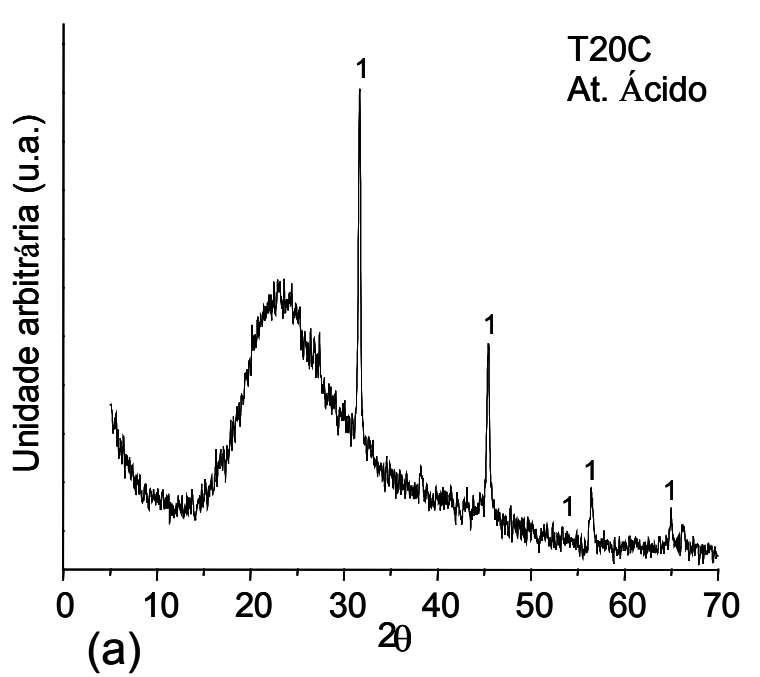

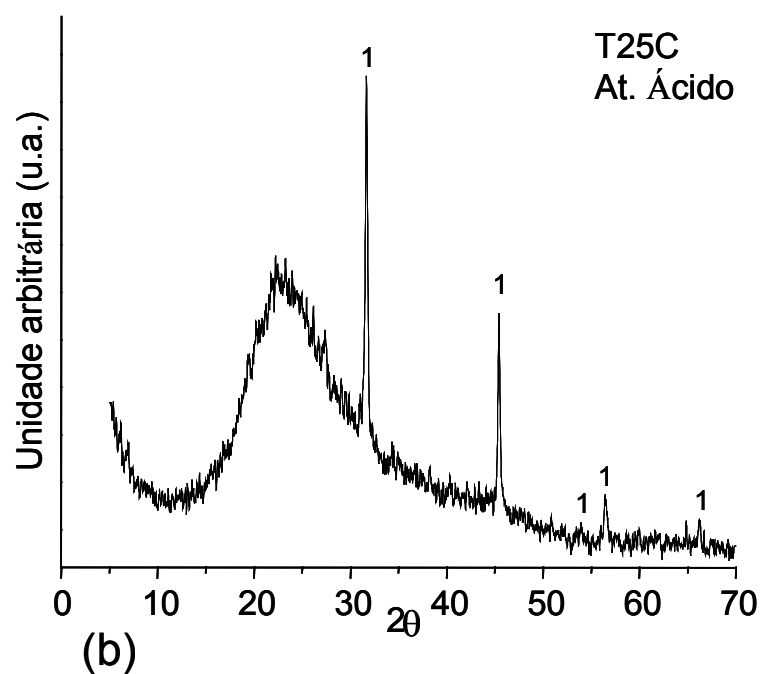

(b)

$1-\mathrm{NaCl}$

FIGURA 5.40 - Difratogramas obtidos por DRX a partir de amostras das composições TC, após o ensaio de ataque ácido: (a) T20C e (b) T25C

Nos vidros TC (Fig. 5.40) observa-se um estreitamento relativo no halo de possível cristalização em $2 \theta$ entre $10^{\circ}$ e $40^{\circ}$, quando comparado aos difratogramas dos vidros antes do ataque (Fig. 5.5), A fase cristalizada observada nos difratogramas dos vidros T20C e T25C, foi identificada como $\mathrm{NaCl}$ (PDF 78-0751). Este $\mathrm{NaCl}$, é produzido durante o ataque ácido pela reação entre o $\mathrm{Na}_{2} \mathrm{O}$ extraído do vidro pelo mecanismo de ataque protônico e o $\mathrm{HCl}$ utilizado da solução de ataque, e indica que o processo de dissolução ocorreu nestes vidros principalmente nos tetraedros de sílica $Q^{0}$ e $Q^{1}$, ou seja, nas regiões da matriz vítrea mais ricas em álcalis fundente e modificadores. Tais resultados estão de acordo com as micrografias (Fig. 5.33) e as análises por FTIR (Fig. 5.39) para estes vidros. O mesmo comportamento foi também observado nos vidros TR (Fig. 5.41). Nos difratogramas correspondentes a estes vidros (Fig. 5.40) observar-se 
os picos correspondentes ao $\mathrm{Cr}_{2} \mathrm{O}_{3} ; \mathrm{Ni}\left(\mathrm{CrO}_{4}\right) ; \mathrm{Cu}_{2} \mathrm{~S} ; \mathrm{e}, \mathrm{Ni}_{3} \mathrm{~S}_{2}$, os quais não foram removidos durante o ataque ácido. $\mathrm{A}$ exceção foi para $\circ \mathrm{Ca}_{3}\left(\mathrm{CrO}_{4}\right)_{2}$, que não foi observado, ou seja, o mesmo se solubilizou durante $o$ ataque.

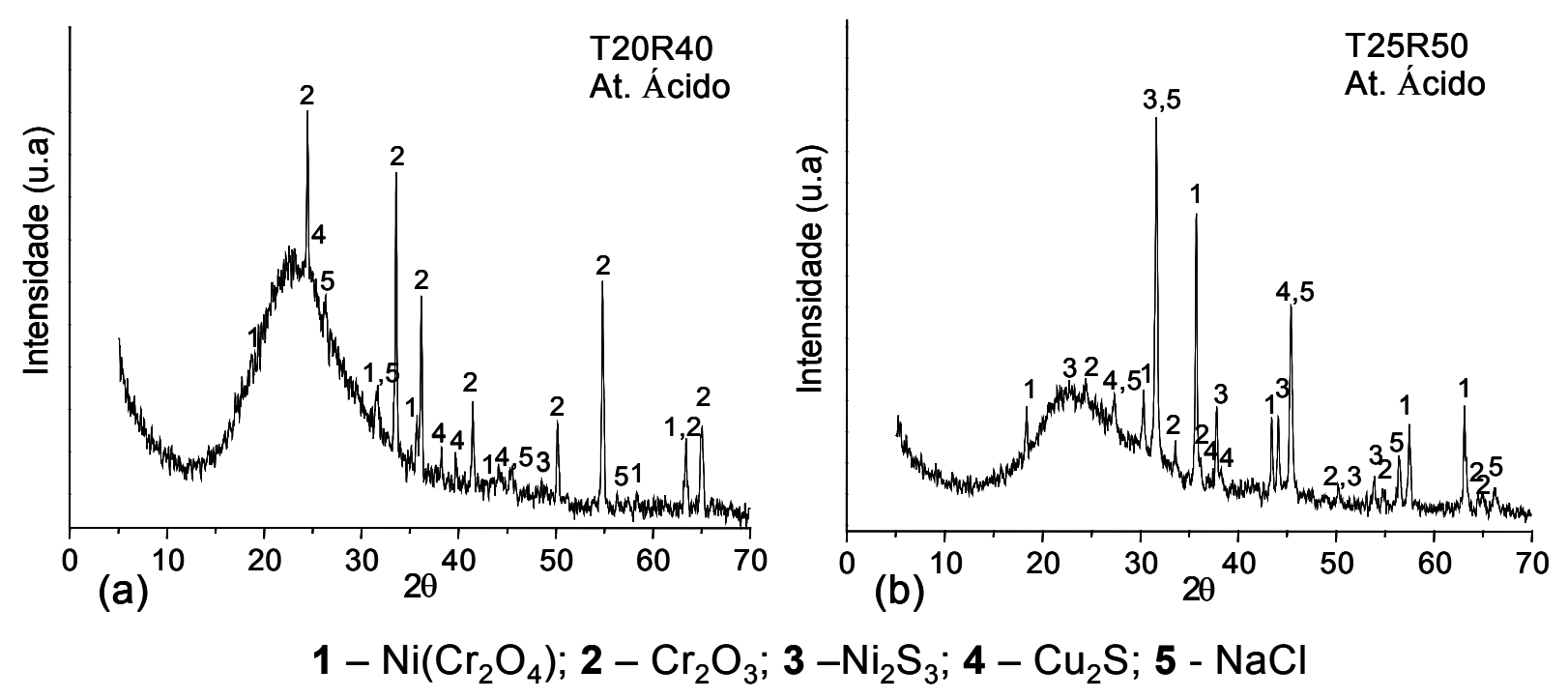

FIGURA 5.41 - Difratogramas obtidos por DRX a partir de amostras das composições TR, após o ensaio de ataque ácido: (a) T20R40 e (b) T25R50.

\subsubsection{3 - Resistência ao ataque alcalino}

Os vidros TC, TR e VR foram submetidos ao teste de resistência ao ataque alcalino, de acordo com a norma ISO 695-1984 (E) ${ }^{(237)}$. Na Fig. 5.42 são expressos os resultados das taxas de dissolução em função da concentração de modificadores. Todos os vidros foram classificados como "pouco atacáveis", segundo a norma. Os vidros contendo resíduo galvânico (TR) apresentam uma resistência ao ataque alcalino superior aos vidros formulados com base em cálcio (TC) e, similar ao vidro VR. Para os vidros TC, o aumento da resistência ocorre em função do aumento da concentração do modificador (cálcio). Entretanto, nos vidros contendo resíduo galvânico, ou seja, vidros TR, a resistência ao ataque alcalino praticamente não varia em função da concentração de metais de transição.

Segundo a literatura $\mathrm{o}$ ataque em meio alcalino nos vidros silicato ocorre com o rompimento das ligações $\mathrm{Si}-\mathrm{O}-\mathrm{Si}{ }^{(23,24)}$ pelo íon $\mathrm{OH}^{-}$. A presença de óxidos $\mathrm{R}_{2} \mathrm{O}_{3}$, tais como o $\mathrm{B}_{2} \mathrm{O}_{3}$ e o $\mathrm{Al}_{2} \mathrm{O}_{3}$ e dos óxidos $\mathrm{RO}$, tais como $\mathrm{ZnO}$ e $\mathrm{MgO}$ 
aumentam a resistência ao ataque alcalino, mesmo quando presentes em pequenas quantidades. A presença óxidos $\mathrm{R}_{2} \mathrm{O}_{3}$ formados pelos metais de transição pode explicar a maior resistência ao ataque dos vidros TR.

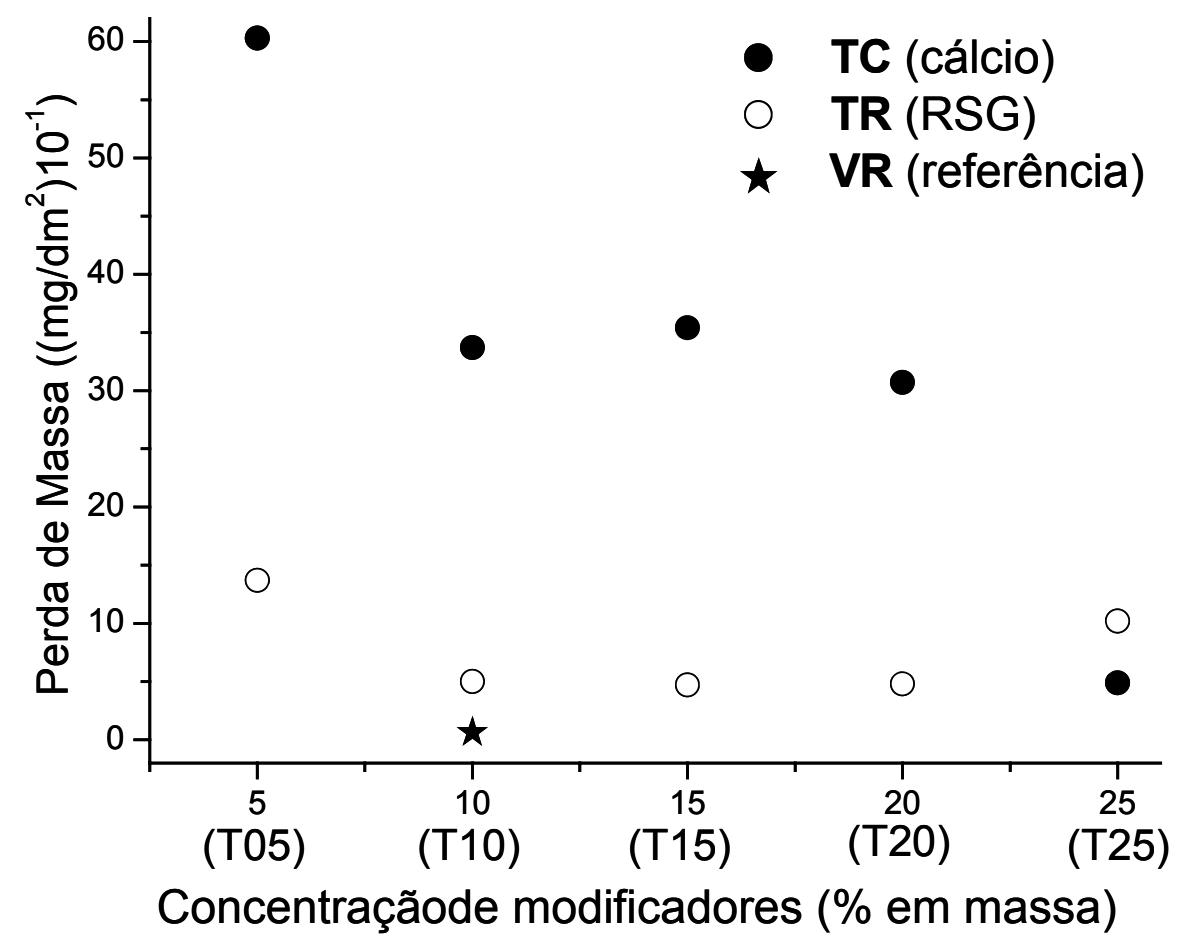

FIGURA 5.42 - Taxa de dissolução em função da concentração de modificadores obtidas no ensaio de resistência ao ataque alcalino de amostras das composições TC, TR e VR.

As micrografias correspondentes a secção transversal dos vidros TC e TR, após o ataque alcalino são apresentadas na Fig. 5.43.

Em nenhuma amostra analisado foi observada a formação de camada superficial, pois provavelmente todo o produto da corrosão dissolveu-se ou desprendeu-se da superfície do vidro. Este fato indica que a corrosão provocada pelo ataque alcalino foi uniforme, ou seja, além da extração de álcalis e de modificadores, a rede de silício também foi dissolvida durante a exposição ao ataque o que, caracterizada desta forma o rompimento das ligações Si-O-Si pelo íon $\mathrm{OH}^{-}$. 


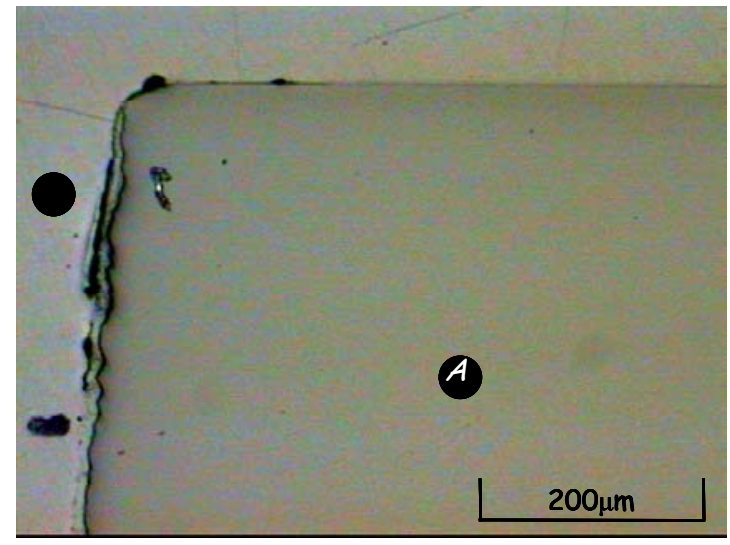

(a) T05C

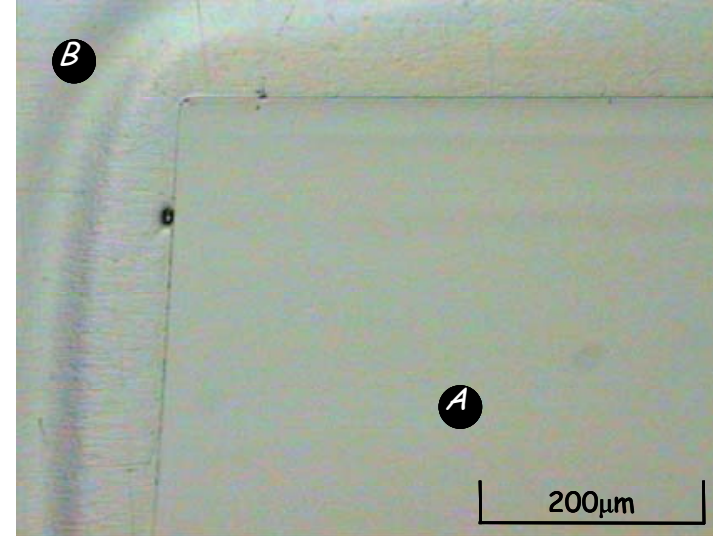

(b) T15C

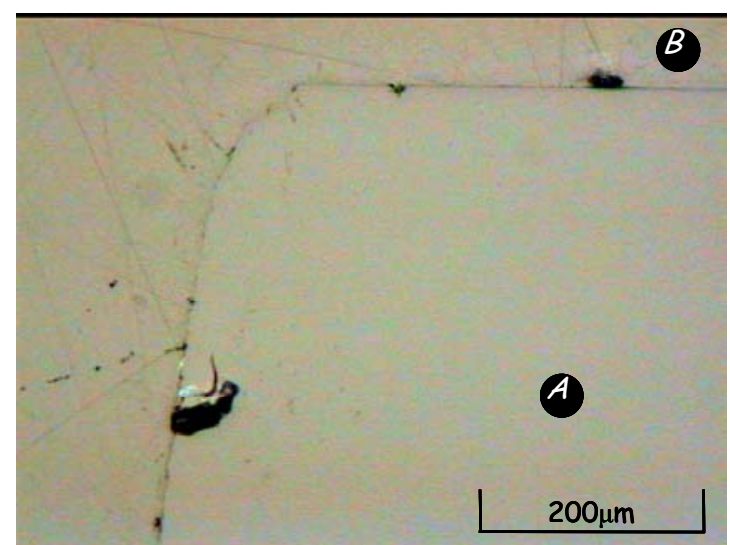

(c) T25C

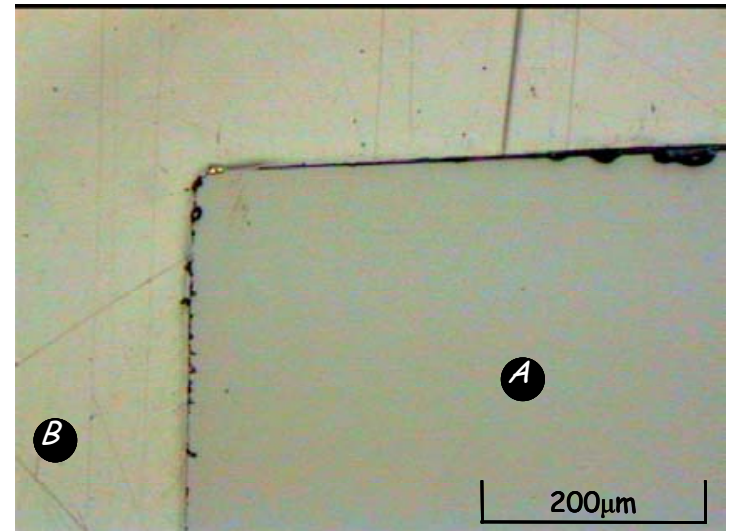

(d) T05R10

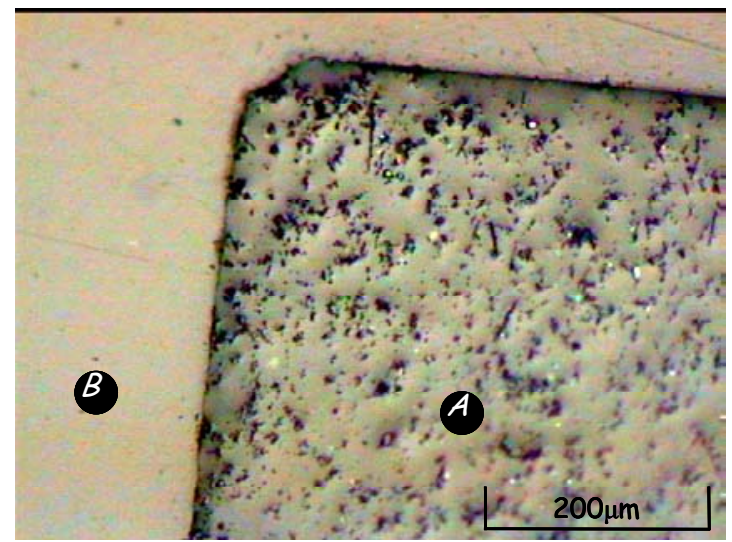

(e) T15R30

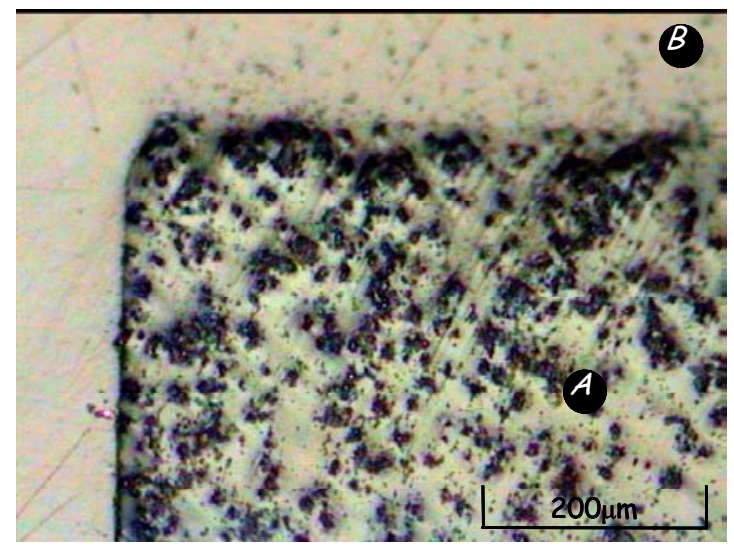

(f) $\mathrm{T} 25 \mathrm{R} 50$

\section{(A) matriz vitrea; $B$ resina do suporte}

FIGURA 5.43 - Micrografias correspondentes á secção transversal de amostras das composições TC e TR, após o ataque alcalino 
As Fig. 5.44 a 5.47 apresentam micrografias obtidas por MEV-EDS das superfícies dos vidros das séries TC, e TR, após o ataque alcalino. Nas micrografias correspondentes aos vidros TC observa-se a formação de trincas ou desprendimento de parte da superfície. De forma geral as imagens apontam que o processo de dissolução teve ocorreu um comportamento uniforme, com pouca alteração da composição química da superfície, segundo os resultados das microanálise por EDS. Apenas para T15C, não foi detectada a presença de cálcio.

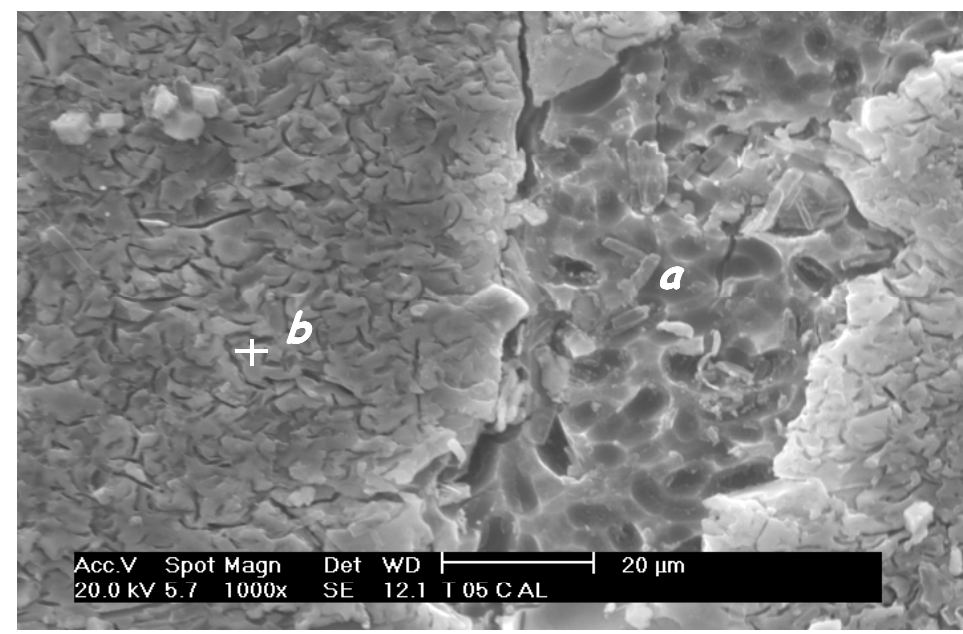

(a) T05C

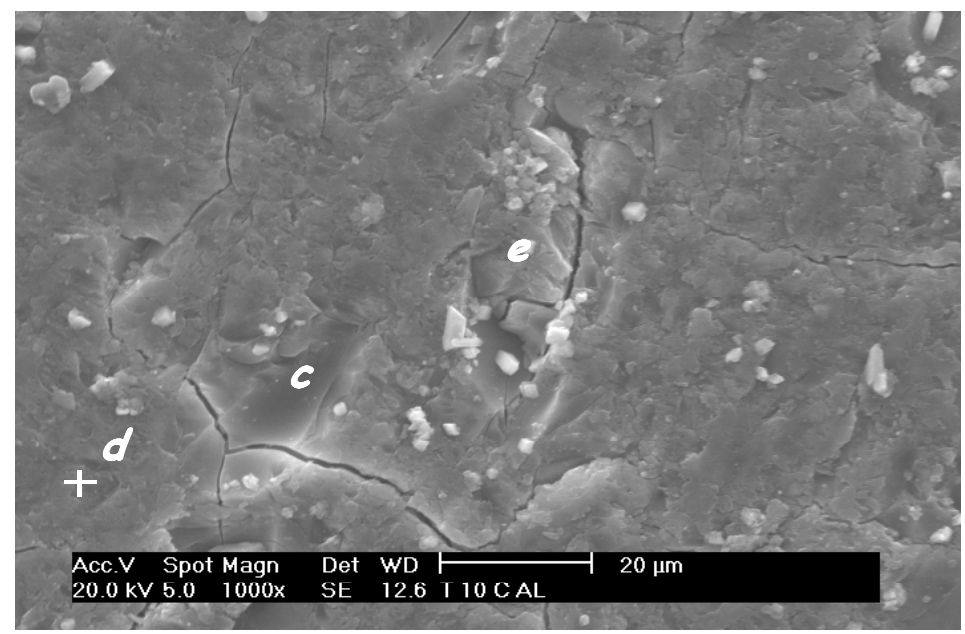

(b) T10C

\section{Análişoânálise \\ T05C \\ Elem. Massa\% \\ (a) (b) \\ $\mathrm{Na} \quad 11,8 \quad 13,26$ \\ $\begin{array}{lll}M g & 0,73 & 0,74\end{array}$ \\ Al $\quad 6,63 \quad 15,02$ \\ Si $\quad 71,17 \quad 67,54$ \\ K $\quad 2,01 \quad 0,73$ \\ $\mathrm{Ca} \quad 7,66 \quad 2,72$ \\ Total 100100}

FIGURA 5.44- Superfície de amostras das composições TC após o ataque alcalino: (a) T05C e (b) T10C (MEV-EDS)

Nos vidros da série TR, não se observa transformações superficiais significativas. No vidro T20R40 (Fig. 5.47(a)) a permanência dos 
cristais de cromita após o ataque é observada. A análise da composição na superfície desses vidros revela a permanência dos metais de transição mesmo após o ataque.
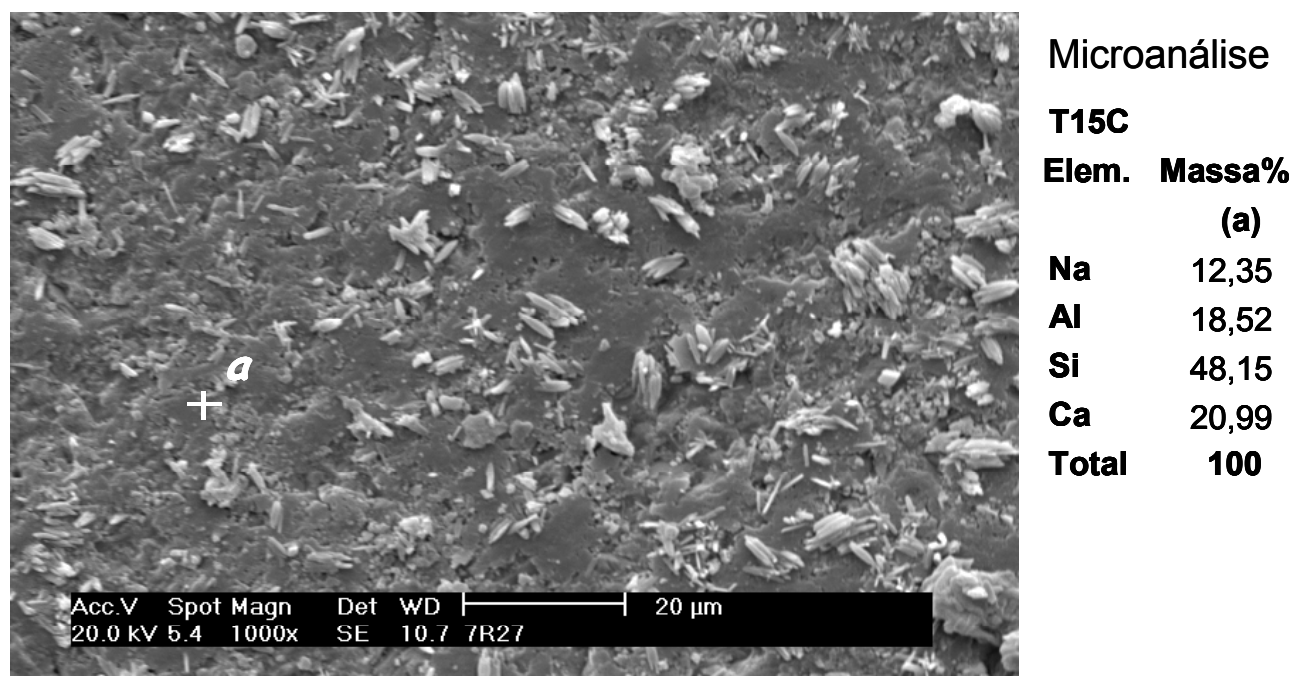

(a) $\mathrm{T} 15 \mathrm{C}$

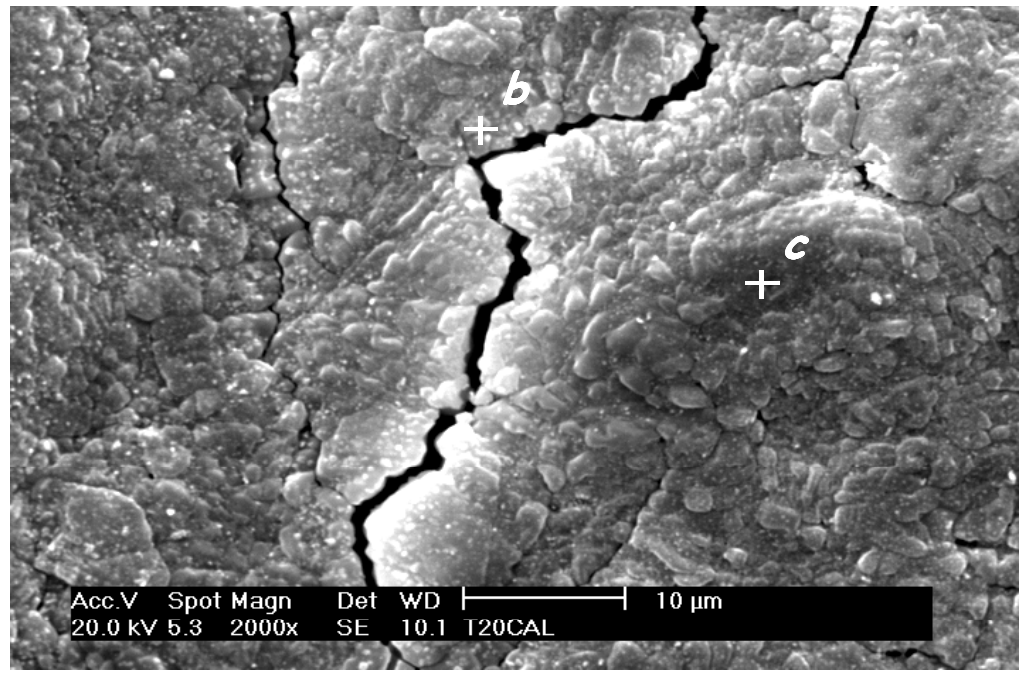

Microanálise

T20C

Elem. Massa\%

$\begin{array}{lcc} & \mathbf{( g )} & \mathbf{( h )} \\ \mathbf{N a} & 70,5 & 86,39 \\ \mathbf{S i} & 29,5 & 13,61 \\ \text { Total } & \mathbf{1 0 0} & \mathbf{1 0 0}\end{array}$

(b) T20C

FIGURA 5.45 - Superfície de amostras das composições TC após o ataque alcalino: (a) T15C e (b) T20C (MEV-EDS)

As curvas relativas aos espectros de FTIR dos vidros TC e TR pulverizados e submetidos ao ataque alcalino são mostradas na Fig. 5.48. Comparando-se os espectros para os vidros TC antes e depois do ataque alcalino (Fig. 5.14(a), e Fig. 5.48(a) respectivamente), observa-se que para os vidros T05C, T10C e T15C, os espectros são similares. 


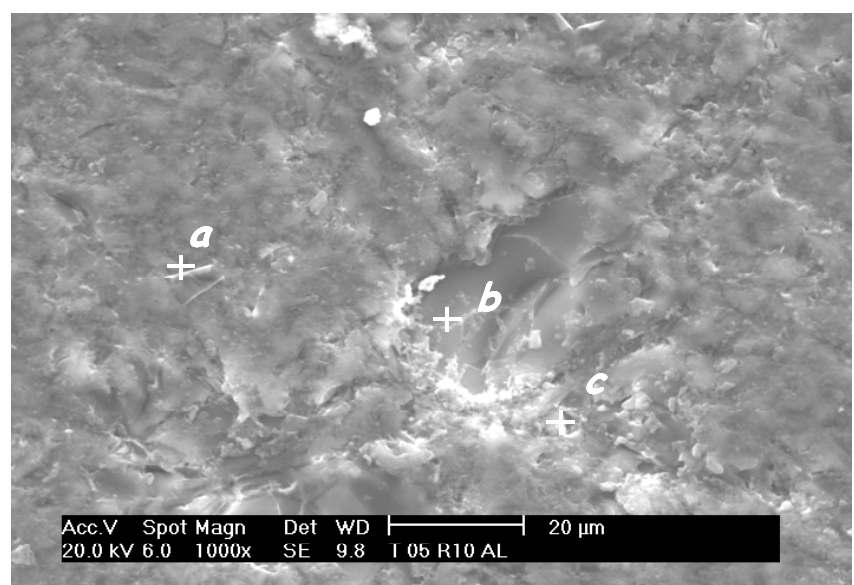

(a) T05R10

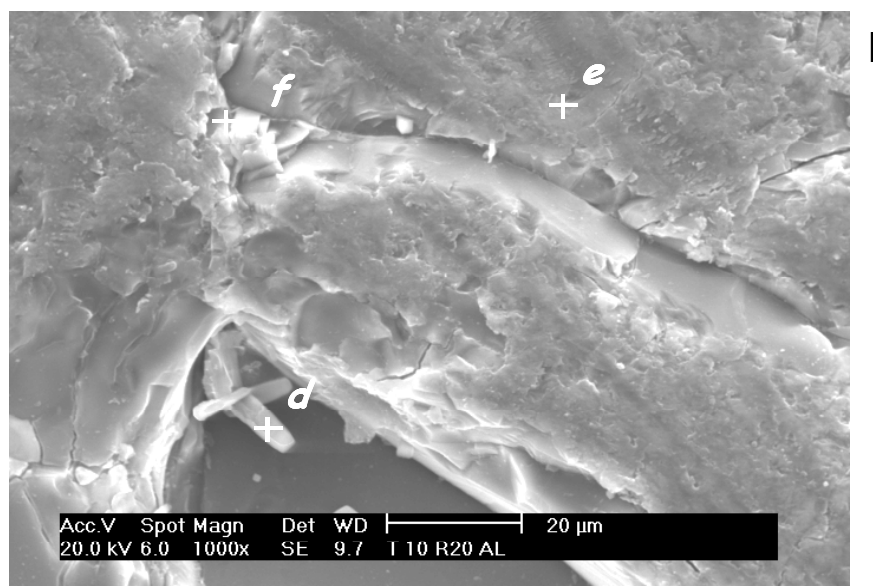

(b) T10R20

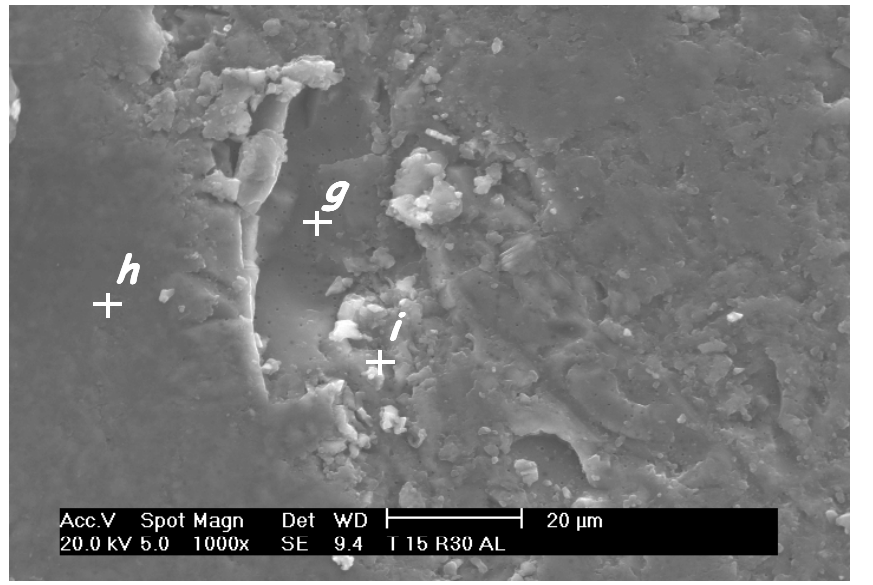

\section{Microanálise}

\begin{tabular}{lccc}
$\begin{array}{l}\text { T15R30 } \\
\text { Elam. }\end{array}$ & \multicolumn{3}{c}{ Massa\% } \\
& $\mathbf{( g )}$ & $\mathbf{( h )}$ & $\mathbf{( i )}$ \\
$\mathbf{N a}$ & 11,43 & 12,98 & 20,83 \\
$\mathbf{M g}$ & 1,69 & 1,86 & 1,61 \\
$\mathbf{A l}$ & 9,63 & 11,09 & 9,86 \\
$\mathbf{S i}$ & 56,10 & 55,06 & 51,40 \\
$\mathbf{K}$ & 2,18 & 2,39 & 2,31 \\
$\mathbf{C a}$ & 7,24 & 4,96 & 4,96 \\
$\mathbf{C r}$ & 6,78 & 6,92 & $\mathbf{5 , 2 7}$ \\
$\mathbf{N i}$ & 4,95 & $\mathbf{4 , 7 3}$ & 3,75 \\
Total & $\mathbf{1 0 0 , 0 0}$ & $\mathbf{1 0 0 , 0 0}$ & $\mathbf{1 0 0 , 0 0}$
\end{tabular}

(c) T15R30

FIGURA 5.46 - Superfície de amostras das composições TR após o ataque alcalino: (a) T05R10, (b) T10R20 e (c) T15R30 (MEV-EDS)

Nestes vidros observa-se apenas pequenas alterações para as bandas associadas as ligações formadas pelos tetraedros de sílica $Q^{1}$ e $Q^{0}$ 
(pontos 7 e 8 nas figuras) e na banda associada a ligação $\mathrm{Na}-\mathrm{O}$ (13 nas figuras). Este resultado indica que para estes vidros a dissolução em meio alcalino, ocorreu de uma forma homogênea para todas as estruturas do vidro. Contudo, nestes vidros T20C e T25C, observa-se uma alteração do pico associado as ligações entre tetraedros de sílica $Q^{2}$ (13 nas figuras). Neste caso a dissolução pode estar envolvendo mais intensamente as estruturas associadas ao modificador $\mathrm{CaO}$.

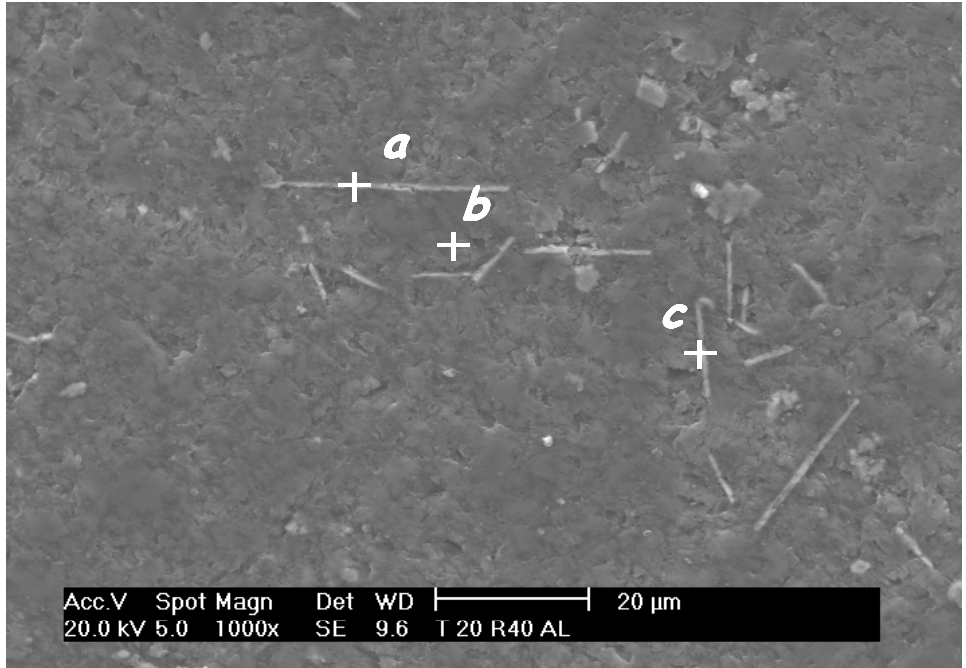

\begin{tabular}{|c|c|c|c|}
\hline \multicolumn{3}{|c|}{ T20R40 } & \\
\hline & (a) & (b) & (c) \\
\hline $\mathrm{Na}$ & 13,28 & 11,37 & 7,34 \\
\hline Mg & 1,35 & 1,48 & 1,76 \\
\hline Al & 9,00 & 14,04 & 3,45 \\
\hline Si & 26,27 & 51,51 & 7,93 \\
\hline $\mathbf{K}$ & 0,94 & 2,42 & 0,29 \\
\hline $\mathbf{C a}$ & 3,68 & 9,80 & 1,18 \\
\hline $\mathrm{Cr}$ & 42,31 & 2,98 & 52,01 \\
\hline $\mathbf{N i}$ & 3,17 & 6,40 & 17,67 \\
\hline Zn & 0,00 & 0,00 & 8,37 \\
\hline
\end{tabular}

(a) T20R40

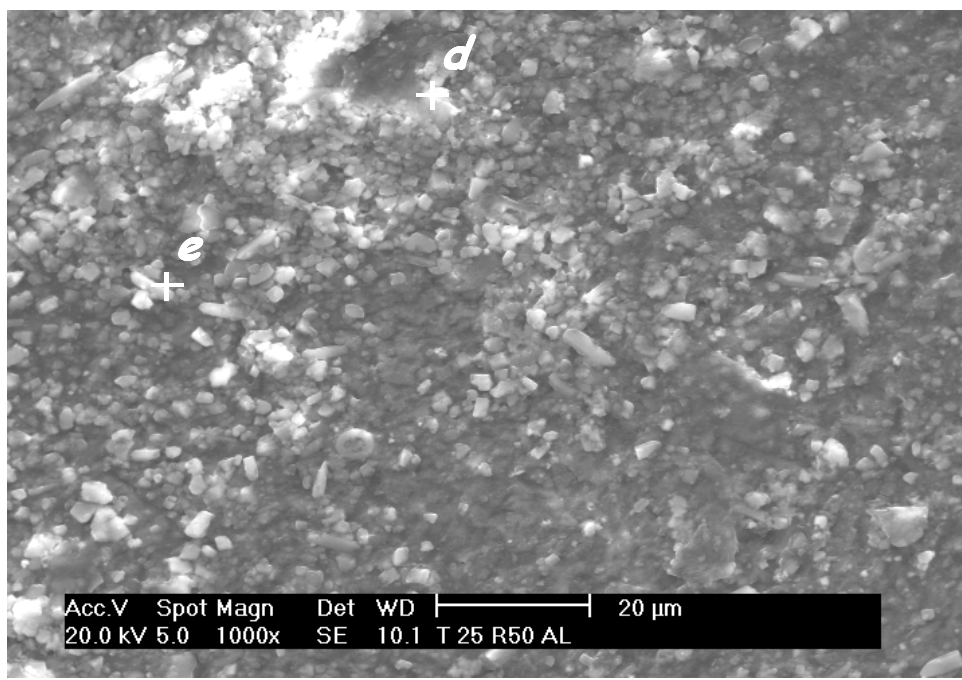

Microanálise

\begin{tabular}{lcc}
$\begin{array}{l}\text { T25R50 } \\
\text { Elem. }\end{array}$ & \multicolumn{2}{c}{ Massa\% } \\
& (d) & $\mathbf{( e )}$ \\
$\mathbf{N a}$ & 7,80 & 12,48 \\
$\mathbf{M g}$ & 2,15 & 2,45 \\
$\mathbf{A l}$ & 7,36 & 11,04 \\
$\mathbf{S i}$ & 25,18 & 38,63 \\
$\mathbf{K}$ & 1,12 & 2,04 \\
$\mathbf{C a}$ & 25,91 & 25,79 \\
$\mathbf{C r}$ & 19,87 & 3,40 \\
$\mathbf{N i}$ & 10,61 & 4,16 \\
Total & $\mathbf{1 0 0 , 0 0}$ & $\mathbf{1 0 0 , 0 0}$
\end{tabular}

(b) T25R50

FIGURA 5.47 - Superfície de amostras das composições TR após o ataque alcalino: (a) T20R40 e (b) T25R50 (MEV-EDS) 


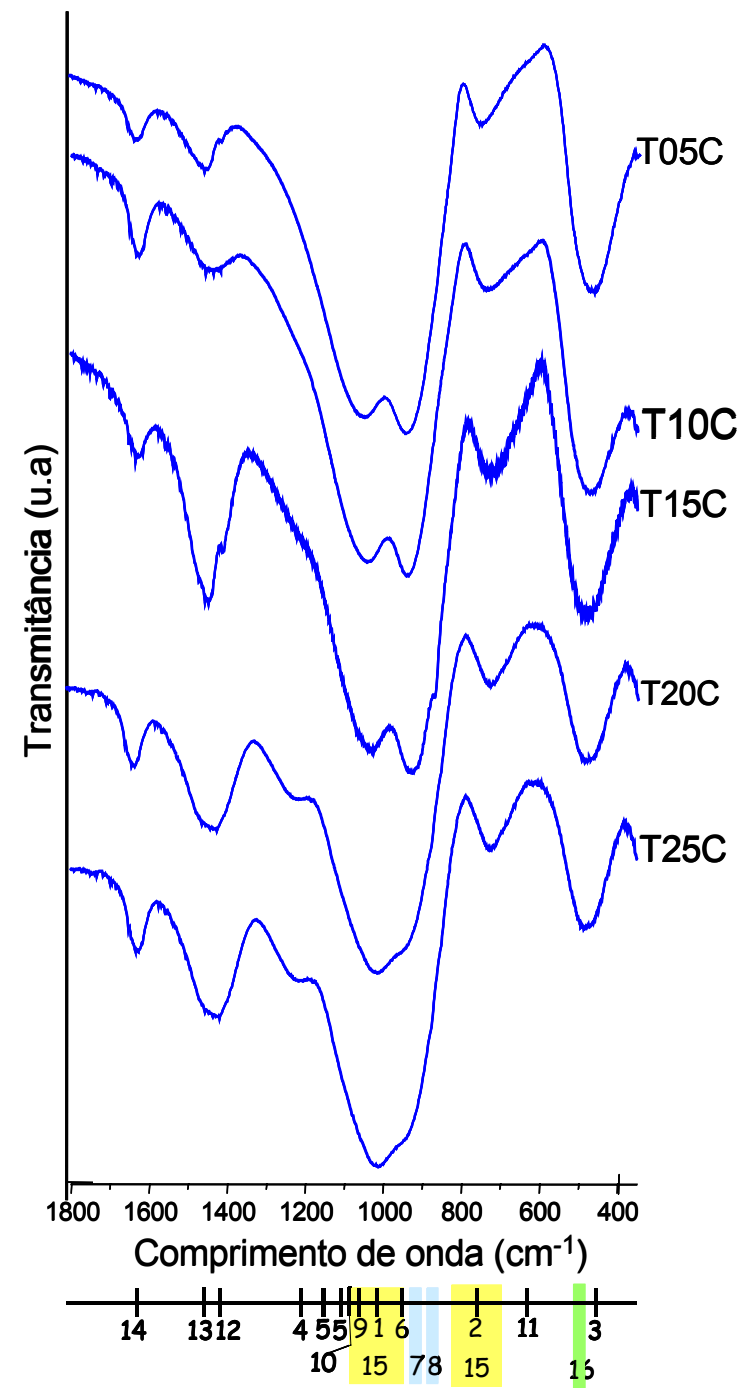

(a) Série TC

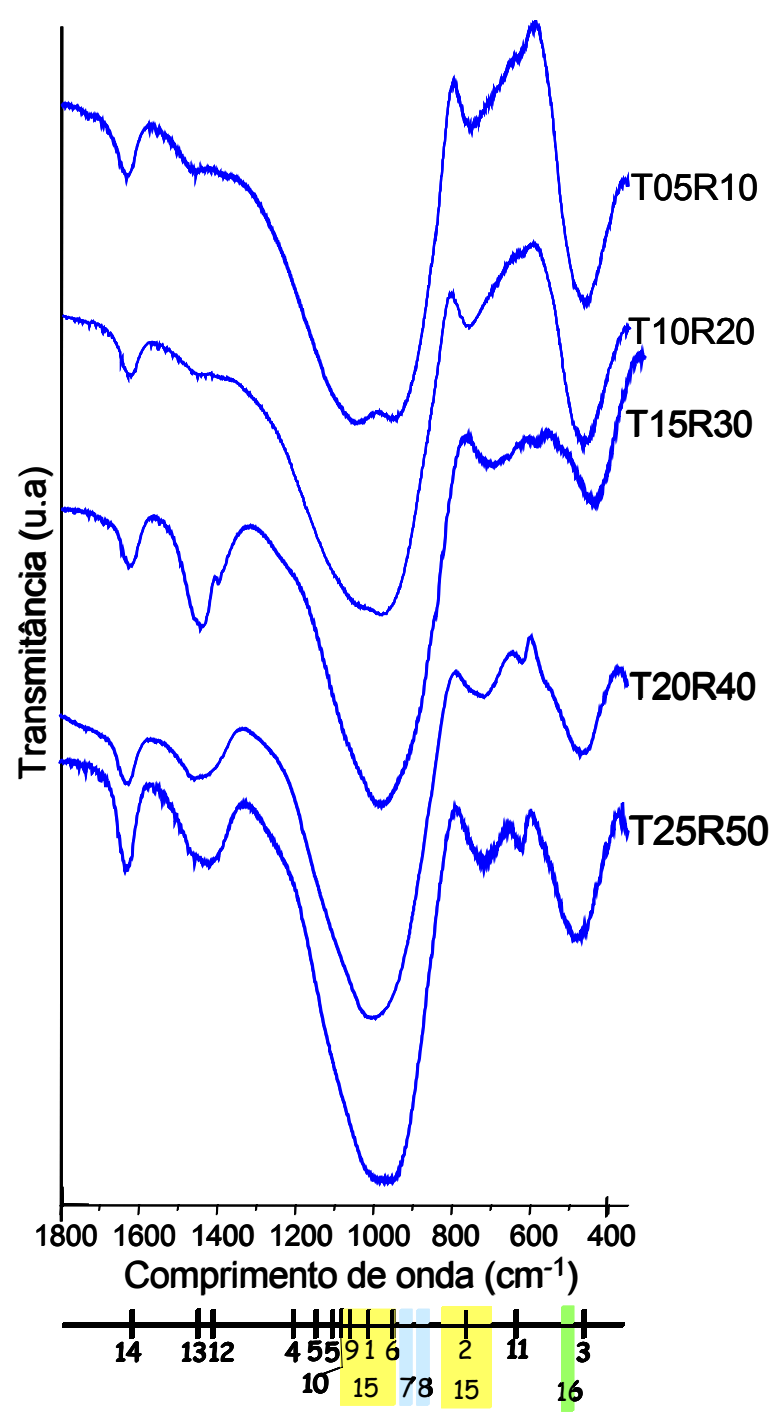

(b) Série TR

(1) Superfície de tetraedros $\mathrm{SiO}_{4}$; (2) Ligações entre tetraedros $\mathrm{SiO}_{4}$; (3) Si-O-Si [Q4];

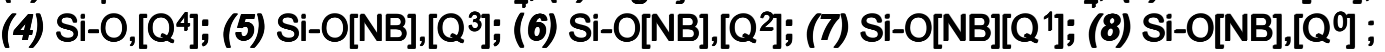

(9) Si-O-Si; (10) Si-O-[NB], plano ; (11) Si-O-B Estrutural; (12) B-O Livre; (13) Na-O;

(14) Água livre; (15) Silicatos de metais; (16) Oxidos metálicos segregados.

FIGURA 5.48 - Espectros de FT-IR de amostras das composições TC e TR após ataque alcalino

Comparando-se os espectros dos vidros TR, antes e depois do ataque alcalino (Fig. 5.18(b), e Fig. 5.48(b) respectivamente), observa-se que são similares para todos os vidros. De modo geral, após o ataque as bandas associadas as ligações entre tetraedros de sílica $Q^{0}$ e $Q^{1}$ (7 e 8 nas 
figuras) revelaram a intensidade espectral relativa reduzida e a distribuição da estrutura parece concentrar-se entre $Q^{3}$ e $Q^{2}$ (5 e 6 nas figuras, respectivamente) e, nas combinações de silicatos com os modificadores (15 na figura). A banda relativa às ligações $\mathrm{B}-\mathrm{O}-\mathrm{Si}$ (11 nas figuras) mostra que estas são pouco envolvidas na dissolução em meio alcalino. Tais resultados indicam que durante o ataque alcalino, o comportamento de dissolução é muito similar entre os vidros TC e TR.

Os espectros DRX correspondentes aos vidros TC e TR após o ataque alcalino são mostradas nas Fig. 5.49 e 5.50, respectivamente. Estes difratogramas, não apresentam alterações em relação aos vidros antes do ataque (Fig. 5.5 e 5.6). Nos vidros TR observa-se a permanência das fases anteriormente observadas, com exceção do $\mathrm{Ca}_{3}\left(\mathrm{CrO}_{4}\right)_{2}$.
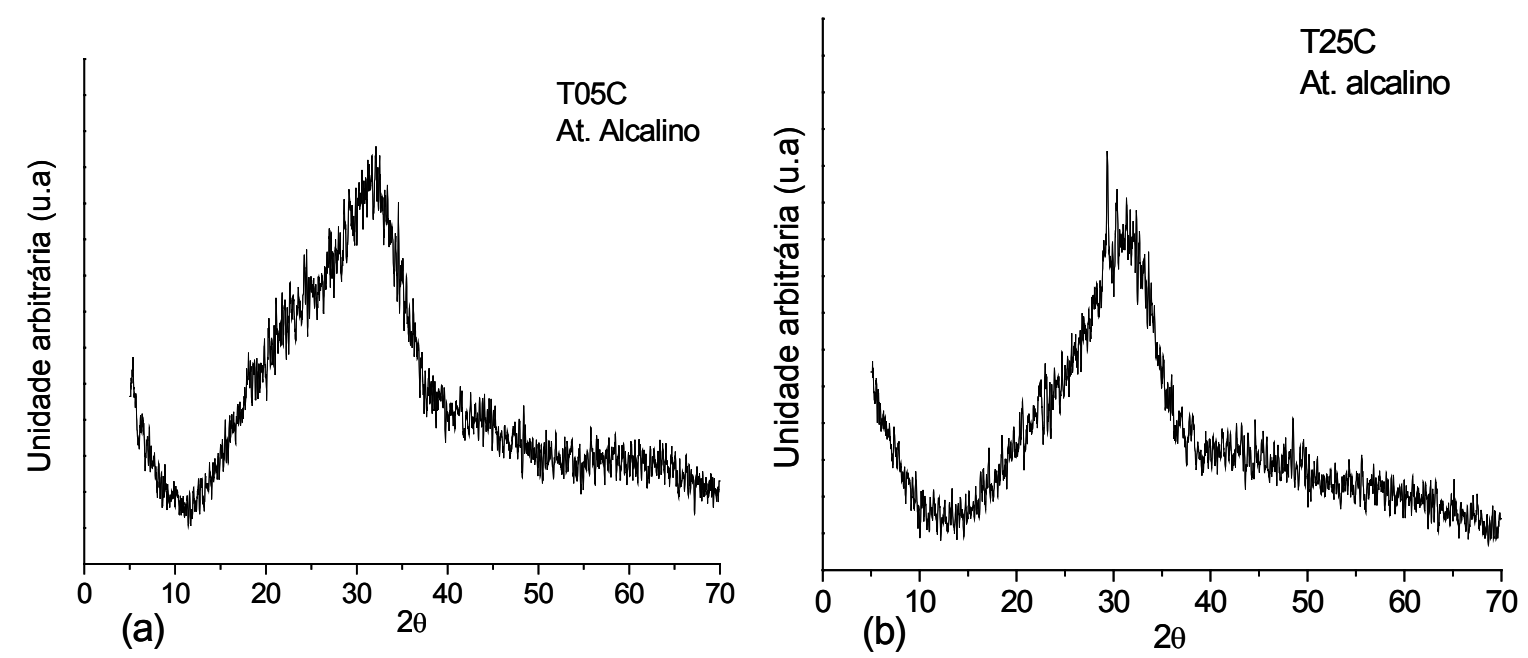

FIGURA 5.49 - Difratogramas obtidos por DRX a partir de amostras das composições TC, após o ensaio de ataque alcalino: (a) T05C e (b) T25C 


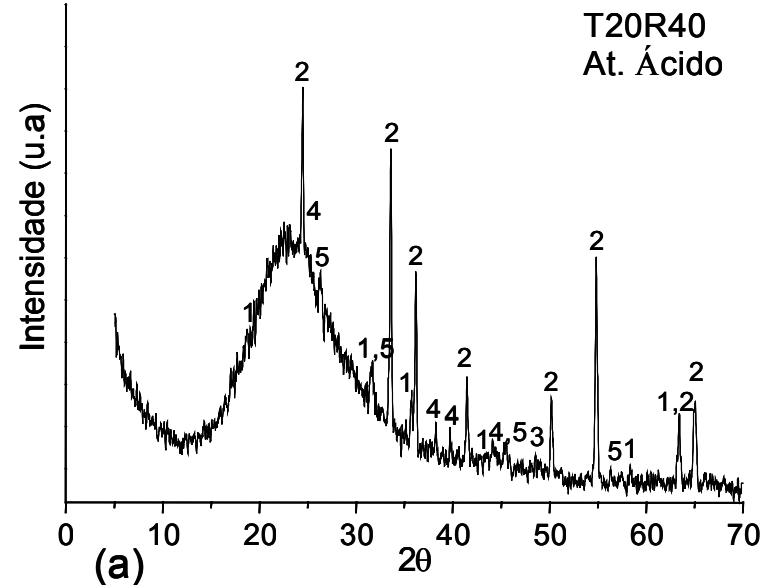

(a)

T20R40

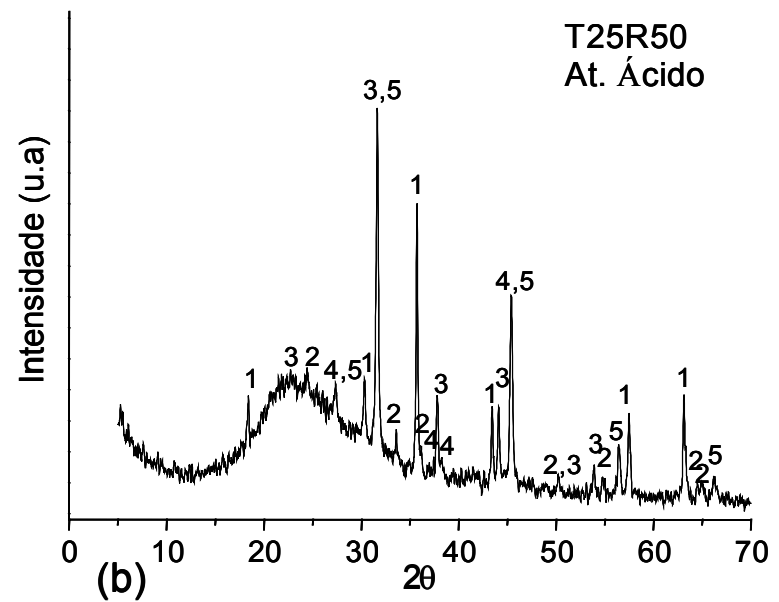

(b)

$$
1-\mathrm{Ni}\left(\mathrm{Cr}_{2} \mathrm{O}_{4}\right) ; 2-\mathrm{Cr}_{2} \mathrm{O}_{3} ; 3-\mathrm{Ni}_{2} \mathrm{~S}_{3} ; 4-\mathrm{Cu}_{2} \mathrm{~S} ; 5-\mathrm{NaCl}
$$

FIGURA 5.50 - Difratogramas obtidos por DRX a partir de amostras das composições TR, após o ensaio de ataque alcalino: (a)

$$
\text { T20R40 e (b) T25R50 }
$$

\subsection{Vitrocerâmicos}

\subsection{1 - Fases cristalinas nos vidros estudados}

Os vidros TC e TR foram submetidos tratamentos térmicos para cristalização ou devitrificação conforme descrito no item 4.4. Após este tratamento, passaram a ser denominados de "vitrocerâmicos", e acrescentou-se o sufixo"D" à denominação do material de origem. Desta forma, os vidros da serie TC e TR, após o ensaio originam as séries de vitrocerâmicos TCD e TRD, respectivamente. Por conseqüência, os vidros T05C, T10C, T15C, T20C e T25C correspondem aos vitrocerâmicos T05CD, T10CD, T15CD, T20CD e T25CD. Analogamente, os vidros T05R10, T10R20, T15R30, T20R40 e T25R50 correspondem aos vitrocerâmicos T05R10D, T10R20D, T15R30D, T20R40D e T25R50D. As amostras dos vitrocerâmicos obtidos são apresentadas na Fig. 5.51.

Estabeleceu-se como critério a padronização do tratamento térmico idêntico para as amostras de uma mesma série. Desta forma os ensaios exploratórios foram realizados com o vidro de menor ponto de fusão teórico (Fig. 4.1), ou seja, T05C. 


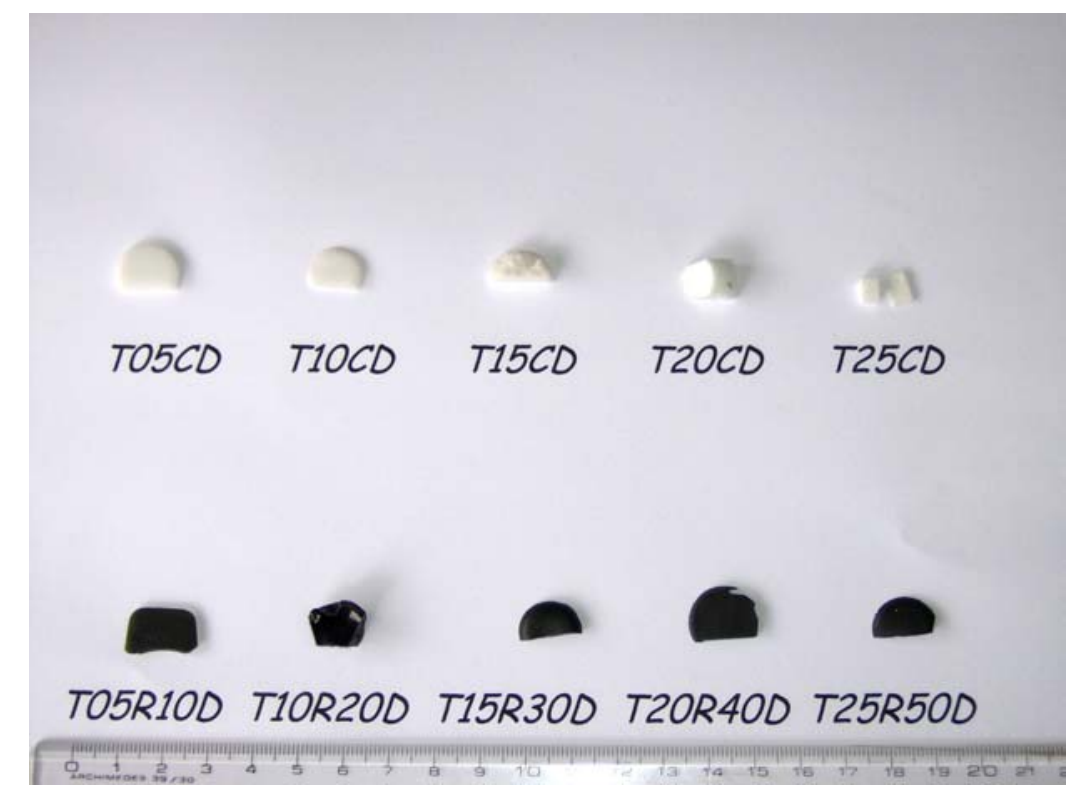

FIGURA 5.51 - Amostras das composições TCD e TRD

O comportamento de cristalização do vidro T05C foi observada na seguinte condição: primeiro patamar à $600^{\circ} \mathrm{C}$ durante $24 \mathrm{~h}$, seguido de um segundo patamar à $700^{\circ} \mathrm{C}$ durante $72 \mathrm{~h}$ ou à $750^{\circ} \mathrm{C}$ durante $48 \mathrm{~h}$. A partir de $800^{\circ} \mathrm{C}$ observa-se a fusão do material. A Tab. 5.6 sumariza os resultados prévios deste ensaio, ficando indicados a temperatura e o tempo inicial para os ensaios nos demais vidros TC. Obteve-se, assim o crescimento de fases cristalinas para todos os vidros desta série, utilizando-se a seguinte condição: primeiro patamar à $600^{\circ} \mathrm{C}$ durante $24 \mathrm{~h}$, seguido de um segundo patamar à $750^{\circ} \mathrm{C}$ durante $72 \mathrm{~h}$, com taxa de aquecimento a $10^{\circ} \mathrm{C} / \mathrm{mim}$.

TABELA 5.6 - Quadro indicativo dos resultados obtidos após tratamento térmico do vidro T05C. Neste quadro, NC indica "não cristalino", IC indica uma cristalização inicial e $\boldsymbol{F C}$, fases cristalinas consolidadas.

\begin{tabular}{c|ccccc}
\hline T05C & $600^{\circ} \mathrm{C}$ & $650^{\circ} \mathrm{C}$ & $7^{\circ} 0^{\circ} \mathrm{C}$ & $7^{\circ} 0^{\circ} \mathrm{C}$ & $800^{\circ} \mathrm{C}$ \\
\hline $\mathbf{2 4 h}$ & NC & NC & IC & IC & Fusão \\
$\mathbf{4 8 h}$ & NC & IC & IC & FC & - \\
$\mathbf{7 2 h}$ & IC & IC & FC & FC & - \\
$96 \mathrm{~h}$ & - & IC & FC & FC & - \\
\hline
\end{tabular}


A Fig. 5.52 apresenta os difratogramas de raios $X$ correspondentes aos vitrocerâmicos TCD.
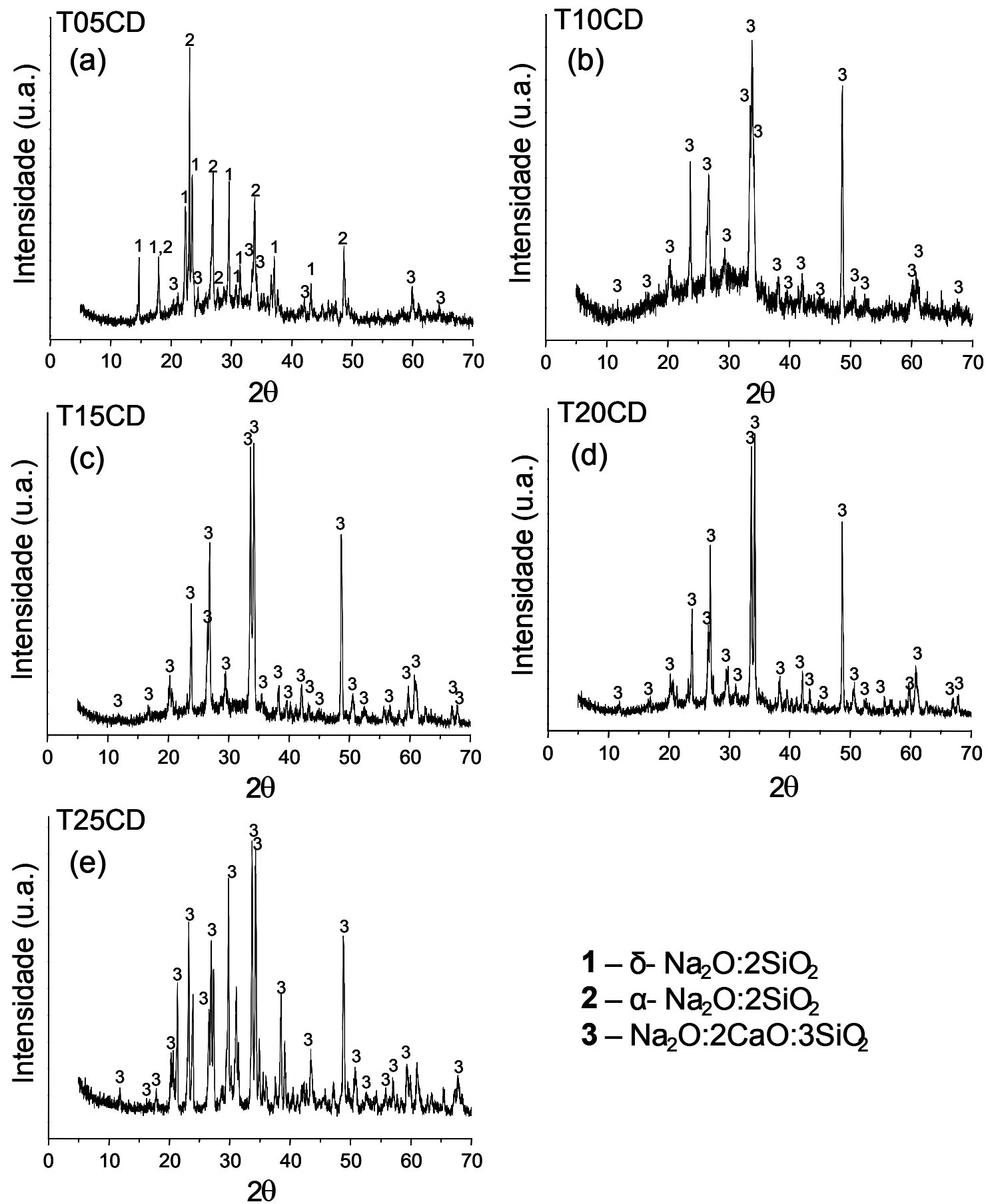

$$
\begin{aligned}
& 1-\delta-\mathrm{Na}_{2} \mathrm{O}: 2 \mathrm{SiO}_{2} \\
& 2-\alpha-\mathrm{Na}_{2} \mathrm{O}: 2 \mathrm{SiO}_{2} \\
& 3-\mathrm{Na}_{2} \mathrm{O}: 2 \mathrm{CaO}: 3 \mathrm{SiO}_{2}
\end{aligned}
$$

FIGURA 5.52 - Difratogramas obtidos por DRX a partir de amostras das composições TCD: (a) T05C, (b) T10CD, (c) T15CD, (d) T20CD, e (d) T25CD 
Comparando-se estes difratogramas com aqueles correspondentes ao vidro TC (Fig. 5.6), observa-se que ocorre a formação de fases cristalinas após o tratamento térmico mencionado. Em todos os vitrocerâmicos TCD foi identificada a fase correspondente a $\mathrm{Na}_{2} \mathrm{O}: 2 \mathrm{CaO}: 3 \mathrm{SiO}_{2}$ (PDF 77-2189). A formação das fases $\alpha-\mathrm{Na}_{2} \mathrm{O}: 2 \mathrm{SiO}_{2}$ e $\delta-\mathrm{Na}_{2} \mathrm{O}: 2 \mathrm{SiO}_{2}$ (PDF 22-1397 e 53-1234), são detectáveis somente para a composição T05CD.

De acordo com os diagramas de equilíbrio para os sistemas $\mathrm{Na}_{2} \mathrm{O}: \mathrm{CaO}: \mathrm{SiO}_{2}{ }^{(105)}$ e $\mathrm{Na}_{2} \mathrm{O}: \mathrm{B}_{2} \mathrm{O}_{3}: \mathrm{SiO}_{2}{ }^{(211))}$ (Fig. 4.1 e 4.2) os compostos a se cristalizar são $\mathrm{Na}_{2} \mathrm{O}: 2 \mathrm{SiO}_{2}$ e $\mathrm{Na}_{2} \mathrm{O}: 2 \mathrm{CaO}: 3 \mathrm{SiO}_{2}$. A presença deste é revelada para as composições TC05D a TC25D.

A Fig. 5.53 apresenta micrografias a partir de secções polidas correspondente às amostras TCD, onde se observam distintas fases. A porosidade presente pode ser remanescente do processo de sinterização.

As Fig. 5.54 e 5.55 apresentam micrografias obtidas por MEV, acompanhadas por microanálise, EDS, nos pontos indicados. A partir dos vitrocerâmicos T10CD, T15CD, T20CD e T25CD, observa-se que, para todas as composições ocorre a formação de fases secundárias. As análises realisadas por EDS dos cristais observados são compatíveis com as fases $\mathrm{Na}_{2} \mathrm{O}: 2 \mathrm{CaO}: 3 \mathrm{SiO}_{2}$ e $\mathrm{Na}_{2} \mathrm{O}: \mathrm{SiO}_{2}$, determinados pela técnica de DRX (Fig. 5.52).

Na seqüência de testes realizados, em nenhum vidro da série TR, foi observado o crescimento de fases secundárias. As amostras submetidas ao tratamento térmico à $600^{\circ} \mathrm{C}$ por $24 \mathrm{~h}$ e à $900^{\circ} \mathrm{C}$ por $72 \mathrm{~h}$, foram selecionadas par as caracterizações subseqüentes (série TRD).

Os espectrogramas por raio $X$ das composições TRD são mostrados na Fig. 5.56 . 


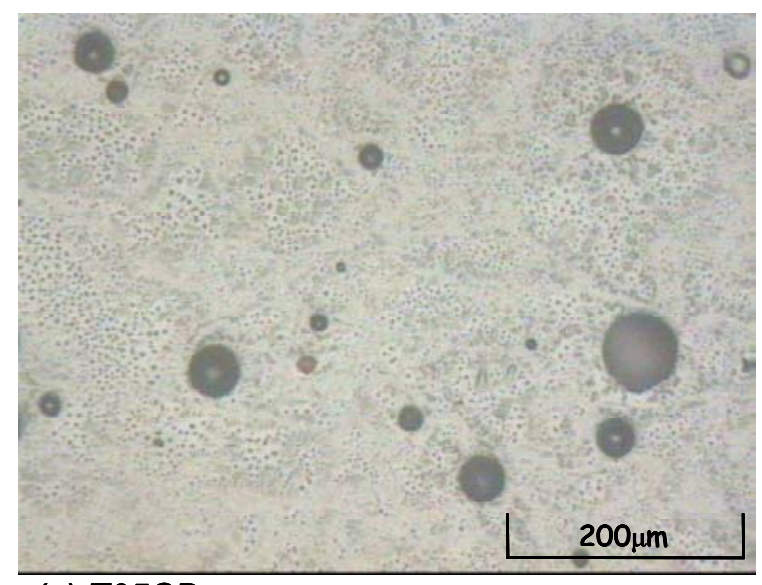

(a) $T 05 C D$

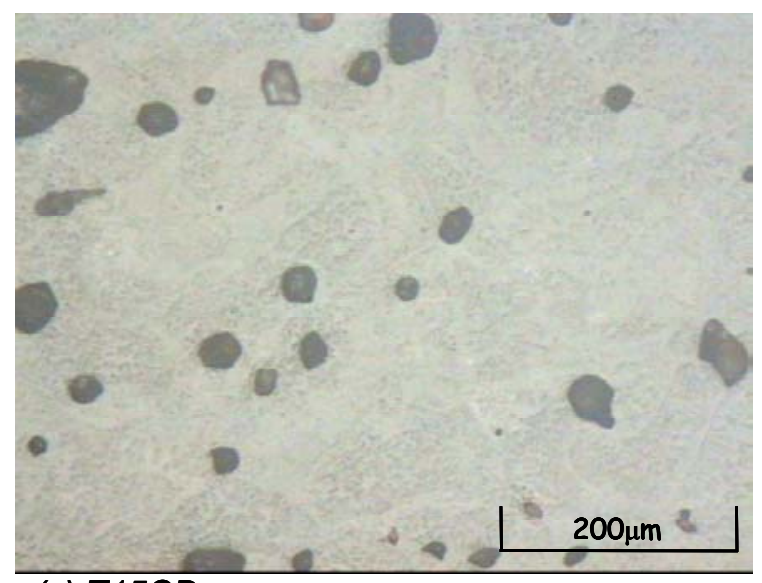

(c) $T 15 C D$

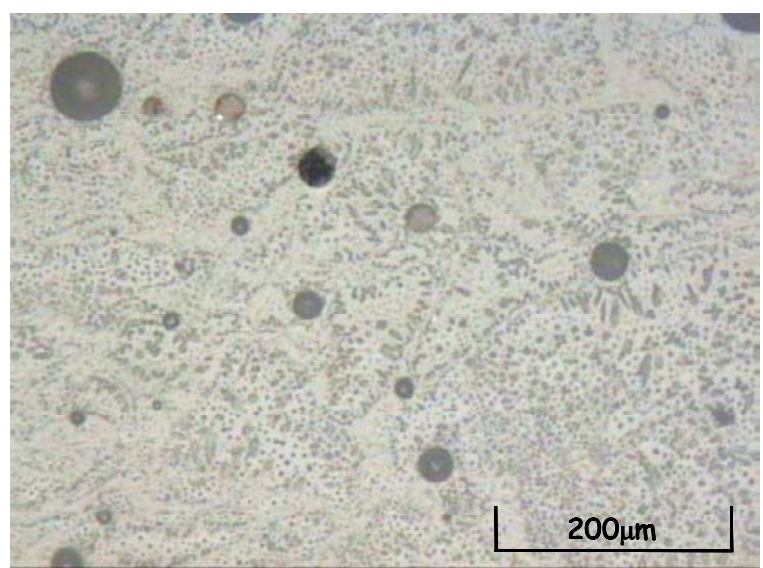

(b) $T 10 C D$

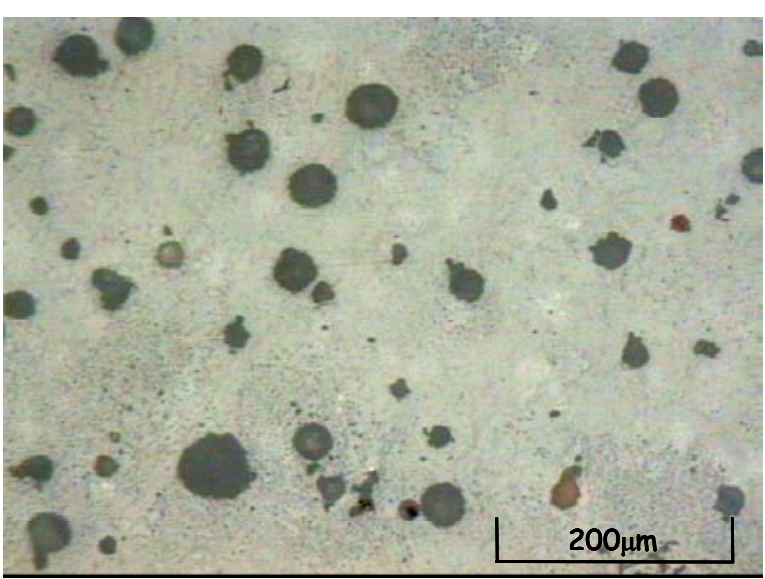

(d) $T 20 C D$

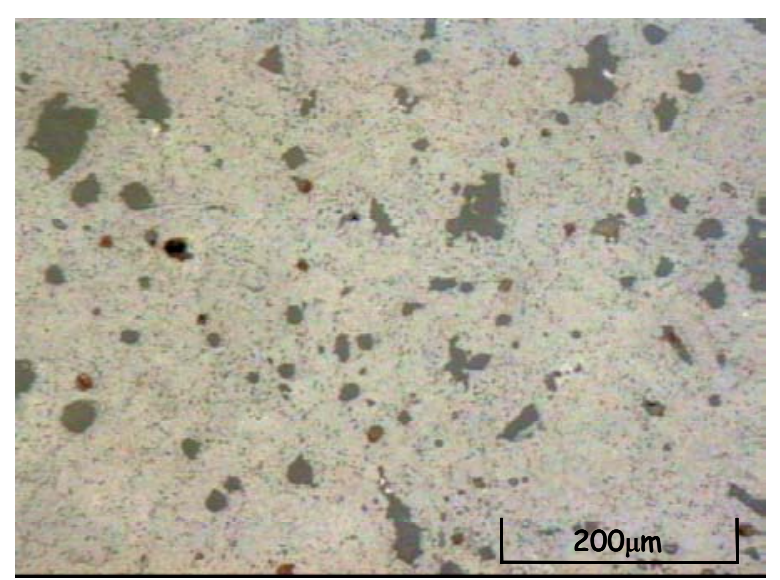

(e) $T 25 C D$

FIGURA 5.53 - Fotos obtidas por microscopia óptica de secções polidas de amostras das composições TCD, onde: (a) T05C, (b) T10CD, (c) T15CD, (d) T20CD e (e) T25CD. 


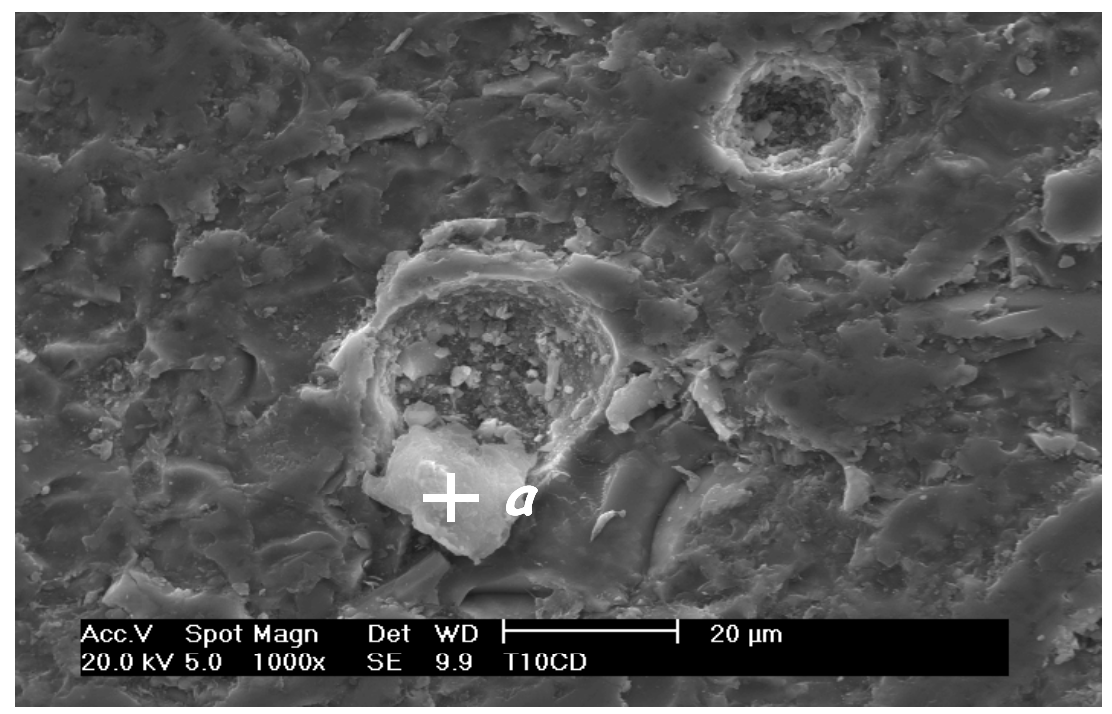

Microanálise

T10CD

Elem . Massa \%

(a)

$\begin{array}{cc}\mathbf{N a} & 35,29 \\ \mathbf{A l} & 10,65 \\ \mathbf{S i} & 43,7 \\ \mathbf{C a} & 10,37 \\ \text { Total } & 100\end{array}$

(a) T10CD

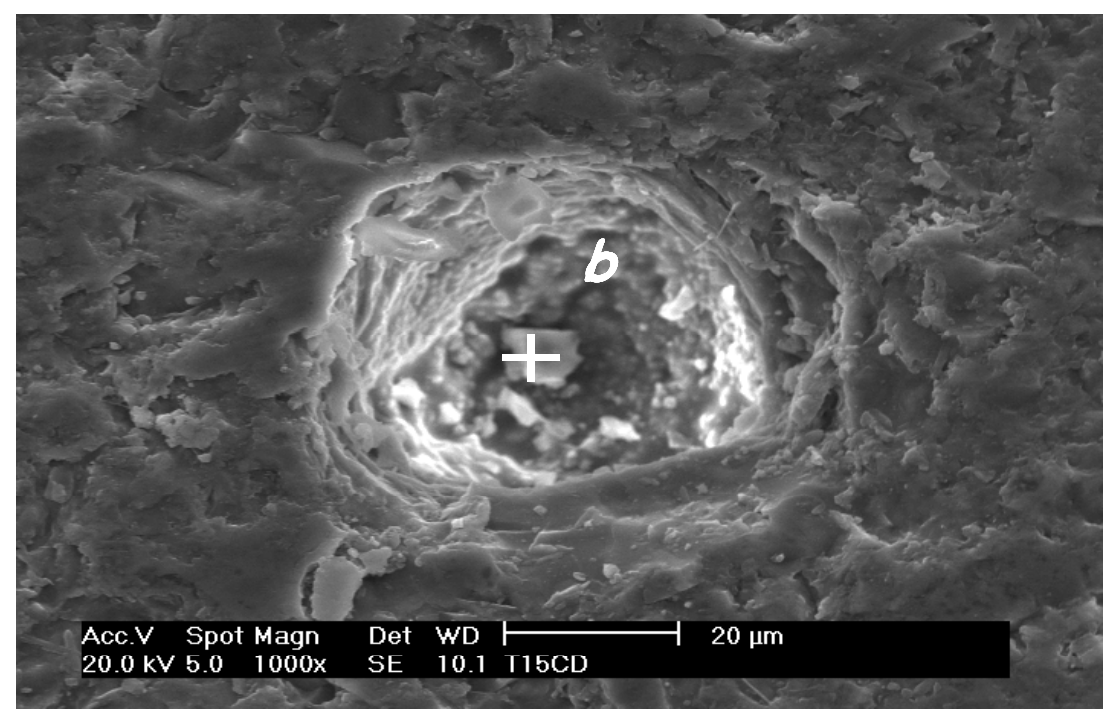

Microanálise

T15CD

Elem . Massa \%

(b)

$\begin{array}{cc}\mathrm{Na} & 21,95 \\ \mathrm{Al} & 7,05 \\ \mathrm{Si} & 42,52 \\ \mathrm{Ca} & 28,48 \\ \text { Total } & 100\end{array}$

(b) T15CD

FIGURA 5.54 - Composições TCD: (a) T10CD, (b) e T15CD (MEV-EDS)

Nestes espectrogramas observa-se a permanência das mesmas fases presentes nos vidros originais (Fig. 5.6), ou seja: $\mathrm{Cr}_{2} \mathrm{O}_{3} ; \mathrm{Ni}\left(\mathrm{CrO}_{4}\right) ; \mathrm{Cu}_{2} \mathrm{~S}$; e, $\mathrm{Ni}_{3} \mathrm{~S}_{2}$, quando comparados com os respectivos difratogramas dos vidros antes do tratamento térmico. A exceção é a fase secundaria $\mathrm{Ca}_{3}\left(\mathrm{CrO}_{4}\right)_{2}$. 


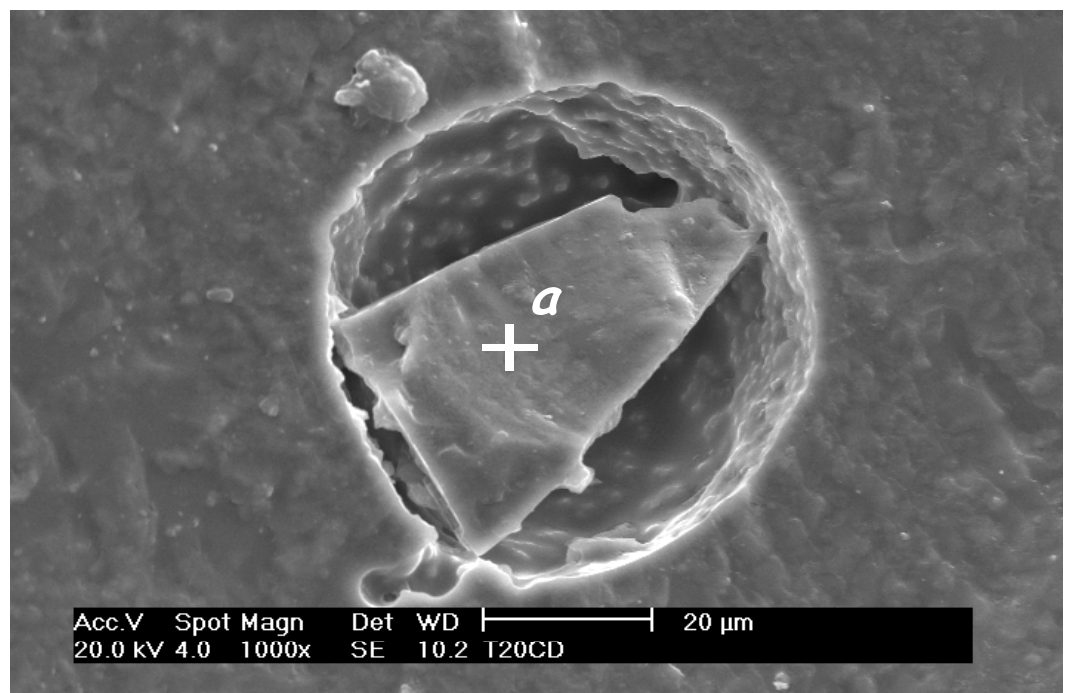

Microanálise

\section{T20CD}

Elem. Massa \%

(a)

$\begin{array}{cc}\text { Na } & 22,72 \\ \text { Al } & 5,23 \\ \text { Si } & 52,94 \\ \text { Ca } & 19,1 \\ \text { Total } & 100\end{array}$

(a) T20CD

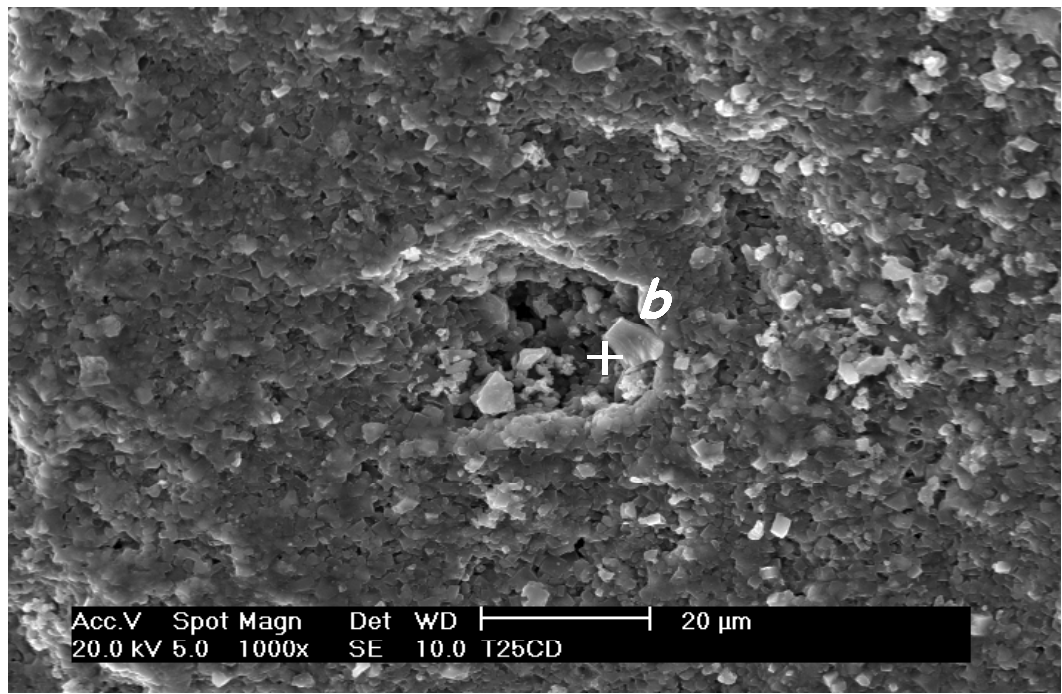

Microanálise

T25CD

Elem. Massa \%

(b)

$\begin{array}{cc}\mathbf{N a} & 14,15 \\ \mathbf{A l} & 11,01 \\ \mathbf{S i} & 47,56 \\ \mathbf{C a} & 27,28 \\ \text { Total } & 100\end{array}$

(b) T25CD

FIGURA 5.55 - Composições TCD: (a) T20CD e (b) T25CD (MEV-EDS)

Desta forma a substituição dos modificadores na formulação básica dos vidros (ex: $\mathrm{CaO}$ ) pelos metais do RSG não contribui para a devitrificação nas composições TR, como se observa nas TC.

A Fig. 5.57 apresenta micrografias a partir de amostras polidas correspondentes as composições TRD. Nestas micrografias observam-se fases secundárias provavelmente dos vidros de origem (Fig. 5.7-8). Foram observados, cristais hexagonais de cromita $\left(\mathrm{Cr}_{2} \mathrm{O}_{3}\right)$.

Em comparação aos vidros sem resíduos galvânicos, foi observada uma menor incidência de poros como conseqüência do processo de sinterização do 
material devido à maior temperatura de tratamento térmico em relação à temperatura inicialmente selecionada.

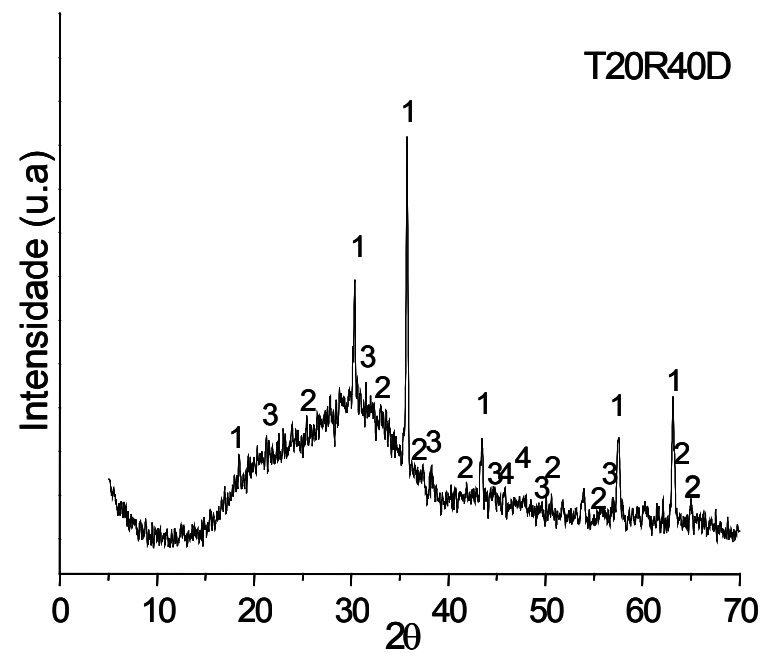

(a)

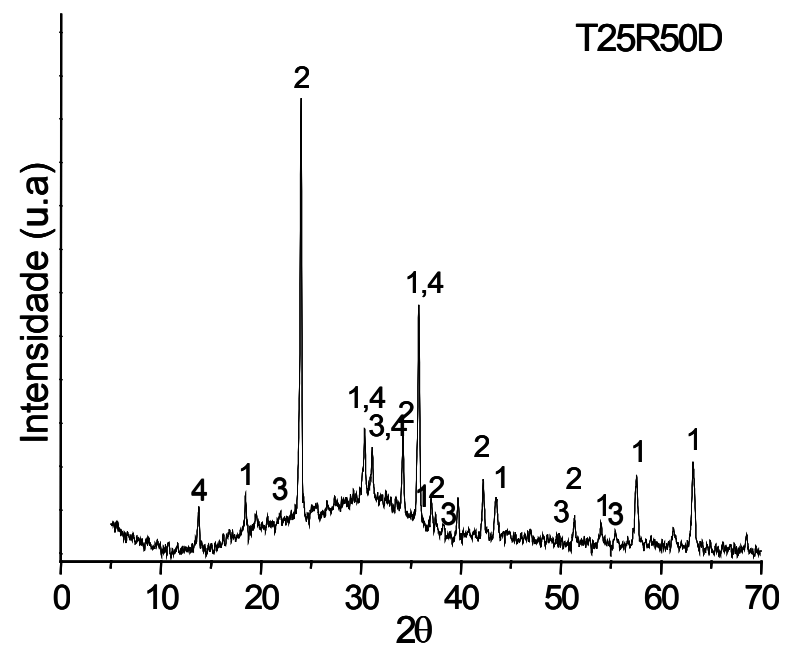

(b)

$1-\mathrm{Ni}\left(\mathrm{Cr}_{2} \mathrm{O}_{4}\right) ; 2-\mathrm{Cr}_{2} \mathrm{O}_{3} ; 3-\mathrm{Ni}_{3} \mathrm{~S}_{2} ; 4-\mathrm{Cu}_{2} \mathrm{~S}$

FIGURA 5.56- Difratogramas obtidos por DRX a partir de amostras das composições TRD: (a) T20R40D e (b) T25R50D.

Micrografias obtidas a partir das amostras correspondentes às composições TRD são apresentados nas FIG. 5.58 e 5.59 (MEV-EDS).

Em todas as micrografias observa-se a presença de fases secundárias precipitadas. As análises da composição em massa das mesmas, indicam que são compostos a base de $\mathrm{Si}$, $\mathrm{Na}$ e $\mathrm{Ca}$. $\mathrm{Na}$ composição T05R10D (Fig. 5.58(a)), a formação de compostos a base de Si e $\mathrm{Na} e ́$ observada, possivelmente silicatos. 


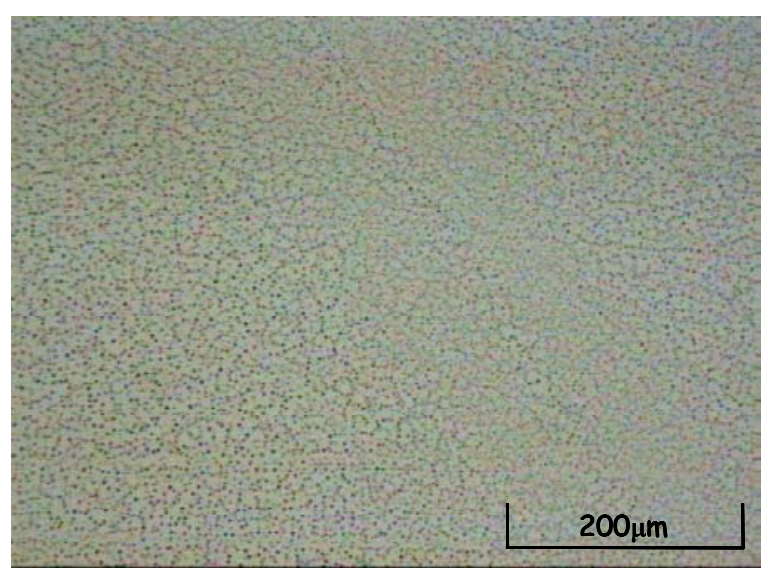

(a) T05R10

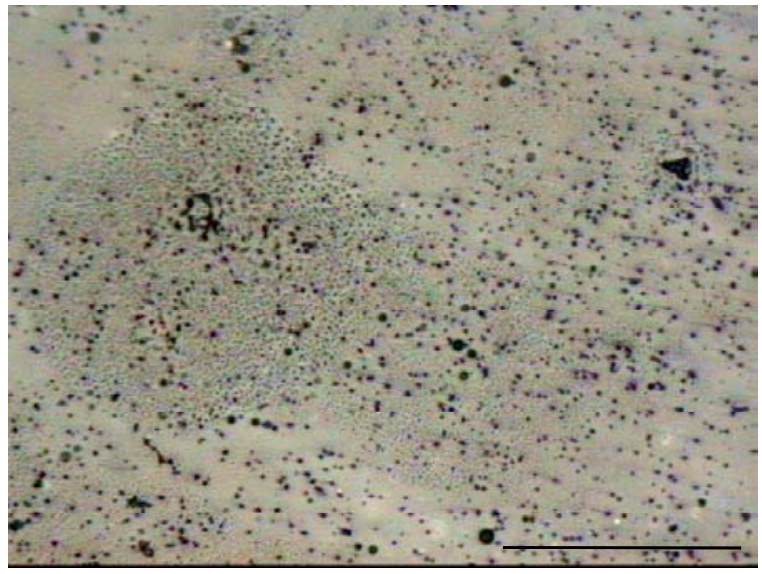

(c) $\mathrm{T} 15 \mathrm{R} 30$

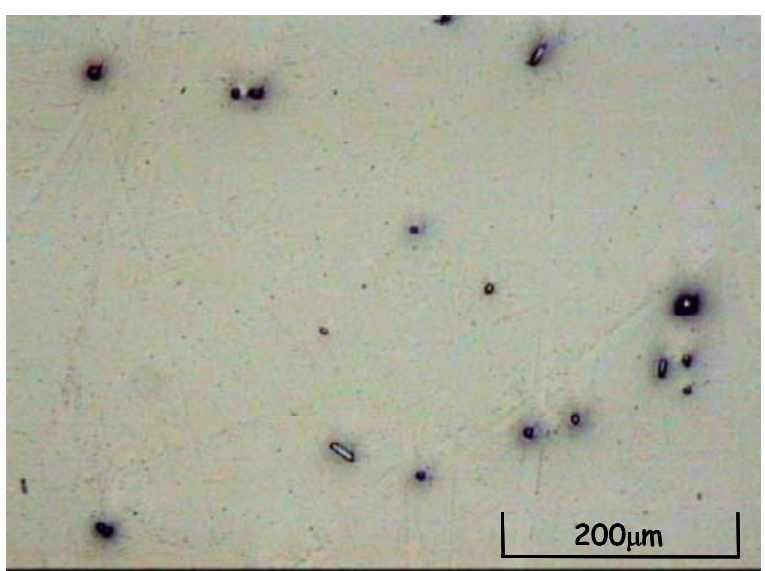

(b) T10R20

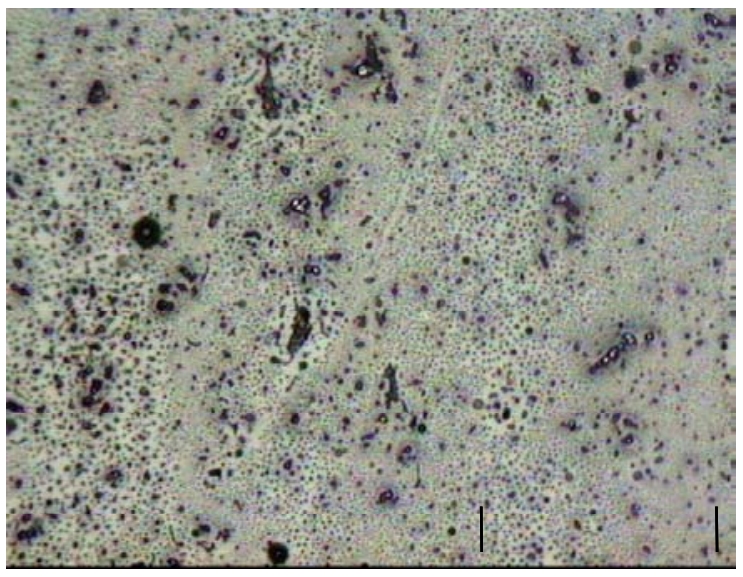

(d) T20R40

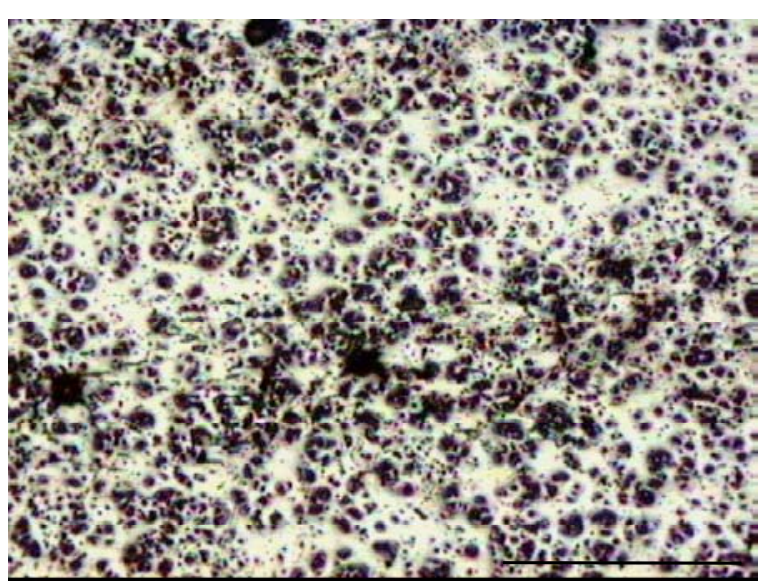

(e) T25R50

FIGURA 5.57 - Micrografias de secções polidas de amostras das composições TRD: (a) T05R10D; (b) T10R20D, (c) T15R30D, (d) T20R40D, e (e) T25R50D 


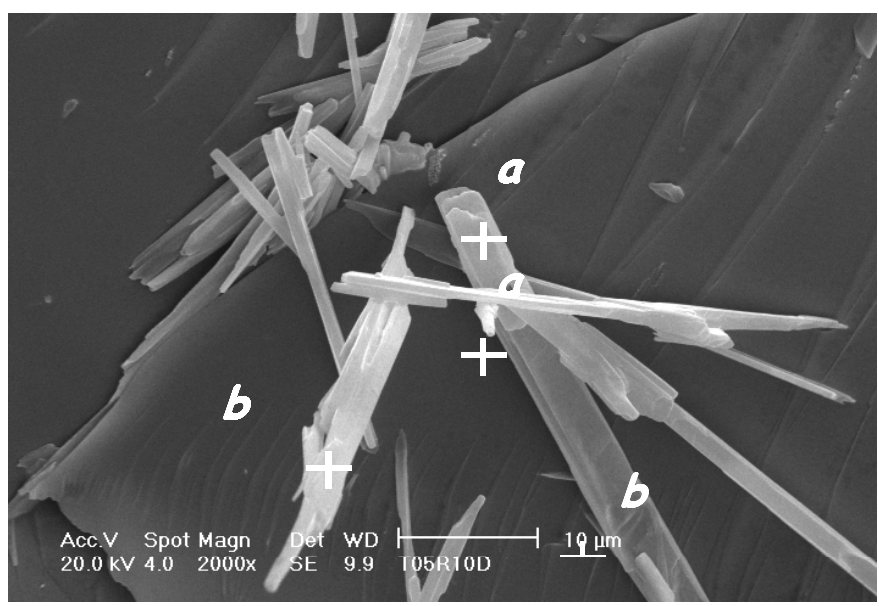

(a) T05R10

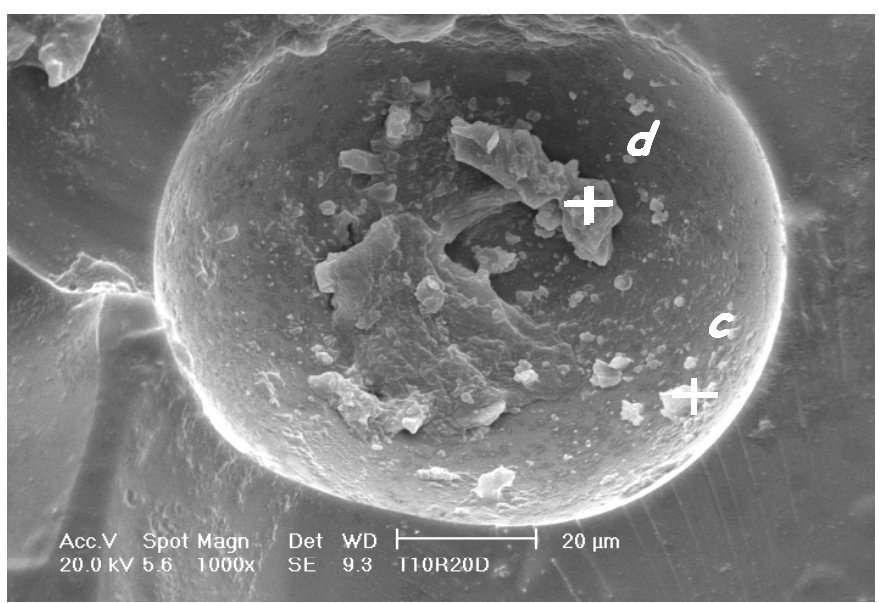

(b) T10R20

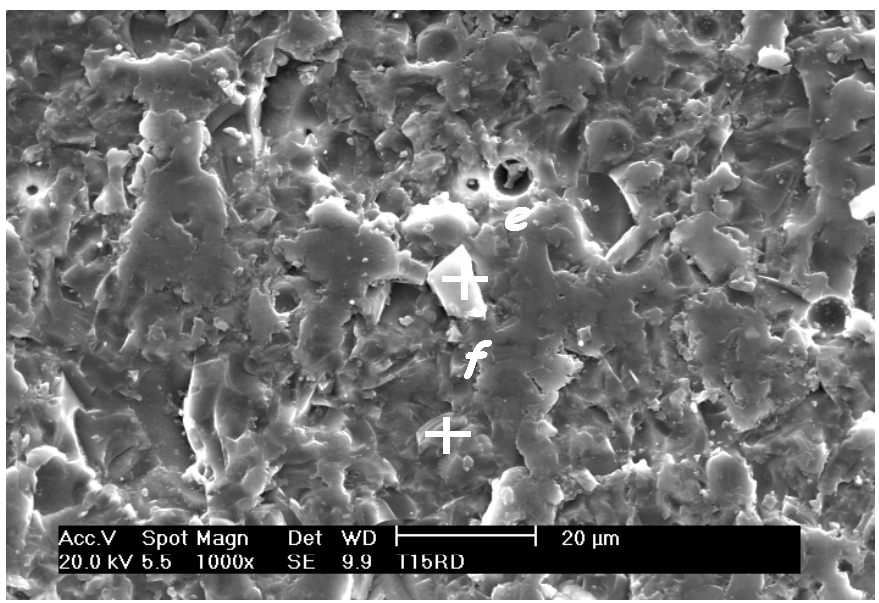

(c) T15R30
Microanálise

T05R10D

Elem Massa\%

(a) (b)

Na $35,82 \quad 40,88$

Al $\quad 6,7 \quad 7,28$

Si $\quad 57,48 \quad 51,83$

Total $100 \quad 100$

Microanálise

T10R20D

Elem. Massa \%

(c) (d)

Na $35,82 \quad 14,93$

Al $6,7 \quad 7,74$

Si $\quad 57,48 \quad 61,91$

Ca $\quad$ - 15,42

Total $100 \quad 100$

Microanálise

T15R30D

Elem. Massa \%

(e) (f)

$\begin{array}{ccc}\mathrm{Na} & 20,27 & 14,11 \\ \mathbf{A l} & 11,52 & 9,74 \\ \mathrm{Si} & 55,94 & 54,66 \\ \mathbf{C a} & 6,41 & 10,04 \\ \mathrm{Cr} & 2,38 & 5,07 \\ \mathbf{N i} & 3,49 & 6,37 \\ \text { Total } & 100 & 100\end{array}$

FIGURA 5.58 - Composições TRD: (a) T05R10D, (b) T10R20D e (c) T15R30D(MEV-EDS) 


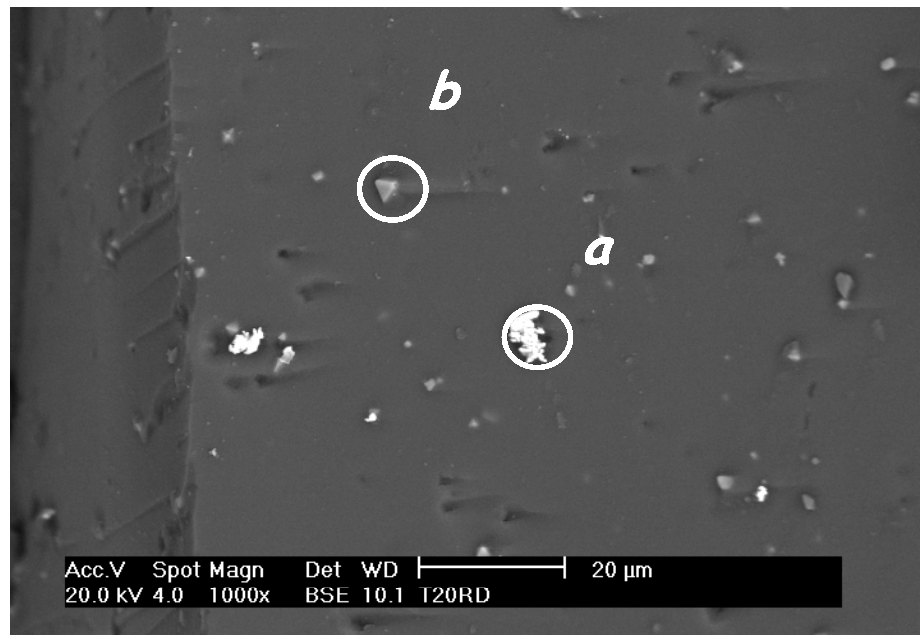

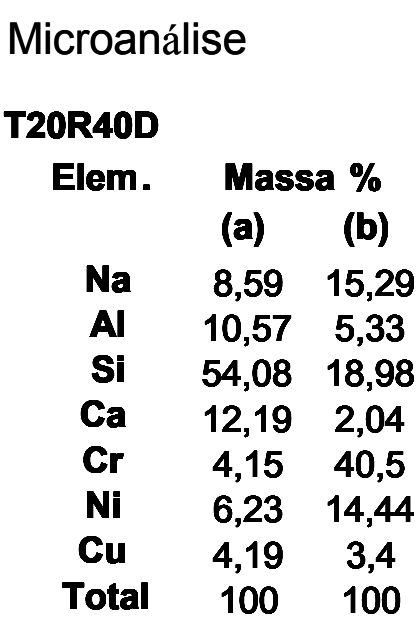

(a) T20R40

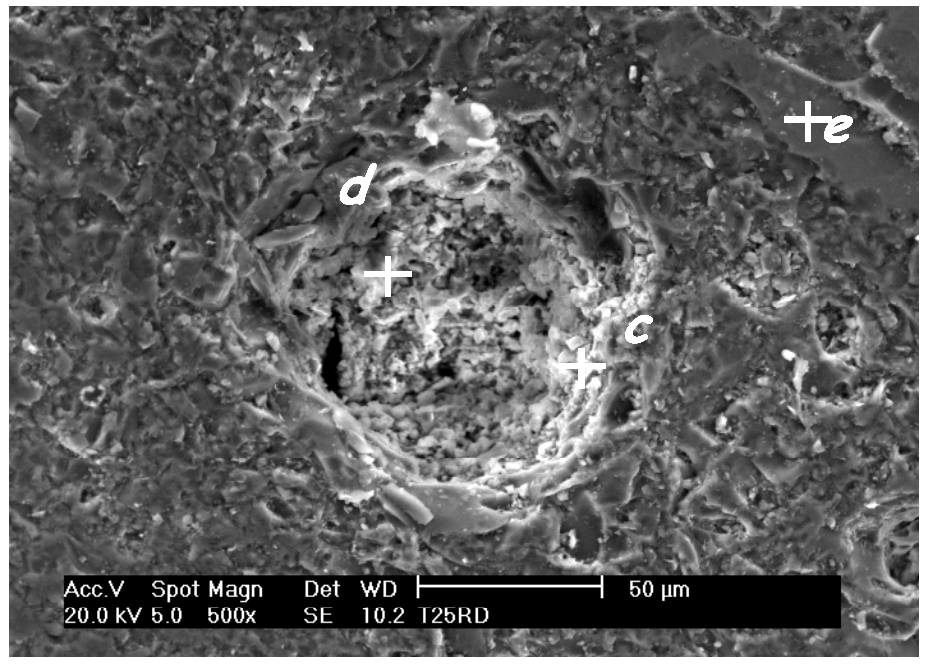

Microanálise

T25R50D

Elem. Massa \%

(c) (d) (e)

$\begin{array}{cccc}\mathbf{N a} & 14,29 & 15,68 & 3,6 \\ \mathbf{M g} & 1,74 & 1,98 & 1,21 \\ \mathbf{A l} & 9,68 & 14,8 & 16,38 \\ \mathbf{S i} & 38,88 & 48,02 & 23,56 \\ \mathbf{C a} & 14,5 & 10,54 & 27,94 \\ \mathbf{C r} & 13,84 & 5,09 & 1,36 \\ \mathbf{N i} & 7,08 & 3,89 & 1,01 \\ \mathbf{S} & - & - & 24,94 \\ \text { Total } & 100 & 100 & 100\end{array}$

(b) T25R50

FIGURA 5.59 - Composições TRD: (a) T20R40D e (b) T25R50D (MEV-EDS)

A formação destes compostos não havia sido observada pela técnica DRX (Fig. 5.56), no entanto são compatíveis com as fases $\alpha$ $\mathrm{Na}_{2} \mathrm{O}: 2 \mathrm{SiO}_{2}$ e $\delta-\mathrm{Na}_{2} \mathrm{O}: 2 \mathrm{SiO}_{2}$, observadas no vitrocerâmico T05CD, indicando a tendência à devitrificação da série TRD. Para algumas composições TRD, observa-se, a presença de fases secundárias compostas também por $\mathrm{Cr}$ e Ni. Como discutido anteriormente o RSG contém cálcio, e por este motivo uma pequena quantidade deste elemento faz parte da composição dos vidros de origem (TR).

Os espectrogramas correspondentes aos ensaios de FT-IR das composições TCD e TRD são apresentados na Fig. 5.60. 
A comparação entre espectros de FTIR dos vitrocerâmicos TCD (Fig. 5.60(a)), com os espectros dos vidros TC, Fig. 5.13(a), mostra que em todas as composições ocorre a presença dos três modos de freqüência característicos para o arranjo estrutural do vidro soda-cal (indicados por 1, 2 e 3 nas figuras) após o tratamento térmico. Entretanto é observado um significativo aumento na intensidade relativa na banda associada às pontes de oxigênio entre tetraedros de sílica $Q^{4}$ (Si-O-Si $\left[Q^{4}\right]$ ), ponto 3 nas Fig. 5.60. Analisando os espectros de todas as composições TCD, observa-se que ocorre o deslocamento da banda associada às pontes de oxigênio entre tetraedros $Q^{2}$ na direção indicada para $Q^{1}$ (7 e 8 na Fig. 5.60). As bandas associadas com as ligações entre os tetraedros de sílica e os metais alcalinos e/ou alcalinos terrosos (ponto 15), são alteradas após o tratamento térmico nos materiais e em particular, a banda relativa aos metais segregados aumenta de intensidade (ponto 16). Estes resultados indicam que ocorre um rearranjo na estrutura dos vidros originais devido a formação das fases secundárias. Este rearranjo estrutural está relacionado principalmente as ligações da sílica tipo $\mathrm{Q}^{2}$, que estão normalmente associado aos modificadores (ex: $\mathrm{CaO}$ ) e fundentes (ex: $\left.\mathrm{Na}_{2} \mathrm{O}\right)^{(23,24)}$. Desta forma as estruturas do tipo $Q^{2}$ participam da formação das fases secundárias contendo $\mathrm{Si}, \mathrm{Ca}$ e $\mathrm{Na}$, observadas nos difratogramas da Fig. 5.52. A formação de dímeros (ligações da sílica tipo $Q^{1}$ ), mostra que pode haver uma desagregação da rede, onde evidentemente, os tetraedros de sílica estão participando das novas fases formadas. A banda indicativa do boro estrutural (ligações Si-O-B, ponto 11 na Fig. 5.60), apresenta um aumento de intensidade relativa após o tratamento térmico, devido ao rearranjo deste óxido da matriz vítrea, ou da formação de uma fase cristalina envolvendo o mesmo. A comparação dos espectros de FTIR para os vitrocerâmicos TRD, Fig. 5.60(b), com os espectros resultantes das análises realizadas para a série TR, Fig. 5.14(b), revela pequenas diferenças, ou seja, pouca alteração como conseqüência do tratamento térmico realizado. Entretanto foram observadas alterações nas bandas relativas à ligações entre os tetraedros de silício e os metais presentes (ponto 15 na figura). Ocorre também um deslocamento das bandas relativas às ligações entre os tetraedros de sílica do tipo $Q^{0}$ e $Q^{1}$ em direção a banda representativa dos tetraedros de sílica $Q^{2}$, indicando que o tratamento térmico não foi suficiente para induzir os vidros TR à formação de fases cristalinas baseadas em silicatos (devitrificação), entretanto, 
ocorreu uma reorganização da rede vítrea. Este fato pode ser melhor exemplificado, fazendo-se uma analogia com o resultado normalmente obtido durante o "recozimento" dos vidros. Como observado no item 5.2.4, os vidros TR apresentam uma viscosidade final inferior aos vidros TC. Os líquidos de menor viscosidade, cristalizam-se com maior facilidade.

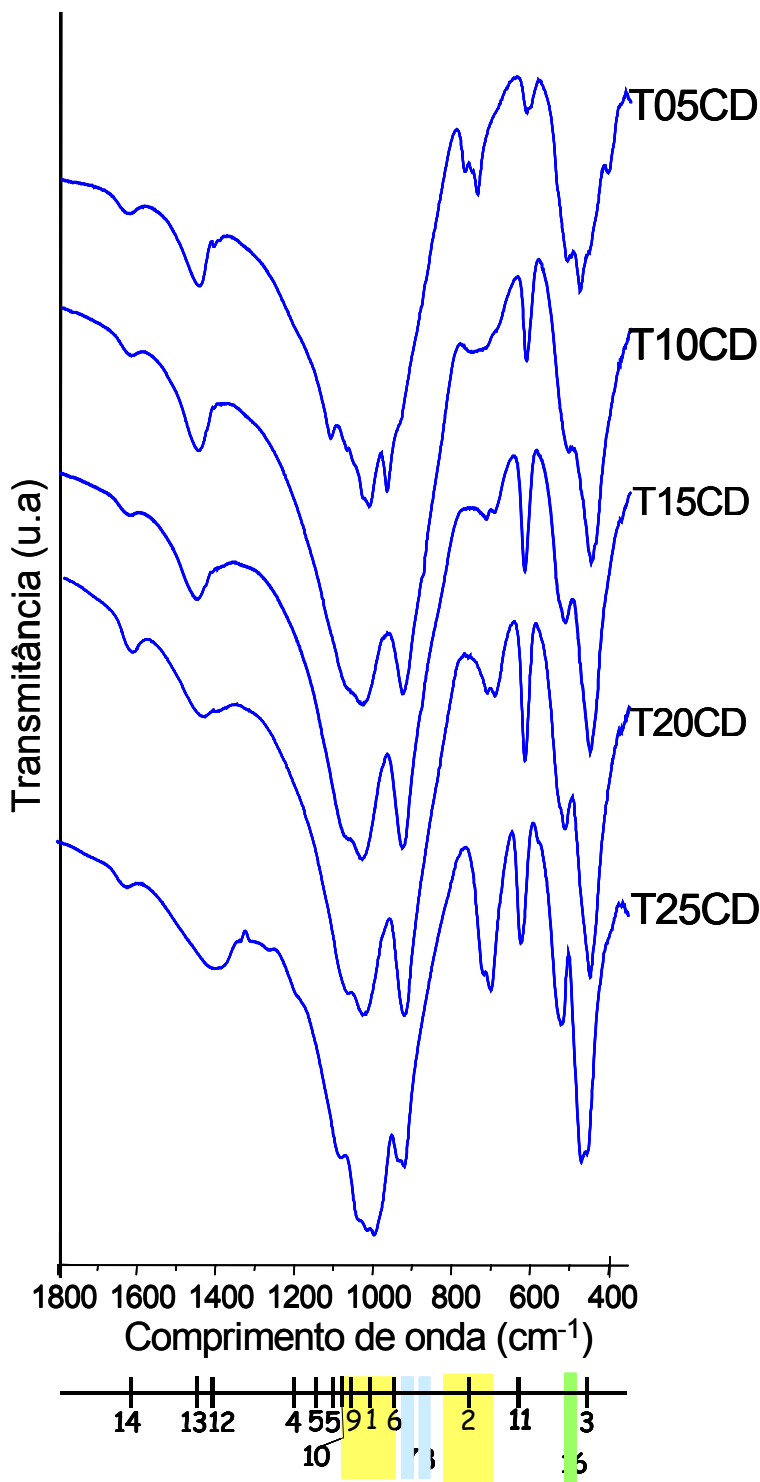

(a) Série TCD

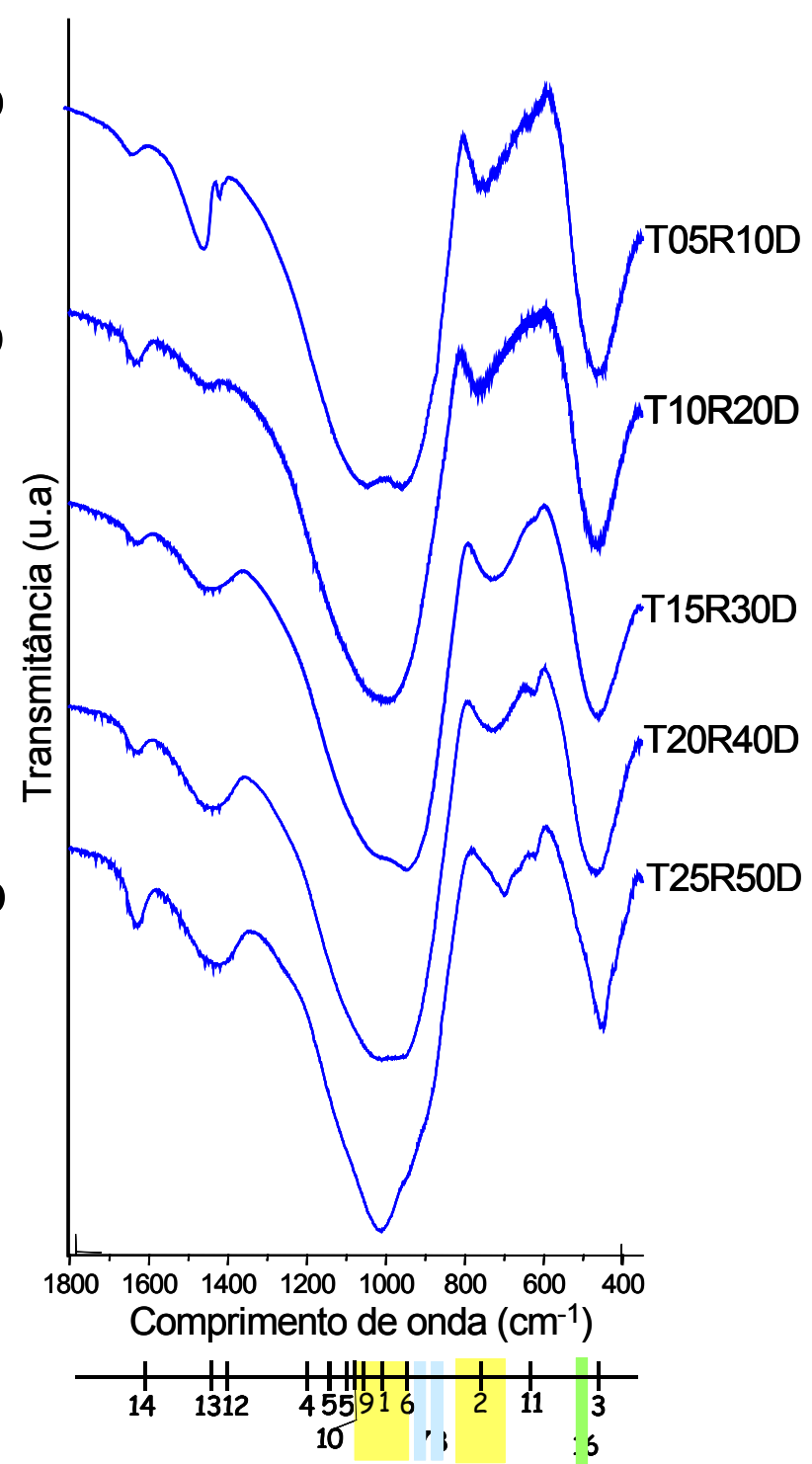

(b) Série TRD

(1) Superfície de tetraedros $\mathrm{SiO}_{4}$; (2) Ligações entre tetraedros $\mathrm{SiO}_{4}$; (3) $\mathrm{Si}-\mathrm{O}-\mathrm{Si}\left[\mathrm{Q}^{4}\right]$;

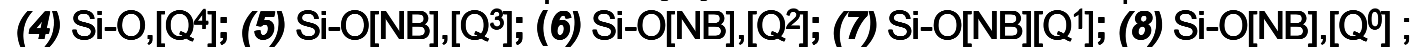

(9) Si-O-Si; (10) Si-O-[NB], plano ; (11) Si-O-B Estrutural; (12) B-O Livre; (13) Na-O; (14) Água livre; (15) Silicatos de metais; (16) Óxidos metálicos segregados.

FIGURA 5.60- Espectros de FT-IR de amostras das composições TCD e TRD 
Estes comportamentos opostos se justificam em um mesmo material considerando-se a possibilidade do mesmo ser formado por dois ou mais líquidos. $\mathrm{O}$ diagrama de fases do sistema $\mathrm{CaO}: \mathrm{Na}_{2} \mathrm{O}: \mathrm{SiO}_{2}$ (Fig. 4.1), indica que o líquido para as composições $\mathbf{T}$ pode ser formado por pelo menos dois líquidos imiscíveis. Tal comportamento permanece com a substituição parcial do $\mathrm{CaO}$ pelos metais de transição. Desta forma, pelo menos um dos líquidos que compõe estes vidros, que apresenta uma maior concentração relativa de $\mathrm{NaO}$ apresenta uma viscosidade relativa menor. Este liquido, forma regiões enriquecidas em $\mathrm{NaO}$ na matriz vítrea. Esta possibilidade foi acompanhada durante os ensaios de resistência ao ataque ácido.

\subsection{2 - Resistência química dos vitrocerâmicos}

\subsubsection{1 - Resistência hidrolítica}

A resistência à dissolução por efeito da água nos materiais vitrocerâmicos foi avaliada pela técnica do ataque hidrolítico.

As Fig. 5.61 e 5.62 apresentam respectivamente os resultados destes ensaios para os vitrocerâmicos TCD e TRD.

$\mathrm{Na}$ Fig. 5.61, correspondente aos vitrocerâmicos TCD, o que se observa de modo geral é um aumento da estabilidade química após as primeiras horas de ensaio. As exceções são dadas pelas amostras T05CD e T25CD. A composição T05CD, assim como seu vidro de origem (T05C na Fig. 5.19), se desagrega em tempos inferiores das às 148 horas de ensaio. Na composição T25CD, observou-se a elevação da taxa de dissolução quando comparada com a sua precursora T25C. Uma possibilidade, para este comportamento é que nesta composição o alto conteúdo de cátions modificadores ( $25 \%$ em massa de $\mathrm{CaO}$ ), contribui na cristalização da fase $\mathrm{N}_{2} \mathrm{aO}: 2 \mathrm{CaO}: 3 \mathrm{SiO}_{2}$. Esta fase é por natureza resistente ao ataque hidrolítico, entretanto ocorre o consumo do $\mathrm{CaO}$, enfraquecendo a matriz, facilitando o ataque hidrolítico.

Observa-se ainda, nos vitrocerâmicos T10CD, T15CD e T20CD, taxas de dissolução significativamente menores que os respectivos vidros de origem, que é característica usual dos vitrocerâmicos ${ }^{(38)}$. Por exemplo as taxas de dissolução de T15C e T15CD são respectivamente 84,0 e 40,1 [g/( $\left.\left.\mathrm{cm}^{2} . \mathrm{s}\right)\right] \times 10^{-8}$. 


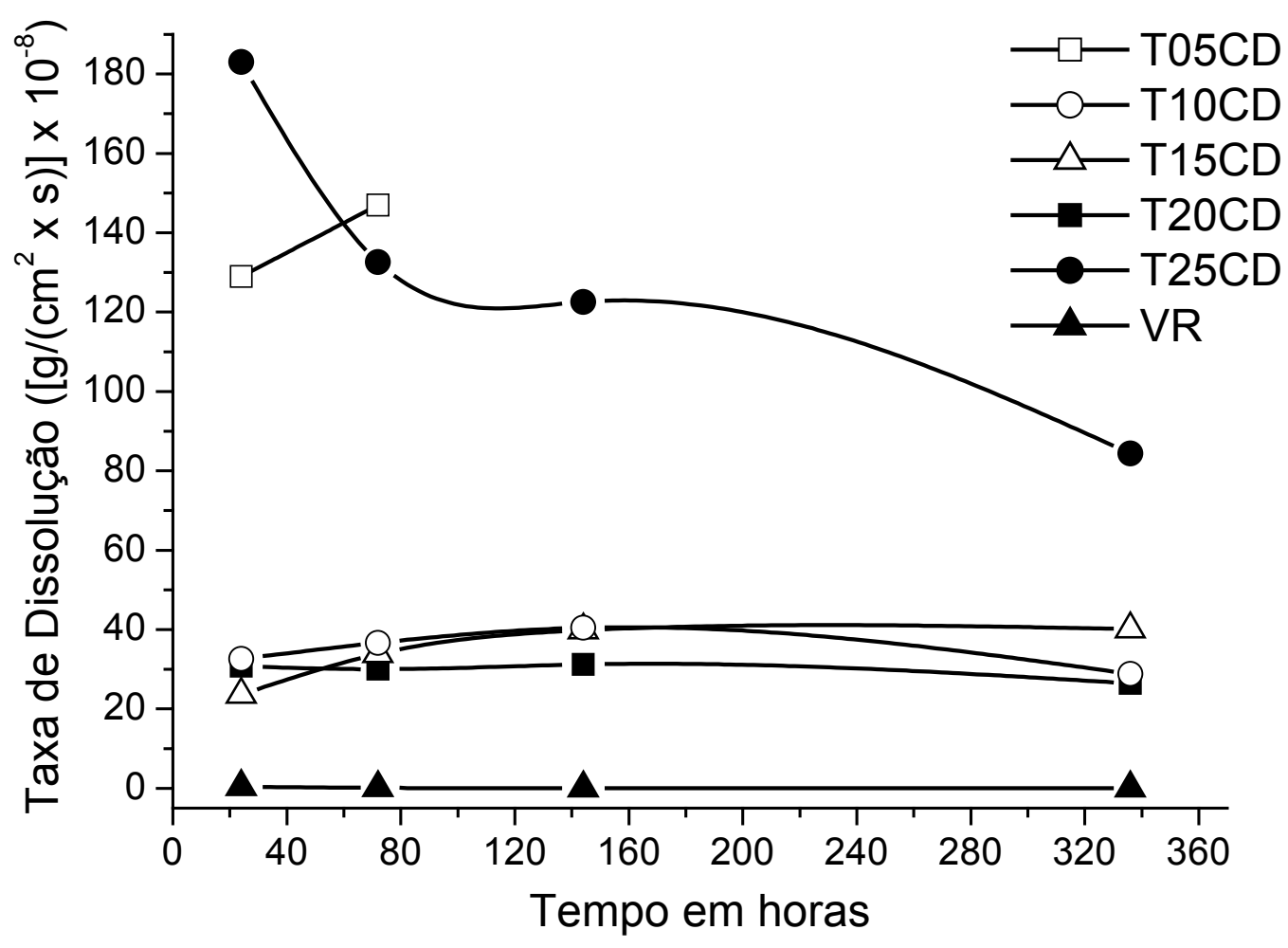

FIGURA 5.61 - Taxa de dissolução em função do tempo obtidas no ensaio de resistência hidrolítica de amostras das composições TCD e VR

$\mathrm{Na}$ Fig. 5.62, observa-se que as composições TRD, apresentam uma resistência química menor que a série TR (Fig. 5.25). Por exemplo as taxas de dissolução de T15R e T15RD são respectivamente 1,6 e 5,2 $\left[\mathrm{g} /\left(\mathrm{cm}^{2} . \mathrm{s}\right)\right] \times 10^{-8}$. As composições TRD, de forma geral apresentaram também maior resistência química que a série TCD (Fig. 5.61), embora esta diferença não seja tão acentuada como a observada para os materiais vítreos de origem (Fig. 5.19 e 5.20). Nestes materiais, com exceção de T05R10D, a resistência hidrolítica aumenta com o aumento de concentração de metais de transição, sugerindo um comportamento similar ao observado nos vidros contendo apenas cálcio (modificador). De forma análoga aos vitrocerâmicos T25CD, na amostra T25R50D, também se observa aumento acentuado na taxa de dissolução em relação às demais composições. Tal fato pode ser atribuído a um mecanismo similar à possibilidade apresentada para o vitrocerâmico T25CD. 
A Fig. 5.63 mostra as micrografias obtidas à partir da superfície polida (secção transversal) das amostras termicamente tratadas (TCD e TRD) após ensaio de resistência ao ataque hidrolítico. Nestas fotos, podese observar que apenas na composição T05R10D, ocorre a formação de uma camada superficial de composição alterada, que pode corresponder à formação de uma camada rica em sílica após a extração dos álcalis (ataque protônico).

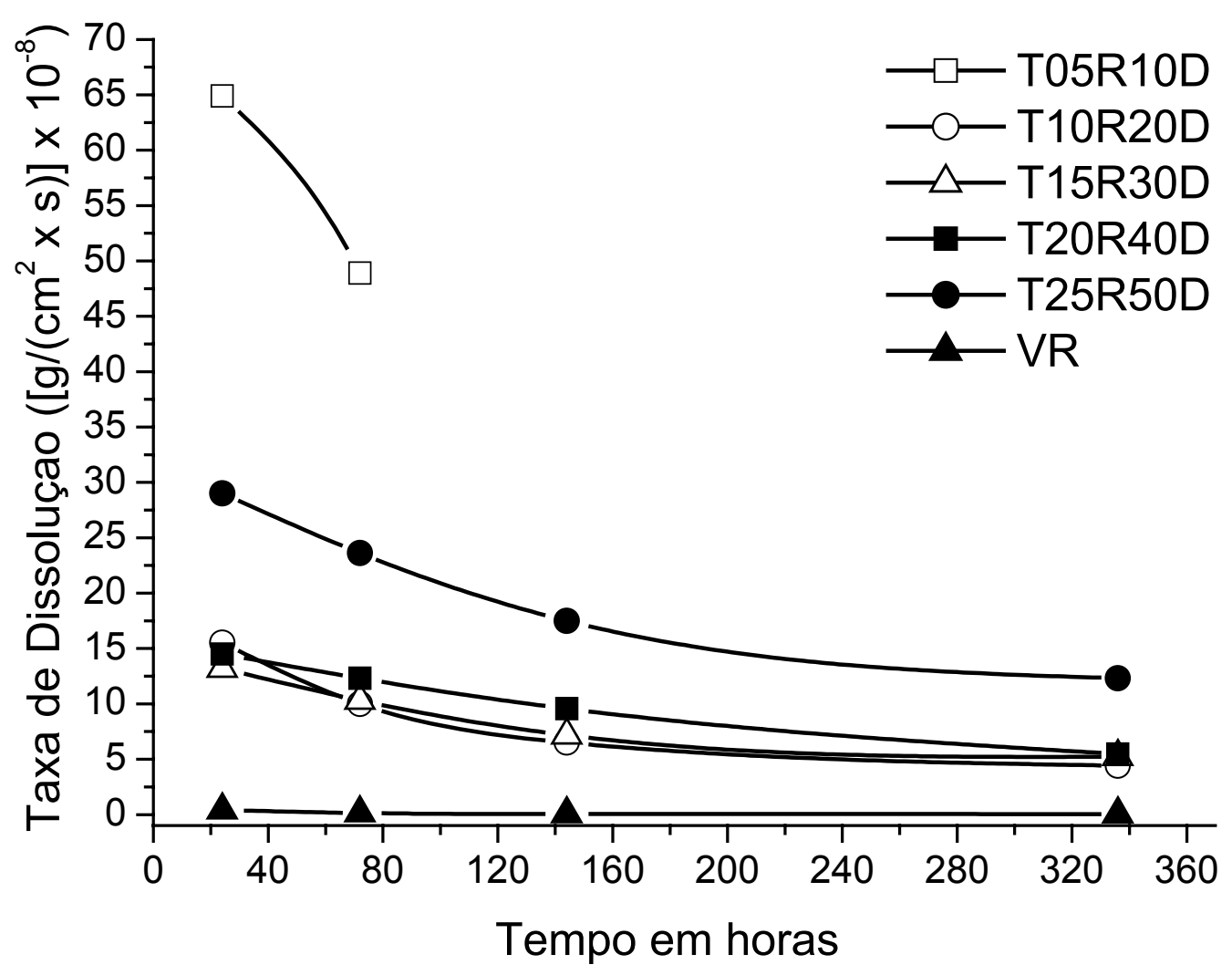

FIGURA 5.62- Taxa de dissolução em função do tempo obtidas no ensaio de resistência hidrolítica de amostras das composições TRD e VR

As micrografias e micro-análises de composição (MEV-EDS) relativas às composições das séries TCD e TRD, são apresentadas nas figuras desde 5.64-67. Nas condições de ensaio a dissolução superficial ocorre para todas as composições. 


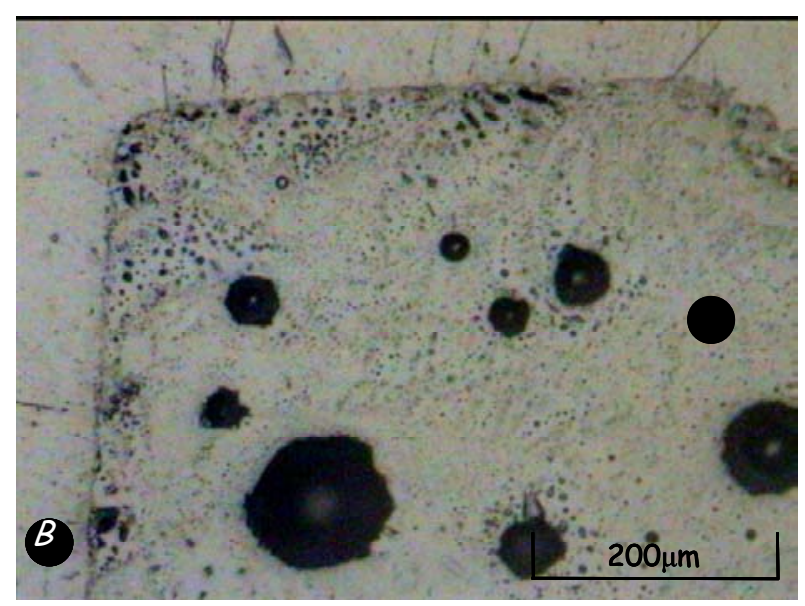

(a) T05CD

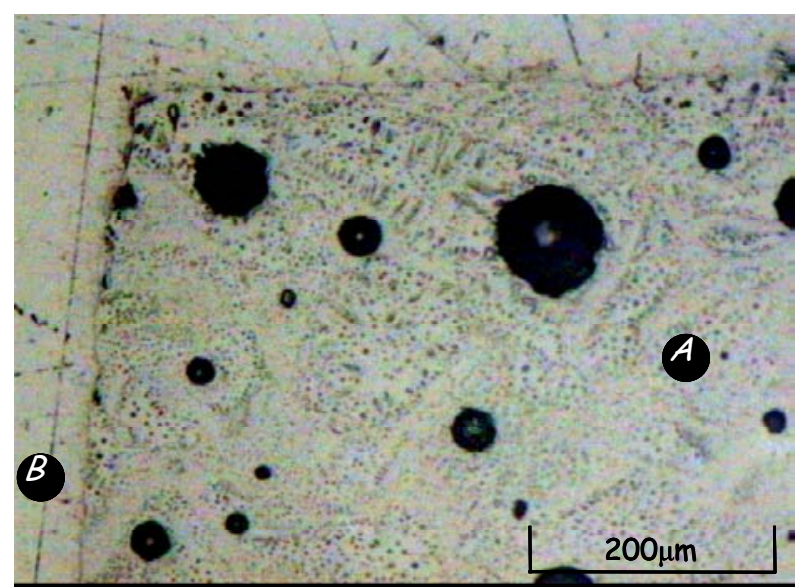

(b) T10CD

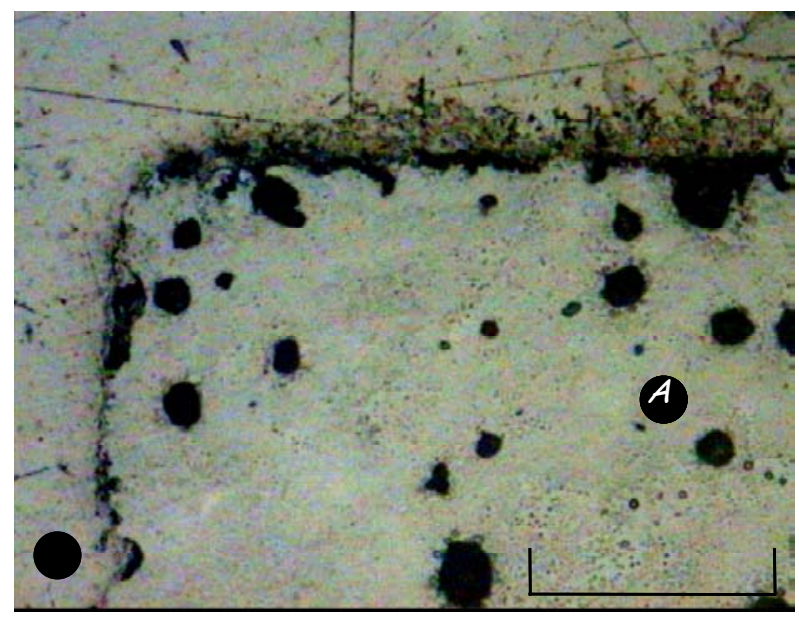

(c) T15CD

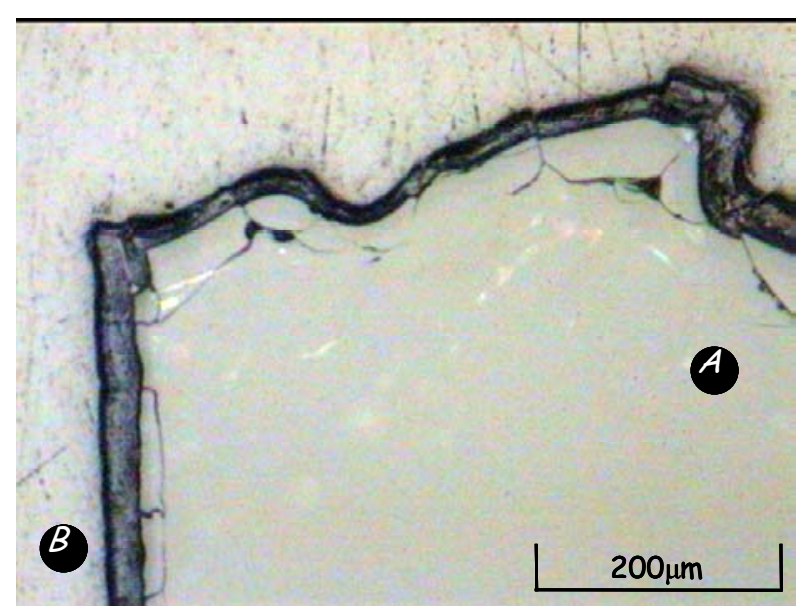

(e) T05R10D

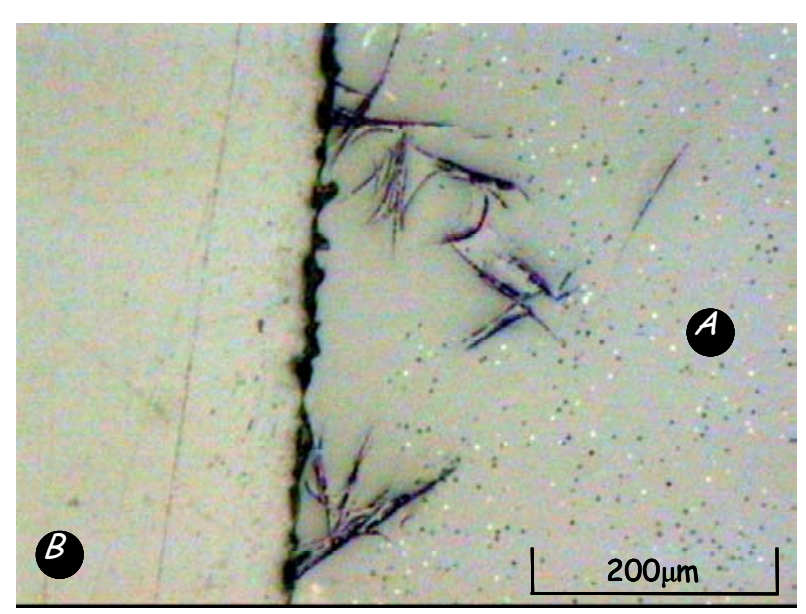

(f) T10R20D

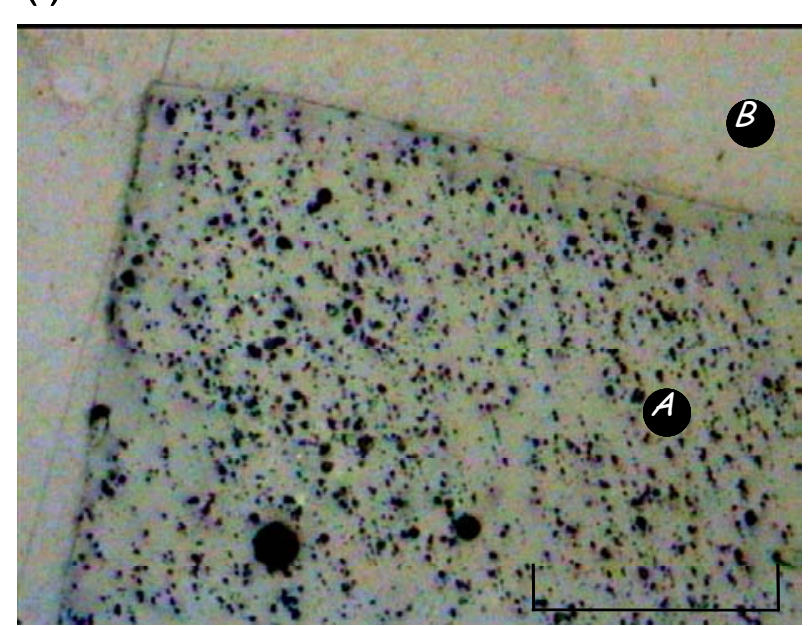

(g) T15R30CD

B resina do suporte

FIGURA 5.63 - Micrografias por microscopia óptica de luz refletida correspondentes à secção transversal obtidas a partir de amostras das composições TCD e TRD, após ataque hidrolítico ( $t=336 \mathrm{~h})$ 
Em todas as amostras foi detectada a presença de sódio na superfície do vidro após o ataque. Provavelmente pode estar ocorrendo a recristalização em presença dos íons cloreto.

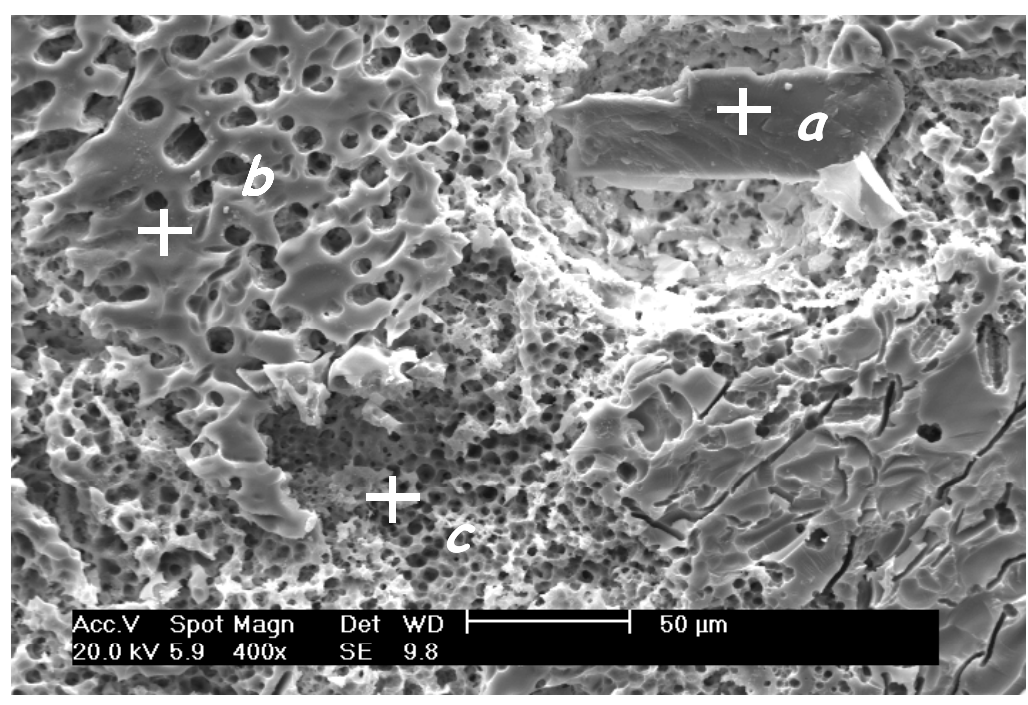

Microanálise

\begin{tabular}{lccc}
\multicolumn{2}{c}{ T10CD } \\
Elem & \multicolumn{3}{c}{ Massa } \\
& (a) & (b) & (c) \\
Na & 6,50 & 12,82 & 15,60 \\
Si & 86,07 & 83,15 & 78,99 \\
Ca & 7,42 & 4,04 & 5,41 \\
Total & $\mathbf{1 0 0}$ & $\mathbf{1 0 0}$ & $\mathbf{1 0 0}$
\end{tabular}

(a) T10CD

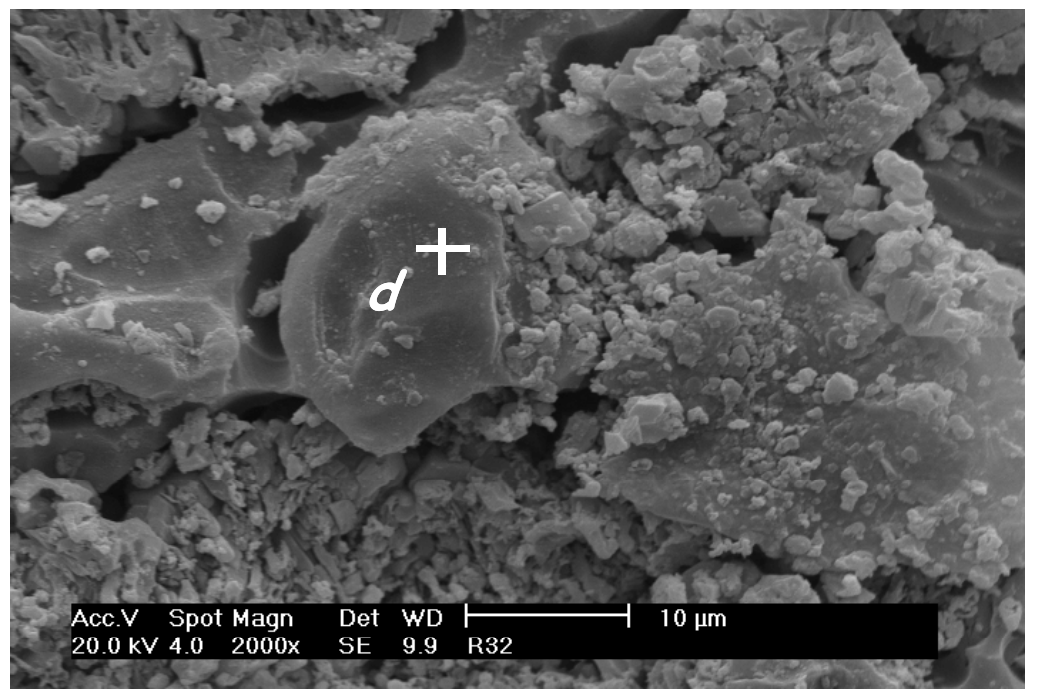

Microanálise

T15CD

Elem . Massa \%

(d)

$\mathrm{Na} \quad 13,19$

Si $\quad 74,73$

Ca 12,09

Total 100

(b) T15CD

FIGURA 5.64 - Superfície de amostras das composições TCD após ataque hidrolítico: (a) T10CD e (b) T15CD (MEV-EDS)

Na micrografia referente à composição T25R50D (Fig 5.66(b)), observase a formação da camada superficial e o desprendimento de parte desta. 
Para as composições TRD foi verificada a presença de cristais contendo cromo e/ou níquel em sua composição após o ataque, confirmado a estabilidade química dos metais na estrutura vítrea.

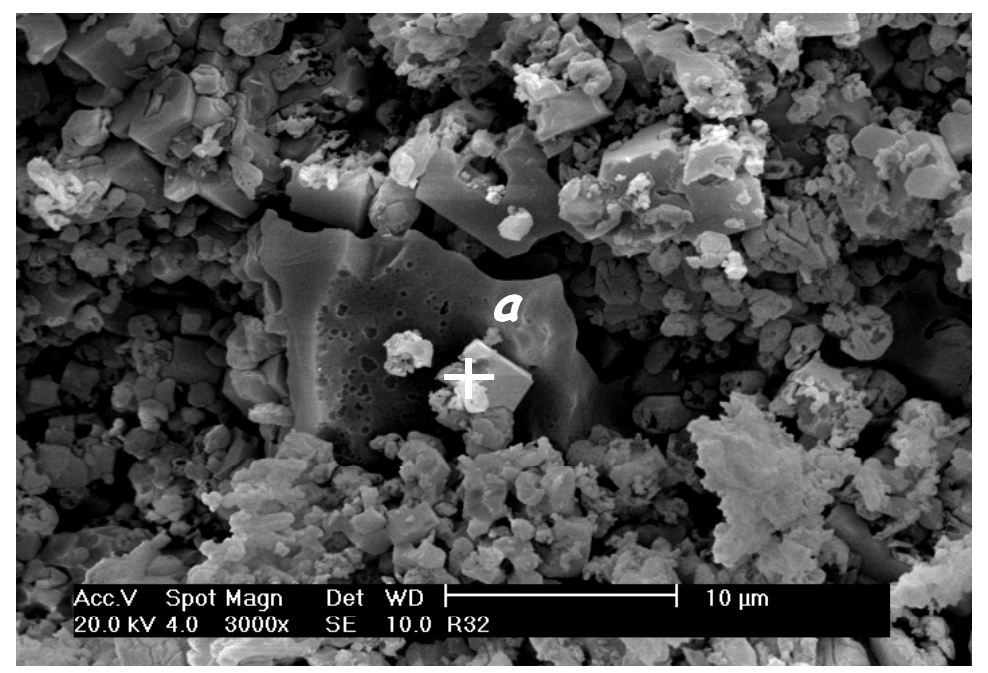

Microanálise

\section{T20CD}

Elem. Massa\%

(a) (b)

$\mathrm{Na} \quad 20,75 \quad 21,74$

Si $\quad 64,15 \quad 69,57$

Ca $\quad 15,09 \quad 8,70$

Total $\quad 100 \quad 100$

(a) T20CD

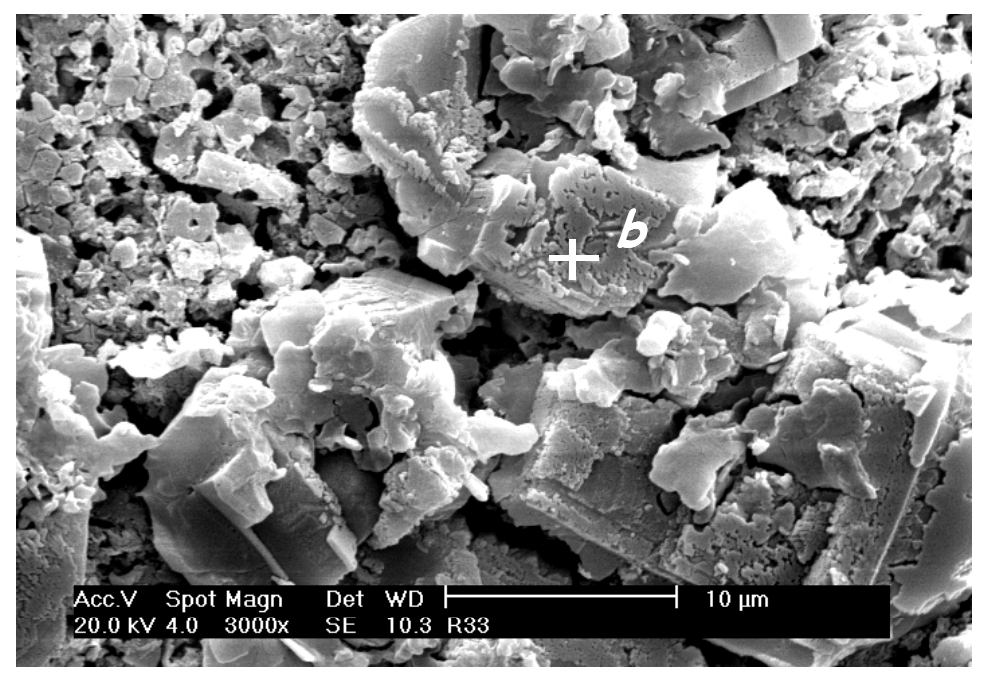

Microanálise

\section{T25CD}

Elem. Massa\%

(c)

Na $\quad 64,86$

Si $\quad 25,68$

Ca $\quad 9,46$

Total 100

(b) T25CD

FIGURA 5.65 - Superfície de amostras composições TCD após ataque hidrolítico:

(a) T20CD e (b) T25CD (MEV-EDS) 


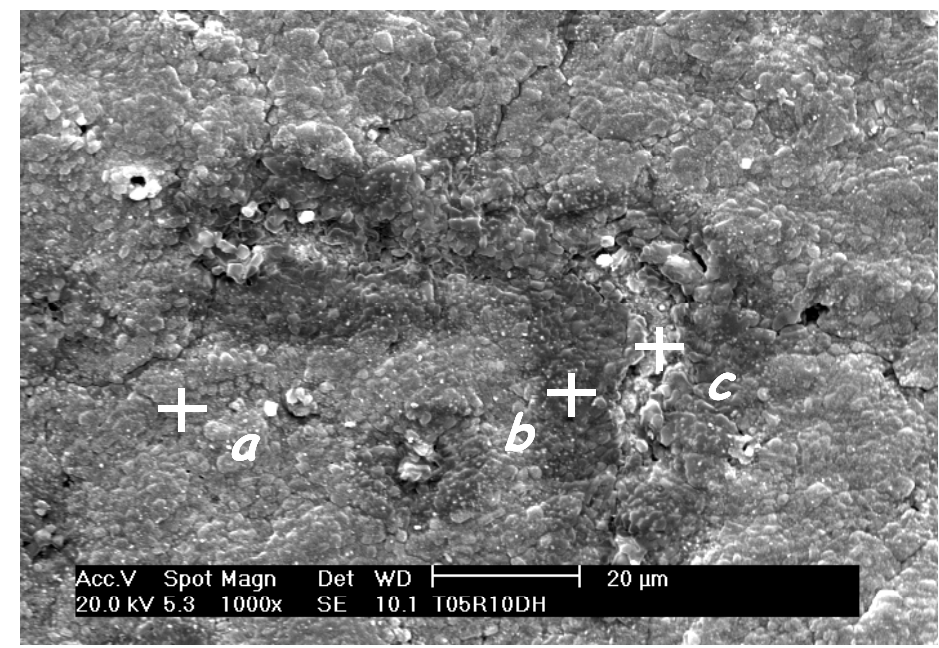

Microanálise T05R10D

\begin{tabular}{|c|c|c|c|}
\hline em & & Massa & $\%$ \\
\hline & (a) & (b) & (c) \\
\hline & 50,23 & 38,79 & 19,83 \\
\hline & 41,99 & 53,2 & 66,11 \\
\hline & 7,78 & 8,02 & 14,06 \\
\hline I & 100 & 100 & 100 \\
\hline
\end{tabular}

(a) T05R10D

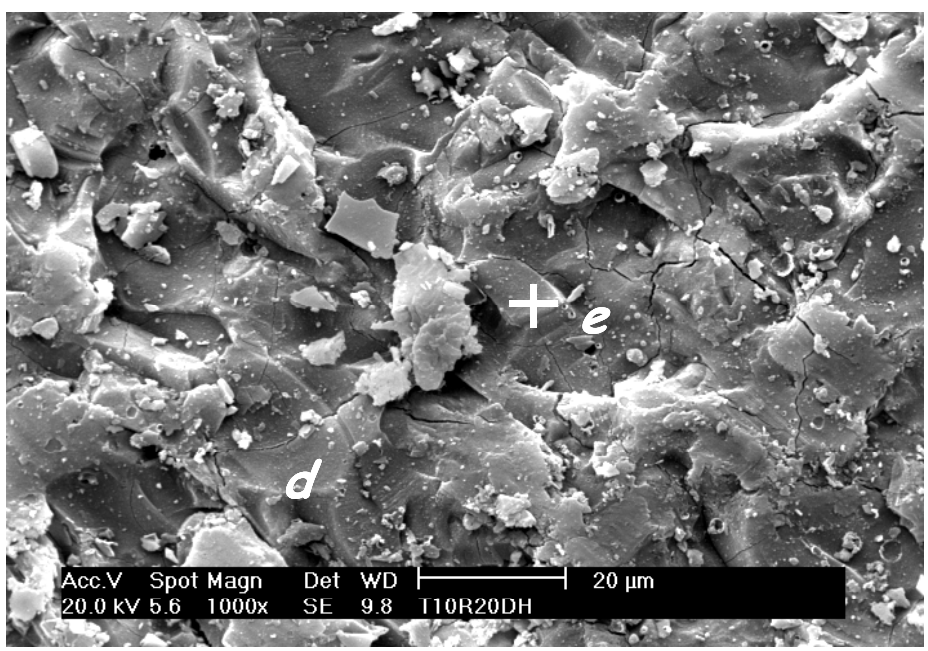

Microanálise

T10R20D
Elem. Massa \%

(d) (e)

$\mathrm{Na} \quad 4,11 \quad 9,70$

Si $\quad 77,05 \quad 81,58$

$\begin{array}{llllllll} & \mathrm{Ca} & - & -\end{array}$

Cr $\quad 2,97 \quad 3,27$

Ni $\quad 25,87 \quad 5,45$

Total $\quad 100 \quad 100$

(b) T10R20D

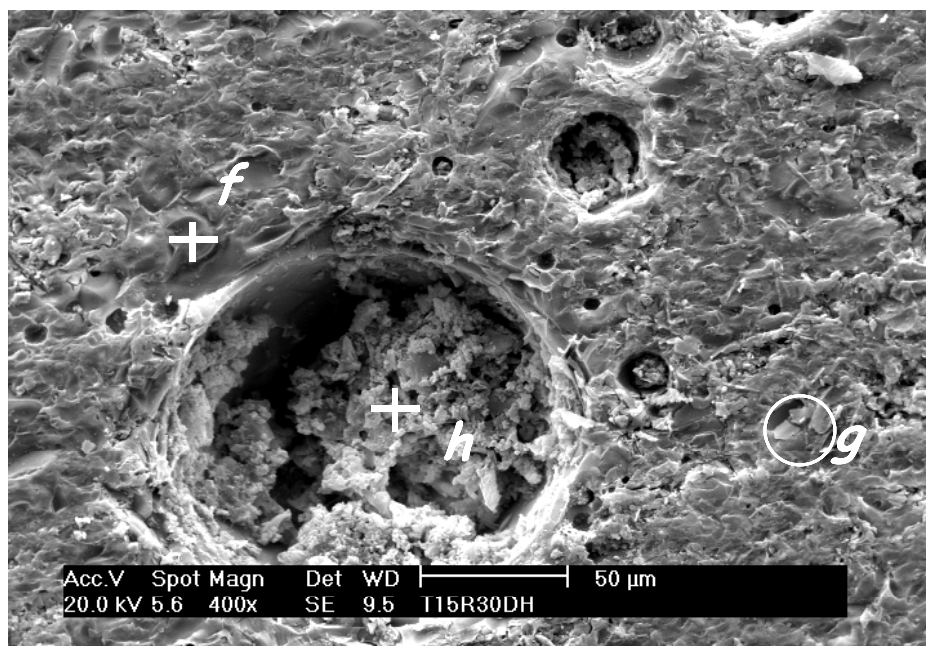

Microanálise

T15R30D

Elem .

$\begin{array}{lll}\text { Massa } & \% \\ \text { (a) } & \text { (b) } & \text { (c) }\end{array}$

$\mathrm{Na} \quad 12,67 \quad 2,67 \quad-$

Si $\quad 69,82 \quad 37,93 \quad 35,45$

$\begin{array}{llll}\mathrm{Ca} & - & 9,72 & 2,12\end{array}$

$\begin{array}{llll}\text { Cr } & 6,34 & 38,28 & 7,13\end{array}$

Ni $\quad 11,36 \quad 11,4 \quad 13,75$

$\begin{array}{llll}\text { Total } & 100 & 100 & 100\end{array}$

(c) T15R30D

FIGURA 5.66 - Superfície de amostras das composições TRD após ataque hidrolítico: (a) T05R10D; (b) T10R20D e (c) T15R30D (MEV-EDS) 


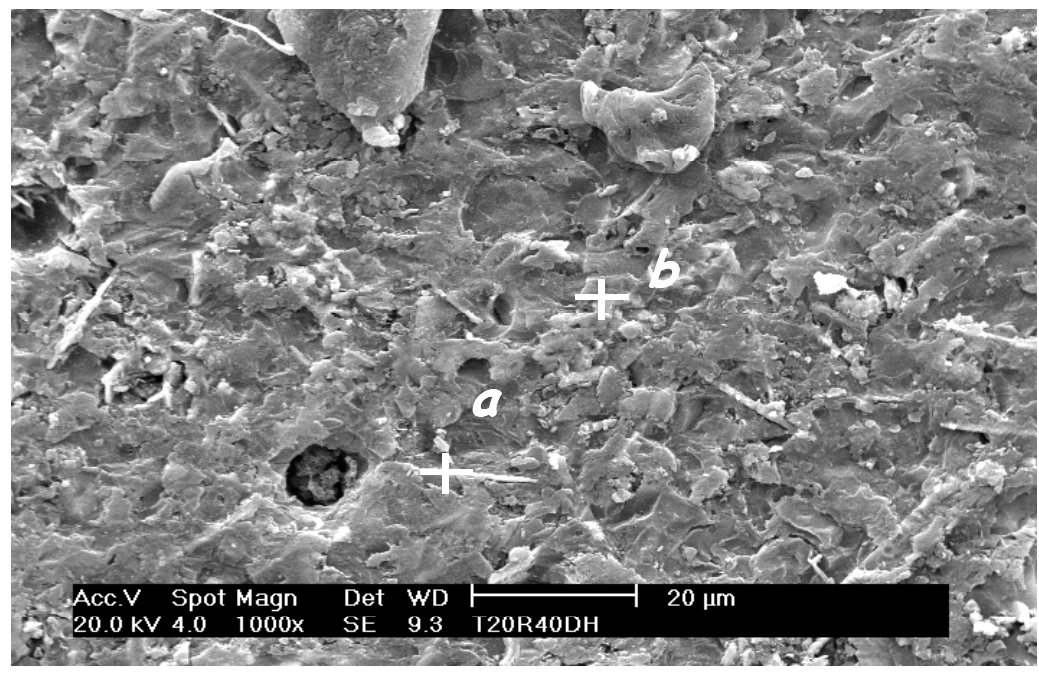

Microanálise

T20R40D

Elem. Massa\%

$\begin{array}{lcc} & (\mathbf{a}) & \mathbf{( b )} \\ \mathbf{N a} & 5,12 & 7,43 \\ \mathrm{Si} & 21,76 & 49,51 \\ \mathbf{C a} & 3,63 & 10,02 \\ \mathbf{C r} & 64,24 & 17,09 \\ \mathbf{N i} & 5,25 & 15,95 \\ \text { Total } & \mathbf{1 0 0} & \mathbf{1 0 0}\end{array}$

(a) T20R40D

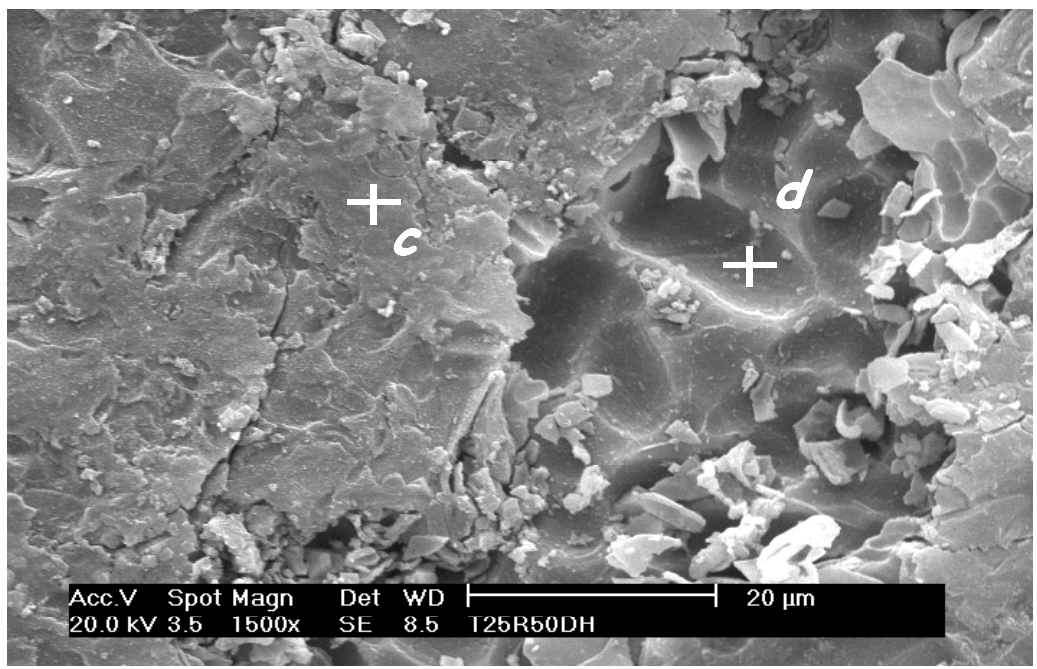

Microanálise

T25R50D

Elem. Massa\%

$\begin{array}{lcc} & (\mathbf{c}) & \mathbf{( d )} \\ \mathbf{N a} & 17,06 & 11,2 \\ \mathbf{S i} & 53,49 & 61,9 \\ \mathbf{C a} & 11,4 & 12,9 \\ \mathbf{C r} & 4,27 & 5,62 \\ \mathbf{N i} & 7,6 & 4,82 \\ \mathbf{C u} & 6,18 & 3,61 \\ \text { Total } & \mathbf{1 0 0} & \mathbf{1 0 0}\end{array}$

(b) T25R50D

FIGURA 5.67- Superfície de amostras das composições TRD após ataque hidrolítico: (a) T20R40D e (b) T25R50D (MEV-EDS)

A figura 5.68 representa os espectros obtidos por FTIR correspondentes aos vitrocerâmicos TCD e TRD após ensaio de resistência ao ataque hidrolítico (336 h).

A comparação entre os espectros de FTIR dos vitrocerâmicos TCD, Fig. 5.68(a), com os espectros dos vidros TC, Fig. 5.30-2 (a) mostram que as alterações ocorrem em todas as bandas analisadas para a composição T05CD. Os espectros revelam que a estrutura menos envolvida na dissolução foi na formada pelas ligações entre tetraedros de sílica e metais alcalino terrosos. 
Para os demais vitrocerâmicos TCD, observa-se que o ataque ocorreu com maior intensidade nas pontes de oxigênio referentes aos tetraedros de sílica $Q^{3}$ e $Q^{2}$ (pontos 5 e 6 na Fig. 5.68), os quais constituem os principais elementos da rede vítrea destes materiais. Observa-se também, a permanência de ligações referentes aos silicatos com o metal alcalino terroso e dos óxidos metálicos segregados (indicados respectivamente pelos pontos 15 e 16). As ligações Si-O-B aparentemente foram pouco envolvidas na dissolução durante $\mathrm{o}$ ataque hidrolítico (ponto 11). Por outro lado o óxido de sódio (Na-O) foi removido por este ataque. Ainda que nestes vidros coexistem fases amorfas e cristalinas de composição similar, a técnica de caracterização utilizada não permite determinar se a dissolução ocorreu preferencialmente para alguma destas fases.

$\mathrm{Na}$ comparação entre os espectros de FTIR dos vitrocerâmicos TRD e os os vidros TR, (Fig. 5.30-2 (b), respectivamente), observa-se que houve poucas alterações entre as composições T20R40 e T25R50, caracterizando uma alta resistência ao ataque hidrolítico. Para as demais composições da série TRD, observa-se que o ataque ocorreu com maior intensidade nas ligações referentes nas pontes de oxigênio referentes tetraedros de sílica $Q^{3}$ e $Q^{2}(5$ e 6 na Fig. 5.68(b)). A dissolução envolveu também as ligações referentes aos silicatos de metais, contudo foi menos acentuada para os óxidos metálicos segregados (indicados respectivamente nos pontos 15 e 16 na figura). As ligações Si-O-B foram aparentemente pouco envolvidas durante o ataque hidrolítico (ponto 11). $\mathrm{Na}$ composição T05R10, o óxido de sódio ( $\mathrm{Na}-\mathrm{O})$ foi removido (ponto 12).

As Fig. 5.69 e 5.70 representam respectivamente os difratogramas correspondentes aos vitrocerâmicos TCD e TRD após ataque hidrolítico. Comparando-se os difratogramas resultantes deste ensaio com os das Fig. $5.54 \mathrm{e}$ 5.56 , os quais representam o material antes de serem submetidos 0 ataque hidrolítico, constata-se que estes praticamente não se alteraram durante o ataque. De modo geral, as fases não foram envolvidas no processo de dissolução. $A$ exceção foi a amostra T05CD, para a qual a fase $\delta-\mathrm{Na}_{2} \mathrm{O} \cdot 2 \mathrm{SiO}_{2}$, não foi observada após o ataque, sugerindo que a mesma foi dissolvida durante o ensaio. 


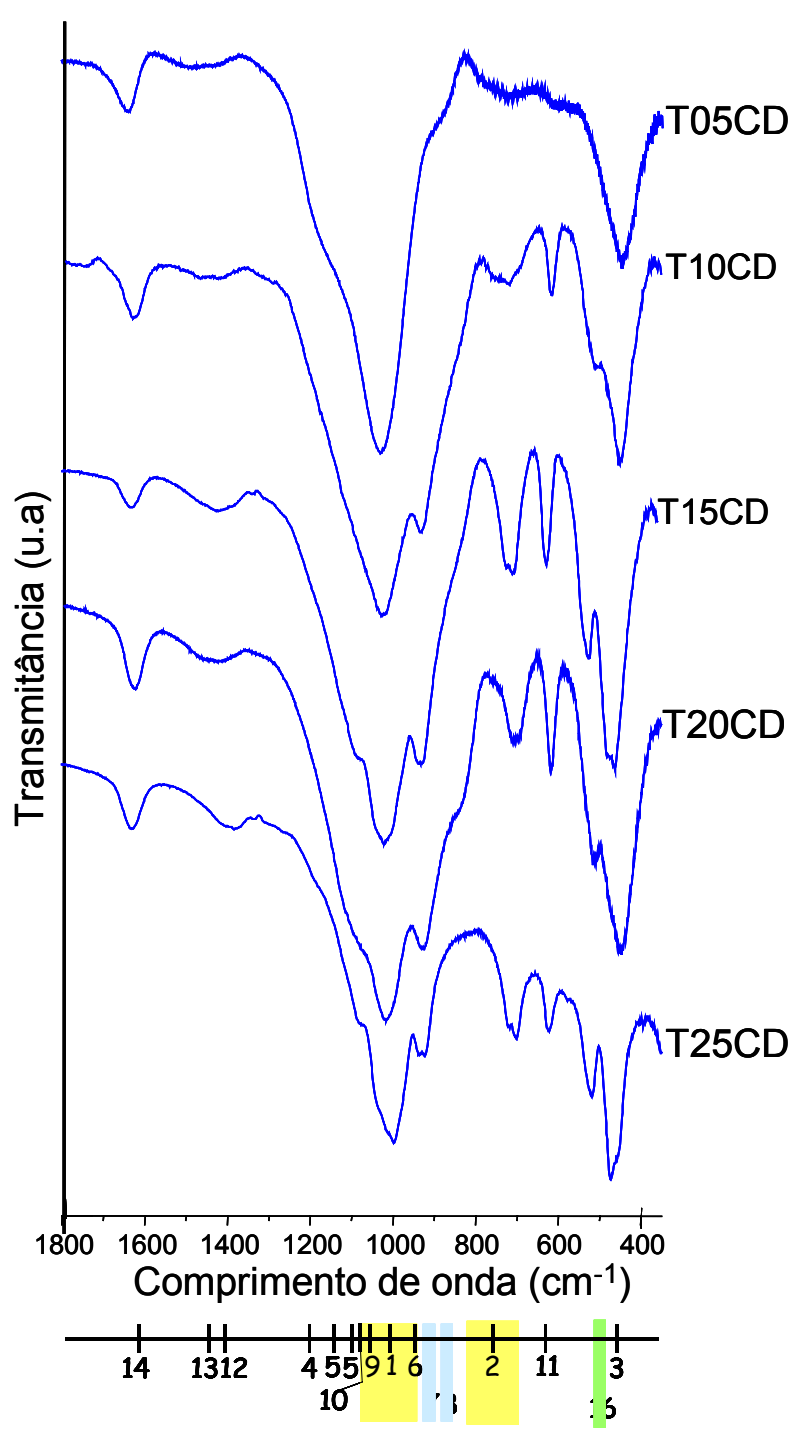

(a) Série TCD

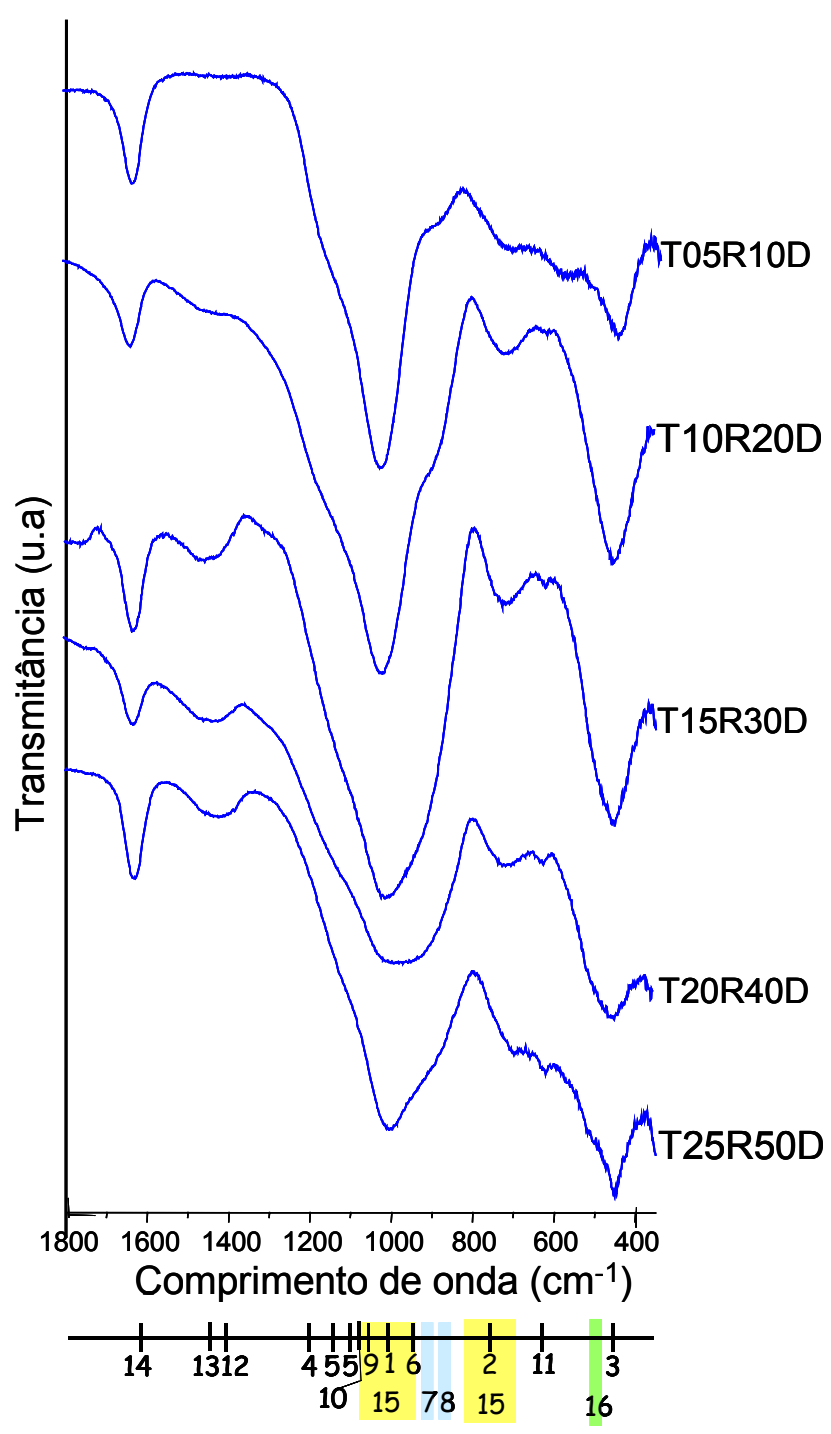

(b) Série TRD

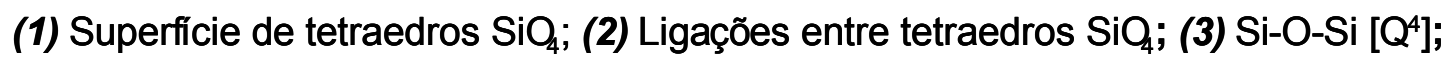

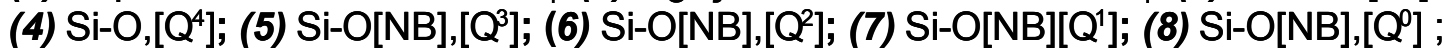

(9) Si-O-Si; (10) Si-O-[NB], plano; (11) Si-O-B Estrutural; (12) B-O Livre; (13) Na-O;

(14) Água livre; (15) Silicatos de metais;(16) Óxidos metálicos segregados.

Figura 5.68 - Espectros FT-IR de amostras das composições TCD e TRD, após ataque hidrolítico (336h).

A permanência das fases cristalinas para quase todos vitrocerâmicos após o ataque hidrolítico indica que as alterações observadas na caracterização por FTIR destes materiais (Fig. 5.68), ocorreram com maior intensidade na matriz 
vítrea. Indicando desta forma, que a matriz vítrea dos vitrocerâmicos, apresenta menor resistência ao ataque hidrolítico que os vidros originais (séries TC e TR).

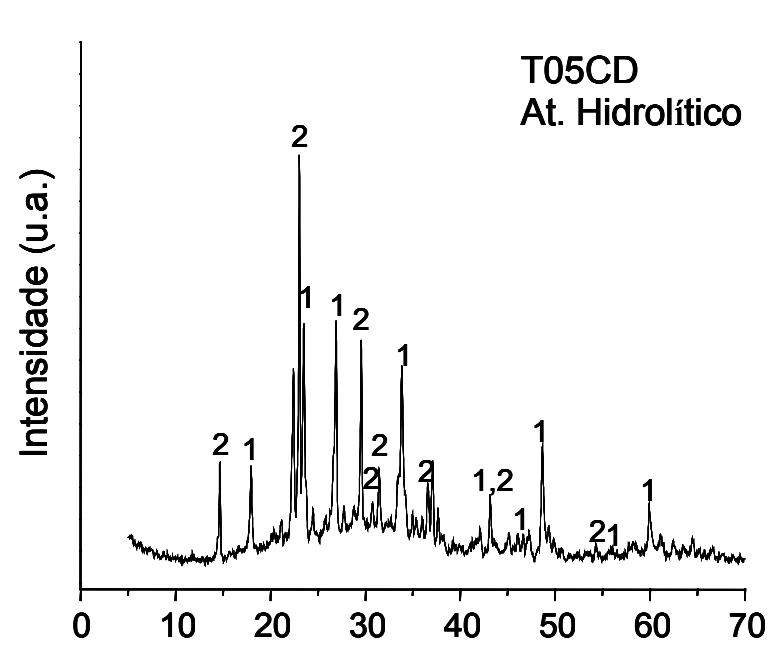

(a)

$2 \theta$

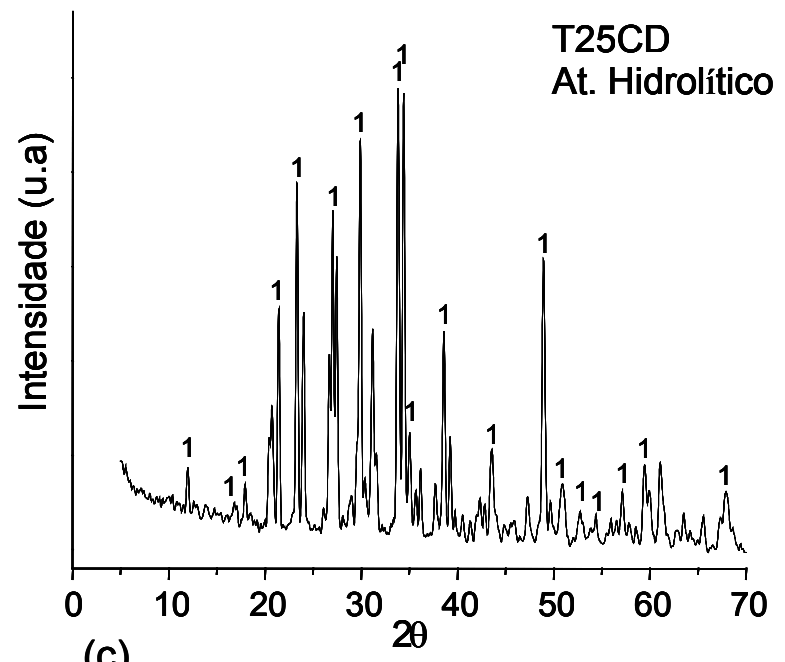

$$
1-\mathrm{Na}_{2} \mathrm{O}: 2 \mathrm{CaO}: 3 \mathrm{Si}_{2} \mathrm{O} ; 2-\alpha-\mathrm{Na}_{2} \mathrm{O}: 2 \mathrm{Si}_{2} \mathrm{O}
$$

FIGURA 5.69 - Difratogramas obtidos por DRX a partir de amostras das composições TCD após ensaios de resistência hidrolítica: (a) T05CD, (b) T10CD e (c) T25CD 


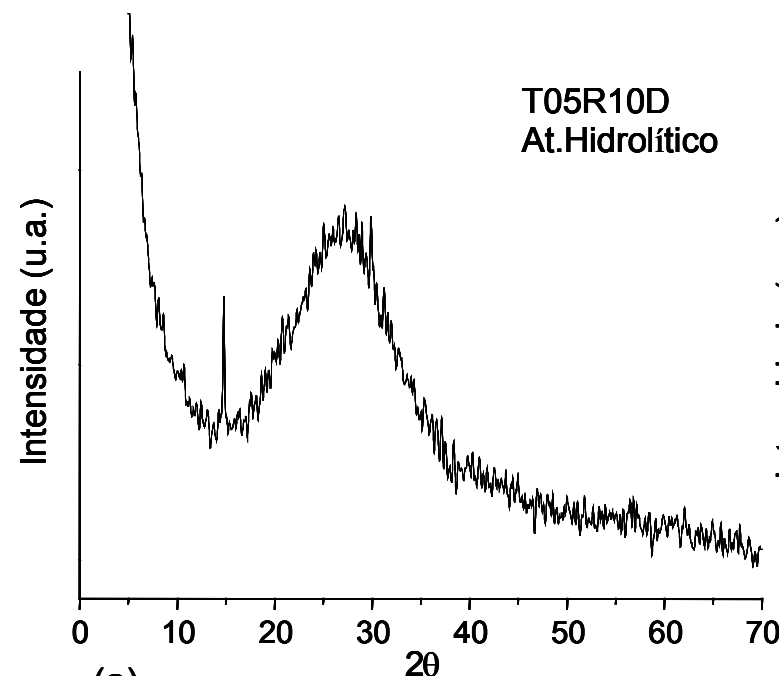

(a)

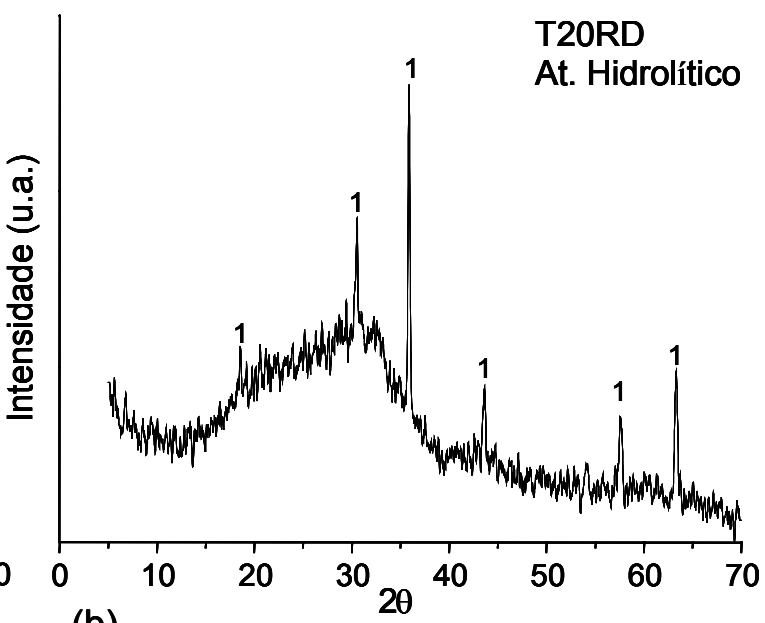

(b)

T25RD

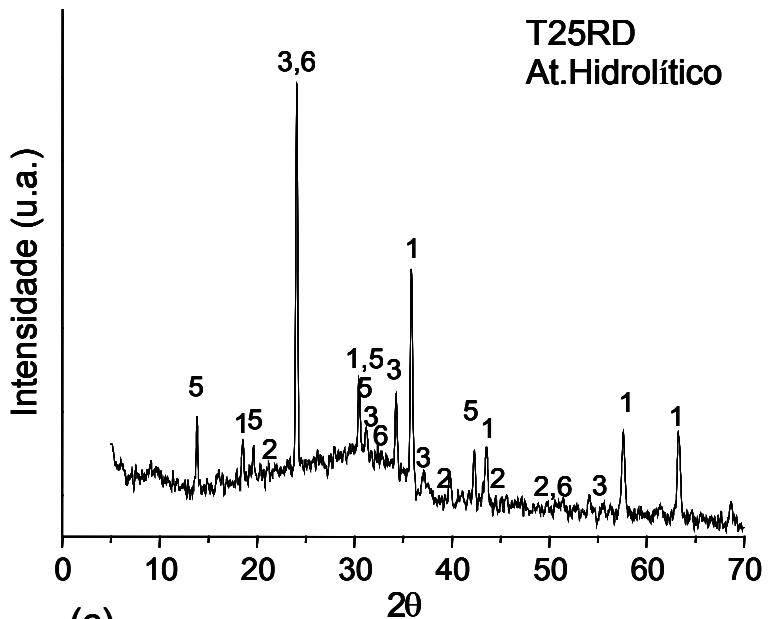

(c)

$$
1-\mathrm{Ni}\left(\mathrm{Cr}_{2} \mathrm{O}_{4}\right) ; 2-\mathrm{Ni}_{3} \mathrm{~S}_{2} ; 3-\mathrm{Cr}_{2} \mathrm{O}_{3} ; 4-\mathrm{NaCrSi}_{2} \mathrm{O}_{6} ; 5-\mathrm{Cu}_{2} \mathrm{~S}
$$

FIGURA 5.70 - Difratogramas obtidos por DRX a partir de amostras das composições TRD após ensaios de resistência hidrolítica: (a) T05R10D,

$$
\text { (b)T20R40D e (c) T25R50D }
$$

\subsubsection{2 - Resistência ao ataque ácido}

A Fig. 5.71 apresenta os resultados expressos em taxa de dissolução em função da concentração de modificadores obtidos no ensaio de resistência ao ataque ácido dos vitrocerâmicos TCD, TRD, e vidro VR. De uma forma geral, as composições TRD apresentam uma resistência ao ataque ácido similar as composições TCD. A queda na resistência, ou seja, o aumento da perda de massa, ocorre com o aumento da concentração de modificadores em ambas as 
séries, o que indica neste caso a maior influência da presença de modificadores do que da natureza do mesmo. A comparando-se estes resultados com os observados para os vidros de origem (TC e TR), tem-se que o processo ocorre de forma similar.

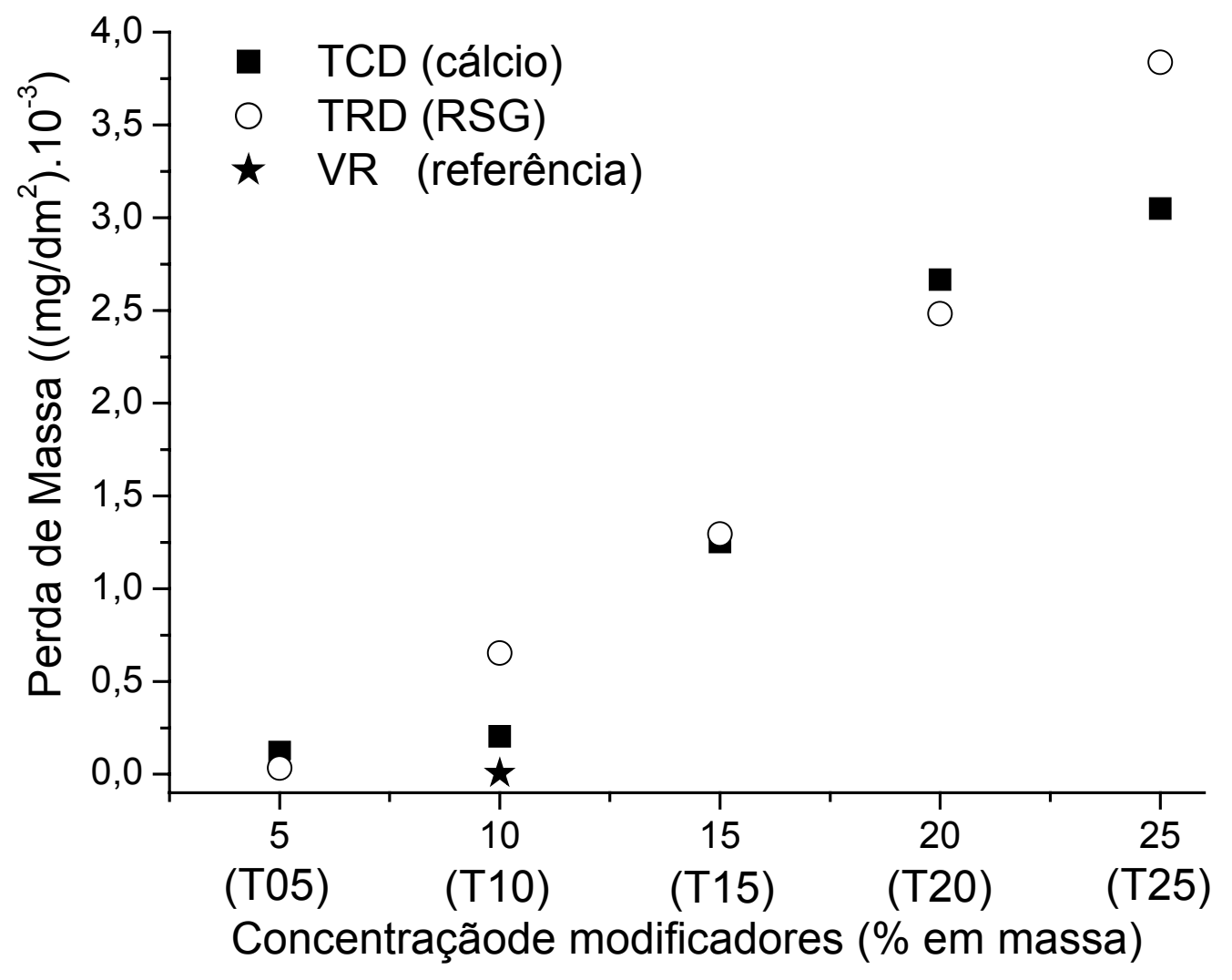

FIGURA 5.71 - Taxa de dissolução em função da concentração de modificadores obtidas no ensaio de resistência ao ataque ácido das amostras de composições TCD, TRD e VR

A Fig. 5.72 apresenta micrografias (microscopia óptica de luz refletida), correspondentes à secção transversal obtida a partir de amostras das composições TCD e TRD, após o ataque ácido. Nestas fotos, pode-se observar o ataque preferencial, o qual colabora para a rápida desagregação destes materiais, de forma similar à observada para os vidros TC e TR (Fig. 5.35). 


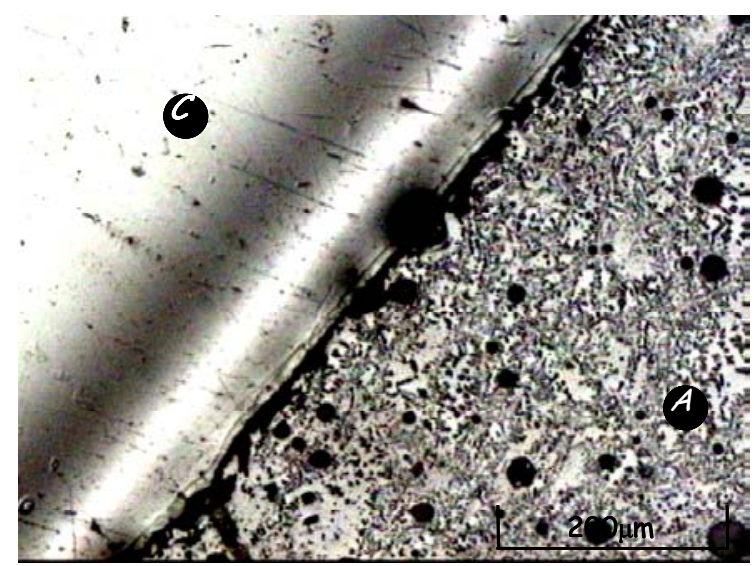

(a) T05CD

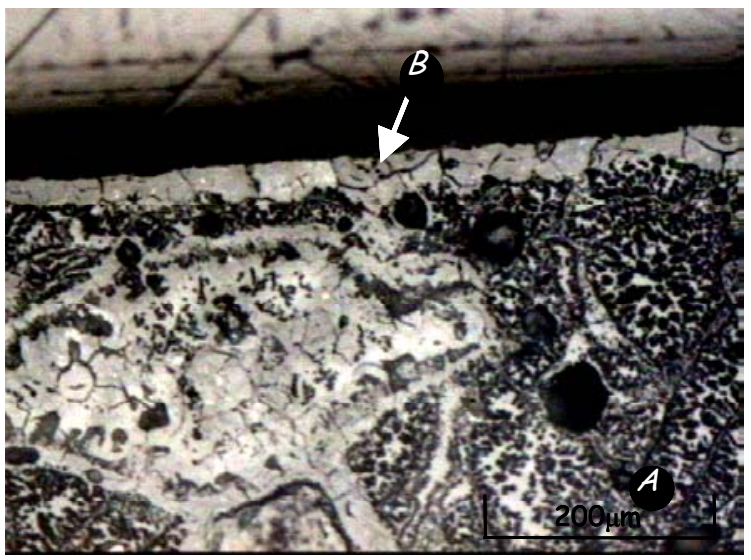

(b) T15CD

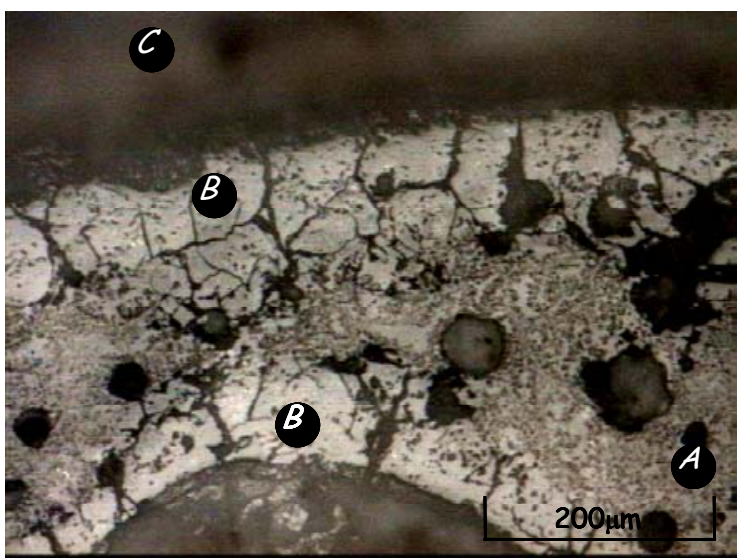

(c) T20CD

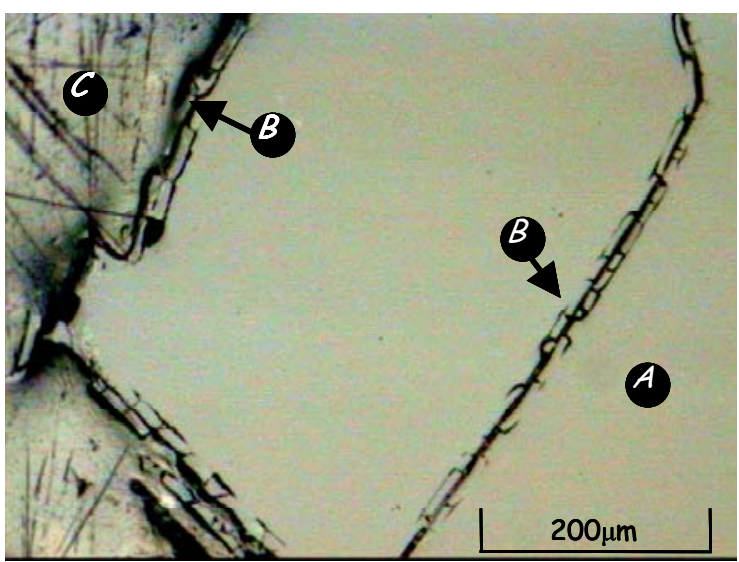

(d) T05R10D

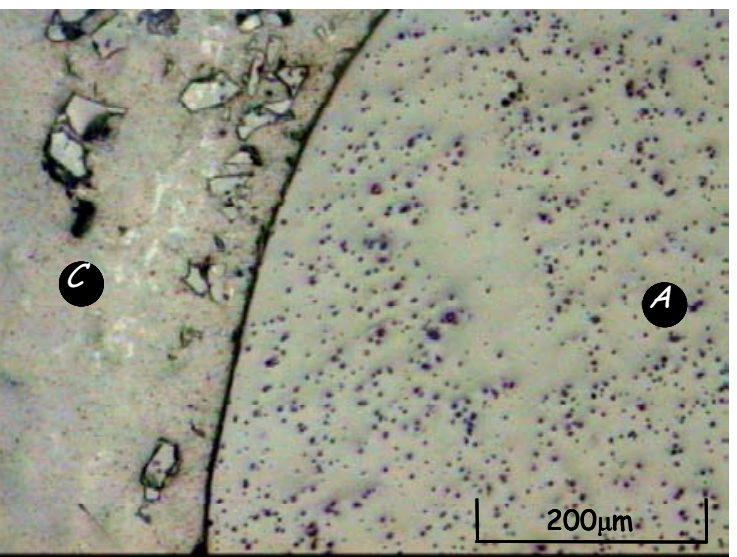

(e) T15R30 D

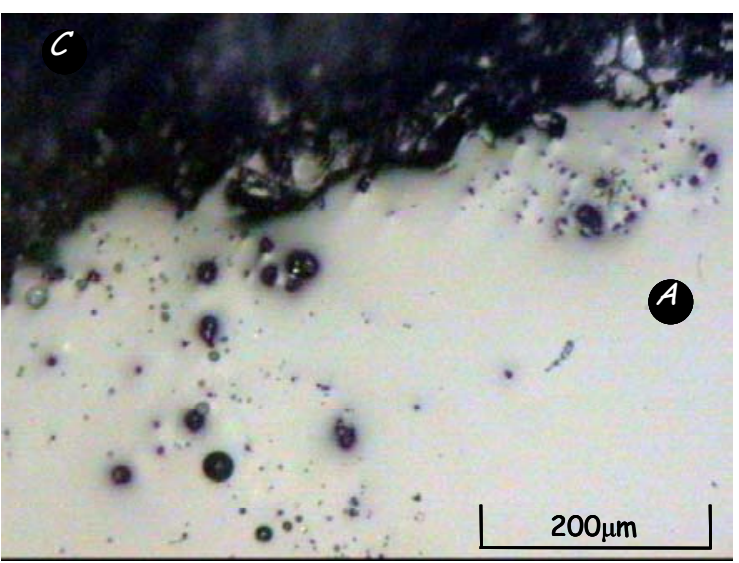

(f) T20R40D

\section{A matriz vitrea; B camada atacada; Cresina do suporte}

FIGURA 5.72 - Micrografias, correspondentes á secção transversal de amostras das composições TCD e TRD, após o ensaio de ataque ácido 
As micrografias e micro-análises de composição (MEV-EDS) relativas às séries TCD e TRD, são apresentadas nas Fig. 5.73-76. Nas condições de ensaio a dissolução superficial ocorre para todas as composições.

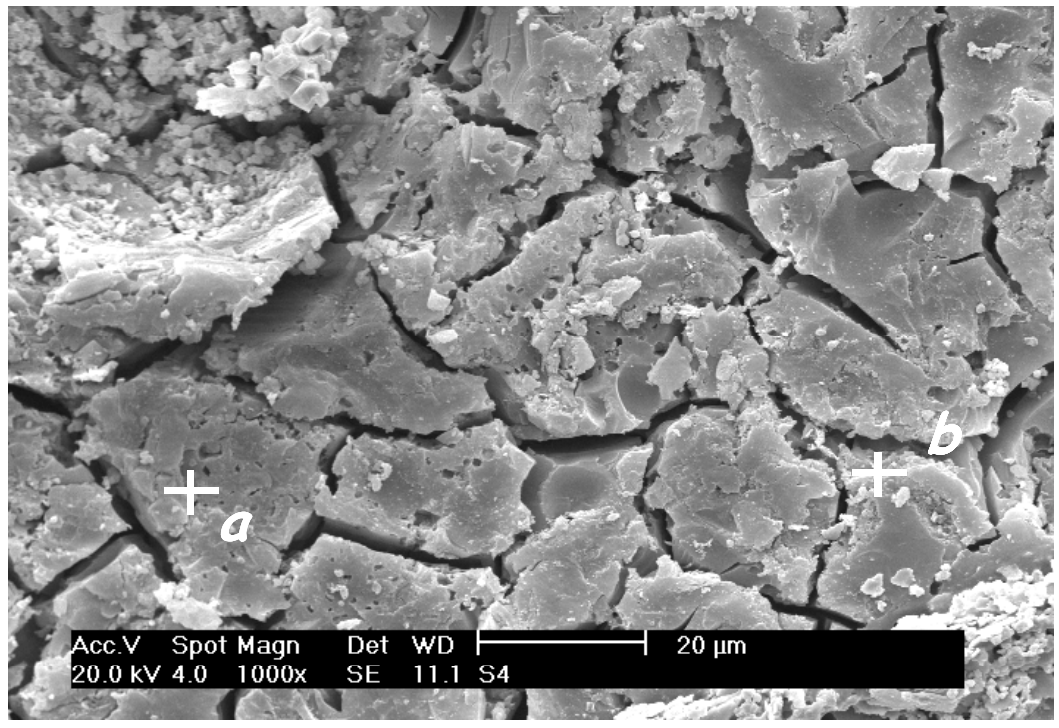

Microanálise

T10C

Elem. Massa\%

(a) (b)

$\mathrm{Na} \quad 0,00 \quad 6,88$

Al $\quad 0,00 \quad 13,44$

Si $\quad 100,00 \quad 57,84$

Ca $\quad 0,00 \quad 21,84$

Total $100 \quad 100$

(a) T10C

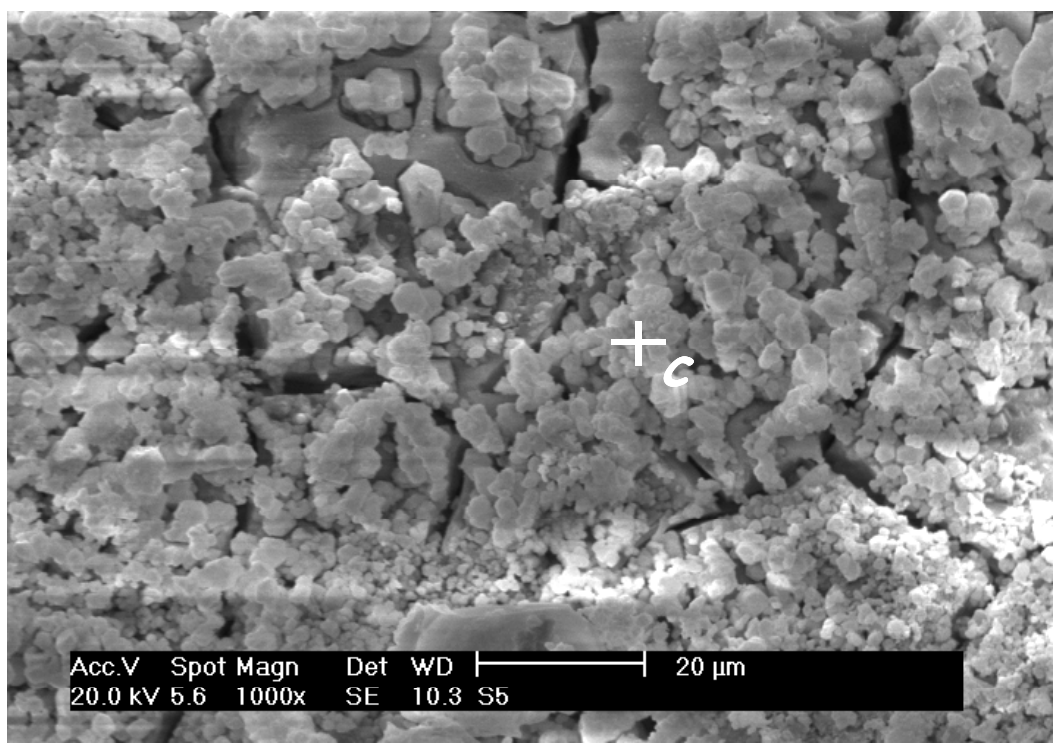

Microanálise

T15C

Elem. Massa\%

$\begin{array}{lc} & (\mathbf{c}) \\ \text { Si } & 100,00 \\ \text { Total } & \mathbf{1 0 0}\end{array}$

(b) T15C

FIGURA 5.73 - Superfície de amostras das composições TCD após ataque ácido: (a) T10C e (b) T15C (MEV-EDS)

Nas composições TCD (Fig. 5.73-74) observa-se para todas as amostras a formação de uma camada superficial, composta de sílica como conseqüência da remoção dos demais elementos pelo ataque em meio ácido. 


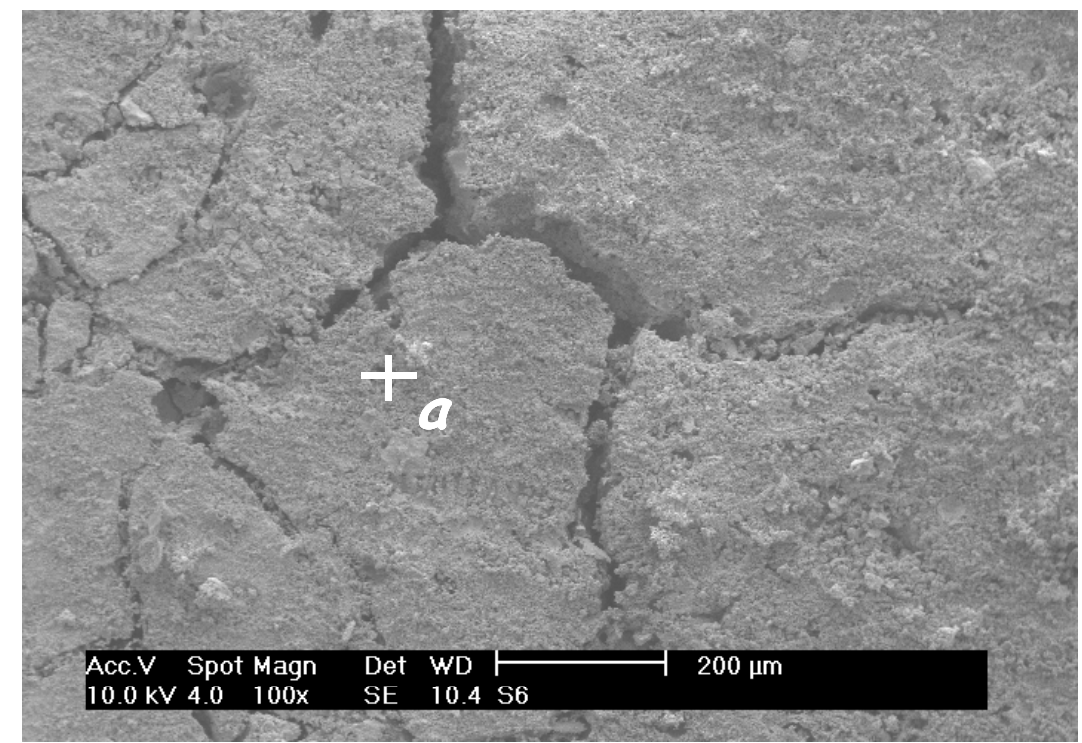

(a) T20C

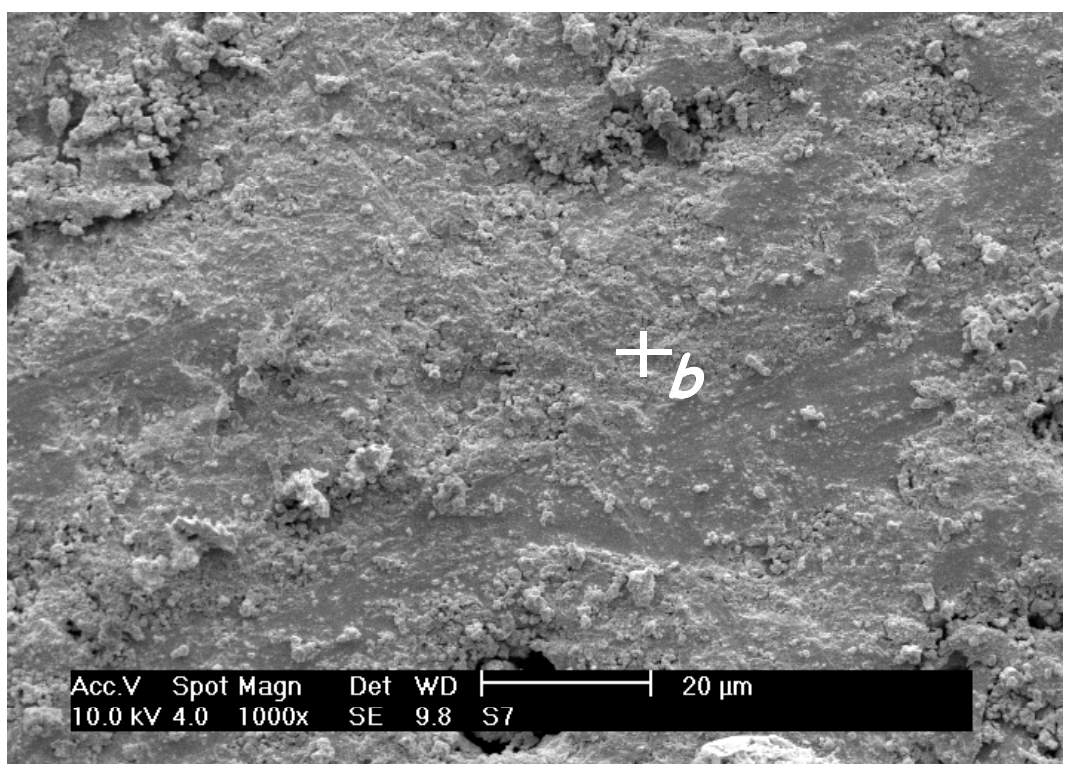

(b) $\mathrm{T} 25 \mathrm{C}$ álise

\section{T20C}

Elem. Massa\%

(a)

Si

Total 100

Microanálise

T25C

Elem. Massa\%

(b)

Na $\quad 6,88$

Al $\quad 13,44$

Si $\quad 57,84$

Ca 21,84

Total 100

FIGURA 5.74 - Superfície de amostras das composições TCD após ataque ácido: (a) T20C e (b) T25C(MEV-EDS)

Nas composições TRD (Fig. 5.75-76) observa-se para todas as amostras a formação e desprendimento da camada superficial, similar ao comportamento observado nas composições TCD. De forma geral esta camada apresenta menores concentrações de cromo e níquel que a matriz vítrea abaixo da mesma. Na Fig. 5.76(a,b) observa-se a permanência de fases secundarias 
contendo cromo e níquel, mostrando que as mesmas não foram removidas em meio ácido.

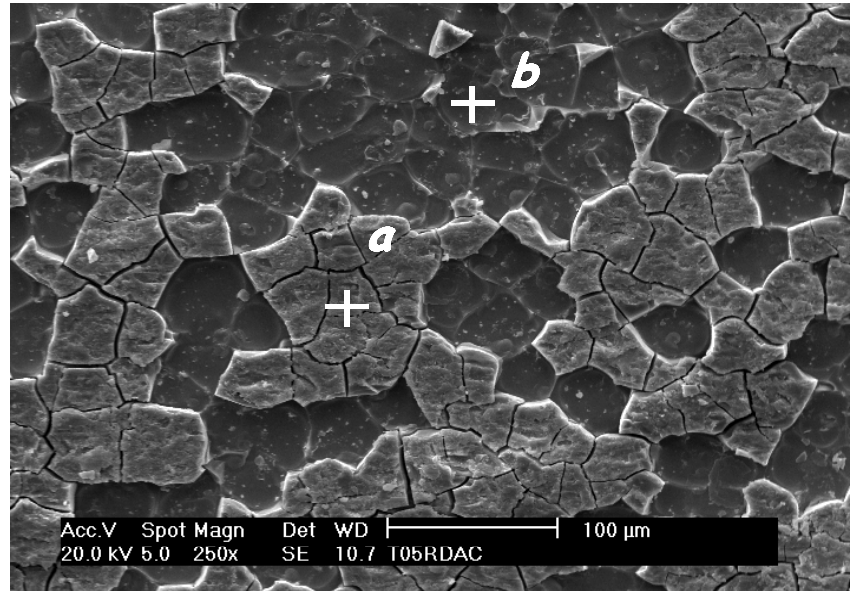

(a) T05R10D

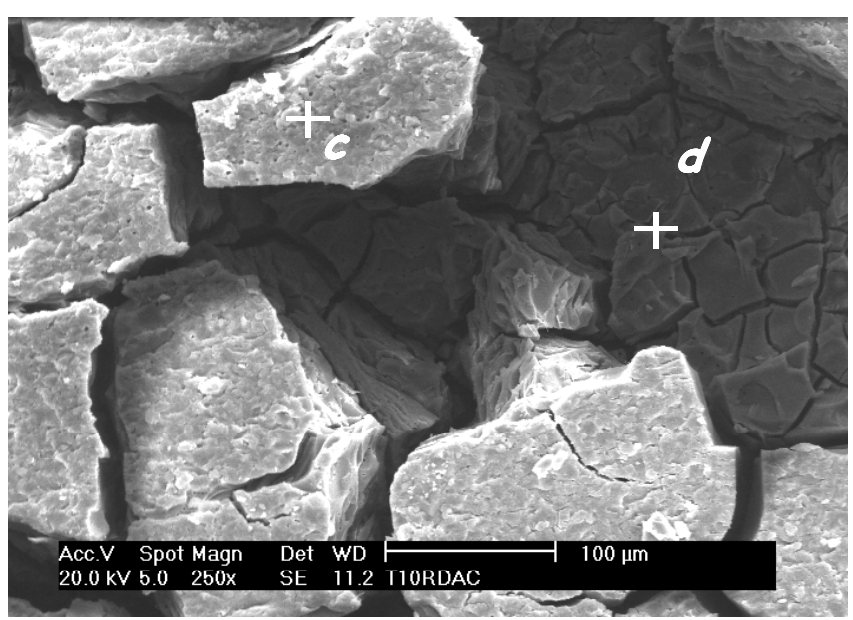

(b) T10R20D

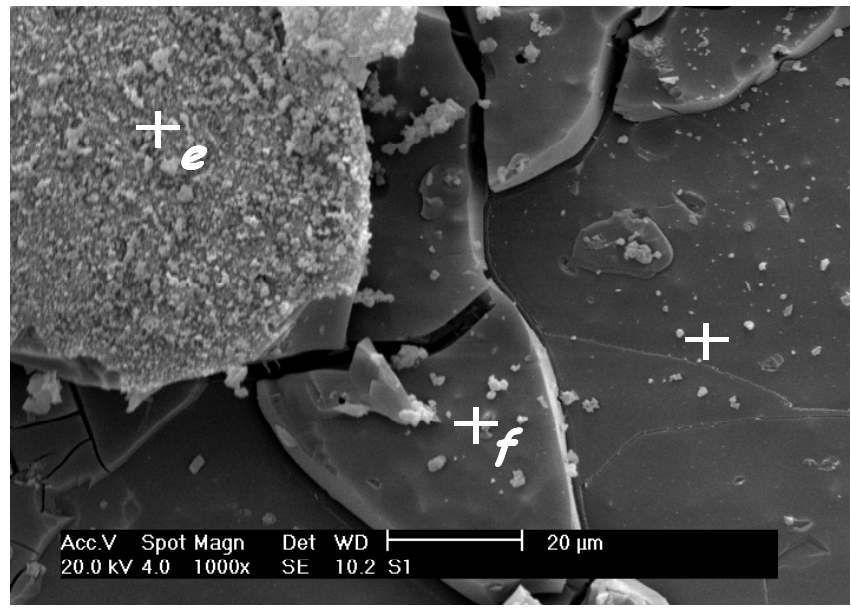

(c) T15R30D
Microanálise

T05R10D

Elem. Massa\%

$\begin{array}{lcc} & (\mathbf{a}) & \mathbf{( b )} \\ \mathbf{N a} & 2,84 & 2,87 \\ \mathbf{A l} & 6,01 & 3,51 \\ \mathbf{S i} & 86,64 & 66,51 \\ \mathbf{C a} & 0,51 & 5,52 \\ \mathbf{C r} & 1,50 & 11,53 \\ \mathbf{N i} & 2,50 & 10,06 \\ \text { Total } & \mathbf{1 0 0} & \mathbf{1 0 0}\end{array}$

Microanálise

T10R20D

Elem. Massa\%

(c) (d)

Na $\quad 1,08 \quad 1,14$

Al $\quad 2,25 \quad 1,86$

Si $\quad 93,1169,81$

Ca $\quad 0,89 \quad 1,16$

Cr $\quad 1,92 \quad 13,72$

Ni $\quad 0,75 \quad 12,31$

Total $100 \quad 100$

FIGURA 5.75 - Superfície de amostras das composições TRD após ataque ácido: (a) T05R10D, (b) T10R20D e (c) T15R30D (MEV-EDS) 


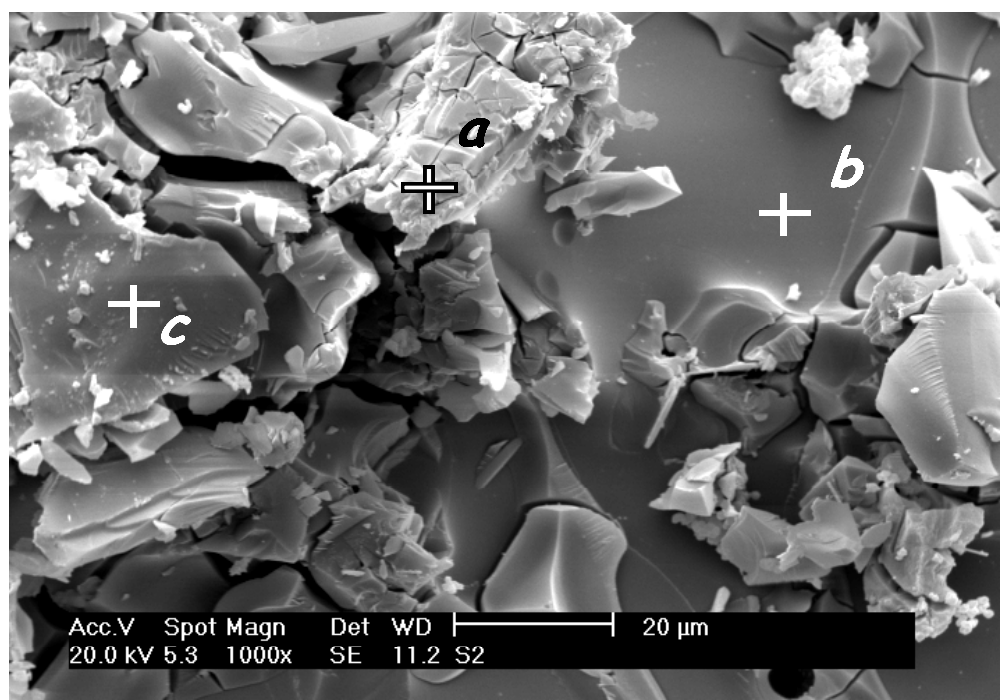

Microanálise

T20R40D

Elem . Massa \%

$\begin{array}{lccc} & (\mathbf{a}) & \mathbf{( b )} & \mathbf{( c )} \\ \mathbf{N a} & 0,00 & 12,18 & 4,63 \\ \mathbf{A l} & 0,00 & 12,38 & 8,90 \\ \mathbf{S i} & 29,02 & 64,62 & 71,00 \\ \mathbf{C r} & 47,89 & 4,54 & 4,33 \\ \mathbf{N i} & 23,09 & 6,28 & 11,14 \\ \text { Total } & \mathbf{1 0 0} & \mathbf{1 0 0} & \mathbf{1 0 0}\end{array}$

(a) T20R40D

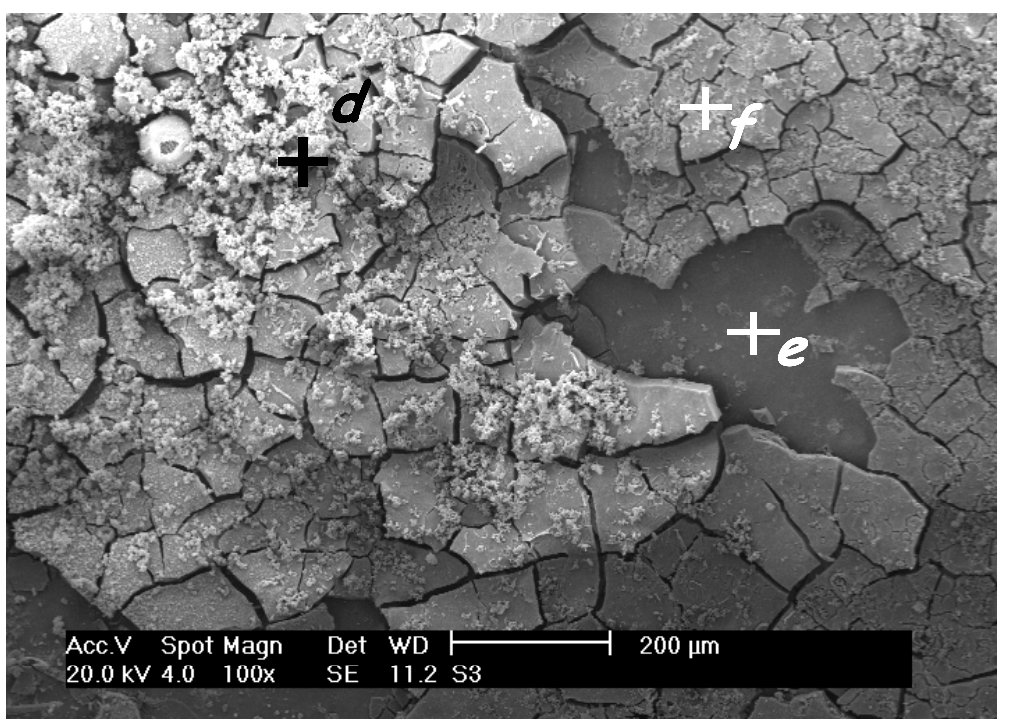

Microanálise

T25R50D

Elem .

Massa \%

$\begin{array}{lccc} & (\mathbf{d}) & \mathbf{( e )} & \mathbf{( f )} \\ \mathbf{N a} & 1,04 & 0,00 & 0,00 \\ \mathbf{A l} & 1,21 & 4,38 & 0,00 \\ \mathbf{S i} & 9,68 & 30,31 & 100,00 \\ \mathbf{C r} & 56,57 & 37,82 & 0,00 \\ \mathbf{N i} & 20,22 & 27,5 & 0,00 \\ \mathbf{Z n} & 11,27 & 0,00 & 0,00 \\ \text { Total } & \mathbf{1 0 0} & \mathbf{1 0 0} & \mathbf{1 0 0}\end{array}$

(b) T25R50D

FIGURA 5.76 - Superfície de amostras das composições TRD após ataque ácido: (a) T20R40D e (b) T25R50D (MEV-EDS)

Os espectros de FTIR (Fig. 5.77(a)) das composições TCD foram comparados com os espectros correspondentes aos mesmos materiais antes do ataque ácido, Fig. 5.60(a). Observa-se que para todos as composições TCD, ocorrem alterações nas bandas analisadas. Estas alterações estão associadas as ligações dos tetraedros de sílica $Q^{2}, Q^{1}$ e $Q^{0}$, que revelam ter sido submetidas a um intenso ataque ácido. As ligações referentes aos silicatos de metais alcalinos 
e alcalinos terrosos também foram envolvidos na dissolução (ponto 15). Tais resultados indicam que o processo de dissolução foi mais intenso nas ligações NBO, ou seja, o processo dominante foi ataque protônico, como apontado na literatura ${ }^{(24)}$. As alterações nas bandas associadas às ligações relativas ao boro estrutural, ao boro segregado, ao óxido de sódio e aos metais segregados (pontos 11, 12, 13 e 16, respectivamente) indicam que estas estruturas também foram amplamente envolvidas na dissolução. Convém destacar que entre as bandas características da estrutura dos vidros, as menos alteradas foram associadas às ligações Si-O-Si (ponto 3 na Fig. 5.77(a)) e nas bandas indicativas das ligações entre tetraedros revela que após o tratamento térmico, a estrutura da matriz vítrea tornou-se mais suscetível ao ataque protônico, ou seja, à degradação em meio ácido, quando comparadas aos vidros de origem (TC).

Comparando-se os espectros de FTIR das composições TRD com os espectros dos vidros TR, (Fig. 5.77(b) e 5.39(b) observa-se que as bandas dos espectrogramas apresentam comportamentos similares aos observados para a série TCD. Neste caso (série TRD), observa-se que ocorrem alterações menos intensas nas bandas associadas às ligações dos tetraedros de sílica $Q^{2}$ e $Q^{1}$. Este resultado esta de acordo com a predomínio do ataque protônico $\left(\mathrm{H}^{+}\right)$sobre as ligações do tipo não ponte (NBO's). Os metais de transição presentes foram mais efetivos na preservação da resistência química ao ataque ácido do que o $\mathrm{CaO}$. Este fato indica mais uma vez que pelo menos parte dos metais de transição, formam ligações mais estáveis com os tetraedros de $\mathrm{SiO}_{2}$, que as ligações iônicas normalmente formadas com o modificador cálcio. As bandas relacionadas às ligações do boro estrutural e do boro segregado (pontos 11 e 12), indicam que estas unidades estruturais permanecem. A resistência do boro ao ataque ácido, pode estar associada à coordenação tetraédrica, cujo o favorecimento nos materiais contendo RSG, foi verificada pelos ensaios utilizando-se RNM-MAS.

A presença do sódio após o ataque ácido, indicada pelo ponto 13 na Fig. 5.77, esta associada à formação de produtos durante a dissolução.

Os espectros DRX a partir de amostras pulverizadas das composições TCD e TRD submetidas ao ataque ácido são mostradas nas Fig. 5.78 e 5.79 .

Nos vitrocerâmicos TCD, figura 5.78, foi observada uma fase cristalina identificada como $\mathrm{NaCl}$. Este $\mathrm{NaCl}$, é provavelmente produto da 
dissolução e reprecipitação sobre a superfície das amostras após a secagem. Estes resultados indicam que o processo de dissolução ocorreu nestes vidros principalmente para as NBO's, como detectado nos resultados de análises por FTIR (Fig. 5.77).

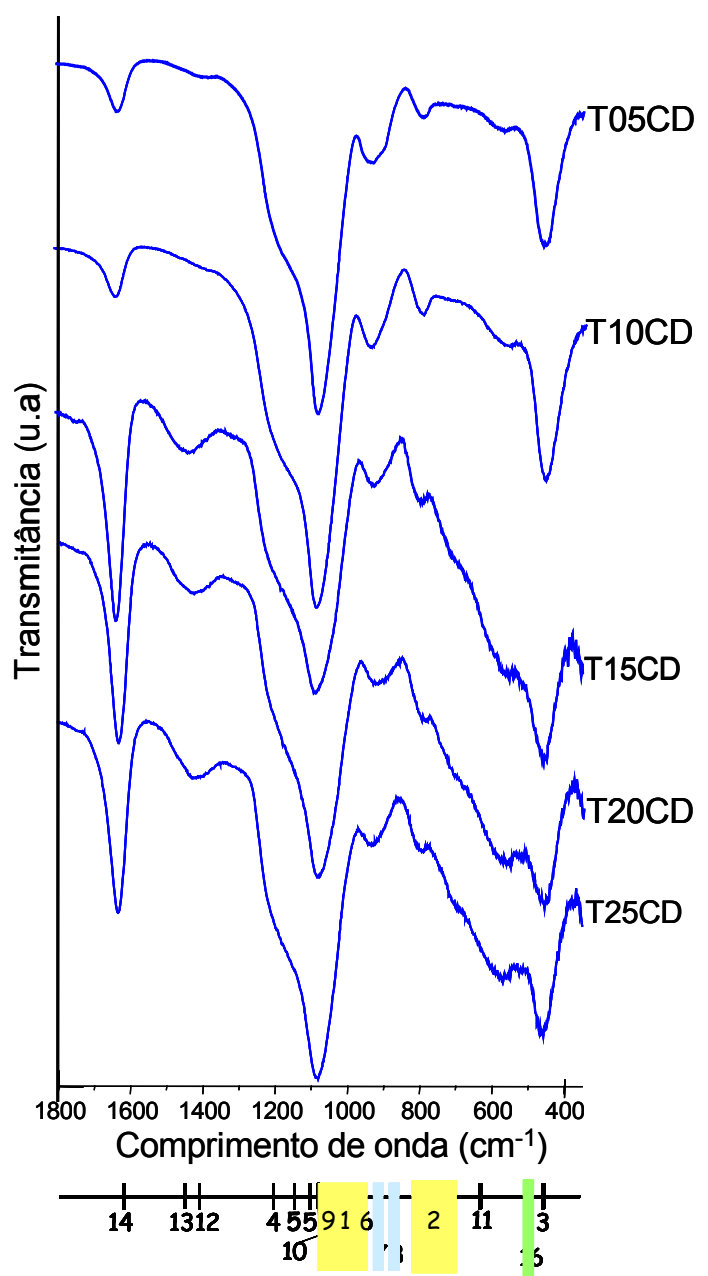

(a) Série TCD

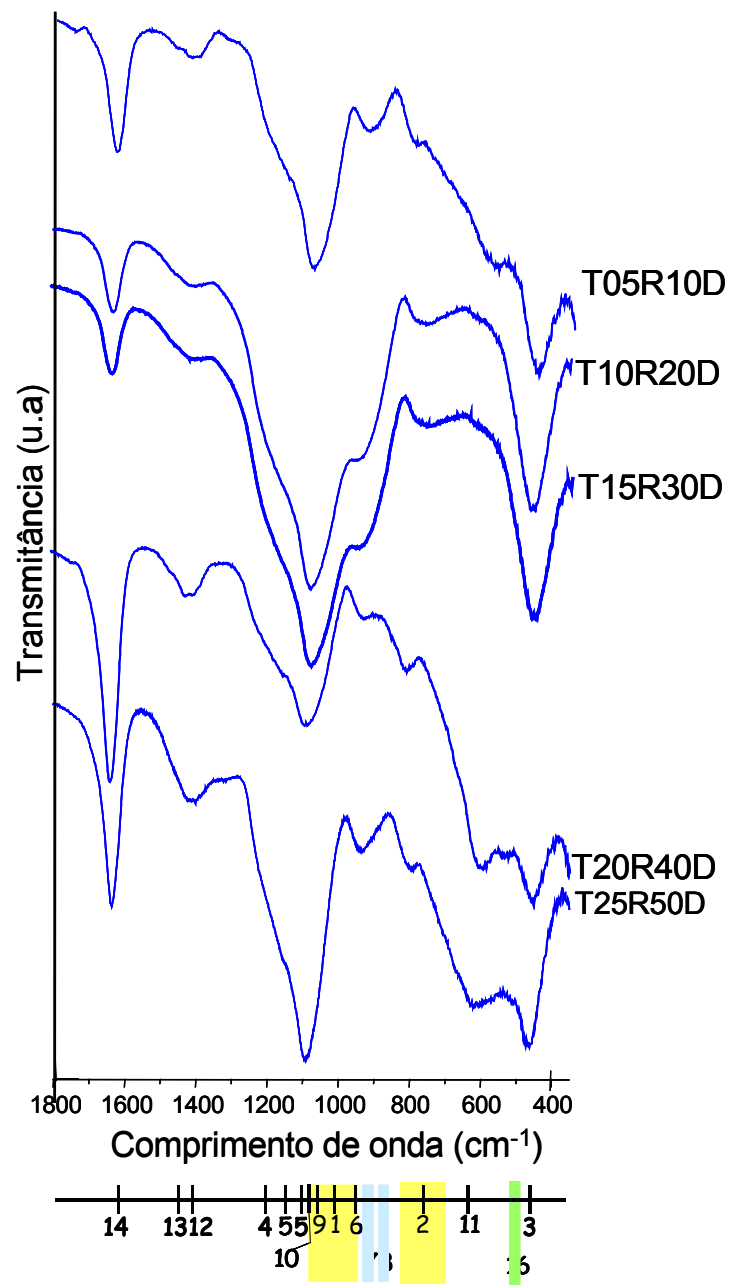

(b) Série TRD

(1) Superfície de tetraedros $\mathrm{SiO}_{4}$; (2) Ligações entre tetraedros $\mathrm{SiO}_{4}$; (3) $\mathrm{Si}-\mathrm{O}-\mathrm{Si}\left[\mathrm{Q}^{4}\right]$;

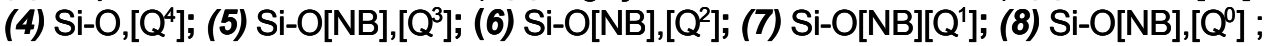

(9) Si-O-Si; (10) Si-O-[NB], plano ; (11) Si-O-B Estrutural; (12) B-O Livre; (13) Na-O; (14) Água livre; (15) Silicatos de metais; (16) Óxidos metálicos segregados.

FIGURA 5.77 - Espectros FT-IR de amostras das composições TCD e TRD após o ensaio de ataque ácido.

Nas composições TRD (Fig. 5.78) além da presença de $\mathrm{NaCl}$ observase picos correspondentes ao $\mathrm{Ni}\left(\mathrm{CrO}_{4}\right)$ (PDF 88-0108), as demais fases compostas pelos metais de transição presentes nos vidros TR, não foram 
observadas após o ataque ácido. Tais resultados indicam que o tratamento térmico prolongado promoveu alterações nos cristais originalmente presentes nos vidros, tornando-se portanto mais suscetíveis à degradação no meio ácido.
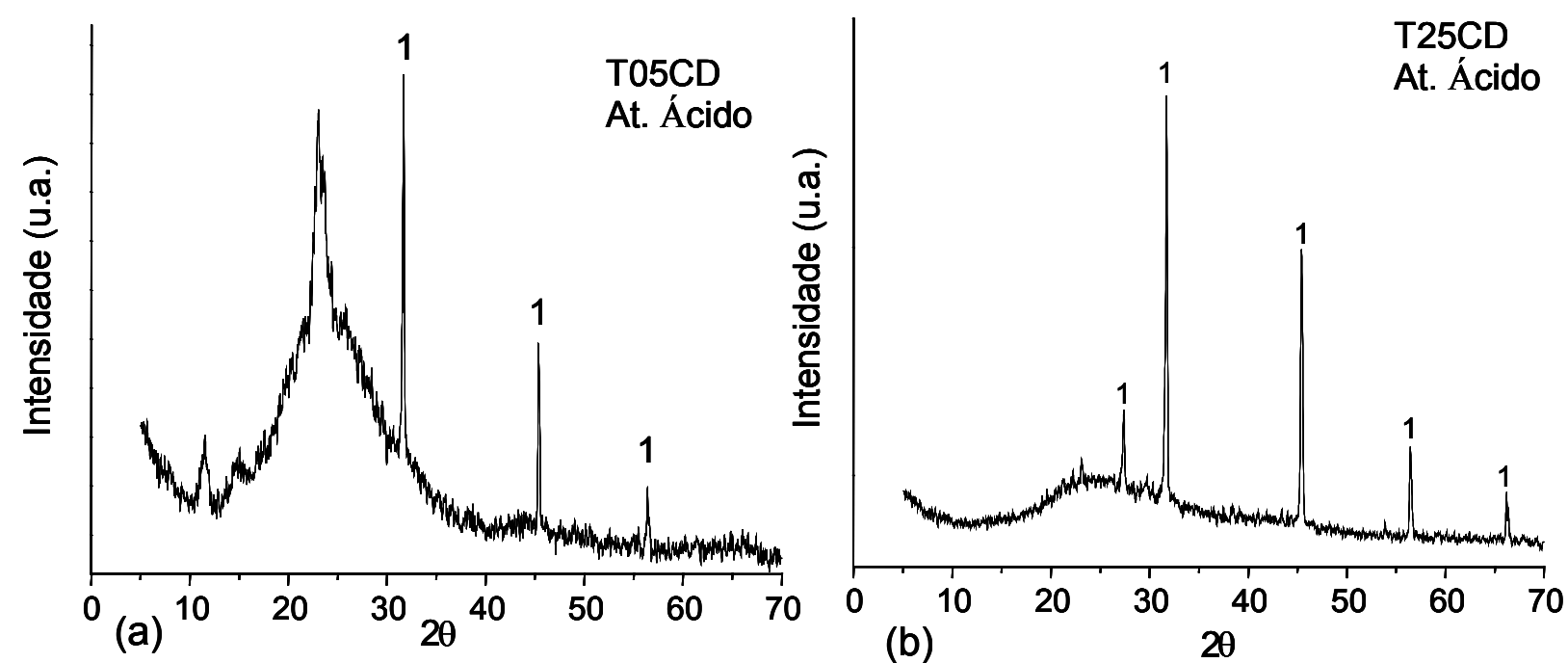

(b)

$2 \theta$

$1-\mathrm{NaCl}$

FIGURA 5.78 - Difratogramas obtidos por DRX a partir de amostras das composições TCD, após o ensaio de ataque ácido: (a) T05CD e (b) T25CD

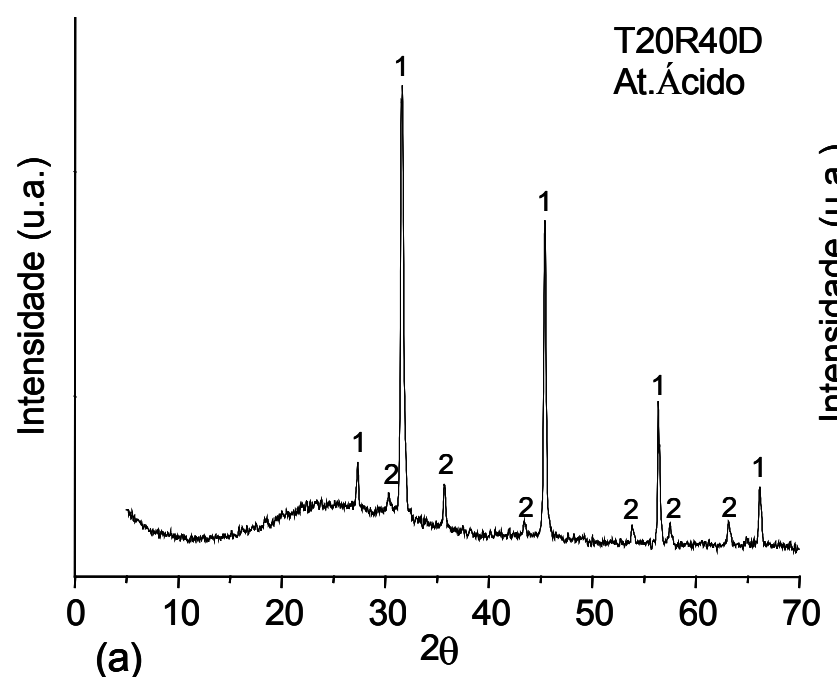

(a)

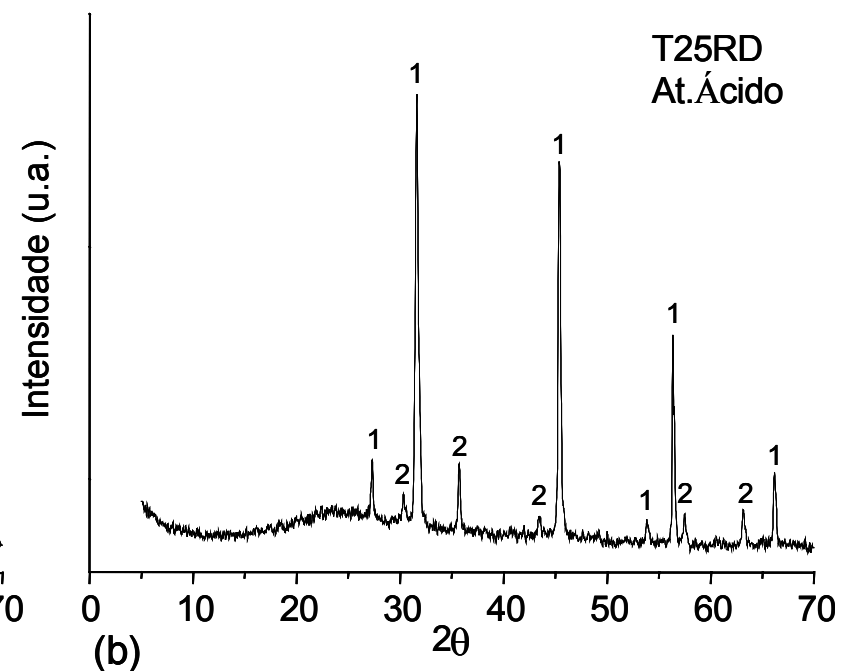

$1-\mathrm{NaCl} ; 2-\mathrm{Ni}\left(\mathrm{Cr}_{2} \mathrm{O}_{4}\right)$

FIGURA 5.79 - Difratogramas obtidos por DRX a partir de amostras das composições TRD, após o ensaio de ataque ácido: (a) T20R40D e (b) 


\subsubsection{3 - Resistência ao ataque alcalino}

A Fig. 5.80 apresenta a taxa de dissolução durante o ensaio de resistência ao ataque alcalino em função da concentração de modificadores das amostras TCD, TRD e VR. De uma forma geral, as composições TRD apresentam uma resistência ao ataque alcalino superior as composições TCD. Ainda assim a resistência ao ataque alcalino das composições TRD mostrou-se inferior a dos vidros TR (Fig. 5.42).

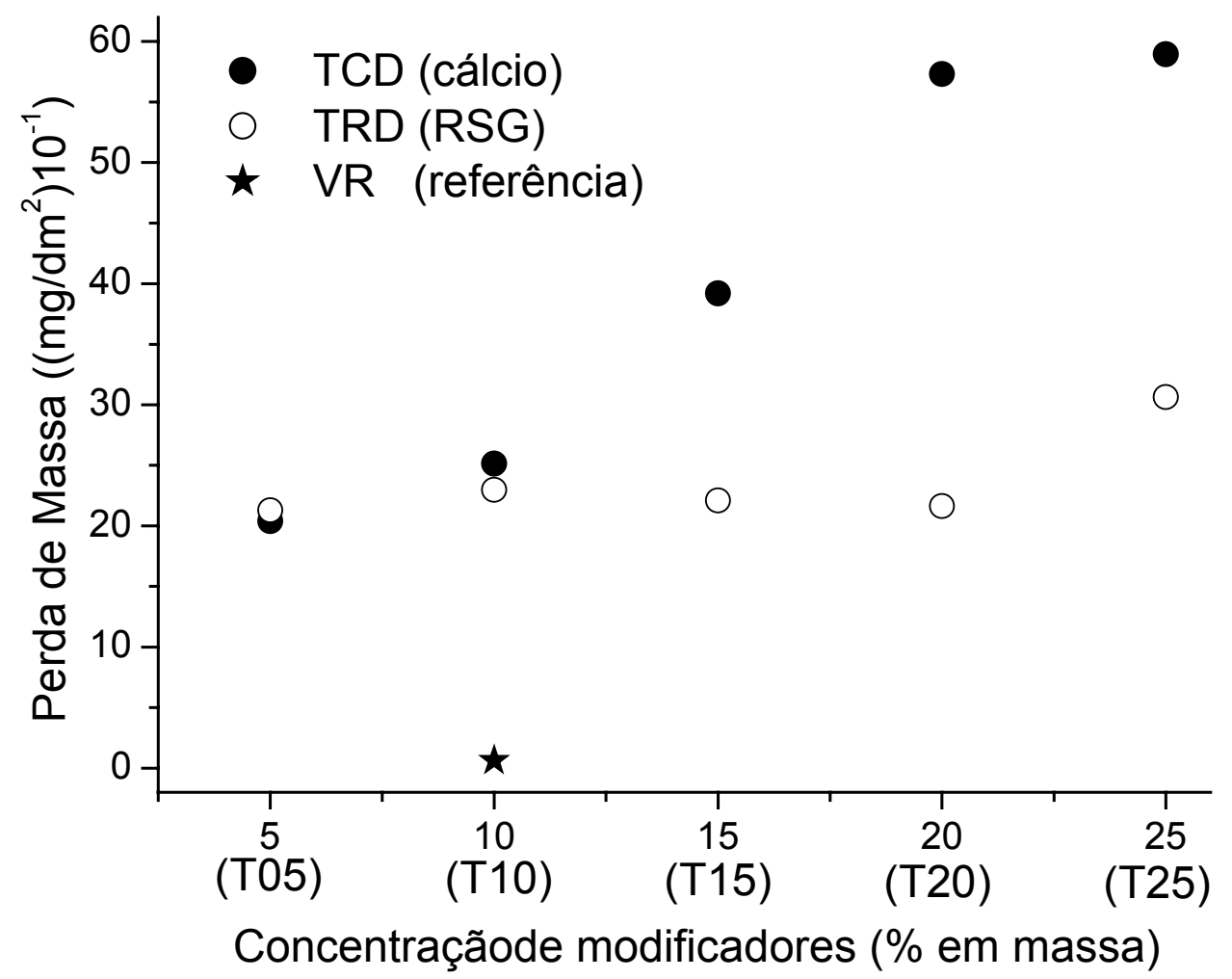

FIGURA 5.80 - Taxa de dissolução em função da concentração de modificadores obtidas no ensaio de resistência ao ataque alcalino das amostras TCD, TRD e VR.

Para as composições TCD o aumento da concentração de modificadores diminui a resistência ao ataque alcalino. Neste caso a formação da fase cristalina $1 \mathrm{Na}_{2} \mathrm{O}: 2 \mathrm{CaO}: 3 \mathrm{SiO}_{2}$, promove um aumento na solubilidade da matriz vítrea em meio alcalino. No caso das composições contendo resíduo galvânico (TRD), a variação da resistência alcalina em função da concentração de metais de transição, é praticamente nula. 
As micrografias obtidas a partir da secção transversal de amostras das séries TCD e TRD, após o ataque alcalino são apresentadas na Fig. 5.81.

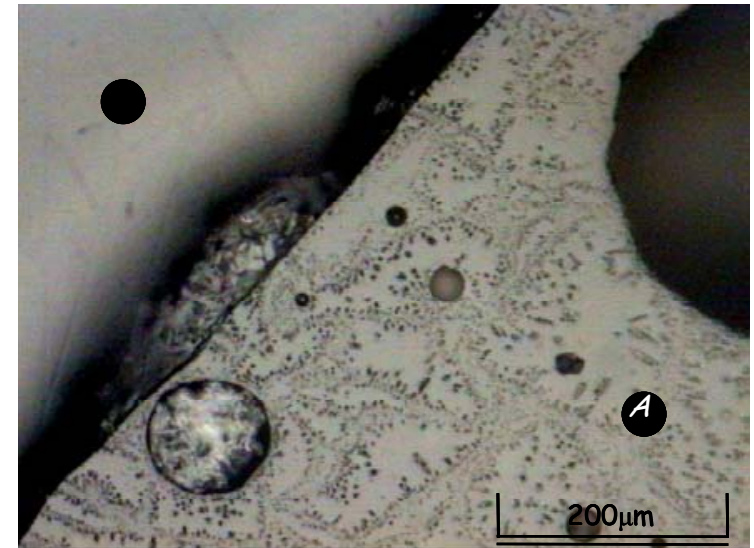

(a) T05CD

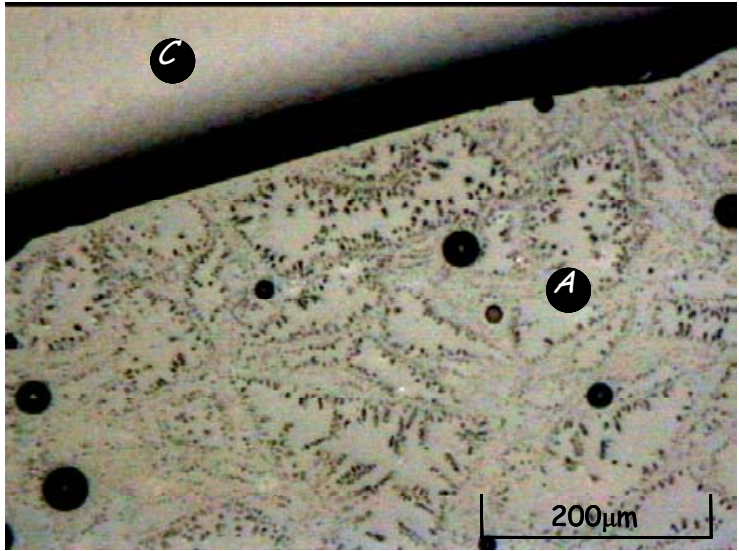

(b) $T 10 C D$

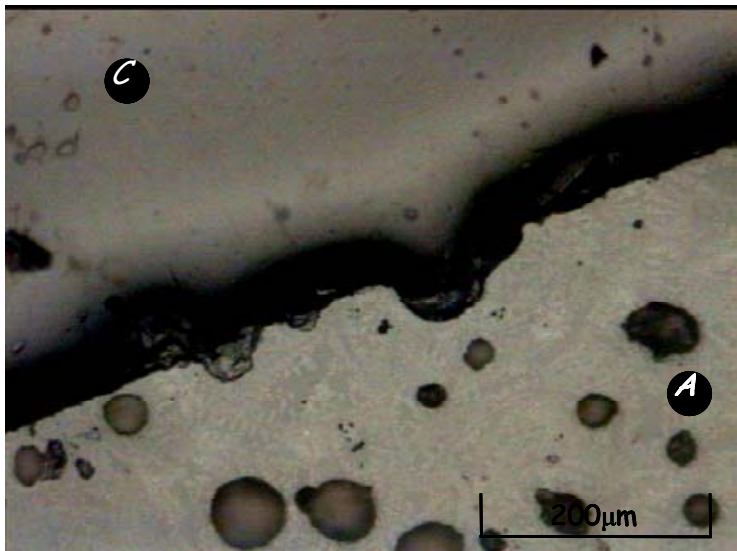

(c) T20CD

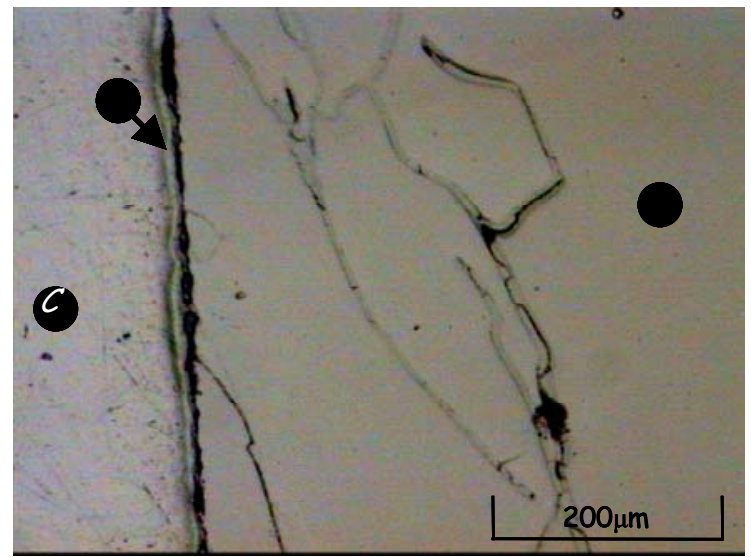

(d) T05R10D

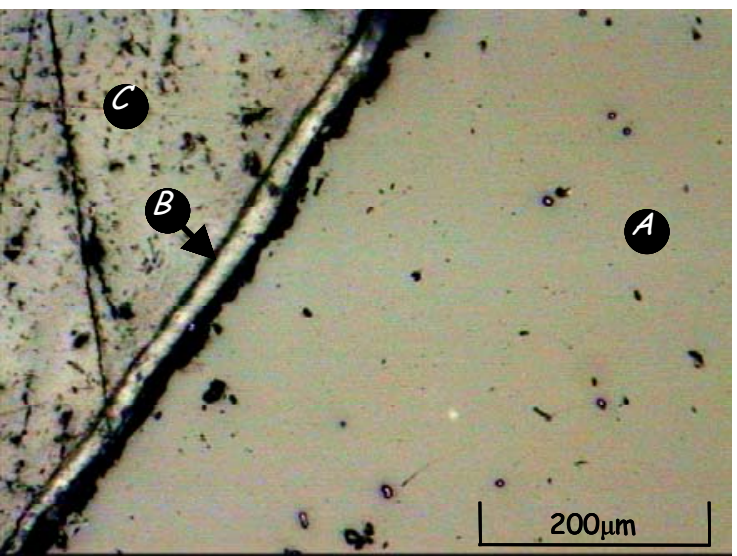

(e) T10R20D

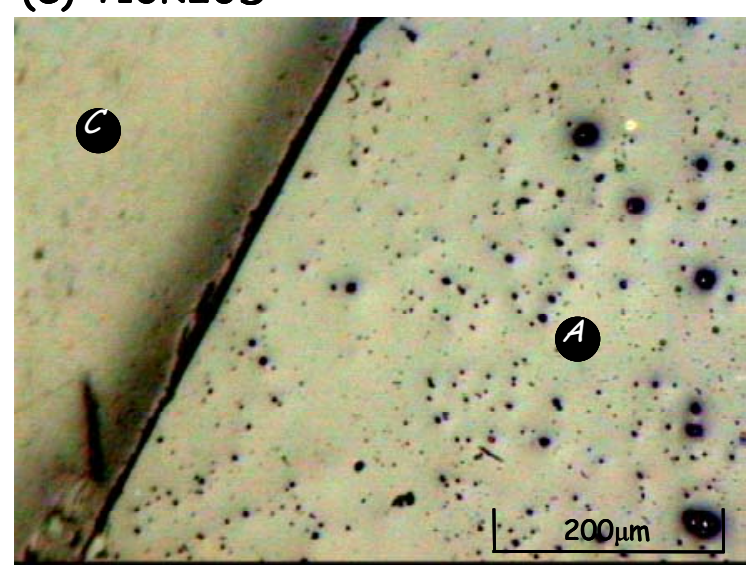

(f) T2OR40D

\section{matriz vitrea; Ocamada atacada; Oresina do suporte}

Figura 5.81 - micrografias correspondentes á secção transversal de amostras das composições TCD e TRD, após o ensaio de ataque alcalino 
Estas micrografias mostram que nas composições T05R10D e T10R20D (Fig. 5.81(a,b) respectivamente) ocorre a permanência de uma camada superficial atacada, ou seja, para os demais materiais todo o produto da dissolução desprendeu-se da superfície do vidro. Este fato indica que de forma geral a dissolução decorrente do ataque alcalino foi uniforme, caracterizada pelo o rompimento das ligações Si-O-Si.

As micrografias das séries TCD e TRD (MEV-EDS) após ataque alcalino são apresentadas nas Fig. 5.82-5,

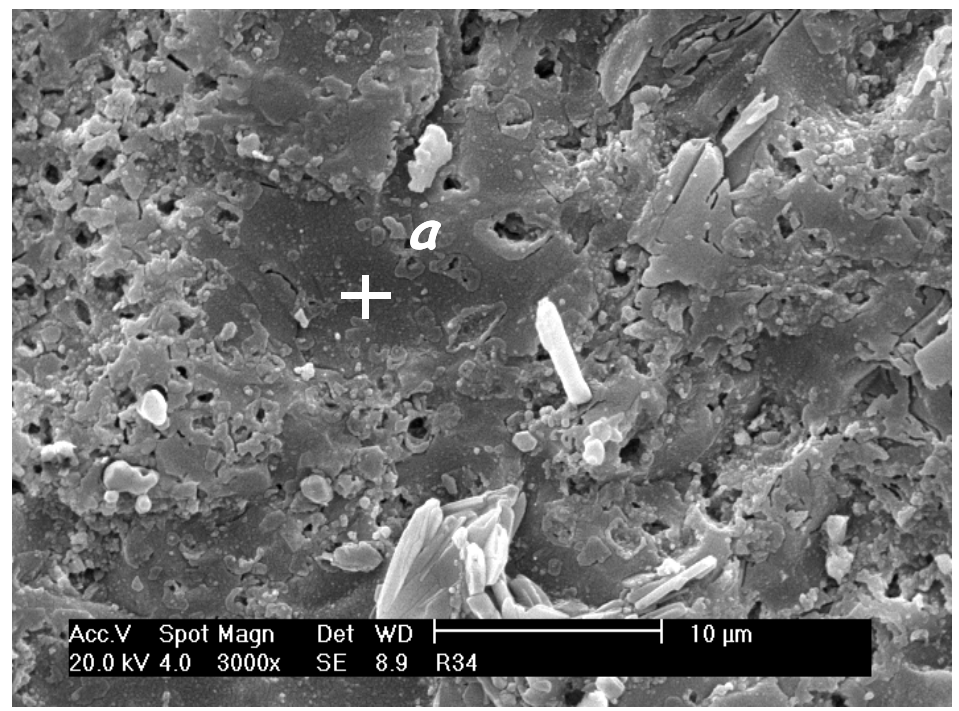

Microanálise

T10CD

Elem. Massa\%

$\begin{array}{lc} & \text { (a) } \\ \mathrm{Na} & 2,97 \\ \mathrm{Si} & 79,21 \\ \mathrm{Ca} & 17,82 \\ \text { Total } & \mathbf{1 0 0}\end{array}$

(a) T10CD

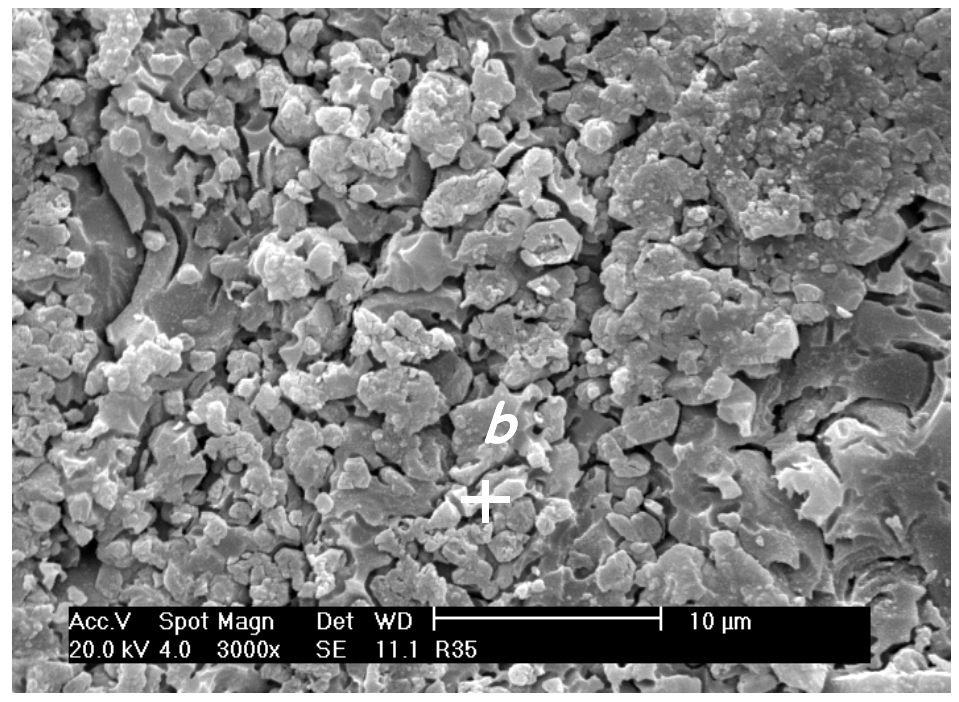

Microanálise

T15CD

Elem. Massa\%

(b)

$\mathrm{Na} \quad 18,63$

Si $\quad 63,73$

$\mathrm{Ca}$

17,65

Total $\quad 100$

(b) T15CD

FIGURA 5.82 - Superfície de amostras das composições TCD após ataque alcalino: (a) T10CD e (b) T15CD (MEV-EDS) 
Nestras micrografias se observam os efeitos da dissolução superficial dos materiais. Nos vitrocerâmicos T20CD, T05R10 e T10R20 foram observados na superfície dos mesmos a presença de cristais contendo sódio (Fig. 5.82(b), 5.83(a,c) respectivamente), a qual foi atribuída à precipitação de sais contidos na solução de ataque, composta por carbonato de sódio e hidróxido de sódio, durante a secagem.

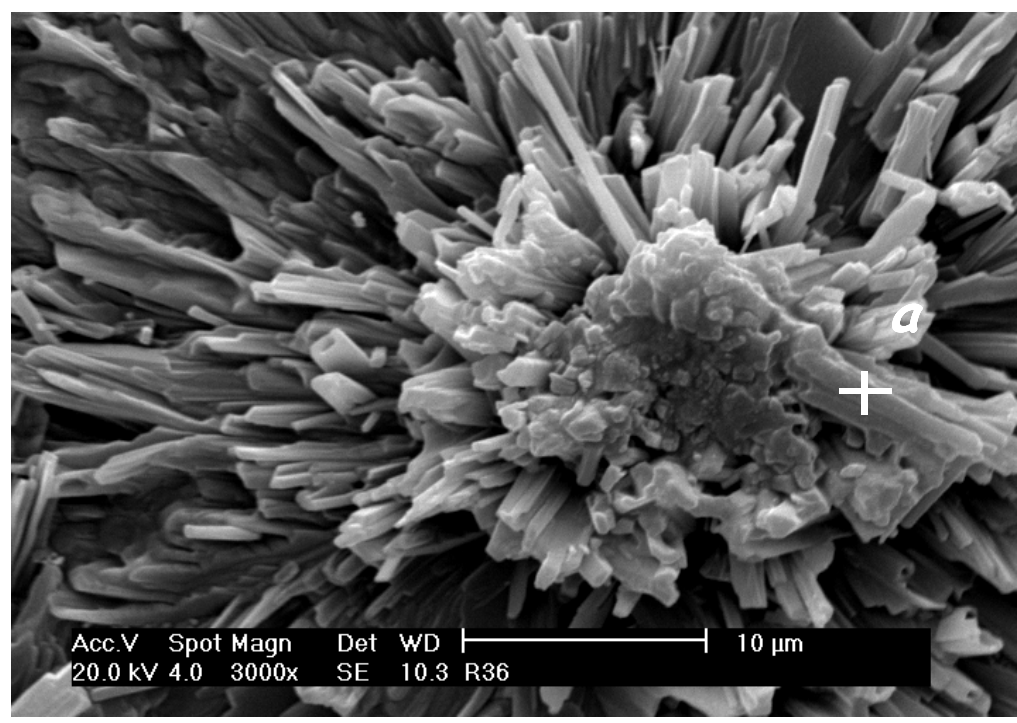

Microanálise

$\begin{array}{lc}\text { T20CD } & \\ \text { Elem. } & \begin{array}{c}\text { Massa\% } \\ \text { (a) }\end{array} \\ \mathrm{Na} & 55,81 \\ \mathrm{Si} & 30,23 \\ \mathrm{Ca} & 13,95 \\ \text { Total } & \mathbf{1 0 0}\end{array}$

(a) T20CD

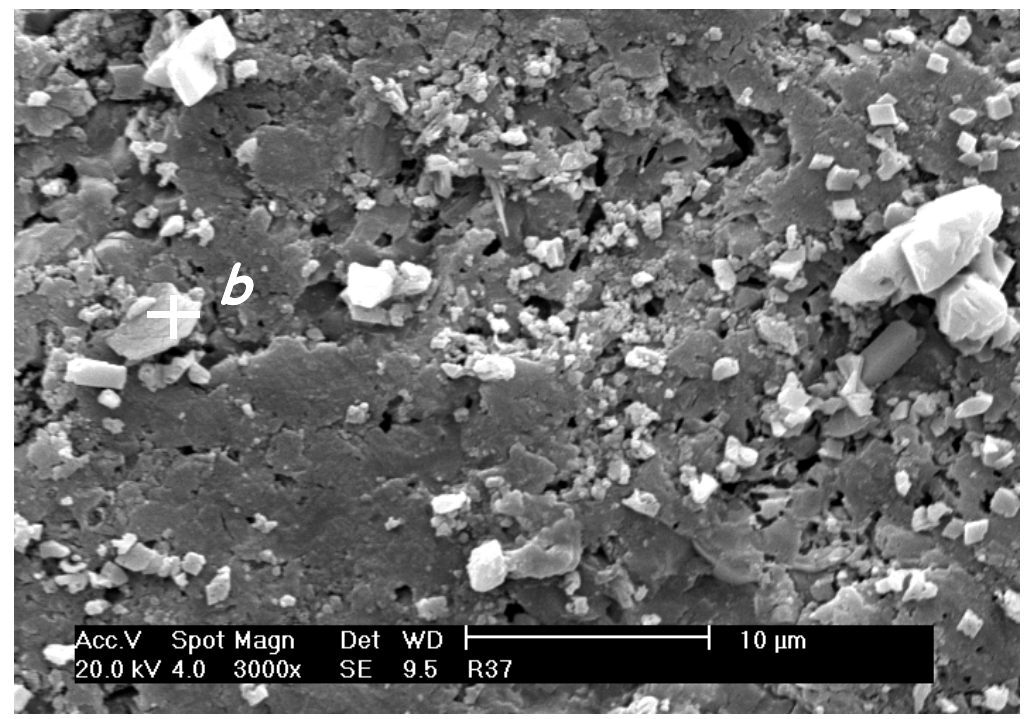

Microanálise

T25CD

Elem. Massa\%

(b)

$\mathrm{Na} \quad 10,39$

Si $\quad 19,48$

Ca $\quad 70,13$

Total $\quad 100$

(b) T25CD

FIGURA 5.83 - Superfície de amostras das composições TCD após ataque alcalino:

(a) T20CD; e, (b) T25CD (MEV-EDS) 
Nas composições T10R20D, T15R30D, T20R40D e T25R50D (Fig. 5.84 e 5.85) a presença de cromo e de níquel foi registrada tanto na matriz como nos precipitados.
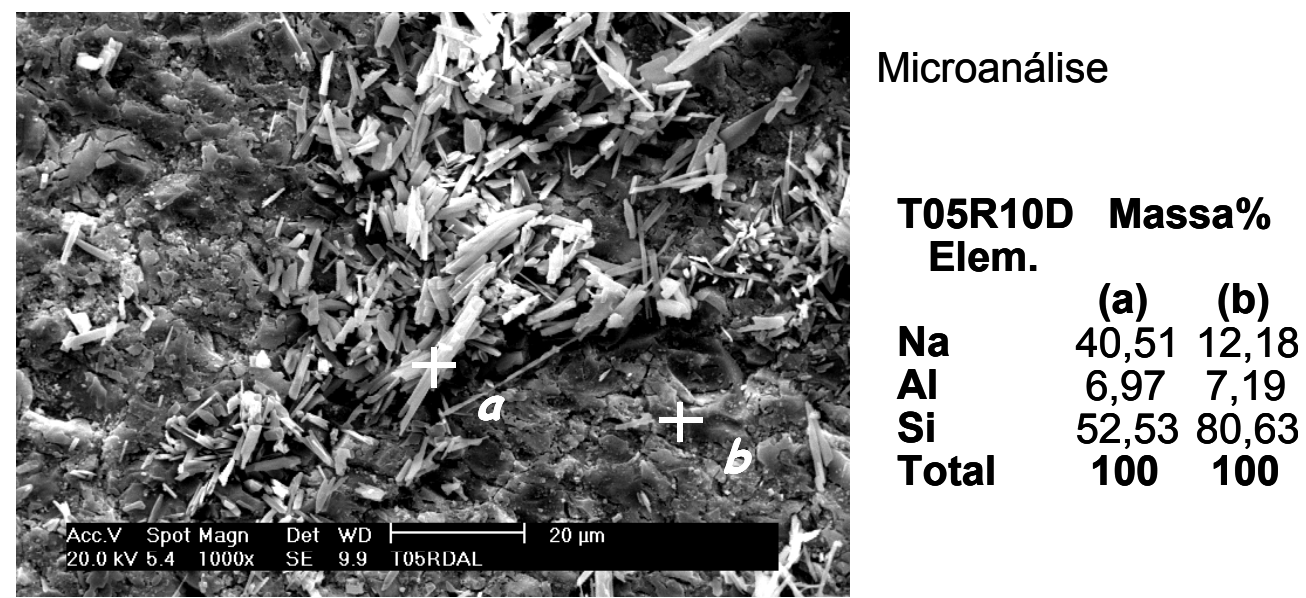

Microanálise

T05R10D Massa\% Elem.

$\mathrm{Na} \quad 40,5112,18$

Al $\quad 6,97 \quad 7,19$

Si $\quad 52,5380,63$

Total $100 \quad 100$

(a) T05R10D

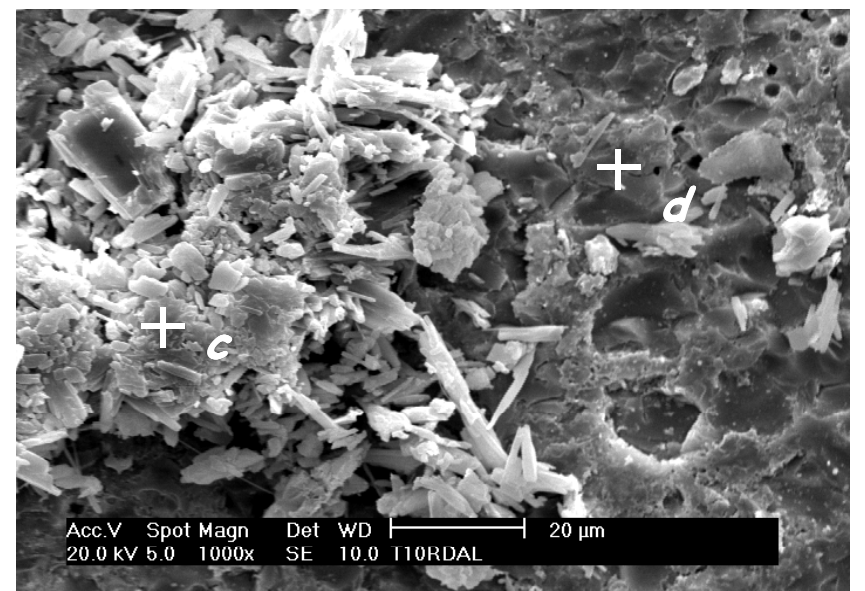

Microanálise

T10R20D Massa\% Elem.

(c) (d)

$\mathrm{Na} \quad 69,9217,26$

Al $\quad-\quad 9,35$

Si $\quad 30,0861,36$

Ca $\quad-\quad 3,32$

Cr $\quad-\quad 3,55$

$\mathrm{Ni} \quad-\quad 5,15$

Total 100100

(b) 10R20D

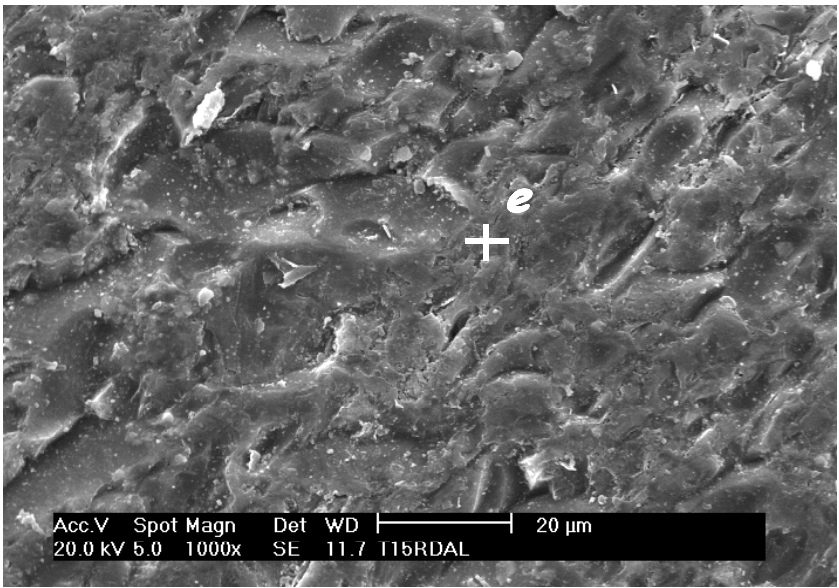

Microanálise

T15R30D Massa\%

Elem.

$\begin{array}{ll}\mathrm{Na} & 15,33 \\ \mathrm{Al} & 11,89 \\ \mathrm{Si} & 58,76 \\ \mathrm{Ca} & 6,81 \\ \mathbf{C r} & 2,63 \\ \mathbf{N i} & 4,57 \\ \text { Total } & \mathbf{1 0 0}\end{array}$

(c) T15R30D

FIGURA 5.84 - Superfície de amostras das composições TRD após ataque alcalino: (a) T05R10D, (b) T10R20D e (c) T15R30D (MEV-EDS) 


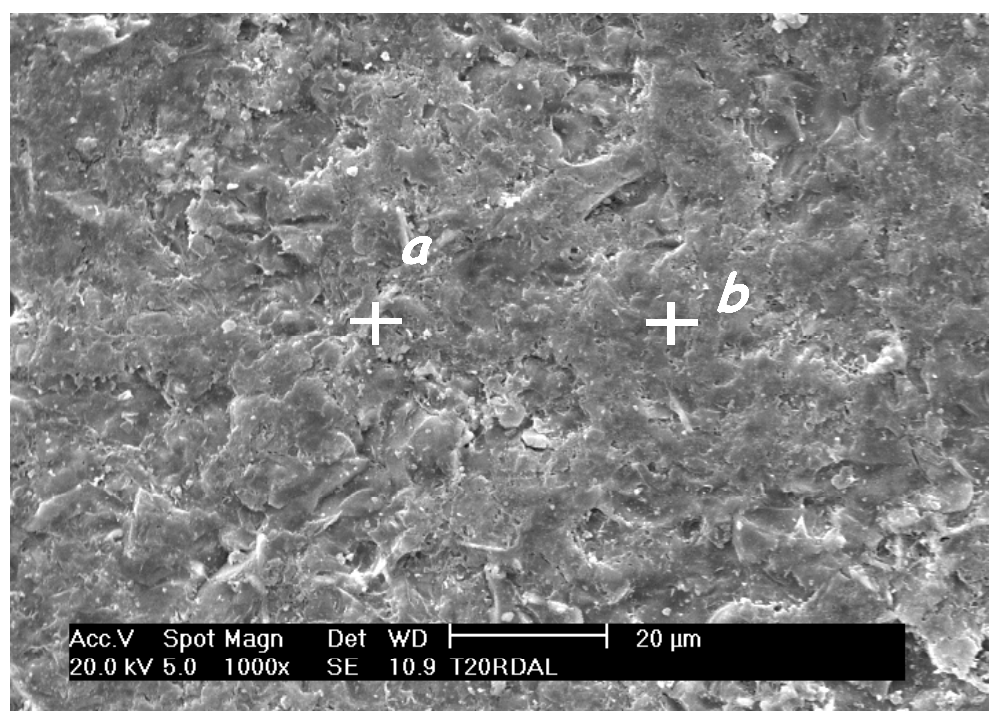

Microanálise

\section{T20R40D Massa\% Elem.}

$\begin{array}{lcc} & (\mathbf{a}) & \mathbf{( b )} \\ \mathbf{N a} & \mathbf{8}, 63 & 13,48 \\ \mathrm{Al} & \mathbf{4 , 2 7} & 10,48 \\ \mathrm{Si} & 13,25 & 55,49 \\ \mathbf{C a} & 2,02 & 10,8 \\ \mathbf{C r} & 66,8 & 4,7 \\ \mathbf{N i} & \mathbf{5 , 0 3} & 5,05 \\ \text { Total } & \mathbf{1 0 0} & \mathbf{1 0 0}\end{array}$

(a) T20R40D

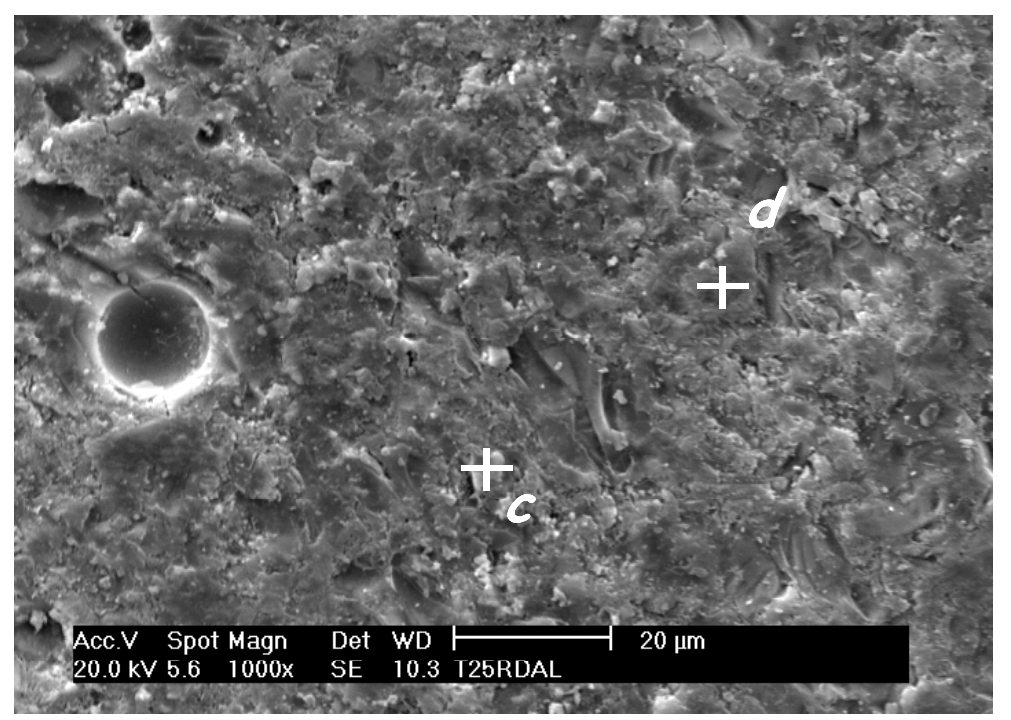

Microanálise

\section{T20R40D Massa\% Elem.}

$\begin{array}{lcc} & (\mathbf{c}) & (\mathbf{d}) \\ \mathbf{N a} & \mathbf{4 , 4 6} & 17,38 \\ \mathrm{Al} & 3,35 & 11,54 \\ \mathrm{Si} & 8,21 & 52,09 \\ \mathbf{C a} & 2,43 & 10,33 \\ \mathbf{C r} & 50,21 & 2,29 \\ \mathbf{F e} & 2,98 & - \\ \mathbf{N i} & 19,88 & 6,36 \\ \text { Zn } & \mathbf{8 , 4 9} & - \\ \text { Total } & \mathbf{1 0 0} & \mathbf{1 0 0}\end{array}$

(b) T25R50D

FIGURA 5.85- Superfície de amostras das composições TRD após ataque alcalino: (a) T20R40D e (b) T25R50D (MEV-EDS)

As curvas representativas dos espectros de FTIR dos vitrocerâmicos TCD e TRD pulverizados e submetidos ao ataque alcalino são mostradas na Fig. 5.86 .

Comparando-se os espectros para os vidros TCD, antes e depois do ataque alcalino (Fig. 5.59(a) e 5.86(a) respectivamente), observa-se que para todas as amostras ocorre um aumento na intensidade relativa para as bandas indicativas das ligações dos tetraedros de sílica $Q^{1}$ e $Q^{0}$ (7 e 8 na Fig. 5.86(a)). 


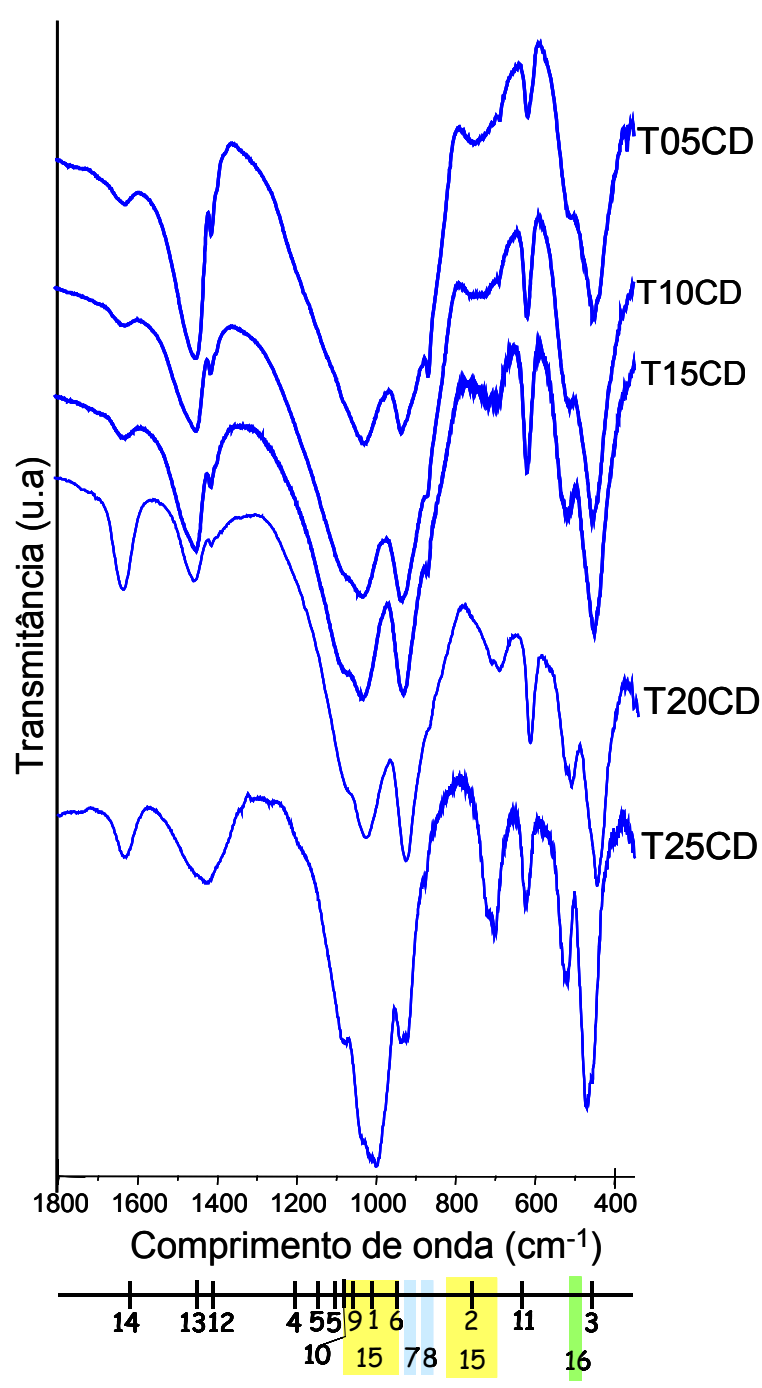

(a) Série TCD

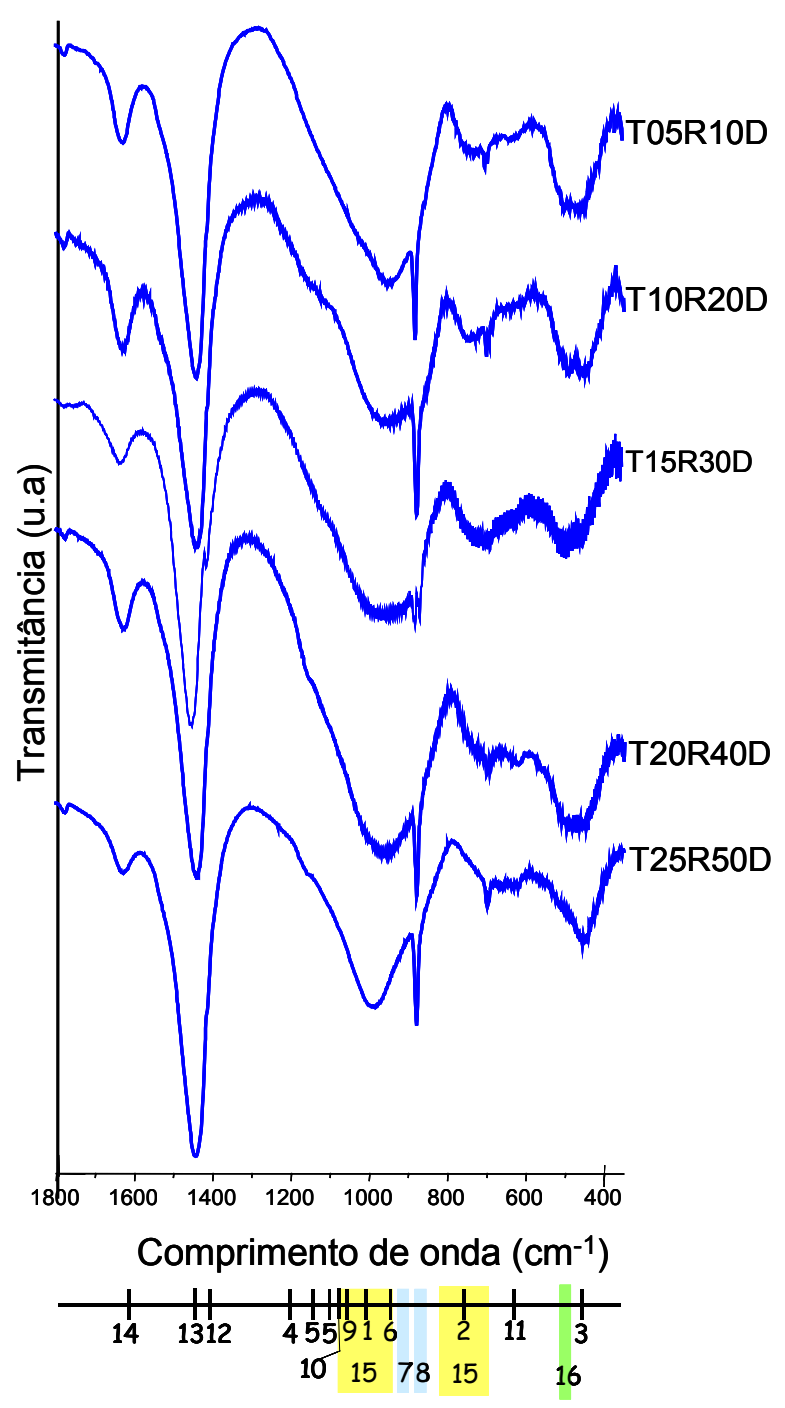

(b) Série TRD

(1) Superfície de tetraedros $\mathrm{SiO}_{4}$; (2) Ligações entre tetraedros $\mathrm{SiO}_{4}$; (3) Si-O-Si $\left[Q^{4}\right]$;

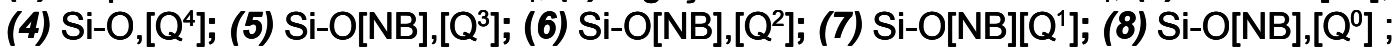

(9) Si-O-Si; (10) Si-O-[NB], plano ; (11) Si-O-B Estrutural; (12) B-O Livre; (13) Na-O;

(14) Água livre; (15) Silicatos de metais; (16) Óxidos metálicos segregados.

FIGURA 5.86- Espectros FT-IR de amostras das composições TCD e TRD, após o ensaio de ataque alcalino

As bandas associadas às ligações do boro estrutural, boro segregado, dos silicatos de metais (metais alcalinos e alcalinos terrosos) e dos metais segregados, são pouco alteradas pelo ataque alcalino (pontos 11, 12, 15 e 16). Estes resultados indicam que o processo de dissolução se concentrou nas ligações Si-O-Si da rede vítrea como relatado na literatura ${ }^{(24)}$. Entretanto, o 
aumento da intensidade relativa observada na banda associada à ligação $\mathrm{Na}-\mathrm{O}$, também pode indicá-lo como produto da dissolução em meio básico.

Comparando-se os espectros resultantes entre as amostras analisadas da série TRD, antes e após do ataque alcalino (Fig. 5.59(b), e 5.86(b), respectivamente), observa-se que de um modo geral ocorre um deslocamento na distribuição das diversas bandas associadas as ligações das unidades estruturais $Q^{x}$, favorecendo as bandas indicativas das ligações dos tetraedros de sílica $Q^{0} \mathrm{e}$ marcadamente, $Q^{1}$ (7 e 8 nas figuras). As alterações nas bandas associadas as ligações do boro estrutural, boro segregado, silicatos de metais e dos metais segregados (bandas indicadas respectivamente por 11, 12, 15 e 16 na figura), são de pequena intensidade, e variam de forma inconstante em função da concentração de RSG. Estes resultados indicam que para os vitrocerâmicos TRD, um mecanismo de dissolução similar ao observado para os vitrocerâmicos TCD.

Os difratogramas correspondentes às análises de DRX das composições TCD e TRD pulverizados e submetidos ao ataque alcalino são mostradas nas Fig. 5.87 e 5.88. Nestes espectros para a série TCD, Fig. 5.86, foi observada permanência da fase $\mathrm{Na}_{2} \mathrm{O}: 2 \mathrm{CaO}: 3 \mathrm{SiO}_{2}$ (PDF 78-0364), ou seja, a dissolução devido ao ataque alcalino concentrou-se na matriz vítrea.

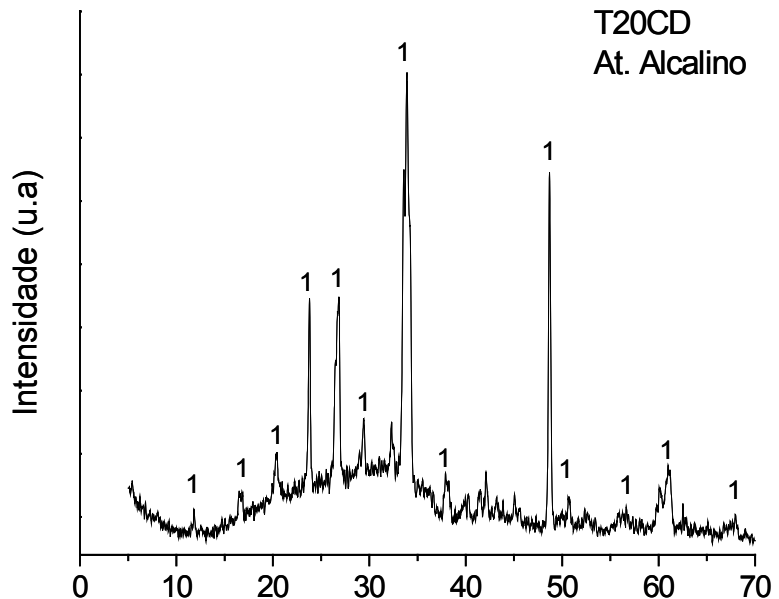

(a)
$2 \theta$

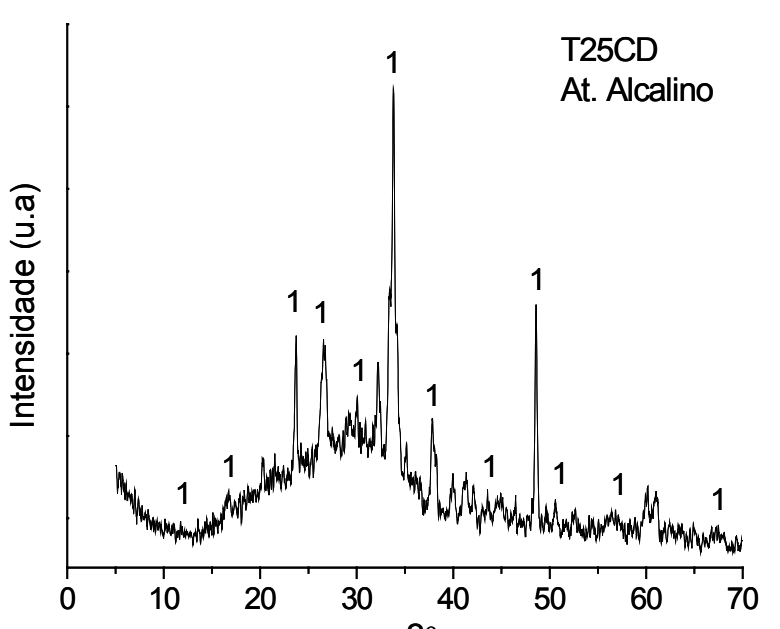

(b)

$1-\mathrm{Na}_{2} \mathrm{O}: 2 \mathrm{CaO}: 3 \mathrm{SiO}_{2}$

FIGURA 5.87 - Difratogramas obtidos por DRX a partir de amostras das composições TCD, após o ensaio de ataque alcalino: (a) T20CD e (b) T25CD 
Nos vitrocerâmicos TRD (Fig. 5.88), os difratogramas apresentam múltiplos picos que dificultam a identificação das fases, presentes. Neste caso foi possível apenas obter indícios da permanência de $\mathrm{Cr}_{2} \mathrm{O}_{3}$ e $\mathrm{Ni}\left(\mathrm{Cr}_{2} \mathrm{O}_{4}\right)$ nas composições T05R10D e T215R30D (Fig. 5.88(a,b)).

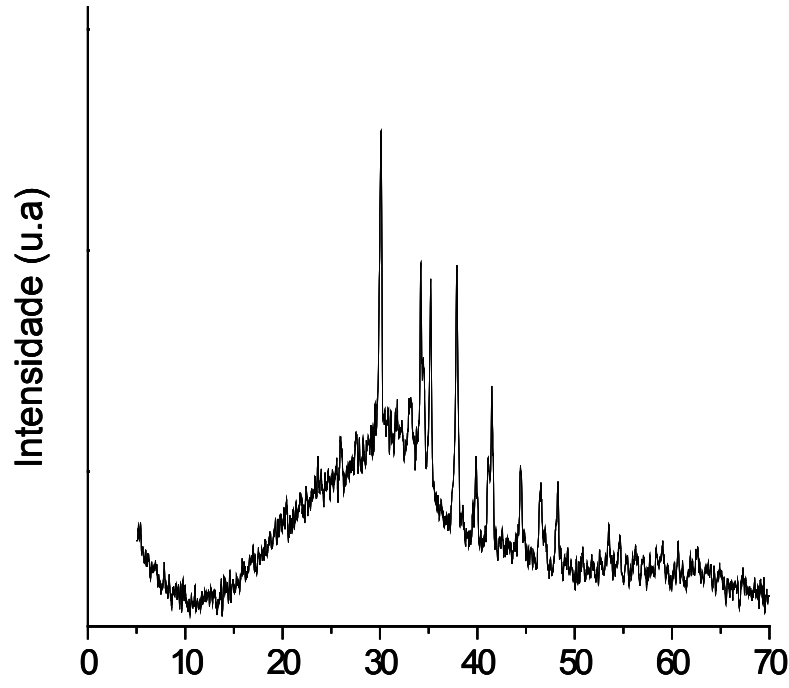

(a)

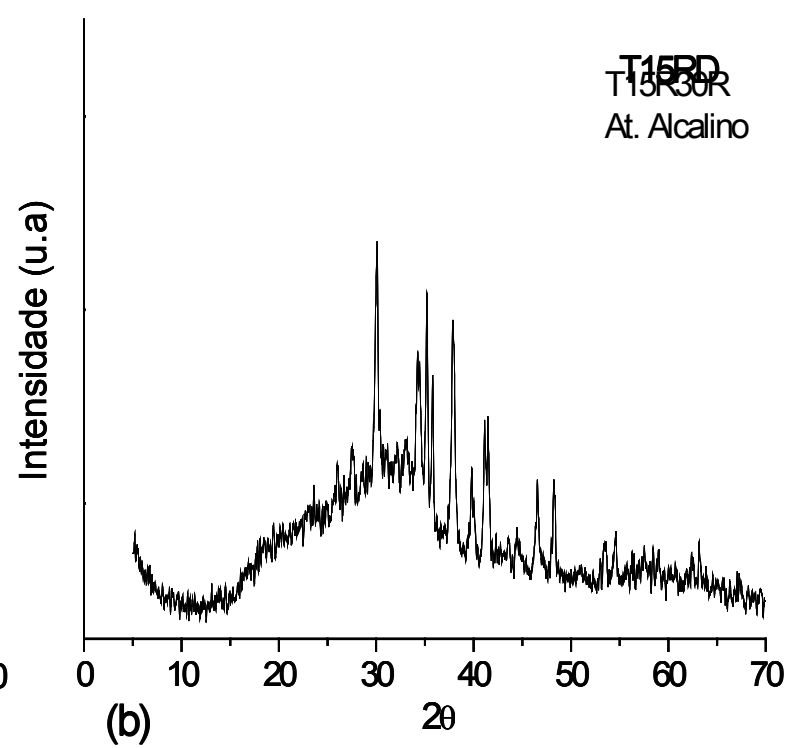

(b)
TIST3BR

At. Alcalino

FIGURA 5.88 - Difratogramas obtidos por DRX a partir de amostras das composições TRD, após o ensaio de ataque alcalino: (a) T05R10D e (b) T15R30D 


\section{6 - Conclusões}

A utilização dos resíduos sólidos galvânicos (RSG) na formação dos vidros silicatos e vitrocerâmicos constitui o foco inovador do presente trabalho. Para as composições e condições ensaiadas. conclui-se:

(1) Os vidros propostos incorporaram os metais de transição em sua estrutura como modificador, substituindo o cálcio.

(2) A utilização dos metais de transição como modificadores da rede vítrea não altera o arranjo da mesma. De forma independente do tipo de modificador utilizado, os tetraedros de sílica se organizam em configurações do tipo $Q^{2}{ }_{2}$ coexistindo com os demais tipos de arranjos $\left(Q^{0}, Q^{1}, Q^{3}, Q^{4}\right)$ em menor freqüência.

(3) Os vidros formulados incorporaram concentrações de até $30 \%$ em massa de resíduo sólido galvânico (T15R30), sem a ocorrência de fases secundárias precipitadas, observáveis pelos métodos de caracterização utilizados.

(4) A saturação na estrutura pelos metais presentes no RSG facilita a formação de fases secundárias contendo metais como cromo $\left(\mathrm{Cr}_{2} \mathrm{O}_{3}\right)$, níquel $\left(\mathrm{Ni}_{3} \mathrm{~S}_{2}\right)$ e cobre $\left(\mathrm{Cu}_{2} \mathrm{~S}\right)$ em composições com adições superiores a $30 \% \mathrm{em}$ massa de RSG (T20R40 e T25R50).

(5) De acordo com os resultados experimentais, as composições TR mostram que o aumento de concentração de RSG favorecem a redução do cromo $\left(\mathrm{Cr}^{6+} \rightarrow \mathrm{Cr}^{3+}\right)$. Destacamos que o $\mathrm{Cr}^{3+}$ é menos nocivo ao meio ambiente que o $\mathrm{Cr}^{6+}$.

(6) A presença dos metais de transição favorece a coordenação tetraédrica do boro em uma estrutura heterogênea com interações entre a sílica, o óxido de boro e estes metais (T20R40).

(7) Os vidros TR apresentaram maior resistência química que os vidros TC.

(8) As fases secundárias identificadas nos vidros TR, são resistentes aos ataques químicos nos meios aquoso, alcalinos e ácido. As matrizes destes vidros se dissolvem pelos mesmos mecanismos observados nos vidros TC, ou 
seja, ataque protônico, pelos íons $\mathrm{OH}^{-}$e a hidrolização das ligações Si-O-Si concentrando-se nas estruturas $Q^{1}$ e $Q^{0}$.

(9) A resistência hidrolítica dos vidros TR é compatível às exigências para vidros destinados a inertização de resíduos nucleares, ou seja, taxa de dissolução da amostra T15R30; 0,1 g/ $/ \mathrm{m}^{2}$ para o Si e 0,04 g/ $/ \mathrm{m}^{2}$ para o $\mathrm{Na}$, e a especificação do U.S.DOE requer $2,0 \mathrm{~g} / \mathrm{m}^{2}$ para o Si e para o Na.

(10) Obteve-se materiais vítreos utilizando-se até $22,5 \%$ em massa de finos de sílica, $8,3 \%$ de pó de rochas graníticas e 50,5\% de lodo galvânico, com boa resistência química (taxa de dissolução em meio aquoso de $1,5.10^{-8}\left[\mathrm{~g} \cdot \mathrm{cm}^{2} . \mathrm{s}^{-}\right.$ $\left.\left.{ }^{1}\right]\right)$.

(11) Com a aplicação do tratamento térmico as composições básicas (TCD) formam vitrocerâmicos com fases secundárias contendo $\mathrm{Si}$, $\mathrm{Ca}$ e $\mathrm{Na}$, e intensificando a freqüência de dímeros de tretraédros de sílica na estrutura (sílica $Q^{1}$ ). A substituição dos modificadores da formulação básica pelos metais do RSG, não contribuiu para a devitrificação. Nas composições TRD não se verificou clara formação de fase cristalina. Os tetraedros de sílica do tipo $Q^{0}$ e $Q^{1}$ se ordenaram para formar cadeias de tetraedros de sílica $\left(Q^{2}\right)$, reorganizando a estrutura vítrea.

(12) Após o tratamento térmico para devitrificação, a resistência química dos materiais é reduzida nos diferentes meios de ataque, e se concentra nas estruturas $Q^{3}$ e $Q^{2}$ Nas amostras TCD e TRD as fases secundarias foram atacadas em meio ácido.

(13) Os melhores resultados foram obtidos para a composição de vidro T20R40, a qual incorpora 40,3\% em massa de resíduo sólido galvânico, 29,2\% em massa de finos de sílica, $9,2 \%$ de pó de rochas graníticas, e resistência química similar aos vidros comerciais, sendo desta forma aplicável ao desenvolvimento de novos produtos.

O estudo permitiu acompanhar a atuação de metais de transição na estrutura de silicatos amorfos, vidros e vitrocerâmicos; como modificadores e condicionalmente como formadores intermediários, resultando em produtos com boa resistência ao ataque em diversos meios. Desta forma a hipótese de se utilizar os resíduos sólidos industriais, transformando-os de resíduos classe I à componentes funcionais de um produto comercial foi confirmada. 
Finalmente, os conceitos e idéias apresentados não devem se restringem apenas ao sistema aqui analisado. Estes podem ser expandidos e aplicados para as situações envolvendo o emprego de resíduos industriais perigosos. Mudando deste modo o conceito de inertização de metais tóxicos para a recuperação e reuso na fabricação de novos produtos com características similares aos de mercado. 


\section{7 - Trabalhos complementares}

- Estudo da coordenação dos metais de transição utilizando-se técnicas de estrutura fina (XANES, EXAFS, NEXAFS).

- Estudo da valência do Níquel, Cobre e Zinco por XPS.

- Estudo do uso combinado de modificadores (cálcio e metais de transição) para facilitar a devitrificação.

- Estudo do comportamento de corrosão do refratário e/ou cadinho quando em contato com o banho de vidro fundido.

- Estudo da adequação do processo para aplicações comerciais.

- Desenvolvimento de produtos.

- Avaliação do impacto econômico e ambiental deste processo. 


\section{8 . Referências Bibliográficas}

(01) LEE, W.E. BOCCACCINI, A.R. LABRINCHA, J.A. LEONELLI, C. DRUMMOND III, C.H. CHEESEMAN, C.R. Green engineering - Ceramic technology and sustainable development. Am. Ceram. Soc. Bul., v. 86 [2], p.18-25, 2007.

(02) HUANG, D. DRUMMOND III, C.H. WANG, J. BLUME, R.D. Incorporation of Chromium(III) and Chromium(VI) Oxides in a Simulated Basaltic, Industrial Waste Glass-Ceramic. J. Am. Ceram. Soc., v.87 [11], p. 2047-2052, 2004.

(03) BARAL, A, STEWART, P. ENGELKEN, R. Chromium-Based Regulations Applicable to Metal Finishing Industries in the United States: A Policy Assessment. Rev. of Pol. Res., v. 23, p. 1-21, 2006.

(04) MAGALHAES, J.M. SILVA, J.E. CASTRO, F.P. LABRINCHA, J.A. Physical and chemical characterisation of metal finishing industrial wastes. J. of Env. Manag., v. 75, p.157-166, 2005.

(05) FRESNER, J.; MAIR, J.; SCHNITZER, H.; BRUNNER, C.; GWEHENBERGER, G.; PLANASCH, M.; Practical experiences with the reduction of the industrial use of water in the galvanising industry. In: European Roundtable on sustainable consumption and Production. May 12-14, 2004. Bilbao, Spain. Disponível em http://www.zerowastewater.at/content/view/18/41/lang,en/ acesso em 28 Set. 2008.

(06) BARBIERI, L. BONAMARTINI, A.C. LANCELLOTTI, I. Alkaline and alkaline-earth silicate glasses and glasses-ceramics from municipal and industrial wastes. $J$. Eur. Ceram. Soc., v. 20, p. 2477-2483, 2000.

(07) KAVOURAS, P. KOMNINOU, P. CHRISSA, K. KAIMAKAMIS, G. KOKKOU, S. PARASKEVOPOULOS, K. KARAKOSTAS T. Microstructural changes of processed vitrified solid waste products. J. Eur. Ceram. Soc., v. 23, p. 1305-1311, 2003.

(08) STERPENICH, J. LIBOUREL, G. Using stained glass windows to understand the durability of toxic waste matrices. Chem. Geol., v. 174, p. 181-193, 2001

(09) ROTH, G. WEISENNBURGER, S. Vitrification of high-level level liquid waste:glass chemistry, process chemistry and process technology. Nucl. Eng. Des., v. 202, p. 197-207, 2000.

(10) DAY, D.E. WU, Z. RAY, C.S. HRMA, P. Chemically durable iron phosphate glass wasteforms. J. Non-Cryst. Solids. v. 241, p. 1-12, 1998

(11) GLATZ, J.P. TOSCANO, E.H. PAGLIOSA, G. NICHOLL, A. Influence of granite on the leaching behavior of different nuclear waste forms. J. Nucle. Mater. v. 223, p. 84-89, 1995.

(12) KIM, C.W. DAY, D.E. Immobilization of Hanford LAW in iron phosphate glasses. J. Non-Cryst. Solids, v. 331, p. 20-31, 2003.

(13) YAN, J. NERETNIEKS, I. Is the glass phase rate always a limiting factor in the leaching processes of combustion residues?. Sci. Total Environ., v. 172, p. 95$118,1995$.

(14) EAZ-ELDIN, F.M. Leaching and mechanical properties of cabal glasses developed as matrices for immobilization high-level wastes. Nucl. Instr. Met. Phys. Res., v. B183, p. 285-300, 2001.

(15) SILVA, A.C. MELLO-CASTANHO, S.R.H. Silicate glasses obtained from fine silica powder modified with galvanic waste addition. J. Non-Cryst. Sol., v.348, p. 211217, 2004.

(16) SILVA, A.C. MELLO-CASTANHO, S.R.H. Vitrified galvanic waste chemical stability. J. Eur. Ceram. Soc., v. 27, p. 565-570, 2007. 
(17) SILVA, A.C. MELLO-CASTANHO, S.R.H. GUITIAN, F. MONTERO, I. ESTEBANCUBILLO, A. SOBRADOS, I. SANZ, J. MOYA, J.S. Incorporation of Galvanic Waste (Cr, $\mathrm{Ni}, \mathrm{Cu}, \mathrm{Zn}, \mathrm{Pb}$ ) in to a Soda-Lime-Borosilicate Glass", J. Am. Ceram. Soc., v. 91[4], p. 1300-1305, 2008.

(18) SILVA, A.C.; MELLO-CASTANHO, S.R.H.; Resistência química de resíduos sólidos galvânicos vitrificados. in: CONGRESSO DE CIÊNCIA E TECNOLOGIA EM RESÍDUOS E DESENVOLVIMENTO SUSTETÁVEL, Florianópolis, SC. 2004, CDROM.

(19) SILVA, A. C. Incorporação de resíduo galvânico em vidro silicato obtido a partir de finos de sílica. 2004. Dissertação (Mestrado) - IPEN, São Paulo.

(20) SILVA, A.C.; MELLO-CASTANHO, S.R.H.; Estudo por FT-IR do processo de corrosão em vidros contendo resíduos sólidos galvânicos. in: CONGRESSO BRASILEIRO DE CERAMICA, 49, São Pedro, SP, 2005, CD-ROM.

(21) ASSOCIAÇÃO BRASILEIRA DE NORMAS TÉCNICAS. Resíduos sólidos Classificação. Rio de Janeiro: ABNT, 2004. (NBR 10004).

(22) ASSOCIAÇÃO BRASILEIRA DE NORMAS TÉCNICAS. Solubilização de resíduos - Procedimento. Rio de Janeiro: ABNT, 1987. (NBR 10006).

(23) Navarro, J.M.F. El Vidrio, $3^{a}$ ed. Madrid, Consejo Superior de Invest. Científicas Fundacion Centro Nacional del Vidrio, 2003.

(24) PAUL, A. Chemistry of glasses. Londres, Inglaterra.: Chapman and Hall, 1982.

(25) KINGERY, W.D. Bowen H.K. UhImann D.R. Introdution to Ceramics. 2.ed. New York.: John Wiley \& Sons, 1976.

(26) STOCH, L.S. Infrared spectroscopy in the investigation of oxide glasses structure. J. Mol. Struct. v. 511-512 p.77-84 1999.

(27) ZACHARIASEN, W.H. J. Am. Chem. Soc. v. 54, p. 3841, 1932.

(28) VAN VLACK, L.H. Princípios de Ciências dos Materiais. $12^{a}$ reimpressão. São Paulo: Editora Edgard Blücher Ltda, 1998.

(29) JIAWEI, S. KWANSIK, C. MYUNG-JAE, S. Vitrification of liquid waste from nuclear power plants. J. Nucle. Mater. v. 297, p. 7-13, 2001.

(30) Encyclopedia of chemical technology. :Kirk and Othmer, 1994. v. 12, p. 555627: BOYD, D.C. DANIELSON, P.S. THOMPSON, D.A. Glass.

(31) MYSEN, B.O. Transport and configurational properties of silicate melts: Relationship to melt structure at magmatic temperatures. Phys. of the Earth and Plan. Inter. V. 107 p. 23-32, 1998.

(32) SEN, S. YOUNGMAN, R.E. NMR study of Q-speciation and connectivity in $\mathrm{K}_{2} \mathrm{O}-$ $\mathrm{SiO}_{2}$ glasses with high silica content. J. Non-Cryst. Solids, v. 331, p. 100-1007, 2003.

(33) MYSEN, B.O. Element partitioning between minerals and melt, melt composition, and melt structure. Chem. Geol. v. 213, p. 1-16, 2004.

(34) TAN, J. ZHAO, S. WANG, W. DAVIES, G. MO, X. The effect of cooling rate on the structure of sodium silicate glass. Mat. Sci. and Eng. B, v. 106, p. 295-299, 2004.

(35) HALTER, W.E. MYSEN, B.O. Melt speciation in the system $\mathrm{Na}_{2} \mathrm{O}-\mathrm{SiO}_{2}$. Chem. Geol., v. 213, p. 115-123, 2004.

(36) FREUND, A.K. FRIEDRICH, H. NISTLER, W. SCHERM, R. Neutron Transmission Properties Of Perfect Silicon Crystals. Nucl. Instr. and Meth. in Phys. Res., v. A234, p. 116-121, 1985.

(37) STEBBINS, J.F. Dynamics and structure of silicate and oxide melts: nuclear magnetic resonance studies. Structure, Dynamics and Properties of Silicate Melts, in: STEBBINS, J.F. DINGWELL, D.B. MCMILLAN, P.F. Reviews in Mineralogy. The Mineralogical Society of America, 1995. v. 32, p. 191-246. 
(38) CALAS, G. CORMIER, L. GALOISY, L. JOLLIVET, P. Structure-property relationships in multicomponent oxide glasses. Chimie, v. 5, p. 831-843, 2002.

(39) AcostA, A. Aineto, M. ROMERO, M. IGLESIAS, I. RINCÓN, J.M. Physicochemical characterization of slag waste coming from GICC thermal power plant. Mat. Letters, v. 50, p. 246-250, 2001.

(40) HOLLAND, D. MEKKI, A. GEE, I.A. MCCONVILLE, C.F. JOHNSON, J.A. APPLEYARD, C.E. THOMAS, P.M. The structure of sodium iron silicate glass - A multi-technique approach. J. Non-Cryst. Solids, v. 253, p. 192-202, 1999.

(41) KURKJIAN, C.R. SIGETY, E.A. Phys. Chem. Glasses, v. 9, p. 73, 1968 apud HOLLAND, D. MEKKI, A. GEE, I.A. MCCONVILLE, C.F. JOHNSON, J.A. APPLEYARD, C.E. THOMAS, P.M. The structure of sodium iron silicate glass - a multi-technique approach. J. Non-Cryst. Solids, v. 253, p. 192-202, 1999.

(42) BISHAY, A.; KINAWI, A.; Proceedings of the International. CONFERENCE ON PHYS. NON-CRYST. SOLIDS, Delft,1964. apud HOLLAND, D. MEKKI, A. GEE, I.A. MCCONVILLE, C.F. JOHNSON, J.A. APPLEYARD, C.E. THOMAS, P.M. The structure of sodium iron silicate glass - A multi-technique approach, J. Non-Cryst. Solids, v. 253, p. 192-202, 1999.

(43) EDWARDS, R.J. PAUL, A. DOUGLAS, R.W. Phys. Chem.Glasses, v. 13, p. 131, 1972 apud HOLLAND, D. MEKKI, A. GEE, I.A. MCCONVILLE, C.F. JOHNSON, J.A. APPLEYARD, C.E. THOMAS, P.M. The structure of sodium iron silicate glass - A multi-technique approach, J. Non-Cryst. Solids, v. 253, p. 192-202, 1999.

(44) FOX, K.E. FURUKAWA, T. WHITE, W.B. Phys. Chem. Glasses, v. 23, p. 169, 1982 apud HOLLAND, D. MEKKI, A. GEE, I.A. MCCONVILLE, C.F. JOHNSON, J.A. APPLEYARD, C.E. THOMAS, P.M. The structure of sodium iron silicate glass - A multi-technique approach, J. Non-Cryst. Solids, v. 253, p. 192-202, 1999.

(45) BUKREY, R.R. KINEALY, P.F. BEARD, G.B. HOOPER H.O., J. Appl. Phys., v. 40, p. 428, 1969 apud HOLLAND, D. MEKKI, A. GEE, I.A. MCCONVILLE, C.F. JOHNSON, J.A. APPLEYARD, C.E. THOMAS, P. M. The structure of sodium iron silicate glass - A multi-technique approach, J. Non-Cryst. Solids, v. 253, p. 192202, 1999.

(46) SANCHEZ, J. P. FREIDL, J. M., J. Phys., v. 43, p. 1707, 198. apud HOLLAND, D. MEKKI, A. GEE, I.A. MCCONVILLE, C.F. JOHNSON, J.A. APPLEYARD, C.E. THOMAS, P. M. The structure of sodium iron silicate glass - A multi-technique approach, J. Non-Cryst. Solids, v. 253, p. 192-202, 1999.

(47) BURZO, E. ARDEleAN, I., Phys. Chem. Glasses, v. 20, p. 15, 1979 apud HOLLAND, D. MEKKI, A. GEE, I.A. MCCONVILLE, C.F. JOHNSON, J.A. APPLEYARD, C.E. THOMAS, P. M. The structure of sodium iron silicate glass - A multi-technique approach, J. Non-Cryst. Solids, v. 253, p. 192-202, 1999.

(48) BURKHARD, D.J.M., Phys. Chem. Glasses, v. 38, p. 317, 1997 apud HOLLAND, D. MEKKI, A. GEE, I.A. MCCONVILLE, C.F. JOHNSON, J.A. APPLEYARD, C.E. THOMAS, P. M. The structure of sodium iron silicate glass - A multi-technique approach, J. Non-Cryst. Solids, v. 253, p. 192-202, 1999.

(49) PINAKIDOU, F. KATSIKINI, M. KAVOURAS, P. KOMNINOU, F. KARAKOSTAS, TH. PALOURA, E.C.Structural role and coordination environment of $\mathrm{Fe}$ in $\mathrm{Fe}_{2} \mathrm{O}_{3}-$ $\mathrm{PbO}-\mathrm{SiO}_{2}-\mathrm{Na}_{2} \mathrm{O}$ composite glasses. J. Non-Cryst. Solids, v. 354, p. 105-111, 2008.

(50) IWAMOTO, N. UMESAKI, N. ATSUMI, T., J. Mater. Sci. Lett., v. 6, p. 271, 1987 apud HOLLAND, D. MEKKI, A. GEE, I.A. MCCONVILLE, C.F. JOHNSON, J.A. APPLEYARD, C.E. THOMAS, P. M. The structure of sodium iron silicate glass - A multi-technique approach, J. Non-Cryst. Solids, v. 253, p. 192-202, 1999. 
(51) W. VOGEL, Glass Chemistry, $2^{\mathrm{a} e d .}$, Berlin, Springer, 1994 apud HOLLAND, D. MEKKI, A. GEE, I.A. MCCONVILLE, C.F. JOHNSON, J.A. APPLEYARD, C.E. THOMAS, P. M. The structure of sodium iron silicate glass - A multi-technique approach, J. Non-Cryst. Solids, v. 253, p. 192-202, 1999.

(52) PINAKIDOU, F. KATSIKINI, M. PALOURA E.C., KAVOURAS, P. KOMNINOU, PH. KARAKOSTAS, T. ERKO, A. XAFS studies on vitrified industrial waste. Phys. Scripta, v. 351, p. 2474-2480, 2005.

(53) LUSVARDI, G. MALAVASI, L. MENABUE, L. MENZIANI, M.C. Synthesis, characterization and molecular dynamics simulation of $\mathrm{Na}_{2} \mathrm{O}-\mathrm{CaO}-\mathrm{SiO}_{2}-\mathrm{ZnO}$ glasses. J. Phys. Chem. v. B 106, p. 9753-9760, 2002.

(54) MEKKI, A. HOLLAND, D. MCCONVILLE, C.F. SALIM, M. An XPS study of iron sodium glass surfaces. J. Non-Cryst. Solids, v. 208, p. 267-276, 1996.

(55) KIMBROUGH, D.E. COHEN, Y. WINER, A.M. CREELMAN, L. MABUNI, C. Crit. Rev. Environ. Sci. Technol., v. 29, p. 1, 1999 apud DAULTON, T.L. LITTLE, B.J. Determination of chromium valence over the range $\mathrm{Cr}(0)-\mathrm{Cr}(\mathrm{VI})$ by electron energy loss spectroscopy. Ultramicroscopy, v. 106, p. 561-573, 2006.

(56) KOTAS, J. STASICKA, Z. Chomium occurrence in the enviroment and methods of its speciation. Environ. Pollut., v. 107, p. 263-283, 2000.

(57) COTTON, F.A. WILKINSON, G. Advanced Inorganic Chemistry, A Comprehensive Text, New York, Wiley, 1966 apud DAULTON, T.L. LITTLE, B.J. Determination of chromium valence over the range $\mathrm{Cr}(0)-\mathrm{Cr}(\mathrm{VI})$ by electron energy loss spectroscopy. Ultramicroscopy, v. 106, p. 561-573, 2006.

(58) HUGHES, M.C. RAO, J.M. MACERO, D.J. Further studies on the stabilization of high and low oxidation states in aromatic imine ligand complexes of first row transition metals. II Substuted bipyridine complex of manganese(II) and chromiun(III). Inorg. Chim. Acta, v. 35, p. L321-L324, 1979.

(59) SALLANS, L. LANE, K. SQUIRES, R.R. FREISER, B.S. J. Am. Chem. Soc., v. 105, p. 6352, 1983 apud DAULTON, T.L. LITTLE, B.J. Determination of chromium valence over the range $\mathrm{Cr}(0)-\mathrm{Cr}(\mathrm{VI})$ by electron energy loss spectroscopy, Ultramicroscopy. v. 106, p. 561-573, 2006.

(60) SHUPACK, S.I. Environ. Health Perspect., v. 92, p. 7, 1991 apud DAULTON, T.L. LITTLE, B.J. Determination of chromium valence over the range $\mathrm{Cr}(0)-\mathrm{Cr}(\mathrm{VI})$ by electron energy loss spectroscopy, Ultramicroscopy, v. 106, p. 561-573, 2006.

(61) GREENWOOD, N.N. EARNSHAW, A. Chemistry of the Elements, Butterworth Heinemann, Oxford, 1998, p. 1002-1039. apud DAULTON, T.L. LITTLE, B.J. Determination of chromium valence over the range $\mathrm{Cr}(0)-\mathrm{Cr}(\mathrm{VI})$ by electron energy loss spectroscopy, Ultramicroscopy. v. 106, p. 561-573, 2006.

(62) BARTLETT, R.J. Environ. Health Perspect., v. 92, p. 17, 1991 apud DAULTON, T.L. LITTLE, B.J. Determination of chromium valence over the range $\mathrm{Cr}(0)-\mathrm{Cr}(\mathrm{VI})$ by electron energy loss spectroscopy, Ultramicroscopy. v. 106, p. 561-573, 2006.

(63) Cieslak-Golonka, M. Toxic and mutagênic effects of chromium(VI). A review. Polyhedron, v. 15, p. 3667-1689,1995.

(64) CODD, R. DILLON, C.T. LEVINA, A. LAY, P.A. Studies on the genotoxicity of chromium: from the test tube to the cell. Coord. Chem. Rev., v. 216-217, p. 537582, 2001.

(65) CALAS, G. MAJÉRUS, O. GALOISY, L. CORMIER, L. Crystal field spectroscopy of $\mathrm{Cr}^{3+}$ in glasses: Compositional dependence and thermal site expansion. Chem. Geol., v. 229, p. 218-226, 2006.

(66) BURNS, R.G. Mineralogical Applications of Crystal Field Theory, $2^{\mathrm{a} e d .}$ Cambridge.: Cambridge University Press, 1993. 
(67) LIPINSKA-KALITA K.E., KALITA P.E., KROL, D.M. HEMLEY, R.J. GOBIN, C.L. $\mathrm{OHKI}, \mathrm{Y}$. Spectroscopic properties of $\mathrm{Cr}^{3+}$ ions in nanocrystalline glass-ceramic composites. J. of Non-Cryst. Sol., v. 352, p. 524-527, 2006.

(68) RUSSELL, D.L. HOLIDAY, K. GRINBERG, M. HOLLIS, D.B. Phys. Rev., v. B 59, p. 13712, 1999 apud LIPINSKA-KALITA K.E., KALITA P.E., KROL, D.M. HEMLEY, R.J. GOBIN, C.L. OHKI, Y. Spectroscopic properties of $\mathrm{Cr}^{3+}$ ions in nanocrystalline glass-ceramic composites. J. of Non-Cryst. Sol., v. 352, p. 524-527, 2006.

(69) KAMINSKA, A. KACZOR, P. DURYGIN, A. SUCHOCKI, A. GRINBERG, M. Lowtemperature high-presure spectroscopy of lanthanum lutetium gallium garnet crystals doped with $\mathrm{Cr}^{3+}$ and $\mathrm{Nd}^{3+}$. Phys. Rev., v. B 65, p. 104106_1-104106_8, 2002.

(70) KOEPKE, C. WISNIEWSKI, K. GRINBERG, M. RUSSEL, D.L. HOLLIDAY, K.Z. BEALL, G. J. Lumin., v. 78, p. 135, 1998 apud LIPINSKA-KALITA K.E., KALITA P.E., KROL, D.M. HEMLEY, R.J. GOBIN, C.L. OHKI, Y. Spectroscopic properties of $\mathrm{Cr}^{3+}$ ions in nanocrystalline glass-ceramic composites. J. of Non-Cryst. Sol., v. 352, p. 524-527, 2006.

(71) FEOFILOV, S.P. KAPLYANSKI, A.A. KULINKIN, A.B. MELTZER, R.S. VASILEVSKAYA, T.N. J. Lumin., v. 100, p. 155, 2002 apud LIPINSKA-KALITA K.E., KALITA P.E., KROL, D.M. HEMLEY, R.J. GOBIN, C.L. OHKI, Y. Spectroscopic properties of $\mathrm{Cr}^{3+}$ ions in nanocrystalline glass-ceramic composites. J. of Non-Cryst. Sol., v. 352, p. 524-527, 2006.

(72) ROSSI, F. PUCKER, G. MONTAGNA, M. FERRARI, M. BUCKENTER, A. Fluorescence line narrowing study of $\mathrm{Cr}^{3+}$ ions in cordeierite glass nucleating $\mathrm{MgAl}_{2} \mathrm{O}_{4}$ nanocrystals. Opt. Mater., v. 13, p. 373-379, 2000.

(73) BAMFORD, A.C. Colour generation and control in glasses, N.York, N.Y.: Elsevier Scientific Pub. Co., 1974.

(74) HRMA, P. VIENNA, J. D. WILSON, B. K. PLAISTED, T. J. HEALD, S. M. Chromium phase behavior in a multi-component borosilicate glass melt. J. of Non-Cryst. Sol., v. 352 p. 2114-2122, 2006.

(75) BROW, R.K. Oxidation States of Chromium Dissolved in Glass Determined by Xray Photoelectron Spectroscopy. J. Am. Ceram. Soc., v. 70 [6], p. C-129-131, 1987.

(76) TOMSIA, A.P. FEIPENG, Z. PASK, J.A. Reactions and Bonding of Sodium Disilicate Glass with Chromium. J. Am. Ceram. Soc., v.68 [ I ], p. 20-24,1985.

(77) HANSON, B. JONES, J.H. The systematics of $\mathrm{Cr}^{3+}$ and $\mathrm{Cr}^{2+}$ partitioning between olivine and liquid in the presence of spinel. Am. Mineral, v. 83, p. 669-684, 1998.

(78) PETERMANN, M. HIRSCHMANN, M.H. Trace-element partitioning between vacancy-rich eclogitic clinopyroxene and silicate melt. Am. Mineral, 87, 13651376. v. 18, p. 207-254, 2002.

(79) BÉDARD, J.H. Partitioning coefficients between olivine and silicate melts. Lithos, v. 83, p. 394-419, 2005.

(80) KNUPP, R.C. BERGER, D.F. Effects of iron in ultraviolet absorbing green glass, The Glass Ind., v. 5, p. 253,1966 apud GUIDAL, O. ADAK, C. A study on $\mathrm{Cr}^{3+} / \mathrm{Cr}^{6+}$ equilibria in industrial emerald green glasses. J. of Non-Cryst. Sol., v.38-39, p. 251-256,1980.

(81) KNUPP, R.C. BERGER, D.F. Colour characteristics of ultraviolet absorbing green glass. Ceram. Bull., v. 3, p. 244, 1969 apud GUIDAL, O. ADAK, C. A study on $\mathrm{Cr}^{3+} / \mathrm{Cr}^{6+}$ equilibria in industrial emerald green glasses. J. of Non-Cryst. Sol., v.38-39, p. 251-256,1980.

(82) GUIDAL, O. ADAK, C. A study on $\mathrm{Cr}^{3+} / \mathrm{Cr}^{6+}$ equilibria in industrial emerald green glasses. J.of Non-Cryst. Sol., v.38-39, p. 251-256,1980. 
(83) JANTZEN, C.M. First principles process-product models for vitrification of nuclear waste: relationship of glass composition to glass viscosity, resistivity, liquidus temperature and durability, Ceramic Transactions, Westerville, OH.: American Ceramic Society, 1991, v. 23, p. 37 apud HRMA, P. VIENNA, J.D. WILSON, B.K. PLAISTED, T.J. HEALD, S.M. Chromium phase behavior in a multi-component borosilicate glass melt. J. of Non-Cryst. Solids, v. 352, p. 2114-2122, 2006.

(84) HRMA, P. VIENNA, J.D. MIKA, M. CRUM, J.V. PIEPEL, G.F. Liquidus temperature data for dwpf glass. PNNL-11790, v. 1. Richland, WA.: Pacific Northwest National Laboratory, 1999 apud HRMA, P. VIENNA, J.D. WILSON, B.K. PLAISTED, T.J. HEALD, S.M. Chromium phase behavior in a multi-component borosilicate glass melt. J. of Non-Cryst. Solids, v. 352, p. 2114-2122, 2006.

(85) HRMA, P. IZAK, P. VIENNA, J.D. IRWIN, G.M. THOMAS, M.L. Phys. Chem. Glasses, v. 43, p. 128, 2002 apud HRMA, P. VIENNA, J.D. WILSON, B.K. PLAISTED, T.J. HEALD, S.M. Chromium phase behavior in a multi-component borosilicate glass melt. J. of Non-Cryst. Solids, v. 352, p. 2114-2122, 2006.

(86) VIENNA, J.D. HRMA, P. CRUM, J.V. MIKA, M. J. Liquidus temperaturecomposition model for multi-component glasses in the $\mathrm{Fe}, \mathrm{Cr}$. $\mathrm{Ni}$, and $\mathrm{Mn}$ spinel primary phase field. J. Non-cryst. Solids, v. 292, p. 1-24, 2001.

(87) BROWN, K.G. JANTZEN, C.M. RITZHAUPT, G.L. Relating liquidus temperature to composition for defense waste processing facility (DWPF) process control (U), WSRC-TR-2001-00520. Westinghouse Savannah River Company, Aiken, SC, 2001 apud HRMA, P. VIENNA, J.D. WILSON, B.K. PLAISTED, T.J. HEALD, S.M. Chromium phase behavior in a multi-component borosilicate glass melt. J. of NonCryst. Solids, v. 352, p. 2114-2122, 2006.

(88) SUSSMILCH, J. The vitrification of accident wastes from the nuclear power plant A-1 in Slovakia, in: Environmental Remediation and Environmental Management Issues, New York.: American Society of Mechanical Engineers, NY, 1993, v. 3, p. 849 apud HRMA, P. VIENNA, J.D. WILSON, B.K. PLAISTED, T.J. HEALD, S.M. Chromium phase behavior in a multi-component borosilicate glass melt. J. of Non-Cryst. Solids, v. 352, p. 2114-2122, 2006.

(89) TEHLI, C. JHYLEE, W. LINHUANG, K. FENGFU, S. CHIEHLAI, A. Vitrification of Chromium Electroplating Sludge, Environ. Sci. \& Technol., v. 41 [8], p. 2950-2956, 2007.

(90) CALAS, G. PETIAU, J. Structure of oxide glasses. Spectroscopicstudies of local order and crystallochemistry. Geochemical implications".Bull. Mineral, v. 106, p. 33-55, 1983.

(91) KEPPLER $\mathrm{H}$. The investigation of phase transitions by electronic absorption spectroscopy. Phys. Chem. Minerals, v. 23, p. 288-296, 1996.

(92) GALOISY, L. CALAS, G. Structural environment of nickel in silicate glass/melt systems. I. Spectroscopic determination of coordination states. Geochim. Cosmochim. Acta, v. 57, p. 3613-3626, 1993.

(93) FARGES, F. BROWN JR., G.E. PETIT, P.E. MUÑOZ, M. Transition elements in water-bearing silicate glasses/melts. Part I. A high-resolution and anharmonic analysis of Ni coordination environments in crystals, glasses, and melts. Geochim. et Cosmochim. Acta, v. 65 [10], p. 1665-1678, 2001.

(94) NORD, A.G. STEFANIDIS, T. Crystal chemistry of $\mathrm{Y}-(\mathrm{Zn}, \mathrm{Me}) 3(\mathrm{PO} 4)$ solid solutions. Mat. Res. Bull., v. 16, p. 1121-1129, 1981.

(95) FARGES, F. BROWN, JR. G.E. CALAS, G. GALOISY, L. WAYCHUNAS, G.A. Structural transformation in Ni-bearing $\mathrm{Na}_{2} \mathrm{Si}_{2} \mathrm{O}_{5}$ glass and melt. Geophys. Res. Lett., v. 21, p.1931-1934, 1994. 
(96) BROWN JR., G.E. FARGES F. CALAS G. X-ray scattering and x-ray spectroscopy studies of silicate melts. In: Structure, Dynamics, and Properties of Silicate Melts. Reviews in Mineralogy, The Mineralogical Society of America. v. 32, pp. 317-410. (1995) apud FARGES, F. BROWN JR., G.E. PETIT, P.E. MUÑOZ, M. Transition elements in water-bearing silicate glasses/melts. Part I. A highresolution and anharmonic analysis of $\mathrm{Ni}$ coordination environments in crystals, glasses, and melts. Geochim. et Cosmochim. Acta, v. 65 [10], p. 1665-1678, 2001.

(97) SHIBATA, M.O. OKAWA, M. YOKOKAWA, T. Studies of NiO dissolved in alkali silicate melts based on redox potential and visible absorption spectra. J. of NonCryst. Solids, v. 190, p. 226-232, 1995.

(98) XUE, X. STEBBINS J.F. KANZAKI, M. Am. Miner., v. 79, p. 31, 1994 apude SHIBATA, M. O. OKAWA, M. YOKOKAWA, T. Studies of NiO dissolved in alkali silicate melts based on redox potential and visible absorption spectra. J. of NonCryst. Solids, v. 190, p. 226-232, 1995.

(99) KAWAZOE, H. hOSONO H. KANAZAWA, T. J. Ceram. Soc, Jpn., v. 86, p. 567, 1978 apud FARGES, F. BROWN JR., G.E. PETIT, P.E. MUÑOZ, M. Transition elements in water-bearing silicate glasses/melts. Part I. A high-resolution and anharmonic analysis of $\mathrm{Ni}$ coordination environments in crystals, glasses, and melts. Geochim. et Cosmochim. Acta, v. 65 [10], p. 1665-1678, 2001.

(100) GALOISY, L. CALAS, G. Structural environment of $\mathrm{Ni}$ in silicate glass/melt systems: Part 2. Geochemical implications. Geochim. Cosmochim. Acta, v. 57, p. 3627-3633, 1993.

(101) CORMIER, L. GHALEB, D. NEUVILLE, D.R. DELAYE, J.M. CALAS, G. Chemical dependence of network topology of calcium aluminosilicate glasses: a computer simulation study. J. Non-Crystal. Solids, v. 332, p. 255-270, 2003.

(102) WANG, P.W. ZHANG, L. Structural role of lead silicate glasses derived from XPS spectra. J. Non-Crystal. Solids, v. 194, p. 129-134, 1996.

(103) CALAS, G. CORMIER, L. GALOYSIS, L. JOLLIVET, P. Structure-property relationships in multi-component oxide glasses. C. $\boldsymbol{R}$. Chim., v. 5, p. 1-13, 2003.

(104) PINAKIDOU, F. KATSIKINI, M. PALOURA, E.C. KAVOURAS, P. KEHAGIAS, TH. KOMNINOU, PH. KARAKOSTAS, TH. ERKO, A. On the distribution and bonding environment of $\mathrm{Zn}$ and $\mathrm{Fe}$ in glasses containing electric arc furnace dust: $\mathrm{A} \mu$ XAFS and $\mu$-XRF study. J. of Hazard. Mat., v. 142, p. 297-304, 2007.

(105) ROTH, S.R. NEGAS, T. CONN, L.P. Phase Diagrams for Ceramists. The American Ceramic Society, Fig.5321.

(106) TORRES, F.J. SOLA, E.R. ALARCÓN, J. Effect of some additives on the development of spinel-based glass-ceramic glazes for floor-tiles. J. of Non-Cryst. Solids, v. 351, p. 2453-2461, 2005.

(107) KARAMBERI, A. ORKOPOULOS, K. MOUTSATSOU A. Synthesis of glassceramics using glass cullet and vitrified industrial by-products. J.of the Eur. Cer. Soc., v. 27, p. 629-636, 2006.

(108) FRANCIS, A.A., Conversion of blast furnace slag into new glass-ceramic material. J. of the Eur. Cer. Soc., v. 24, p. 2819-2824, 2004.

(109) ROMERO, M. RINCÓN, J.M. RAWLINGS, R.D. BOCCACCINI, A.R. Use of vitrified urban incinerator waste as raw material for production of sintered glass-ceramics. Mat. Res. Bull., v. 36, p. 383-395, 2001.

(110) RABINOVICH, E.M. Cordierite Glass-Ceramics Produced by Sintering, in: Advances in Ceramics, Columbus, The American Ceramic Society, 1982, v. 4, pp. 327-333. apud COLOMBO, P. BRUSATIN, G. BERNARDO, E. SCARINCI, G. Inertization and reuse of waste materials by vitrification and fabrication of glass- 
based products, Curr. Op. in Sol. State and Mat. Sci., v. 7, p. 225-239, 2003.

(111) NAKASHIMA, K. NODA, K. MORI, K. -Temperature-Transformation diagrams for borosilicate glasses and preparation of chemically durable porous glasses, J. Am. Ceram. Soc., v. 80, p. 1101-1110, 1997.

(112) CANTALINI, C. PELINO, M. Characterization of crystal phases, morphology and crystallization processes in lithium aluminosilicate glass-ceramic. J. Mater. Sci., v. 27, p. 448-452, 1992.

(113) UHLMANN, D.R. A kinetic treatment of glass formation J. Non-Cryst. Solids, v. 7, p. 337-348, 1974.

(114) WEINBERG, M.C. Nose method of calculating critical cooling rates for glass formation. J. Am. Ceram. Soc., v. 72, p. 2054-2058, 1989.

(115) PINAKIDOU, F. KATSIKINI, M. PALOURA, E.C. KAVOURAS, P. KOMNINOU, PH. KARAKOSTAS, TH. ERKO, A. Study of annealing induced devitrification of stabilized industrial waste glasses by means of micro-X-ray fluorescence mappingand absorption fine structure spectroscopy. J. of Non-Cryst. Solids, v. 351, p. 2474-2480, 2005.

(116) KAVOURAS, P. KAIMAKAMIS, G. IOANNIDIS, T.A. KEHAGIAS, T. KOMNINOU, P. KOKKOU, S. PAVLIDOU, E. ANTONOPOULOS, I. SOFONIOU, M. ZOUBOULIS, A. HADJIANTONIOU, C.P. NOUET, G. PRAKOURAS, A. KARAKOSTAS, T. Vitrification of lead-rich solid ashes from incineration of harzardous industrial wastes. Waste Manage., v. 23, p. 361-371, 2003.

(117) EROL, M. KUCUKBAYRAK, S. ERSOY-MERICBOYOU, A. OVESOGLU, M. L. Crystallization behavior of glasses produced from fly ash. J. Eur. Ceram. Soc., p. 2835-2841, 2001.

(118) BEALL, G.H. PINCKNEY, L.R. Nanophase glass-ceramics. J. Am. Ceram. Soc., v. 82 [1], p. 5-16,1999.

(119) PERET, D. CROSIVIER, J. L. STILLE, P. SHIELDS, G. MADER, U. ADVOCAT, T. SCHENK, K. CHARDONNENS, M.Thermodynamic stability of waste glasses comparated to leaching behavior. Ap. Geoch., v.18, p. 1165-1184, 2003.

(120) JAMES, P.F. Glass ceramics: new compositions and uses. J. Non-Cryst. Solids, v. 181, p. 1, 1995.

(121) STRNAD, Z. Glass-Ceramics Materials. Liquid phase separation, nucleation and crystallization in glasses. in: Glass science and technology, Amsterdam.: 1986, Elsevier, apud ROMERO, M. RINCÓN, J.M. RAWLINGS, R.D. BOCCACCINI, A.R. Use of vitrified urban incinerator waste as raw material for production of sintered glass-ceramics. Mat. Res. Bull., v. 36, p. 383-395, 2001.

(122) WILLIAMSON, J. The kinetics of crystal growth in an aluminosilicate glass containing small amounts of transition-metal ions. Min. Mag., v. 37 [291], p. 759 770, 1970.

(123) SHELESTAK, L.J. CHAVEZ, R.A. MACKENZIE, J.D. Glasses and glass-ceramics from naturally occurring $\mathrm{CaO}-\mathrm{MgO}-\mathrm{Al}_{2} \mathrm{O}_{3}-\mathrm{SiO}_{2}$ materials (I) glass formation and properties. J. Non-Cryst. Solids, v. 27, p. 75-81, 1978.

(124) SHELESTAK, L.J. CHAVEZ, R.A. MACHENZIE, J.D. Glasses and glass-ceramics from naturally occurring $\mathrm{CaO}-\mathrm{MgO}-\mathrm{Al}_{2} \mathrm{O}_{3}-\mathrm{SiO}_{2}$ materials (II) crystallization behaviour. J. Non-Cryst. Solids, v. 27, p. 83-97, 1978.

(125) OMAR, A. ELSHENNAURI, A.W. KHATER, G.A. The role of $\mathrm{Cr}_{2} \mathrm{O}_{3}$, LiF and their mixtures on crystalline phase formation and microstructure in $\mathrm{Ba}, \mathrm{Ca}, \mathrm{Mg}$ aluminosilicates glass. Br. Ceram. Trans. J., v. 90, p. 179-183,1991.

(126) REZVANI, M. EFTEKHARI-YEKTA, B. SOLATI-HASHJIN, M. MARGHUSSIAN, V.K. Effect of $\mathrm{Cr}_{2} \mathrm{O}_{3}, \mathrm{Fe}_{2} \mathrm{O}_{3}$ and $\mathrm{TiO}_{2}$ nucleants on the crystallization behaviour of $\mathrm{SiO}_{2}-\mathrm{Al}_{2} \mathrm{O}_{3}-\mathrm{CaO}-\mathrm{MgO}\left(\mathrm{R}_{2} \mathrm{O}\right)$ glass-ceramics. Cer. Inter., v. 31, p. 75-80, 2005. 
(127) BARBIERI, L. LEONELLI, C. MANFREDINI, T. PELLACANI, G.C. SILIGARDI, C. TONDELLO, E. BERTONCELLO, R. Solubility reactivity and nucleation effect of $\mathrm{Cr}_{2} \mathrm{O}_{3}$ in the $\mathrm{CaO}-\mathrm{MgO}-\mathrm{Al}_{2} \mathrm{O}_{3}-\mathrm{SiO}_{2}$ glassy system. J. Mater. Sci., v. 29, p. 62736280, 1994.

(128) KARAMANOV, A. PISCIELLA, P. PELINO, M. The effect of $\mathrm{Cr}_{2} \mathrm{O}_{3}$ as a nucleating agent in iron-rich glass-ceramics. J. Eur. Ceram. Soc., v. 19, p. 2641-2645, 1999.

(129) MARGHUSSIAN, V.K. ARJOMANDNIA, S. Effect of $\mathrm{Cr}_{2} \mathrm{O}_{3}$ on nucleation of $\mathrm{SiO}_{2}-$ $\mathrm{Al}_{2} \mathrm{O}_{3}-\mathrm{CaO}-\mathrm{MgO}\left(\mathrm{R}_{2} \mathrm{O}, \mathrm{Fe}_{2} \mathrm{O}_{3}, \mathrm{TiO}_{2}\right)$ glass ceramics. Phys. Chem. Glass., v. 39 [4], p. 246-251, 1998.

(130) MARGHUSSIAN, V.K. ARJOMANDNIA, S. Crystallisation behaviour of $\mathrm{SiO}_{2}-\mathrm{Al}_{2} \mathrm{O}_{3}-$ $\mathrm{CaO}-\mathrm{MgO}\left(\mathrm{R}_{2} \mathrm{O}, \mathrm{Fe}_{2} \mathrm{O}_{3}, \mathrm{TiO}_{2}\right)$ glass ceramics in the presence of a $\mathrm{Cr}_{2} \mathrm{O}_{3}$ nucleant. Phys. Chem. Glass., v. 40 [6], p. 311-313, 1999.

(131) BEVILACQUA, A. M. BERNASCONI, N. B. RUSSO, D. O. AUDERO, M. A. STERBA, M. E. HEREDIA, A. Immobilization of simulated high-level liquid wastes in sintered borosilicate, aluminosilicate and aluminoborosilicate glasses. J. Nucle. Mater., v. 229, p. 187-193, 1996.

(132) ABRAITIS, P. K. McGRAIL, B. P. TRIVEDI, D. P. LIVENS, F. R. VAUGHAN, D. J. Single-pass flow-though experiments on a simulated waste glass in alkaline media at $40^{\circ} \mathrm{C}$. I - Experiments conducted at variable flow rate to glass surface and ratio. J. Nucle. Mater., v. 280, p. 196-205, 2000.

(133) SHENG, J. LOU, S. TANG, B. The leaching behavior of borate waste glass SL-1. Waste Manag., v. 19, p. 401-407, 1999.

(134) NEWTON, R.G. PAUL, A. A new approach to predicting the durability of glasses from their chemical compositions. Glass Tech., v. 21, p. 307-309, 1980.

(135) NEWTON, R.G. The durability of glass. Glass Tech., v. 26, p. 21-38, 1985.

(136) KIM, I. T. KIN, J. H. LEE, K. S. SEO, Y. C. KOO, J. K. Leaching characteristics of glassy forms containing two different incineration ashes. Waste Manage., v. 20, p. 409-416, 2000.

(137) SPENCE, R.D. GILLIAM, T.M. MATTUS, C.H. MATTUS, A.J. Laboratory stabilization/solidification of surrogate and actual mixed-waste sludge in glass and grout. Waste Manag., v. 19, p. 453-465, 1999.

(138) FENG, X. PEGG, I. L. A glass dissolution model for the effects of S/V on leachate pH. J. Non-Cryst. Solids, v. 175, p. 281-293, 1994.

(139) HAMILTON, J.P. PANTANO, C.G. Effects of glass structure on the corrosion behavior of sodium-aluminosilicate glasses. J. Non-Cryst. Solids, v. 222, p. $167-$ 174, 1997.

(140) KOENDERINK, R.H. BRZESOWSKY, R.H. BALKENENDE, A.R. Effect of the initial stages of leaching on the surface of alkaline earth sodium silicate glasses. J. NonCryst. Solids, v. 262, p. 80-98, 2000.

(141) SIGOLI, F.A. KAWANO, Y. DAVOLOS, M.R. JAFELICCI JR., M. Phase separation in pyrex glass by hidrothermal treatment: Evidence from micro-raman spectroscopy. J. Non-Cryst. Solids, v. 284, p. 49-59, 2001.

(142) COOPER, C.I. COX, G.A. The aqueous corrosion of potash-lime-silica glass in the range $10-250^{\circ} \mathrm{C}$. Appli. Geochem., v. 11, p. 511-521, 1996.

(143) NOGUES, J.L. VERNUZ, E.Y. JACQUET-FRANCILLON, N. Nuclear glass corrosion mechanism applied to the French LWR reference glass. Mater. Res. Soc., v. 44 p. 89-98, 1985.

(144) YALMALI, V.S. DESHINGKAR, D.S. WATTAL, P.K. BHARADWAJ, S.R. Preparation and characterization of vitri.ed glass matrix for high level waste from MOX fuel processing. J. of Non-Cryst. Solids, v. 353, p. 4647-4653, 2007. 
(145) FERREIRA, C. RIBEIRO, A. OTTOSEN, L. Possible applications for municipal solid waste .y ash. J. Hazard. Mater., v. B96, p. 201-216, 2003.

(146) ROMERO, M. RAWLINGS, R.D. RINCÓN, J. MA. Development of a new glassceramic by means ofcontrolled vitriffcation and crystallization of inorganic wastes from urban incineration. J. Eur. Ceram. Soc., v. 19, p. 2049-2058, 1999.

(147) BOCCACCINI, A.R. KOPF, M. STUMPFE, W. Glass-ceramics from filter dusts from waste incinerators. Ceram. Int., v. 21, p. 231-235, 1995.

(148) CHENG, T.W. CHEN, Y.S. On formation of $\mathrm{CaO}-\mathrm{Al}_{2} \mathrm{O}_{3}-\mathrm{SiO}_{2}$ glass-ceramics by vitriffcation of incinerator fly ash. Chemosphere, v. 51, p. 817-824, 2003.

(149) CHENG, T.W. UENG, T.H. CHEN, Y.S. CHIU, J.P. Production of glassceramic from incinerator fly ash. Ceram. Int., v. 28, p. 779-783, 2002.

(150) PARK, Y.J. HEO, J. Conversion to glass-ceramics from glasses made by MSW incinerator fly ash for recycling. Ceram. Int., v. 28, p. 689-94, 2002.

(151) BOCCACCINI, A. RAWLINGS, R. Producing glass-ceramics from waste materials. Mater. World, v. 5, p. 16-18, 2002.

(152) RINCÓN, J.M. ROMERO, M. BOCCACCINI, A.R. Microstructural characterisation of a glass and a glass-ceramic obtained from municipal incinerator fly ash, $J$. Mater. Sci., v. 34, p. 4413-4423, 1999.

(153) BOCCACCINI, A.R. PETITMERMET, M. WINTERMANTEL, E. Glassceramics from municipal incinerator fly ash. Bull. Am. Ceram. Soc., v. 76, p. 75-78,1997.

(154) ROMERO, M. RAWLINGS, R.D. RINCÓN, J.M. Crystal nucleation and growth in glasses from inorganic wastes from urban incineration. J. Non-Cryst. Sol., v. 271, p. 108-118, 2000.

(155) PARK, Y.J. HEO, J. Vitrification of fly ash from municipal solid waste incinerator. J. Hazard. Mater., v. B91, p. 83-93. 2002.

(156) KARAMANOV, A. PELINO, M. HREGLICH, S. Sintered glass-ceramics from municipal solid waste-incinerator fly ashes-part I: the influence of the heating rate on the sinter-crystallization. J. Eur. Ceram. Soc., v. 23, p. 827-832, 2003.

(157) BARBIERI, L. KARAMANOV, A. CORRADI, A. LANCELLOTTI, I. PELINO, M. RINCÓN, J.M. Structure, chemical durability and crystallization behavior of incinerator-based glassy systems. J. of Non-Cryst. Solids, v. 354, p. 521-528, 2008.

(158) KÁROLY, Z. MOHAI, I. TÓTH, M. WÉBER, F. SZÉPVÖLGYI, J. Production of glass-ceramics from fly ash using arc plasma. J. of the Eur. Cer. Soc., v. 27, 1721-1725, 2007.

(159) PELINO, M. Recycling of zinc-hydrometallurgy wastes in glass and glass ceramic materials. Waste Manag., v. 20, p. 561-568, 2000.

(160) LEROY, C. FERRO, M.C. MONTEIRO, R.C.C. FERNANDES, M.H.V. Production of glass-ceramics from coal ashes. J. Eur. Ceram. Soc., v. 21, p. 195-202, 2001.

(161) EROL, M. KÜÇÜKBAYRAK, S. ERSOY-MERIÇBOYU, A. Comparison of the properties of glass, glass-ceramic andceramic materials produced from coal fly ash. J. of Hazard. Mat., v. 153, p. 418-425, 2008.

(162) FRANCIS, A.A. RAWLINGS, R.D. BOCCACCINI, A.R. Glass-ceramics from mixtures of coal ash and soda lime glass by the petrurgic method. J. Mater. Sci. Lett., v. 21, p. 975-980, 2002.

(163) KAVOURAS, P. IOANNIDIS, TH. A. KEHAGIAS, TH. TSILIKA, I. CHRISSAFIS, K. KOKKOU, S. ZOUBOULIS, A. KARAKOSTAS, TH. EAFD-loaded vitreous and glass-ceramic materials. J. Eur. Ceram. Soc., v. 27, p. 2317-2323, 2007. 
(164) BARBIERI, L. CORRADI, A. LANCELLOTTI, I. Thermal and chemical behavior of different glasses containing steel fly ash and their transformation into glassceramics. J. Eur. Ceram. Soc., v. 22, p. 1759-1765, 2002.

(165) BARBIERI L, FERRARI AM, LANCELLOTTI I, LEONELLI C., "Crystallization of $\left(\mathrm{Na}_{2} \mathrm{O}-\mathrm{MgO}\right)-\mathrm{CaO}-\mathrm{Al}_{2} \mathrm{O}_{3}-\mathrm{SiO}_{2}$ glassy systems formulated from waste products", J. Am. Ceram. Soc., v. 25, p. 15-20, 2000.

(166) PINCUS, A.G. Soviet building with slag sitall. Glas. Ind., v. 53, p. 6-9, 1972.

(167) KARAMANOV, A. TAGLIERI, G. PELINO, M. Iron-rich sintered glassceramics from Industrial Wastes. J. Am. Ceram. Soc., v. 82 [11], p. 3012-3016, 1999.

(168) KARAMANOV, A. TAGLIERI, G. PELINO, M. Sintering Behavior and Properties of Iron-Rich Glass-Ceramics. J. Am. Ceram. Soc., v. 87 [8], p. 1571-1574. 2004.

(169) BLUME, R.D. DRUMMOND, C.H. High Grade Abrasive Product Development from Vitrified Industrial Waste. in: Environment Issues and WasteManagement Technology in Ceramic and Nuclear Industries II, Ceramic Transaction Series, Westerville, OH, Ceramic Society, 1996. v. 72. pp. 229-39 apud HUANG, D. DRUMMOND III, C.H. WANG, J. BLUME, R.D. Incorporation of Chromium(III) and Chromium(VI) Oxides in a Simulated Basaltic, Industrial Waste Glass-Ceramic. J. Am. Ceram. Soc., v. 87 [11], p. 2047-2052, 2004.

(170) FERREIRA, M. C. Obtenção de fritas vitrocerâmicas a partir de resíduos sólidos industriais. 2006. Dissertação (Mestrado) - IPEN, São Paulo.

(171) BERNSTEIN, A.G. BONSEMBIANTE, E. BRUSATIN, G. CALZOLARI, G. COLOMBO, P. DALL'IGNA, R. Inertization of hazardous dredging spoils. Waste Manag., v. 22, p. 865-869, 2002.

(172) BRUSATIN, G. BERNSTEIN, A.G. BONSEMBIANTE, E. CALZOLARI, G. COLOMBO, P. DALL'IGNA, R. Vitrification of hazardous wastes. Glass Mach. Plants Acc., v. 4, p. 77-81, 2002.

(173) ROBERTS, D. STUART, J.H., Vitrification of asbestos waste. United States Patent 4.820.328, 11 abril, 1989.

(174) BERNARDO, E. CASTELLAN, R. HREGLICH, S. LANCELLOTTI, I. Sintered sanidine glass-ceramics from industrial wastes. J. of the Eur. Cer.Soc., v. 26, p. 3335-3341, 2006.

(175) PARK, Y.J. MOON, S, HEO, J. Crystalline phase control of glass ceramics obtained from sewage sludge fly ash. Ceram. Int., v. 29, p. 223-237, 2003.

(176) ZANOTTO, E.D. Isothermal and adiabatic nucleation in glass. J. Non-Cryst. Solids, v. 89, p. 361-370,1987.

(177) BLOOMER, P.E. FENG, X. CHANTARAPRACHOOM, N. GONG, M. MCCREADY, D.E. Effect of crystallization, redox, and waste loading on the properties of several glassy waste forms. J. Am. Ceram. Soc., v. 11, p. 2999-3011, 1999.

(178) TASHIRO, M. Crystallization of glasses: science and technology. J. Non-Cryst. Sol., v. 73, p. 575-584, 1985.

(179) GUTZOW, I. PASCOVA, R. KARAMANOV, A. SCHMELZER, J. The kinetics of surface induced sinter-crystallization and the formation of glass-ceramic materials. J. Mater. Sci., v. 33, p. 5265-5273, 1998.

(180) CLARK, T.J. REED, J.S. Kinetic processes involved in the sintering and crystallization of glass powders. J. Am. Ceram. Soc., v. 69, p. 837-846, 1986.

(181) MÜLLER, R. ZANOTTO, E.D. FOKIN, V.M. Surface crystallization of silicate glasses: nucleation sites and kinetics. J. Non-Cryst. Sol., v. 274, p. 208-231, 2000.

(182) PRADO, M. O. ZANOTTO, E.D. Glass sintering with concurrent crystallization. C. R. Chimie, v. 5, p. 773-786, 2002. 
(183) KARAMANOV, A. TAGLIERI, G. PELINO, M. Iron-rich sintered glassceramics from industrial wastes. J. Am. Ceram. Soc., v. 82, p. 3012-2016,1999.

(184) KARAMANOV A, PISCIELLA P, CANTALINI C, PELINO M. Influence of $F e_{3 p} / \mathrm{Fe}_{2 p}$ ratio on the crystallization of iron-rich glasses made with industrial wastes. J. Am. Ceram. Soc., v. 83, p. 3153-3157, 2000.

(185) ROMERO, M. RINCÓN, J. M. Surface and bulk crystallization of glass-ceramic in the $\mathrm{Na}_{2} \mathrm{O}-\mathrm{CaO}-\mathrm{ZnO}-\mathrm{PbO}-\mathrm{Fe}_{2} \mathrm{O}_{3}-\mathrm{Al}_{2} \mathrm{O}_{3}-\mathrm{SiO}_{2}$ system derived from a goethite waste. J. Am. Ceram. Soc., v. 82, p. 1313-1317, 1999.

(186) FRANCIS, A.A. RAWLINGS, R.D., SWEENEY, R. BOCCACCINI, A.R. Processing of coal ash into glass ceramic products by powder technology and sintering, Glass Technol., v. 43, p. 58-62, 2002.

(187) BARBIERI, L. CORRADI, A. LANCELLOTTI, I. MANFREDINI, T. Use of municipal incinerator bottom ash as sintering promoter. Waste Manag., v. 22, p. 859-863, 2002.

(188) HERNÁNDEZ-CRESPO, M.S. RINCÓN, J.M. New porcelainized stoneware materials obtained by recycling of MSW incinerator fly ashes and granite sawing residues. Ceram. Int., v. 27, p. 713-720, 2001.

(189) SCARINCI, G. BRUSATIN, G. BARBIERI, L. CORRADI, A. LANCELLOTTI, I. COLOMBO, $P$. Vitrification of industrial and natural wastes with production of glass fibres. J. Eur. Ceram. Soc., v. 20, p. 2485-2490, 2000.

(190) BOCCACCINI, A.R. BÜCKER, M. TRUSTY, P.A. ROMERO, M. RINCÓN, J. M. Sintering behaviour of compacts made from television tube glasses. Glass. Technol., v. 38, p. 128-133, 1997.

(191) MARABINI, A.M. PLESCIA, P. MACCARI, D. BURRAGATO, F. PELINO, M. New materials from industrial and mining wastes: glassceramics and glass- and rockwool fibre. Int. J. Miner. Process, v. 53, p. 121-134, 1998.

(192) LYNSAVAGE, B.W. Foam glass. Bull. Amer. Ceram. Soc., v. 30, p. 230-231, 1951.

(193) D. SOLOMON, M. ROSSETTI, Foamed glass manufacture. US Patent 5.516.351, 14 Maio 1996.

(194) DUCMAN, V. KOVÁCEVÍC, M. The foaming of waste glass. Key Eng. Mater., v. 132-136, p. 2264-2267,1997.

(195) BRUSATIN, G. SCARINCI, G. ZAMPIERI, L. COLOMBO, P. Foam glass from cullet. Glass Mach Plants Acc., v. 1, p. 108-110, 2002.

(196) BOCCACCINI, A.R. BÜCKER, M. BOSSERT, J. MARSZALEK, K. Glass matrix composites from coal fly ash and waste glass. Waste Manag., v. 17, p. 39-45, 1997.

(197) BERNARDO, E. SCARINCI, G. HREGLICH, S. ZANGIACOMI, G., Effect of time and furnace atmosphere on the sintering of glasses from dismantled cathode ray tubes. J. of the Eur. Cer.Soc., v. 27, p. 1637-1643, 2007.

(198) BERNARDO, E. SCARINCI, G. HREGLICH, S. Development and mechanical characterization of $\mathrm{Al}_{2} \mathrm{O}_{3}$ platelet-reinforced glass matrix composites obtained from glasses coming from dismantled cathode ray tubes. J. of the Eur. Cer.Soc., v. 25, p. 1541-1550, 2005.

(199) HREGLICH S, FALCONE R, VALLOTTO M. The recycling of end of life panel glass from TV sets in glass fibres and ceramic productions, in: Recycling and reuse of glass cullet. London.: Thomas Telford; 2001. pp. 123-34. Apud COLOMBO, P. BRUSATIN, G. BERNARDO, E. SCARINCI, G., Inertization and reuse of waste materials by vitrification and fabrication of glass-based products, Curr. Op. in Sol. State and Mat. Sci., v. 7, p. 225-239, 2003. 
(200) DIAZ, C. GRACIA, H. ZAYAS, MA. E. ESPINOZA, F. J. VALLE-FUENTES, F. J. Producing optical glass with geothermal waste. Bull. Am. Ceram. Soc., v. 79, p. 57-59, 2000.

(201) DALL'IGNA, R. FALCONE, R. HREGLICH, S. PROFILO, B. VALLOTTO, M. CADORE, A. Production of mineral fertilizer glass from inertized asbestos containing wastes, Riv. Staz. Sper. Vetro., v. 6, p. 13-15, 2002 Apud COLOMBO, P. BRUSATIN, G. BERNARDO, E. SCARINCI, G., Inertization and reuse of waste materials by vitrification and fabrication of glass-based products, Curr. Op. in Sol. State and Mat. Sci., v. 7, p. 225-239, 2003.

(212) BARBA, M.F. CALLEJAS, P. ARABE, J.O. AJÓ, D. Characterization of two frit ceramics materials in low cost fertilizers. J. Eur. Ceram. Soc., v. 18, p. 13131317, 1998.

(203) JIN, W. MEYER, C. BAXTER, S. Glascrete-concrete with glass aggregate. ACl Mater. J., v. 97, p. 208-213, 2000.

(204) SCHROEDER, R. L. The use of recycled materials in highway construction. Public roads, v. 58, p. 32-41, 1994.

(205) SU, N. CHEN, J.S. Engineering properties of asphalt concrete made with recycled glass. Resour. Conserv. Recy., v. 35, p. 259-274, 2002.

(206) GAO, Z. DRUMMOND, C. H. Thermal analysis of nucleation and growth of crystalline phases in vitrified industrial wastes. J. Am. Ceram. Soc., v. 82 [3], p. $561-565,1999$.

(207) ROTH, S. R. NEGAS, T. CONN, L. P. Phase Diagrams for Ceramists. The American Ceramic Society, Fig. 485.

(208) JIAWEI, S. KWANSIK, C. MYUNG-JAE, S. Vitrification of liquid waste from nuclear power plants. J. Nucle. Mater. v. 297, p. 7-13, 2001.

(209) ROTH, S. R. NEGAS, T. CONN, L. P. Phase Diagrams for Ceramists. The American Ceramic Society, Fig.381.

(210) ROTH, S. R. NEGAS, T. CONN, L. P. Phase Diagrams for Ceramists. The American Ceramic Society, Fig.483.

(211) ROTH, S. R. NEGAS, T. CONN, L. P. Phase Diagrams for Ceramists. The American Ceramic Society, Fig.515.

(212) LEE. J. D. Anew concise inorganic chemistry, $3^{\mathrm{a}}$ ed. London.: 1977, Von Nostrand Reinhold Company Ltd.

(213) IONESCU, D. MEADOWCROFT, T.R. BARR, P.R. Glassification of EAF dust: The limits for $\mathrm{Fe}_{2} \mathrm{O}_{3}$ and $\mathrm{ZnO}$ content and assessment of leach performance. Canad. Metal. Quart., v. 36 nº $^{\circ}$, p. 269-281, 1997.

(214) BARBIERI, L. LANCELLOTTI, I. RINCON, J. M. MANFREDINI, T. Design, obtainment and properties of glasses and glass-ceramics from coal fly ash. Fuel. v. 78, p. 271-276, 1999.

(215) ELBERT, L. WOLF, S.F. An interlaboratory study of a standard glass for acceptance testing of low-activity waste glass. J. Nucle Mater., v. 282, p. 112-124, 2000.

(216) FONSECA, M. V. A. Reciclagem de Rejeitos Sólidos; Desenvolvimento em Escala de Laboratório de Materiais Vítreos à Partir do Xisto Retortado de São Mateus do Sul - PR. 1990. Tese (Doutorado) - Escola Politécnica da USP, São Paulo.

(217) MASCARÓS, S.M. Difracción de Rayos-X in: Técnicas de análises $y$ caracterización de materiales, Madrid.: Consejo Superior de Investigaciones Científicas, 2002, pp. 395-454. 
(218) EWING, G.W. Métodos instrumentais de análise química, São Paulo.: 20012002, Edgard Blücher, Ed. da Universidade de São Paulo

(219) BENNETT, H. OLIVER, G.J. XRF analysis of ceramics, minerals, and allied materials, New York.: 1992, Wiley.

(220) MAR-ALONSO, M. Espectrometria Ultravioleta-Visible (UV-VIS) de líquidos e sólidos in: Técnicas de análises y caracterización de materiales, Madrid.: Consejo Superior de Investigaciones Científicas, 2002, pp. 53-122.

(221) ARONNIEMI, M. SAINIO, J. LATINEEN, J. Chemical state quantification of iron and chromium oxides using XPS: the effect of the background subtraction method. Surf. Sci., v. 578, p. 108-123, 2005.

(222) CAMPOS, j.M. Espectroscopia fotoeléctrica de rayos X (XPS) in: Técnicas de análises y caracterización de materiales, Madrid.: Consejo Superior de Investigaciones Científicas, 2002. pp. 491-530.

(223) DÍAS, I. LANDA, A. R. OTERO-DÍAZ, L.C. Microscopía electrónica de transmisión (TEM) y de barrido (SEM) in: Técnicas de análises y caracterización de materiales, Madrid.: Consejo Superior de Investigaciones Científicas, 2002, pp. 455-490

(224) GUO, G. CHEN, Y. Thermal analysis and infrared measurements of a lead-bariumaluminium phosphate glass. J. Non-Cryst. Solids, v. 201, p. 262-266, 1996.

(225) MAcDONALD, S.A. SCHARDT, C.R. MASIELLO, J.H. SIMMONS, J.H. Dispersion analysis of FTIR reaction measurements in silicate glasses. J. Non-Cryst. Solids, v. 275, p. 72-82, 2000.

(226) ZAYAS, M.E. ARIZPE-CHAVEZ, H. ESPINOZA-BELTRAN, F.J. DIAZ-FLORES, L.L. YANEZ-LIMON, J.M. GONZALES-HERNANDEZ, J. Spectroscopic studies on $\mathrm{Na}_{2} \mathrm{O}-\mathrm{SiO}_{2}$ glasses with different $\mathrm{Ag}$ concentration using silica obtained from wastes of a geothermal plant. J. Non-Cryst. Solids, v. 324, p. 67-72, 2003.

(227) LÓPEZ, A. MÁRQUEZ, C. Espectroscopía Infrarroja (IR) in: Técnicas de análises y caracterización de materiales, Madrid.: Consejo Superior de Investigaciones Científicas, 2002. pp. 153-188.

(228) SLICHTER, C.P. Principles of Magnétic Resonance, New York.: Harper Raw, 1963.

(229) ZHONG, J. BRAY, P.J. Change in boron coordination in alkali borate glasses, and mixed alkali effects, as elucidated by NMR. J. Non-Cryst. Solids, v. 11, p. 67-76, 1989.

(230) SOBRADOS, I. Espectroscopía de Resonancia Magnética nuclear (RMN) in: Técnicas de análises y caracterización de materiales, Madrid.: Consejo Superior de Investigaciones Científicas, 2002, pp. 605-628.

(231) BOCCACCINI, A.R. HAMANN, B. In Situ high-temperature optical microscopy. J. of Mat. Sci., v. 34, p. 5419 - 5436, 1999.

(232) LARA, C. PASCUAL, M.J. PRADO, M.O. DURÁN, A., Sintering of glasses in the system $\mathrm{RO}-\mathrm{Al}_{2} \mathrm{O}_{3}-\mathrm{BaO}-\mathrm{SiO}_{2}(\mathrm{R}=\mathrm{Ca}, \mathrm{Mg}, \mathrm{Zn})$ studied by hot-stage microscopy. Sol. State lonics, v. 170, p. 201-208, 2004.

(233) PASCUAL, M.J. PASCUAL, L. DURÁN, A. Determination of the viscositytemperature curve for glasses on the basis of fixed viscosity points determined by hot stage microscopy. Phys. Chem. Glasses, v. 42 [1], p. 61-66, 2001.

(234) LARA, C. PASCUAL, M.J. DURÁN, A. Glass forming ability, sinterability and thermal properties in the sistems $\mathrm{RO}-\mathrm{BaO}-\mathrm{SiO}_{2}(\mathrm{R}=\mathrm{Mg}, \mathrm{Zn})$. J. Non-Cryst. Solids, v. 348, p. 149-155, 2004. 
(235) SCHOLZE, H. Influence of viscosity and surface tension on hot-stage microscopy measurements on glasses. Ver. Dtsch Keram. Ges., v. 391, p.63-68, 1962.

(236) AMERICAN SOCIETY FOR TESTING AND MATERIALS (ASTM), Standard Test Methods for Determining Chemical Durability of Nuclear, Hazardous, and Mixed Waste Glasses: The Product Consistency Test (PCT), C 1285-97, (1998).

(237) INTERNATIONAL ORGANIZATION FOR STANDARTIZATION. Glass Resistance to attack by a boiling aqueus solution of mixed alkali - Method of test and classification. Genéve Switzerland, 1991. (695-1984 (E)).

(238) DEUTSCHES INSTITUT FUR NORMUNG. Prufung von glass; Griessverfahen zur prufung der wasserbestandigkeit von glass als werstoff bei $98^{\circ} \mathrm{C}$ und Einteilung der glasser in hydrolytiscle klassen. Colônia, Alemanha, 1976. (DIN12116).

(239) ROTH, S.R. NEGAS, T. CONN, L.P. Phase Diagrams for Ceramists. The American Ceramic Society, Fig.3965.

(240) ROTH, S.R. NEGAS, T. CONN, L.P. Phase Diagrams for Ceramists. The American Ceramic Society, Fig.1891.

(241) PRASAD, S. CLARK, T.M. SEFZIK, T.H. KWAK, H.T. GAN, Z. GRANDINETTI, P.J. Solid-state multinuclear magnetic resonance investigation of Pyrex®, J. NonCryst. Solids, v. 352, p. 2834-2840, 2006.

(242) PINAKIDOU, F. KATSIKINI, M. PALOURA, E.C. KAVOURAS, P. KALOGIROU, O. KOMNINOU, PH. TH. KARAKOSTAS, ERKO, A. On the coordination environment of $\mathrm{Fe}$ - and $\mathrm{Pb}$-rich solidified industrial waste: An X-ray absorption and Mössbauer study. J. Non-Cryst. Solids, v. 352 , p. 2933-2942, 2006.

(243) GÜLDAL, O. ANAK, C. A Study on $\mathrm{Cr}^{3+} / \mathrm{Cr}^{6+}$ equilibria in industrial emerald grenn glasses. J. Non-Cryst. Solids, v. 38 \& 39, p. 251-256, 1980.

(244) NAVAS, A.S. REDDY, B.J. NIETO, F. Spectroscopic Study of Chromium, Iron, OH Fluid and Mineral Inclusions in Uvarovite and Fuchsite. Spec. Acta Part A, v. 60, p. 2261-2268, 2004.

(245) SCHOLZE, H. Influence of viscosity and surface tension on hot-stage microscopy measurements on glasses. Ver. Dtsch Keram. Ges., v. 391, p.63-68, 1962.

(246) DE PABLOS, A. DURAN, A. NIETO, M.I. Adjusting of laboratory filature furnace for obtaining fiberglass." Bol. Soc. Esp. Ceram. Vidr., v. 36, p. 517-523, 1997.

(247) JACKSON, W.E. FARGES, F. YEAGER, M. MABROUK, P.A. ROSSANO, S. WAYCHUNAS, G.A. SOLOMON, E.I. BROWN JR., G.E. Multi-spectroscopic study of $\mathrm{Fe}(\mathrm{II})$ in silicate glasses: Implications for the coordination environment of $\mathrm{Fe}(\mathrm{II})$ in silicate melts. Geochim. et Cosmochim. Acta, v. 69 [17], p. 4315-4332, 2005.

(248) FARGES, F. LEFRERE, Y. ROSSANO, S. BERTHEREAU, A. CALAS, G. BROWN JR., G. E. The effect of redox state on the local structural environment of iron in silicate glasses: a combined XAFS spectroscopy, molecular dynamics, and bond valence study, J. Non-Cryst. Solids, v. 344, p.176-188, 2004.

(249) ROSSANO, S. FARGES, F. RAMOS, A. DELAYE, J.M. BROWN JR., G.E. Bond valence in silicate glasses. J. Non-Cryst. Solids, v. 304, p. 167-173, 2002.

(250) ROSSANO, S. RAMOS, A.Y. DELAYE, J.M. Environment of ferrous iron in $\mathrm{CaFeSi}_{2} \mathrm{O}_{6}$ glass; contributions of EXAFS and molecular dynamics, J. Non-Cryst. Solids, v. 273, p. 48-52, 2000. 


\section{Apêndice A}

Tabela 9.1 - Planilha de calculo em \% de massa dos componentes para a composição T15C, onde: RSG = Resíduo sólido galvânico; DFS = Descarte de

finos de sílica; e, RRG = Resíduos de rochas graníticas .

\begin{tabular}{|c|c|c|c|c|c|c|c|c|c|c|c|c|c|c|}
\hline \multirow{2}{*}{\multicolumn{2}{|c|}{\begin{tabular}{|l|l|} 
T15C & $1300^{\circ} \mathrm{C}$ \\
\end{tabular}}} & & & & & & & & & \multicolumn{3}{|c|}{ Subst.SiO2 por B2O3 (\%wt) } & \multicolumn{2}{|l|}{6,9} \\
\hline & & $\mathbf{F}$ & \multicolumn{7}{|c|}{ Composição das matérias primas } & \multicolumn{5}{|c|}{ Acerto diagrama } \\
\hline Oxido & $\%$ massa & 1,00 & RSG & DFS & RRG & $\mathrm{B} 2 \mathrm{O3}$ & $\mathrm{Na2O}$ & $\mathrm{CaO}$ & $\mathrm{K} 2 \mathrm{O}$ & $\mathrm{A} / 2 \mathrm{O} 3$ & Diagrama & Ad.Boro & Vidro & Moles EQ \\
\hline $\mathrm{SiO} 2$ & 47,6 & - & 22,0 & 98,0 & \begin{tabular}{l|l}
72,0 \\
\end{tabular} & - & - & - & - & - & 56,5 & 49,6 & 47,6 & $\overline{0,81}$ \\
\hline $\mathrm{B} 2 \mathrm{O} 3$ & 6,9 & - & - & - & - & 99,0 & - & - & - & - & - & 6,9 & 6,9 & 0,10 \\
\hline $\mathrm{Na} 2 \mathrm{O}$ & 27,5 & - & 1,2 & 0,2 & 4,9 & - & 97,0 & - & - & - & 28,5 & 28,5 & 27,5 & 0,50 \\
\hline $\mathrm{CaO}$ & 15,0 & - & 14,0 & 0,1 & - & - & - & 95,0 & - & - & 15,0 & 15,0 & 15,0 & 0,27 \\
\hline $\mathrm{K} 2 \mathrm{O}$ & 1,0 & - & 0,2 & 0,2 & 6,2 & - & - & - & 99,0 & - & - & - & 1,0 & 0,01 \\
\hline $\mathrm{Al} 2 \mathrm{O} 3$ & 2,0 & - & 0,9 & 0,9 & 16,0 & - & - & - & - & 100,0 & - & - & 2,0 & 0,03 \\
\hline $\mathrm{MgO}$ & - & - & 3,5 & - & 0,0 & - & - & - & - & - & - & - & - & - \\
\hline $\mathrm{Cr} 2 \mathrm{O} 3$ & - & - & 21,0 & - & - & - & - & - & - & - & - & - & - & - \\
\hline $\mathrm{NiO}$ & - & - & 13,0 & 0,0 & - & - & - & - & - & - & - & - & - & - \\
\hline $\mathrm{CuO}$ & - & - & 6,9 & - & - & - & - & - & - & - & - & - & - & - \\
\hline $\mathrm{ZnO}$ & - & - & 4,7 & - & 0,0 & - & - & - & - & - & - & - & - & - \\
\hline $\mathrm{PbO}$ & - & - & 1,3 & - & - & - & - & - & - & - & - & - & - & - \\
\hline $\mathrm{Fe} 2 \mathrm{O} 3$ & - & - & 1,1 & 0,2 & 0,7 & - & - & - & - & - & - & - & - & - \\
\hline $\mathrm{SO} 3$ & & & 7,4 & 0,1 & 0,1 & & & & & & & & & \\
\hline \multirow[t]{2}{*}{ Outros } & - & - & 2,8 & 0,4 & 0,1 & 1,0 & 3,0 & 5,0 & 1,0 & - & - & - & - & - \\
\hline & 100,0 & 100,0 & 100,0 & 100,0 & 100,0 & 100,0 & 100,0 & 100,0 & 100,0 & 100,0 & 100,0 & 100,0 & 100,0 & 1,7 \\
\hline \multicolumn{2}{|c|}{ Composição final } & & - & 41,2 & 10,0 & 6,9 & 26,9 & 14,9 & 0,3 & 0,0 & $\mathrm{Mol}$ & Moles & Moles.EQ & Moles EQ \\
\hline & 47,6 & - & 40,4 & 7,2 & - & - & - & - & - & 58,96 & 0,8069 & 0,8069 & 0,81 \\
\hline \multicolumn{2}{|l|}{$\mathrm{B} 2 \mathrm{O} 3$} & 6,9 & - & - & - & 6,9 & - & - & - & - & 69,63 & 0,0991 & 0,0991 & 0,10 \\
\hline \multicolumn{2}{|l|}{$\mathrm{Na} 2 \mathrm{O}$} & 27,5 & - & 0,1 & 0,5 & - & 26,9 & - & - & - & 54,97 & 0,5003 & 0,5003 & 0,50 \\
\hline \multicolumn{2}{|l|}{$\mathrm{CaO}$} & 14,9 & - & 0,1 & - & - & - & 14,9 & - & - & 56,07 & 0,2661 & 0,2661 & 0,27 \\
\hline \multicolumn{2}{|l|}{$\mathrm{K} 2 \mathrm{O}$} & 1,0 & - & 0,1 & 0,6 & - & - & - & 0,3 & - & 70,99 & 0,0141 & 0,0141 & 0,01 \\
\hline \multicolumn{2}{|l|}{$\mathrm{Al} 2 \mathrm{O} 3$} & 2,0 & - & 0,4 & 1,6 & - & - & - & - & 0,0 & 61,46 & 0,0325 & 0,0325 & 0,03 \\
\hline \multicolumn{2}{|l|}{$\mathrm{MgO}$} & 0,0 & - & - & 0,0 & - & - & - & - & - & 40,29 & 0,0001 & 0,0001 & - \\
\hline \multicolumn{2}{|l|}{$\mathrm{Cr} 2 \mathrm{O} 3$} & - & - & - & - & - & - & - & - & - & 151,97 & - & - & - \\
\hline \multicolumn{2}{|l|}{$\mathrm{NiO}$} & 0,0 & - & 0,0 & - & - & - & - & - & - & 74,69 & 0,0001 & 0,0001 & - \\
\hline \multicolumn{2}{|l|}{$\mathrm{CuO}$} & - & - & - & - & - & - & - & - & - & 79,54 & & & - \\
\hline \multicolumn{2}{|l|}{$\mathrm{ZnO}$} & 0,0 & - & - & 0,0 & - & - & - & - & - & 81,37 & 0,0000 & 0,0000 & - \\
\hline \multirow{2}{*}{\multicolumn{2}{|c|}{$\begin{array}{l}\mathrm{PbO} \\
\mathrm{Fe} 2 \mathrm{O} 3\end{array}$}} & - & - & - & - & - & - & - & - & - & 223,19 & & & - \\
\hline & & 0,1 & - & 0,1 & 0,1 & - & - & - & - & - & 154,67 & 0,0008 & 0,0012 & - \\
\hline \multicolumn{2}{|l|}{$\mathrm{SO} 3$} & 0,1 & - & 0,0 & 0,0 & - & - & - & - & - & & & & \\
\hline Outros & & 1,9 & - & 0,2 & 0,0 & 0,1 & 0,8 & 0,8 & 0,0 & - & - & - & - & - \\
\hline Soma & & 101,9 & - & 41,2 & 10,0 & 7.0 & 27,8 & 15,7 & 0,3 & 0,0 & - & - & . & _. \\
\hline Percurs & & & RSG & RFS & Feldspato & $\mathrm{H} 3 \mathrm{BO} 3$ & $\mathrm{NaOH}$ & $\mathrm{CaO}$ & $\mathrm{K} 2 \mathrm{O}$ & $\mathrm{A} 2 \mathrm{O} 3$ & - & - & - & - \\
\hline$\%$ mass & ercursor & 115,5 & 0,0 & 41,2 & \begin{tabular}{|l|}
10,0 \\
\end{tabular} & 12,3 & 35,8 & 15,7 & 0,4 & $\overline{0,0}$ & - & - & - & - \\
\hline$\%$ Corro & & 100,0 & 0,0 & 35,7 & \begin{tabular}{|l|}
8,7 \\
\end{tabular} & 10,7 & 31,0 & 13,5 & 0,4 & 0,0 & - & - & - & - \\
\hline Pureza & & 1,00 & 1,00 & 1,00 & \begin{tabular}{|l|}
1,00 \\
\end{tabular} & 0,99 & 0,97 & 0,95 & 0,99 & 1,00 & - & - & - & - \\
\hline Pesage & $100 \mathrm{gr}$ & 100,0 & - & 35,7 & \begin{tabular}{|l|}
8,7 \\
\end{tabular} & 10,6 & 30,1 & 12,9 & 0,4 & $\overline{0,0}$ & - & - & - & - \\
\hline Pesage & $30 \mathrm{gr}$ & 30,00 & - & 10,71 & \begin{tabular}{|l|}
2,60 \\
\end{tabular} & 3,17 & 9,03 & 3,86 & 0,11 & $\overline{0,01}$ & - & - & - & - \\
\hline
\end{tabular}


Tabela 9.2 - Planilha de calculo em \% de massa dos componentes para a composição T15R30, onde: $\mathbf{R S G}=$ Resíduo sólido galvânico; $\mathbf{D F S}=$ Descarte de finos de sílica; e, $\mathbf{R} \mathbf{R G}=$ Resíduos de rochas graníticas .

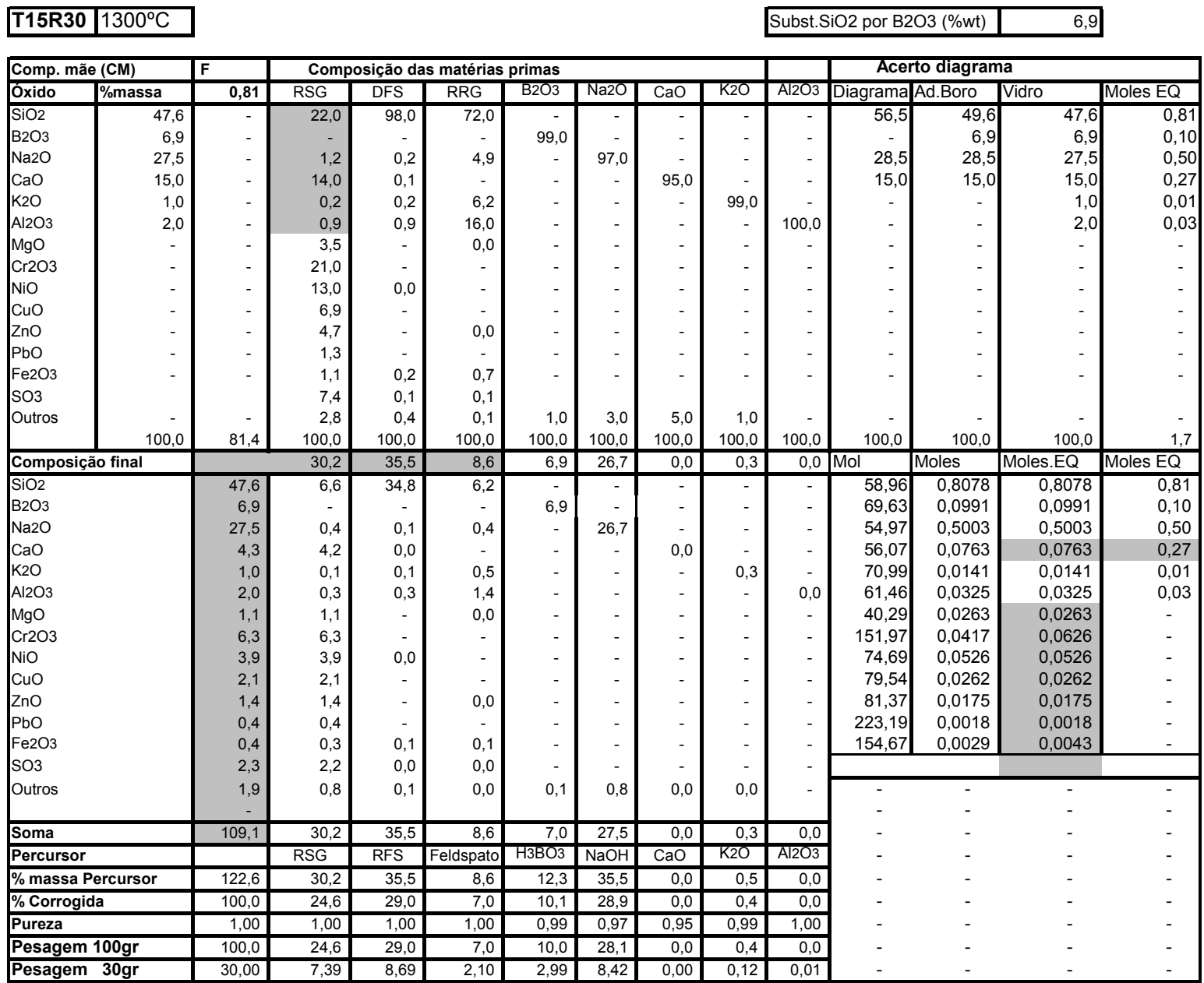

